\title{
Quality and Workflow Integration in
}

Flexible Manufacturing 


\title{
QUALITY AND WORKFLOW INTEGRATION IN FLEXIBLE MANUFACTURING
}

\section{PROEFSCHRIFT}

\author{
ter verkrijging van \\ de graad van doctor aan de Universiteit Twente, \\ op gezag van de rector magnificus, \\ prof. dr. H. Brinksma \\ volgens besluit van het College voor Promoties \\ in het openbaar te verdedigen op \\ woensdag 14 november 2012 om 12:45 uur
}

door

Dennis Christian ten Dam

geboren op 8 november 1982

te Enschede 
Dit proefschrift is goedgekeurd door de promotoren

Prof. dr. ir. F.J.A.M. van Houten

Prof. dr. ir. D. Lutters 


\section{QUALITY AND WORKFLOW INTEGRATION IN FLEXIBLE MANUFACTURING}


Dissertation committee:

Prof. dr. F. Eising

Prof. dr. ir. F.J.A.M. van Houten

Prof. dr. ir. D. Lutters

Dr. J. Váncza

Prof. dr. ir. A.C. Brombacher

Prof. dr. I. Horvath

Prof. dr. R.J. Boucherie

Prof. dr. ir. L.A.M. van Dongen
University of Twente, Chairman/secretary

University of Twente, Promoter

Stellenbosch University, Promoter

MTA SZTAKI, Hungary

Eindhoven University of Technology

Delft University of Technology

University of Twente

University of Twente

ISBN 978-90-365-3463-5

DOI $\quad 10.3990 / 1.9789036534635$

(C) Dennis ten Dam, 2012

Cover design by Frederik Hoolhorst

Printed by Ipskamp Drukkers BV, Enschede, The Netherlands

All rights reserved. No part of this publication may be reproduced, stored in a retrieval system or transmitted, in any form or by any means, electronic, mechanical, photocopying, recording or otherwise, without the prior written permission of the author. 
Aan mijn ouders 


\section{Summary}

In recognising the relevance of production networks and flexible manufacturing, $\mathrm{CNC}$ Worknet aims to be a company that approaches the new era of flexible manufacturing by developing a novel business model that combines the technologies of e-Business with production networks. The business model of CNC Worknet is based on an Internet portal that acts as an intermediary between the company and its customers. It allows customers to request quotations and place orders for the manufacture of simple products. These products are produced on $\mathrm{CNC}$ machining centres or through layered manufacturing techniques. The complexity of the machined products is relatively low as these products do not seek the boundaries of the available production capabilities. Consequently, process planning for these products is rather straightforward. The Internet portal is connected to a coordinated network of manufacturing plants in which the ordered products are manufactured. The manufacturing plants that are connected to the portal operate within a franchise model. CNC Worknet aims to provide the customer access to a univocal, direct and easily accessible global manufacturing network that consistently manufactures products according to the needs and specifications of the customer.

As is often the case with innovative approaches, the relation between vision and (industrial) practice is intractable. This research aims to enable CNC Worknet to successfully implement and industrialise the theory in the business model. The overall goal is to establish a supply chain that adheres to the business model of CNC Worknet as effective and efficient as possible. This requires the adequate development and implementation of a generic manufacturing system that enables and supports the required transformations in the supply chain. With this, the cooperation between companies in the franchise concept of CNC Worknet becomes feasible.

Based on the CNC Worknet business model as well as on both the envisaged environment and supply chain, requirement specifications are established for the generic manufacturing system. These requirement specifications address the system as a whole as well as the functionality of the individual entities of the manufacturing system. Based on the system specification, an architecture is developed that acts as a guideline for the further development and implementation of the manufacturing system. This architecture focuses on the integration of both workflow and quality management as these play a central role in all processes in the manufacturing system. In the context of this architecture a manufacturing system is implemented that closes the gap between theory and practice. This manufacturing system forms the backbone of CNC Worknet, upon which the different entities of CNC Worknet are developed and implemented. This system and many of its functional and operational constituents have been devised, elaborated and have subsequently been implemented.

Based on a generic and modular architecture, a system is proposed for the distributed manufacturing of products in small batches. This system has been implemented in two cases; milling and layered manufacturing. The system derives its strength from the integration of quality and workflow management, leading to a manufacturing environment that is focussed on both the quality of the product and the quality of the processes throughout the entire supply chain. 


\section{Samenvatting (Summary in Dutch)}

Door het belang van produceren in netwerken en flexibele productie te onderkennen, heeft $\mathrm{CNC}$ Worknet een nieuw business model voor flexibel produceren kunnen ontwikkelen. Dit model combineert de technologieën van e-Business met het produceren in netwerken en is gebaseerd op het gebruik van een Internet portaal dat dienst doet als een intermediair tussen het bedrijf en haar klanten. Klanten kunnen via dit portaal offertes aanvragen en orders plaatsen voor het produceren van eenvoudige producten. Deze producten worden geproduceerd op CNC-bewerkingscentra of middels 3D printen. De complexiteit van de prismatische producten is relatief laag, zodat deze niet de grenzen benaderen van de mogelijkheden van de bewerkingscentra. Hierdoor is de werkvoorbereiding voor deze producten relatief eenvoudig. Het Internet portaal is verbonden met een onderling afgestemd netwerk van productielocaties waar de producten geproduceerd kunnen worden. Deze fabrieken zijn onderdeel van een franchise organisatie. CNC Worknet wil de klant toegang bieden tot een eenduidig, direct en gemakkelijk te benaderen wereldwijd productie netwerk dat op consequente wijze producten vervaardigt die voldoen aan de behoeften en specificaties van de klant.

Zoals vaak het geval is bij innovatieve ideeën, is de relatie tussen visie en (industriële) praktijk moeilijk te doorgronden. Dit onderzoek heeft als doel om de theorie van het business model van CNC Worknet doelmatig te implementeren en te industrialiseren. Het doel is om een supply chain op te zetten dat het business model van CNC Worknet zo effectief en efficiënt mogelijk realiseert. Voorwaarde hiervoor is de adequate ontwikkeling en implementatie van een generiek productiesysteem dat deze veranderingen in de supply chain ondersteunt. Hierdoor zal de samenwerking tussen de bedrijven in de franchise organisatie mogelijk gemaakt worden.

De vereiste specificaties voor het generieke productie systeem zijn opgesteld aan de hand van het business model en de beoogde supply chain die daar uit voortkomt. Deze specificaties hebben betrekking op het systeem als geheel, maar ook op de individuele onderdelen ervan. Op basis van deze specificaties is een architectuur voor de opzet en implementatie van het productiesysteem ontwikkeld. Deze architectuur richt zich in het bijzonder op de integratie van workflow- en kwaliteits management, aangezien deze beiden een centrale rol spelen in alle processen van het productiesysteem. Aan de hand van deze architectuur is een productiesysteem opgezet dat de kloof tussen theorie en praktijk overbrugt. Deze architectuur is de ruggengraat van CNC Worknet waarop alle afzonderlijke entiteiten worden ontwikkeld en geïmplementeerd. Het productiesysteem voor CNC Worknet als geheel en veel van de operationele bestandsdelen zijn ontworpen, uitgewerkt en vervolgens geïmplementeerd.

Dit leidt tot een productiesysteem voor de geografisch verspreide productie van producten in kleine series. Dit systeem is gebaseerd op een generieke en modulaire architectuur en is geïmplementeerd in twee cases; frezen en 3D printen. Het systeem ontleent zijn kracht aan de integratie van workflow- en kwaliteitsmanagement, waardoor een productieomgeving is gerealiseerd die gericht is op de kwaliteit van zowel het product als de processen in de gehele supply chain. 


\section{Preface}

Taking on a $\mathrm{PhD}$ project had never crossed my mind until one of the last weeks of finishing my masters project. My supervisor at that time asked me the famous question: "What are you going to do after you have finished your masters?" Without a single doubt in my mind I replied: "I am going to apply for a job as an engineer at a company somewhere in Twente." As you are now reading this little text in front of my dissertation, you will understand that things went a little different from that moment on. My supervisor told me about a company called CNC Worknet and their business model that would be part of a PhD project for which he found me a suitable candidate. A long story short: I took on that $\mathrm{PhD}$ project, my master supervisor became one of my promoters and now 5 years and a few months later, I am almost at the end of my long to road $\mathrm{PhD}$-hood. This $\mathrm{PhD}$ road had been a road with high hills to climb and deep ravines to cover. There were times that I thought I would never see the end of this road. Fortunately I had a number people around me who supported me and kept me going forward on this long PhD road. I would like to acknowledge these people, without whom this dissertation would have never been written.

First of all my gratitude goes to my two promoters Fred van Houten and Eric Lutters. I thank you for believing in me and giving me the opportunity to take on this $\mathrm{PhD}$ project. My promoter Eric Lutters was absolutely vital for keeping me on track and he had a tremendous impact on the quality of this work. Thank you for supporting me, for answering my questions with even more questions, and for being my beacon on the horizon. It was remarkable how topics could become so clear while discussing them with you, and how quickly these could become vague again after I stepped out of your office. Thank you Eric!

I want to thank CNC Worknet and 3D Worknet for allowing me to work on this $\mathrm{PhD}$ project. I really enjoyed taking the long journeys to Ede. Unfortunately everything did not work out as planned, with the bankruptcy of CNC Worknet as one of the worst moments of this PhD road. Fortunately, 3D Worknet was born shortly after that and I am happy we could continue our work there. Henk, Sander, Marcel, Jens, Frank, and Jana I thank you for our many discussions and for letting me experience the difficult link between theory and practice first hand.

During my PhD project I was part of the group of Design, Production and Management (OPM). The many coffee breaks and lunches with my colleagues were often a welcome change to my sometimes difficult wandering along the $\mathrm{PhD}$ road. Especially the trips and dinners with the group have left behind fond memories. The tutoring of first year mechanical engineering students was a fun and very rewarding experience; I really enjoyed watching these 'schoolboys' turn into students during the course of Project A. As part of my PhD project, I supervised a number of students on their bachelor and master projects. Maarten, Jelte, Tom, and Bayram thank you for developing parts of this project and for the joy I had in supervising you.

A special thanks goes out to my roommates of N-211, you guys are a small but crazy community within the OPM community. The atmosphere in this office was one that I had never experienced before, and probably will not experience again. It was not always the best location to be productive, but I really enjoyed our conversations and entertaining actions. Every day in that room was an experience in itself, and it made you come back the next day for more. We should have started that N-211 big brother project, it would have been a guaranteed moneymaker. Cleaning up my desk, so Maarten could take 'my spot,' was a very strange feeling as from that moment on I knew that these good times were over. I really miss you all. 
I also want to thank my current employer Tecnotion for allowing me to take the time I needed to finish my PhD project.

Ook ben ik mijn dank verschuldigd aan mijn vriendengroep. Mark \& Kim, Michiel \& Nienke, Jeroen \& Sanne, Danny \& Margot, Ilse, Inge, Martijn en Marco; jullie hebben gezorgd voor de soms broodnodige afleiding die nodig was om af en toe de batterij weer eens goed te kunnen opladen.

Tenslotte wil ik mijn ouders en mijn zus bedanken. Jullie hebben mij gestimuleerd om dit project aan te gaan en hebben mij ondersteund op de momenten dat het nodig was. Jullie hebben mij de mogelijkheid gegeven om mijzelf te ontdekken en de dingen te doen waar ik van hou. Geen woorden kunnen beschrijven hoe blij en trots ik ben om door jullie, en samen met zo'n zus, te zijn opgevoed. Jullie hebben mij gemaakt tot wat ik nu ben.

Enschede, 21 Oktober 2012

Dennis ten Dam 


\section{Table of contents}

1. Introduction...................................................... 1

1.1. Manufacturing system and environment........................... 1

1.2. Background of Manufacturing............................................ 1

1.3. Production.............................................................................. 2

1.4. Product Types.......................................................................... 4

1.5. Manufacturing Constraints................................................. 4

1.6. From Mass Production to Flexible Manufacturing............ 4

1.7. CNC Worknet....................................................................... 5

1.8. Research Approach................................................................. 5

2. Manufacturing Environment................................. 7

2.1. Supply Chain........................................................................ 7

2.1.1. Supply Chain Paradigm....………………………………………... 8

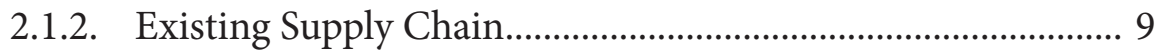

2.2. Manufacturing Entities........................................................... 11

2.2.1. Supply Chain Management........................................................ 11

2.2.2. Process Planning....................................................................... 17

2.2.3. Planning and Scheduling......................................................... 31

2.2.4. Knowledge Management.......................................................... 33

2.2.5. Workflow Management.................................................................. 34

2.2.6. Quality Management................................................................. 40

2.5.1. Networked Manufacturing...................................................... 52

2.3.1. e-Business and Manufacturing................................................. 58

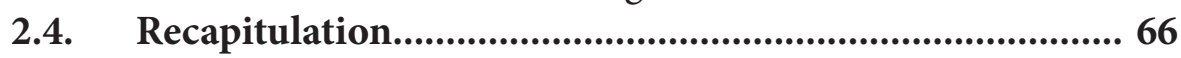

2.4.1. Difficulties and Disadvantages................................................... 66

3. Reference Model................................................ 71

3.1. Manufacturing Engineering Reference Model.................... 71

3.2. Reference Model Entities \& Interactions............................. 71

3.2.1. Company Management................................................................. 71

3.2.2. Product Engineering.................................................................. 71

3.2.3. Order Engineering..................................................................... 71

3.2.4. Resource Engineering................................................................ 72

3.2.5. Information Management....................................................... 72

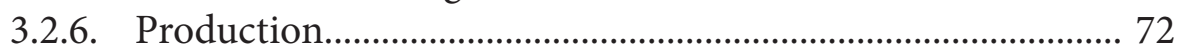

3.2.7. Interactions in the reference model........................................ 72

4. CNC Worknet.................................................... 73

4.1. CNC Worknet Business Model.............................................. 73

4.2. Envisaged Environment......................................................... 74 
4.3. Envisaged Supply Chain.................................................. 75

4.4. Supply Chain Comparison.............................................. 77

4.5. CNC Worknet Specification............................................ 79

4.5.1. Functional Description.............................................................. 79

4.5.2. CNC Worknet Requirements..................................................... 85

5. Workflow and Quality Integration....................... 93

5.1. Workflow and Quality Management Importance.............. 93

5.2. CNC Worknet Workflow Management............................. 94

5.3. CNC Worknet Quality Management................................ 94

5.4. CNC Worknet Workflow and Quality Integration............. 96

6. CNC Worknet Development................................. 97

6.1. Architecture development............................................... 97

6.1.1. Reference Models and Architectures...................................... 97

6.1.2. Architecture Based on Information Management.................. 98

6.2. Architecture Application................................................ 102

6.2.1. Functional Modules............................................................. 103

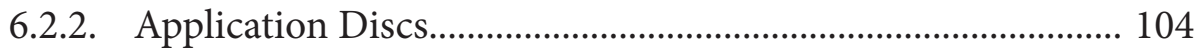

6.3. Workflow and Quality Management Role.......................... 107

6.3.1. Quality Management Disc......................................................... 107

6.3.2. Workflow Management Functional Module............................. 109

6.4. Functioning.................................................................... 109

6.4.1. Example.................................................................................. 110

7. Implementation............................................. 113

7.1. CNC Worknet - Milling....................................................... 113

7.1.1. Implementation Priorities.................................................... 115

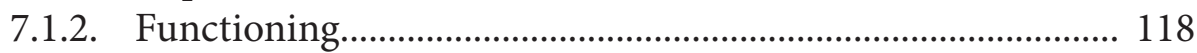

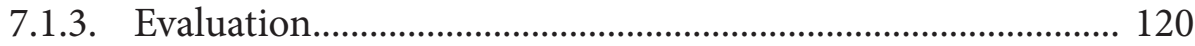

7.2. CNC Worknet - Layered Manufacturing............................. 122

7.2.1. Implementation Priorities.................................................... 122

7.2.2. Functioning.......................................................................... 125

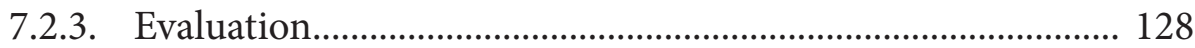

8. Future Vision.................................................. 131

8.1. Future of technology........................................................... 131

8.2. Future of Organisation ...................................................... 132

8.3. Future of Business ......................................................... 132

9. Conclusions and Recommendations.................... 135

9.1. Generic System..................................................................... 135 
9.1.1. Workflow and Quality Integration........................................... 135

9.1.2. Generic and Modular Architecture........................................ 135

9.1.3. Distributed Manufacturing........................................................ 136

9.2. CNC Worknet ................................................................. 136

9.2.1. Portal Environment..................................................................... 136

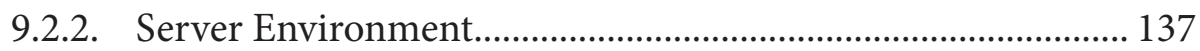

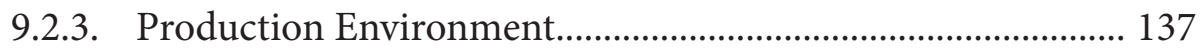

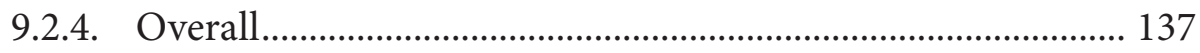

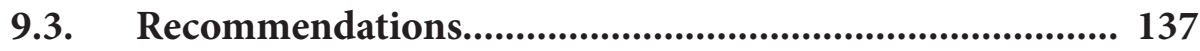

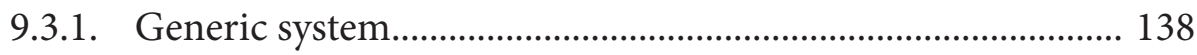

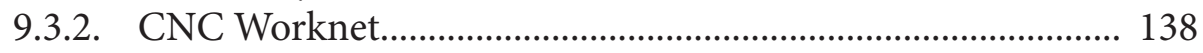

9.4. Closing Remarks............................................................. 140

10. References...................................................... 141

Appendix 1.Layered Manufacturing Techniques............ 155

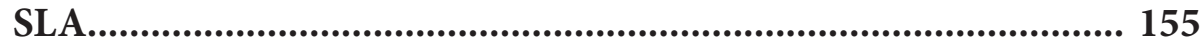

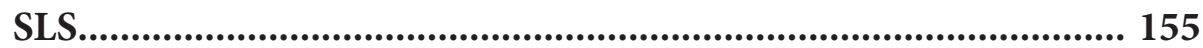

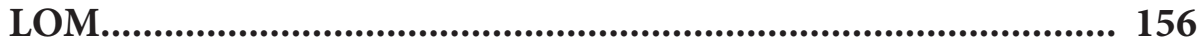

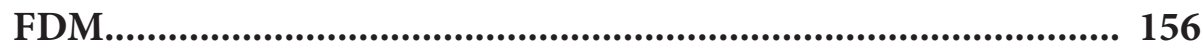

Ink Jet Printing techniques.................................................... 157

Appendix 2.Application Discs................................... 158

Sales Application Disc..................................................................... 158

Process Planning Application Disc (Milling)............................... 159

Purchasing Applications Disc........................................................ 161

Logistics Application Disc........................................................... 162

Manufacturing Application Disc..................................................... 163

Business Administration Application Disc................................ 165

Franchise and Marketing Application Disc................................... 166 


\section{Introduction}

Flexible manufacturing is the topic of this thesis. Manufacturing, in its essence, is the process of converting raw materials into products. A manufacturing system can be modelled as functional units that enable the transformation of material, energy and information [Houten, 1991]. According to the definition by CIRP, manufacturing 'is the series of interrelated activities and operations involving design, material selection, planning, production, quality assurance, management and marketing of the products of manufacturing industries' [Chisholm, 1990]. This definition outlines the broad context of manufacturing. Lutters proposed a more general notion of the term manufacturing and defined it as the series of all interrelated activities and operations conjointly and directly aimed at the engendering of products and accompanying resources, methods and procedures' [Lutters, 2001]. These definitions emphasise the broad scope of manufacturing, consisting of many different activities and operations. Lutters grouped these into three main groups as depicted in figure 1.1.

\begin{tabular}{|c|c|c|c|c|}
\hline \multicolumn{5}{|c|}{ Manufacturing } \\
\hline \multicolumn{2}{|c|}{ Engineering } & \multicolumn{2}{|c|}{ Production } & $\begin{array}{c}\text { Completion, } \\
\text { Conveyance }\end{array}$ \\
\cline { 2 - 3 } Design & Planning & Fabrication & Assembly & \\
\hline
\end{tabular}

Figure 1.1 Terminology in manufacturing

\subsection{Manufacturing system and environment}

Manufacturing is described as the process leading to the creation of products. This process only has significance if its course and control are adequately embedded in an appropriate environment. This environment consists of two enclosing echelons. First, the process has to be implemented in an environment that provides the means to enable its execution. This environment is named the manufacturing system. Manufacturing systems are part of a larger environment that also comprises customers and other interested parties in the market, and institutes related to legislation, standards etc. [Lutters, 2001].

\subsection{Background of Manufacturing}

Manufacturing dates back to as early as 4000 B.C. Over time, manufacturing has steadily evolved through the invention of new materials and manufacturing operations. The production rate increased steadily and the complexity and quality of the products increased as well. Until the Industrial Revolution, which started at the end of the 18th century, products had been manufactured by craftsmen who usually manufactured the entire product, often custom and almost always unique. With the invention of the steam engine, large amounts of energy became available at one location. By bringing together all labour, machines and tools around this energy source in a factory, this vast amount of energy could be employed for manufacturing. This resulted in an environment where the factory became the focal point for most manufacturing activities, as is often still the case today. The organisation and layout of factories have, however, evolved considerably since the industrial revolution. Henry Ford revolutionised the factory by the introduction of mass production through the 
invention of the assembly line. Mass production dramatically decreased the production costs for almost all manufactured products. Mass production was made possible through the advance in designing, producing and using of interchangeable parts. Prior to the introduction of interchangeable parts, no two parts could be produced exactly the same, which resulted into a lot of hand-fitting and rework during assembly. In the 1960s, the Toyota Motor Corporation improved the ideas of Henry Ford by reducing waste, increasing efficiency and seeking employee input to improve manufacturing. This has led to a heavy dependence on automation to reduce costs. The development of information technology over the last decades has provided manufacturing with the means to manage the increasing complexity that is characteristic of manufacturing processes, products and companies. The chain of processes that converts raw material into a finished product in a modern factory involves a complex variety of computers, logistics equipment, machine tools and robotics. These are all driven by the information they require; moreover, they generate information to be consumed elsewhere. Information and the management thereof has become one of the most important qualities in modern manufacturing. This is all the more relevant as demands on the quality performance of products, services and logistics continue to increase. For companies, this implies among others an increasing pressure on lead times and an expanded occasion to co-operate more closely with both suppliers and customers. Especially the more explicit and relevant connections between entities in the manufacturing environment have led to the formation of manufacturing networks, sometimes called production networks [Wiendahl, 2002]. The main rationale behind manufacturing networks is the mutual use of resources and the joint planning of the value-added processes. Companies participating in these networks communicate intensively with each other and information is exchanged between them. A recent development is the employment of e-Business in manufacturing. E-Business involves the application of information and communication technology in support of all activities of a business. Every day, companies enter the field of e-Business to broaden their market reach and to enter the 24/7 economy with their business. Examples of such companies are:

- eMachineShop; an online machine shop that enables any company, organisation or individual to design, quote, and instantly order custom mechanical parts [Emachineshop, 2011]

- WebMachining; an initiative that aims at the remote manufacturing of cylindrical parts through the Internet [Alvares \& Ferreira, 2008].

- 247TailorSteel.com; a company that provides customers with an online tool to instantly order custom sheet metal parts [247tailorsteel, 2011]

- Shapeways; an online rapid prototyping company that offers the service of uploading your designs and prototyping them on order [Shapeways, 2011].

\subsection{Production}

One of the three main groups in manufacturing as depicted in Figure 1.1 is production. Based on the results of the engineering processes, the physical creation of the product is performed by the production processes. Production is the act or process of physically making a product from its material constituents [Chisholm, 1990]. An extensive and continuously expanding variety of production processes are currently used to produce products. Products can often be produced through different production processes or combinations thereof. These production processes range from sand-casting to nano-fabrication [Kalpakjian \& Schmid, 2006]. Cutting (in particular milling) and layered manufacturing (in particular 3D printing) are two 
production processes that both play an important role in this thesis. Both these processes are shortly described in the following two paragraphs.

\section{Cutting}

Machining is a general term for describing the production processes that remove material and modify the surfaces of a work piece. Machining can be subdivided into three main types of material-removal processes: cutting, abrasive processes and advanced machining processes [Kalpakjian \& Schmid 2006]. In cutting, material is removed from the surface of the work piece by a cutting tool. Cutting processes are versatile and capable of producing a wide variety of shapes. Different cutting techniques exist, like milling, turning, and drilling, which can be performed on dedicated machines for these techniques. Recently these machines are increasingly replaced by $\mathrm{CNC}$ machining centres. A CNC machining centre, as shown in figure 1.2, is a computer-controlled machine tool that is capable of performing a wide variety of cutting operations on different surfaces and orientations of a work piece without having to remove it from its work holding device or fixture. In general, machining centres are capable of performing multiple

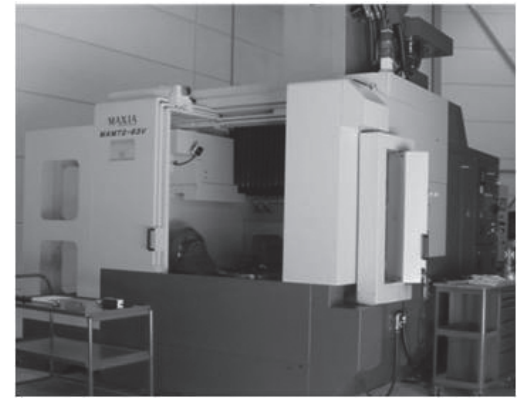

Figure 1.2 CNC machining centre cutting operations like milling, drilling, and tapping.

\section{Layered Manufacturing}

Layered manufacturing is a relative new production process, as its industrial application started in the 1980's. There are many different layered manufacturing techniques but the main principle that is employed to produce a part is similar. All techniques produce a part by adding layers of material on top of each other and joining them together. Layer by layer, a product is created. Figure 1.3 displays how layered manufacturing is applied to the production of an elliptically shaped

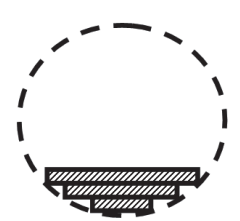

Figure 1.3 Layered manufacturing of a elliptical shape

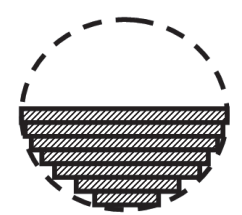
product. The difference

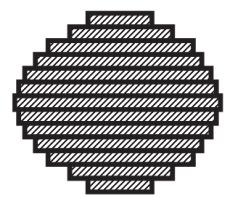

between the different techniques lies in the used materials, the method of how the individual slices are produced and how these are joined together. Layered manufacturing techniques roughly encompass:

- Fused Deposition Modelling (FDM)

- Direct Metal Laser Sintering (DMLS)

- Selective Laser Melting (SLM)

- Ink-jet based technique

- Stereolithograhpy (SLA)

- Selective Laser Sintering (SLS)

- Laminated Object Modelling (LOM) 
A more detailed description of these layered manufacturing techniques is given in appendix A.

\subsection{Product Types}

A product is defined as the end item resulting from manufacturing [Chisholm, 1990]. This product can either be a physical item and/ or service that is delivered to the customer. Two types of products can be distinguished; finished products that are delivered to the end user and products that are part of a supply chain and subsequently included as
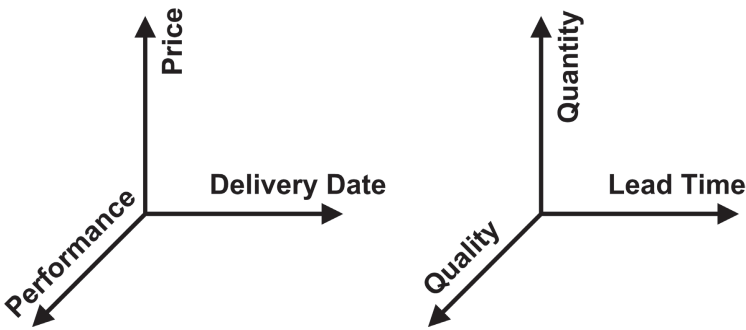

Figure 1.4 Ways to Characterise Products a component or subassembly of another product. Product properties can be characterised in a co-ordinate system [Lutters, 2001] as shown in figure 1.4. Products can be characterised differently depending on the perspective. From a consumers perspective; performance, delivery date and price properties of a product are typically of importance. While the same product can be characterised by a manufacturer in terms of quality, lead time and quantity. This clearly demonstrates that both the consumer and the manufacturer interpret a product differently.

\subsection{Manufacturing Constraints}

Each manufacturing company has to optimise its performance under certain constraints. These constraints can be visualised in a triangle that interrelates the entities time, quality and cost, as depicted in figure 1.5. A change in the scope of one of the entities will affect at least one other entity; for example, a focus on reducing the priority of the time entity generally results in an increase in costs, a reduced quality or both. The corners of the triangle of constraints can, in the current manufacturing climate, be

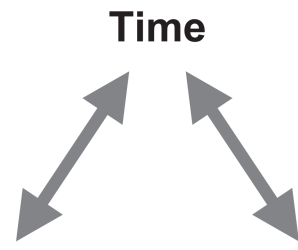

Cost

Figure 1.5 Triangle of Constraints matched to certain initiatives or markets. Manufacturing companies that focus on the time entity generally employ a form of the Lean manufacturing concept, see section 2.2.6. Premium products are manufactured by companies that focus on quality. The costing aspect can be associated with companies that seek inexpensive labour and abundant resources in Asia, Eastern Europe, Latin and South America.

\subsection{From Mass Production to Flexible Manufacturing}

For many decades, cost and production rate were the dominant performance criteria in manufacturing. This resulted in dedicated mass production systems that are designed to achieve optimal economy of scale. With mass production, there is an important focus on engineering, in order to develop products and production processes/environments that are suitable for mass production. Due to the focus on large production quantities, it can be beneficial to locate 
the factory in lower wage countries with abundant resources. Nowadays, customer focus is shifting towards customised products that are ordered in smaller quantities. Because of this situation, it is no longer beneficial to develop production processes/environments dedicated for one product. Therefore, the focus shifts towards the development of production processes that are able to efficiently produce various products in the demanded smaller quantities. This makes flexibility an increasingly important attribute of specific manufacturing environments. Due to the lower demanded quantities and the relative high transportation costs involved, the benefits of producing in lower wage countries is decreasing. As a consequence, interest in distributed production networks is increasing [Vancza et. al., 2011]. Factories in these networks are located close to the customer to lower the delivery times and costs.

\subsection{CNC Worknet}

In recognising the relevance of production networks [see section 2.5.1] and flexible manufacturing [see section 2.2.1], CNC Worknet aims to be a company that approaches this new era of flexible manufacturing by developing a new business model that combines the technologies of e-Business with production networks. The business model of CNC Worknet is based on an Internet portal that acts as an intermediary between the company and its customers. It allows customers to request quotations and place orders for the manufacture of simple products; in the interaction between customers and the company both the logistic and technical aspects are included. The products are produced on CNC machining centres capable of milling, drilling and tapping operations or through layered manufacturing techniques. The complexity of the machined products is relatively low; as the products do not seek the boundaries of the required production capabilities, process planning is rather straightforward. The Internet portal is connected to a coordinated network of manufacturing plants in which the ordered products are manufactured. The manufacturing plants that are connected to the portal operate within a franchise model. The business model is illustrated in figure 1.6. CNC Worknet aims to provide the customer access to an univocal, direct and easily accessible global manufacturing network that consistently manufactures products according to the needs and specifications of the customer. It is foreseen that this approach results in a supply chain that is both more streamlined and responsive.

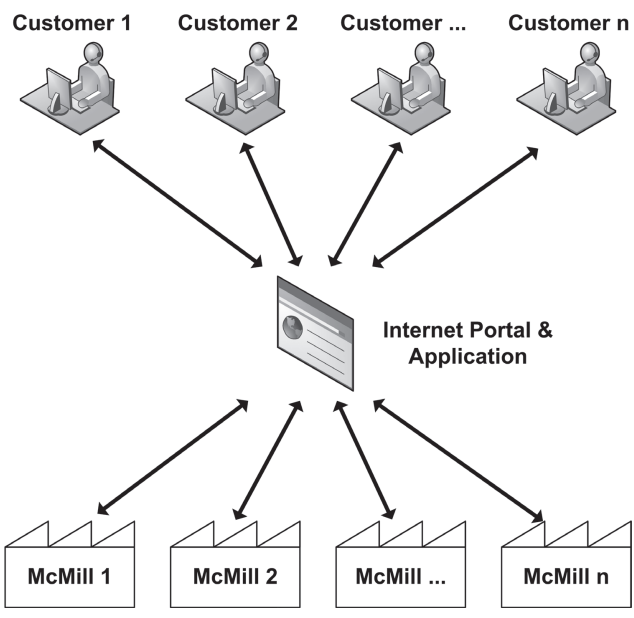

Figure 1.6 CNC Worknet Business Model

\subsection{Research Approach}

As if often the case with innovative approaches, the relation between vision and (industrial) practice is intractable. This research aims to enable CNC Worknet to successfully implement and industrialise the theory envisioned in the business model. The overall goal is to establish 
a supply chain that adheres to the business model of CNC Worknet as effective and efficient as possible. This requires the adequate development and implementation of a generic manufacturing system that enables and supports the required transformations in the supply chain. With this, the co-operation between companies in the franchise concept of CNC Worknet becomes feasible.

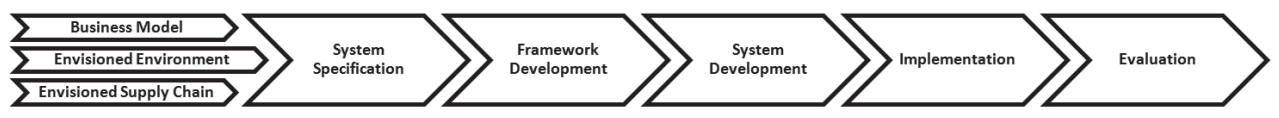

Figure 1.7 Research Approach

A structured approach, which is shown in figure 1.7, is applied to reach the objectives. Based on the CNC Worknet business model as well as on both the envisaged environment and supply chain, requirement specifications are established for the generic manufacturing system. These requirement specifications address both the system as a whole as well as the functionality of the different entities of the manufacturing system. Based on the system specification, a framework will be developed that acts as a guideline for the further development and implementation of the manufacturing system. The implementation of the manufacturing system in the context of the theoretical framework envisages to close the gap between theory and industrial practice. Ultimately, the system design becomes the backbone of CNC Worknet, upon which the different entities of CNC Worknet are developed and implemented. In order to assess the validity of the approach, the system and many of its functional and operational constituents are devised, elaborated and subsequently implemented. Based on the actualised system and the corresponding production network, the overall result is evaluated in order to determine the extent to which the envisaged supply chain has been realised, especially with respect to the aspects cost, time and quality. 


\section{Manufacturing Environment}

This chapter describes the manufacturing environment that is the focus of this dissertation. Present approaches and initiatives in manufacturing environments are explored and elaborated upon. First, the typical existing supply chain for the provision of demand-driven engineerto-order products is presented. The different entities and research topics that influence the manufacturing environment are discussed next. Recent developments concerning supply chains as a whole are discussed in the last section of this chapter.

\subsection{Supply Chain}

Global supply chains are international networks of organisations that are involved, through upstream and downstream linkages, in different processes and activities that produce value in the form of products and services to the ultimate customer [Scholz-Reiter et al., 2011]. A supply chain encompasses the material and information interchanges in the logistic process stretching from the acquisition of raw materials to the delivery of finished products to the customer. Suppliers, manufacturing or assembly plants, warehouses, distributors, retailers and customers are, for example, all links in the supply chain. Every product has its own specific supply chain. Supply chains perform two principal functions; firstly the physical function of transformation, storage and transportation, and secondly the function of market mediation by matching demand and supply [Fisher 1997]. A depiction of a supply chain given by Akkermans is presented in figure 2.1. This depiction shows the supply chain, the flows at the operational level and the supporting entities of the supply chain [Akkermans et al., 2003].

At the operational level, three flows can be identified within the supply chain:

- material flows: represent physical product flows from suppliers to customers as well as the reverse flows for product returns, servicing, and recycling.

- information flows: represent order transmission and order tracking, and coordinate the physical flows

- financial flows: represent credit terms, payment schedules, and consignment arrangements.

A supply chain is supported by three entities:

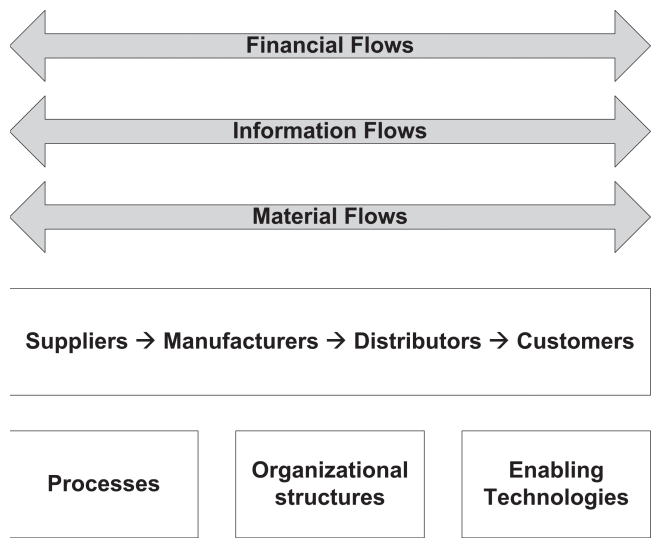

Figure 2.1 Supply chain depiction

- processes: embed the companies' capabilities in logistics, new product development, and knowledge management.

- organisational structures: encompass a range of relationships and management approaches, and performance measurement and reward schemes.

- enabling technologies: include both process and information technologies. 


\subsubsection{Supply Chain Paradigm}

A supply chain paradigm is presented in figure 2.2. In this paradigm the supply chain transforms resources (input) into products (output). The supply chain interacts with customers in order to align supply with demand in terms of material, information and finances. The supply chain has to perform and deliver under certain constraints. These constraints can be visualised by a triangle, that interrelates the entities time, costs and quality. All activities in a supply chain are aimed at finding an adequate solution within this triangle of constraints. A change in the scope of one of the dimensions will affect at least one other dimension. For example, a focus on reducing the time entity generally results in an increase in costs, a reduced quality or both. The interpretation of this triangle of constraints is dependent on the aggregation levels in a supply chain. Examples of such viewdependent interpretations are shown in table 2.1.

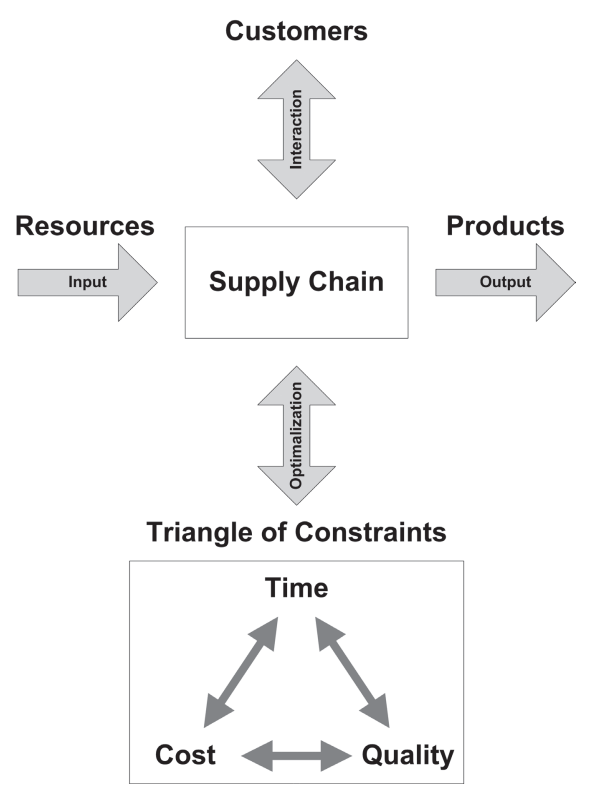

Figure 2.2 Supply chain paradigm

\begin{tabular}{|c|c|c|c|}
\hline & Time & Cost & Quality \\
\hline Operational & Delivery Time & Product Cost & Product Quality \\
\hline Tactical & Scheduling & Process Cost & Process Quality \\
\hline Strategic & Capacity Planning & Capital Investments & System Quality \\
\hline
\end{tabular}

Table 2.1 Interpretations of Triangle of Constraints

When reviewing the relation between the customer and the supplier one can notice that typically customers are primarily interested in the operational aspects and that the aspects on the tactical and strategic level are of less importance to them. These other aspects are however of vital importance to the supplier as these enable the supplier to meet the aspects of the customer on the operational aggregation level. This view is illustrated in figure 2.3. The figure shows a triangle of constraints from the customers point of view with its primary selection criteria for a supplier and another triangle of constraints from the suppliers point of view with aspects that are used to meet these customer criteria. As can be seen in the figure these aspects are interpretations of the aspects on the different aggregation levels shown in table 2.1.

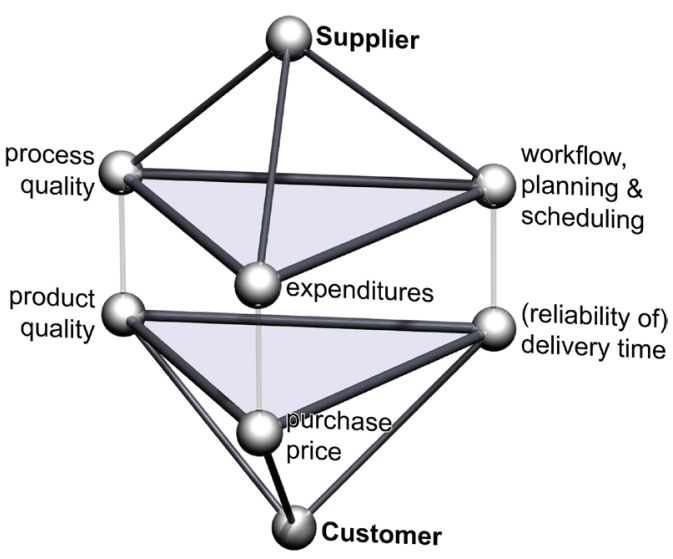

Figure 2.3 Supplier - customer relation 


\subsubsection{Existing Supply Chain}

A typical supply chain in the manufacturing environment that is the subject of this thesis is shown in figure 2.4. This supply chain contains many different departments of both the customer and the suppliers, that communicate and cooperate with each other on various levels of detail in order to supply the product to the customer. The tasks and roles of the different departments of both the customer and the supplier are described per department in the following sections. In all descriptions, the situation as it is presupposed to exist in representative manufacturing environments is basis.

\section{Engineering (customer)}

At the engineering department of the customer the product is designed and engineered. All decisions concerning the specifications and requirements imposed on the product are taken here. All the technical product data (TPD) is generated here. The TPD accurately and unambiguously conveys all the required information that will allow the manufacturer to manufacture that product.

\section{Purchasing (customer)}

The purchasing department selects potential suppliers for the product. Requests for quotations (RFQ) are send to these suppliers. The TPD is enclosed in the RFQ together with the required lead time and the requested quantities. From all the received quotations, the best fitting quotation is selected. Suitability of quotations is determined by a number of requirements that are important for the customer at the time of the decision and that can vary over time. In general, these requirements relate to cost, time and quality as discussed earlier. Based upon the accepted quotation an order contract is negotiated with the supplier for the delivery of the desired product.

\section{Sales (supplier)}

The sales department receives requests for quotations from many different potential customers. Requests for quotations are registered and a calculation is made to roughly determine the production costs and times. The are made based upon the experience of the employee or by quickly generating a rough process plan

\section{Engineering \\ (customer)}

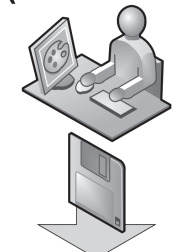

Purchasing

(customer)

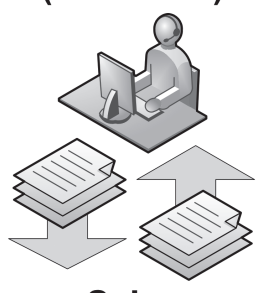

Sales

(supplier)

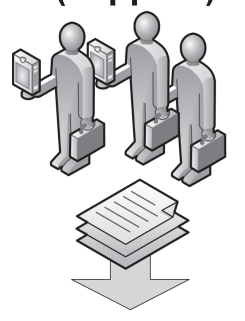

Process Planning

(supplier)

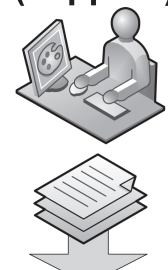

Planning

(supplier)
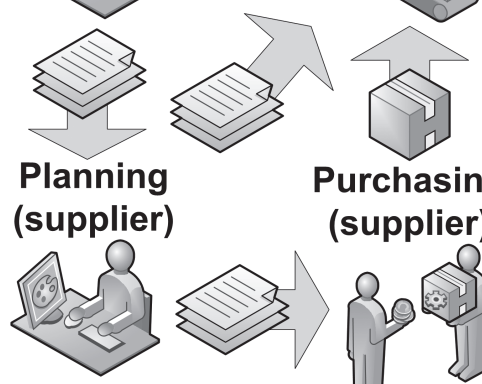

Figure 2.4 Existing supply chain
Purchasing

(supplier)

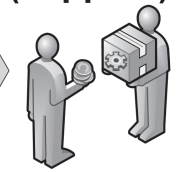

Shipping
(supplier)

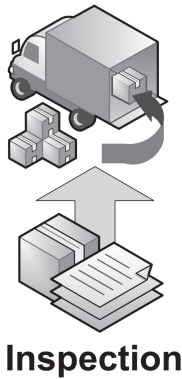

(supplier)

Production

(supplier)

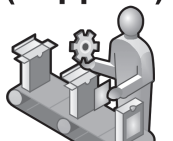


based on a comparable product. Based on the current planning of the shop floor a lead time for the production is generated. The costs for the requested products and their delivery time span is specified in the quotation. This quotation is subsequently send to the customer. When the quotation is accepted by the customer an order contract is negotiated with the purchasing department of the customer.

\section{Process Planning (supplier)}

The process planning department starts with the creation of the process plans after the order contract is negotiated and agreed upon. The process plans are generated based on the provided TPD through the use of Computer Aided Process Planning (CAPP) techniques. The products are analysed and manufacturing methods, machines and tools are selected and specified. Raw material dimensions and type are selected and ordered from a supplier. The generated process plan is send to the production department where the product will be manufactured according to this plan.

\section{Planning (supplier)}

The planning department plans and schedules the production of the order based upon the production times detailed in the process plan in order to meet the dates specified in the order contract.

\section{Purchasing (supplier)}

The purchasing department negotiates with next tier supplier for the provision of the required production resources. These resources are subsequently delivered by the next tier supplier to the production company. When requested, quality documentation such as material certificates and certificates of conformance are also provided.

\section{Production (supplier)}

The products are produced according to the process plan provided by the process planning department and the schedule provided by the planning department.

\section{Inspection (supplier)}

Inspection generates inspection plans for the inspection of the products according to the quality requirements set in the order contract. The products are subsequently inspected according to these inspections plans. Products that do not meet the quality requirements are rejected; either for rework or discarding. The inspection results are reviewed and the required inspection documentation proofing the conformity of the products is generated.

\section{Shipping (supplier)}

The products are prepared for shipping by this department. The products are packaged according to the requirements set in the order contract. The required shipment documentation is collected from the different departments and attached to the shipment. The shipment is then delivered to the customer.

\section{Receiving (customer)}

Upon receiving the shipment of the supplier, the customer verifies the conformity of the contents. The supplier is notified upon the discovery of nonconforming products and a 
solution to this situation is worked out between the customer and the supplier. Satisfactory products are accepted by the customer.

Financial (supplier \& customer)

The financial departments of both the customer and the supplier are not specifically shown in the supply chain. The financial department manages the financial transactions between the supplier and its customers and next tier suppliers in accordance with the financial flows as depicted in figure 2.1 .

\subsection{Manufacturing Entities}

The existing supply chain described in the previous section consists of activities from several disciplines and processes. Figure 2.5 gives an overview of the topics that influence the manufacturing environment. This overview is, however, not intended to be complete as indicated by the dotted box. Many more topics influence the manufacturing environment in one way or another. However, the topics in the presented overview are considered as the main topics that have relevance to the subject of this thesis.

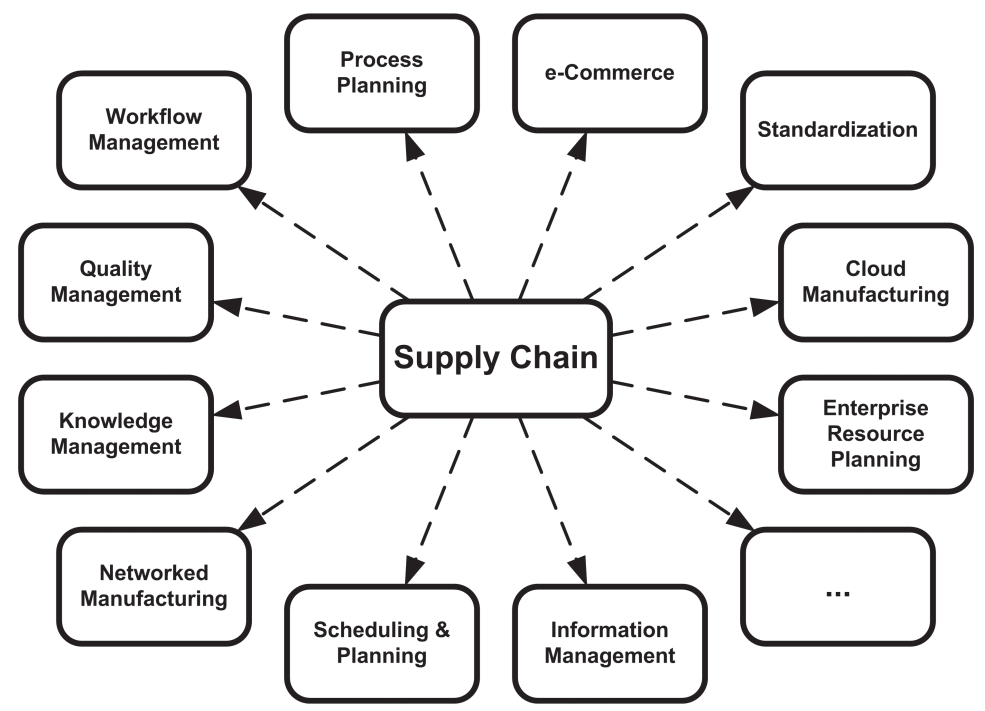

Figure 2.5 Overview manufacturing environment influences

\subsubsection{Supply Chain Management}

Supply chains are generally formed naturally through the up and down stream linkage of the entities required for the provision of a customer certain need. Each of these entities within the supply chain tries to optimise its own processes according to the triangle of constraints as explained in section 2.1. As a consequence, the supply chain is optimised locally which generally does not result in an optimal solution for the entire supply chain. In order to improve their competitiveness on the market, companies need to establish efficient strategic cooperation with the entities of the supply chain. This can be achieved by supply chain management, that aims at a faster and more flexible coordination of the supply chain [Mourtzis, 2011]. 
Supply chain management is defined by the Council of Supply Chain Management Professionals as: "Supply chain management encompasses the planning and management of all activities involved in sourcing and procurement, conversion, and all logistics management activities. Importantly, it also includes coordination and collaboration with channel partners, which can be suppliers, intermediates, third party service providers, and customers. In essence, supply chain management integrates supply and demand management within and across companies". [CSCMP, 2010]

Wiendahl defines supply chain management as: "the inter-organisational management of the flow of material and information along the entire value-added chain" [Wiendahl, 2002].

According to Swaminathan supply chain management is "a network of autonomous or semiautonomous business entities collectively responsible for procurement, manufacturing and distribution activities associated with one or more families of related products". [Kuei et al., 2002]

The Global Supply Chain Forum defines supply chain management as: "the integration of key business processes from end users through original suppliers that provides products, services and information that add value for customer and other stakeholders" [Martins et al., 2004].

Given these definitions, adequate supply chain management would be the panacea for the challenges in adjusting demand and supply in the supply chain as described above. However, managing a supply chain is not easy. Any disturbance on any entity in the supply chain may impact the entire chain, and disturbances may be related to material, information or finances. An example from the logistic domain is the well-known Bullwhip Effect [Chase et al., 2004], which describes the considerable consequences caused by small disturbances.

A supply chains ability to respond to competitive challenges and sustaining its competitive advantage is a key element of success in the global market. Supply chains are therefore required to be responsive. A responsive supply chain is a network of companies that is capable of creating value in a competitive environment by reacting quickly and cost effectively to changing market requirements [Gunasekaran et al., 2008]. Responsiveness is a continuous quest for solutions that work in reality and under changing conditions [Vanzca et al., 2011]. Keys in achieving a responsive supply chain are both the flexibility and agility of a supply chain. Flexibility of a supply chain refers to the ability of a supply chain to reduce lead time, ensure production capacity, and provide product variety while fulfilling customer expectations [Swafford et al., 2008]. Agility refers to the ability of a supply chain to operate efficiently in a competitive environment dominated by change and uncertainty [Candido et al., 2009]. An agile supply chain is 'market sensitive' in the sense that it accommodates fluctuations in the real demand rather than basing decisions on elusive forecasts [Christopher, 2000]. Flexibility refers in other words to the adaptability and versatility of the supply chain to produce a range of products and agility refers to the reaction time and efficiency by which that can be achieved. In order to achieve these aspects a company needs to integrate design, engineering, and manufacturing with marketing and sales and this can only be achieved with a proper information technology (IT) infrastructure [Ribeiro et al., 2009].

\section{Supply Chain Information Management}

An information system can be considered as the nerve system of a company. It facilitates the exchange of information among the constituent departments of a company. Hereby, it supports 
the co-operative work of managers, sellers, market analysts, administrative employees, engineers, machine operators, etc. Next to this, information systems allow the automation of a variety of functions that otherwise would have required the direct intervention of human operators.

In a dynamic enterprise environment, flexible information systems are required that can be quickly re-configured or re-grouped. The ability of data sharing in a dynamic enterprise environment is also a crucial factor. The data in the information system is to be accessed by, and acquired from, numerous related systems such as CAD/CAM and ERP. Therefore, reconfigurable interfaces are required to perform the data transfer with these related systems. The scale and requirements of an information system in a dynamic enterprise are continuously changing. The information system should therefore be capable to expand along with the growth of enterprise [Tang et al., 2007].

Several researchers have developed concepts and systems to facilitate adequate information management within the supply chain. Several of these concepts and systems are discussed in the following sections.

\section{Total Manufacturing Information System}

Lee introduced a concept for a strategic tool for companies to help them achieve competitive advantages [Lee, 2003]. The concept is called Total Manufacturing Information System (TMIS) and it focuses on the integration of manufacturing technologies and business strategy into an information system. It enables companies to efficiently produce multiple products, respond quickly to market changes, reduce time-to-market, adapt to shorter product life cycles and develop high quality custom designs. TMIS is an integrated system of all functional activities and processes required for manufacturing products. It consists of a set of computer-based integrated applications that together provide manufacturers with a common framework and a single access and control mechanism for all items of information, both hardware and software. This conceptual system consists of seven subsystems as shown in figure 2.6:

- business and market analysis

- product research and development

- computer integrated manufacturing

- production planning and control

- quality control

- business decision support

- feedback

TMIS distinguishes itself from other conventional computerised manufacturing systems, in its capability to integrate marketing, engineering, manufacturing and business databases into a decision support system. It requires a thorough understanding of the planning process, the particular requirements and capabilities of the process, and business strategies. A wellimplemented TMIS minimises the time required for engineering changes, contains costs, reduces scrap and rework, and decreases product time-to-market. TMIS also supports the quality efforts by meeting customers' needs and expectations for a 'good' product at a competitive price in a short time frame. 


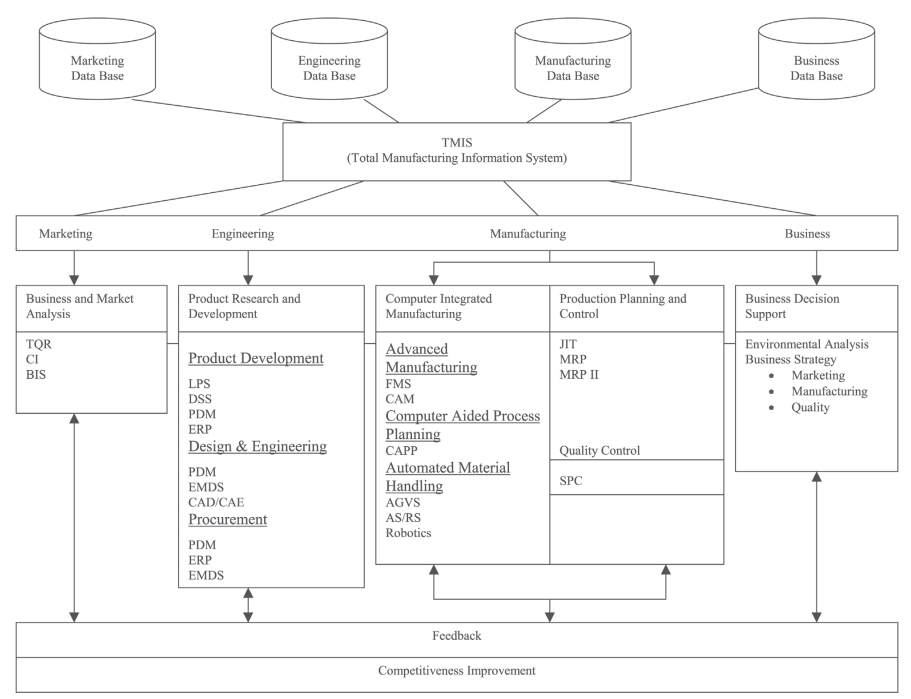

Figure 2.6 TMIS Overview

The TMIS is, however, not a system that can be implemented effortlessly in a company. Instead, TMIS is a framework that merely can serve as the basis for the implementation of an information system.

\section{Service-Oriented Architectures}

A service-oriented architecture (SOA) is an architecture in which functionalities are represented by interoperable services. SOA is an architectural style whose goal is to achieve loose coupling among interacting software agents. A service is a unit of work done by a service provider to achieve a desired end result for a service consumer. Both provider and consumer are roles played by software agents on behalf of their owners [Ugarte et al., 2009]. SOA takes business applications and breaks them down into individual functions and processes and represents them as services. Services are autonomous platform-independent computational elements that can be described, published, discovered orchestrated and programmed using XML for the purpose of developing distributed interoperable applications [Shen et. al., 2007].

A service in a SOA is considered to be an abstract business concept that represents the functionalities of a business. These services can be re-composited, reconstructed, and reused to create applications [Xu, 2011]. SOA can integrate heterogeneous systems and can function as an architecture for integrating platform, protocol, and legacy systems within an enterprise. It is considered as a suitable enterprise architecture as it is characterised by simplicity, flexibility, and adaptability. Services can also be made available to other members of the supply chain, enabling the integration of a whole supply chains. Hereby an environment is created that enables data exchange, responsiveness, collaboration, synchronisation, and visibility to be performed in real-time across the entire supply chain [Xu, 2011].

\section{Intranet Based Contract Management and Control System}

Hussain developed an intranet based contract management and control system that is based on the integration of quality and information management [Hussain et al., 2009]. This integration aims to improve operational performance by integrating all the data and 
information requirements of an organisation. Hussain employed an intranet based solution for this purpose, that allows all users of the system to maintain and access specific data locally within the framework of a quality management system. The system improved the management of contract and project information at the company where it was implemented and showed the following benefits:

- Easy storage, retrieval and management of information

- Improved team working and continuity between engineers

- Coordination, management and communication between geographically dispersed engineers

- Increased efficiency and effectiveness of the quality management system.

\section{Demand Activated Manufacturing Architecture}

The Demand Activate Manufacturing Architecture (DAMA) [Chapman \& Petersen, 2000] is an inter-enterprise architecture and collaborative model for supply chains. The model aims at enabling improved collaborative business across any supply chain. The DAMA model (figure 2.7) is a high-level model for collaboration to achieve demand activated manufacturing. The developed DAMA model consists of five elements:

- Activity: the activity(s) or processes involved in the accomplishment of a goal

- Information: the derived knowledge from the application of data that supports the process

- Application: the transformation of data into information

- Data: the detailed facts required providing information to support the activity

- Infrastructure: the underlying technical, business, and social foundations that support the process

The model assumes a collaborative supply chain, with multiple companies, working collaboratively to meet consumer demand. The companies share information about their products, manufacturing capabilities, allocations of capacity to the partnership, and day-today operational status.

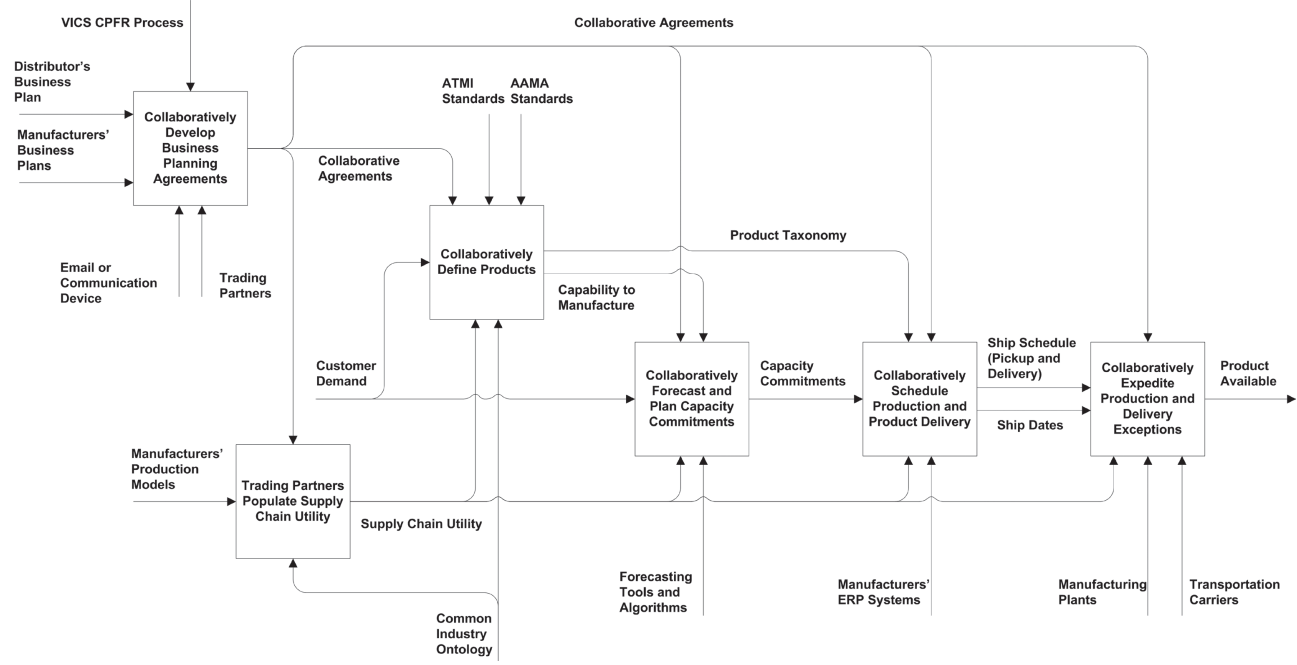

Figure 2.7 DAMA overview 


\section{Enterprise Resource Planning}

Enterprise Resource Planning (ERP) is a software application that automates the integration of internal and external management information across the functional areas of an organisation. It facilitates the flow of information between all the business functions and entities inside an organisation and manages the connections with the stakeholders outside the organisation. Traditionally, companies developed separate computer applications to satisfy needs of each of their functional segments, such as accounting, purchasing and planning. These systems, however, grew into inconsistent islands of information [Cardoso et al., 2004]. ERP systems promise to effectively integrate islands of information and structure systems to reflect best practices and ensuring total transparency and real-time information sharing [Gupta \& Kohli, 2006]. This combination and integration of business processes in the organisation and IT into one solution, is something that earlier initiatives, like material requirement planning (MRP) and manufacturing resource planning (MRPII), lacked. ERP can be considered as an extension of MRPII, but with enhanced and added functionality [Laframboise \& Reyes, 2005].

According to Akkermans [Akkermans et al., 2003]: "ERP is a comprehensive transaction management system that integrates many kinds of information processing abilities and places data into a single database. An ERP system primarily supports the management and administration of the deployment of materials, production capacity, human resources or capital within a company. ERP systems contribute to this aim by providing three types of functionality:

- Transaction processing functions: allowing integrated data management

- Workflow management functions: controlling the process flows

- Decision support functions: assisting in the generation of plans or in deciding the acceptance of customer orders"

Wallace and Kremzar define ERP as: "An enterprise-wide set of management tools that balances demand and supply, containing the ability to link customers and suppliers into a complete supply chain, employing proven business processes for decision making, and providing high degrees of cross-functional integration among sales, marketing, manufacturing, operations, logistics, purchasing, finance, new product development, and human resources, thereby enabling people to run their business with high levels of customer service and productivity, and simultaneously lower costs and inventories; and providing the foundation for effective e-commerce. [Wallace \& Kremzar, 2001]"

\section{Benefits and Drawbacks}

The introduction and implementation of an ERP system has a number of effects on the functioning of a company. ERP systems allow companies to manage their resources better, which leads to cost reductions and increased efficiency [Cardoso et al., 2004]. Because information becomes visible across the whole company, decisions can be made more quickly and accurate and with less errors. ERP systems are data-centric and provide a common homogeneous data infrastructure across the organisation aimed at the integration of distributed data. Its objective is to provide an integrated basis for serving all business units from one base of information, eliminating the need for complex synchronisation activities between different systems. 
Implementing an ERP system requires extensive investments, both in terms of capital and in terms of effort. Generally, ERP systems are implemented around the idea of prefabricated applications. Different vendors develop applications for particular sectors of the industry. Organisations acquire these applications according to their needs. These applications are parameterised to allow for some flexibility. To represent the business processes of a company closely within the ERP system, applications often need to be tailored by setting thousands of parameters [Cardoso et al., 2004]. This is the most time consuming part of an ERP implementation, as it requires a complete and formal capturing of all business processes. As such, this is beneficial, as the tacit knowledge within the company can partially be made explicit, thus allowing for business process re-engineering opportunities.

Quite often, ad-hoc pieces of software are internally developed in order to support activities like choosing a supplier. These ad-hoc pieces of software are internally developed as these are usually poorly supported in the generic prefabricated applications of the ERP system. These ad-hoc pieces of software can be very efficient, being often developed by their users themselves. The problem is that these additional systems take data from the ERP system that is seldom returned, this situation may set into question the consistency and continuity of the information flow. When the ERP system is integrated in the information flow of the supply chain, while taking into account these additional systems, one can conclude that ERP systems are only a method to create, structure and maintain information that can be used by other more reactive systems [Worley et al., 2002]

A disadvantage of an ERP implementation is that it often hinders the continuous improvement approach used by many companies. Any change to the system after the initial implementation will require an effort over a long period of time because of difficulties or impossibilities to make changes to the system.

Although the initial intention of ERP had a 'within-organisation' focus, many organisations have addressed supply chain challenges with their ERP systems [Laframboise \& Reyes, 2005]. ERP systems allow for the transmission and processing of information necessary for synchronous decision making, which is an essential SCM competency [Kuei et al., 2002]. However, the advantage of the fact that an ERP system is fully integrated for one company becomes a strategic disadvantage in a supply chain. Current ERP systems primarily focus on a single company and therefore lack the functionalities needed to connect different ERP system within an inter-organisational supply chain. The integration of ERP into a supply chain is therefore a complex and equivocal task. ERP systems are designed to reflect a particular way of doing business, and organisations therefore have to adapt to the ERP system and the other way around. This makes the integration of two or more different businesses in the supply chain difficult [Cardoso et al., 2004]. Modular, open and flexible ERP systems are required for these inter-organisational supply chains [Akkermans et al., 2003].

\subsubsection{Process Planning}

Process planning is one of the most important steps in the supply chain because it plays a key role in determining the cost of products and affects all manufacturing activities, competitiveness, production planning and product quality. Process planning is the bridge between product design and product manufacturing. It translates the design data into manufacturing information that can be used in production. It is the manufacturing function 
in a company that selects the manufacturing processes and parameters to be used to convert a part from an initial form to a final form. The available manufacturing capabilities of the company are during this step matched with the product needs in order to generate a process plan for the fabrication of the product. This process plan shows the different combinations of machines, setups, tools, operation times etc. that are needed to convert the raw material into the desired product. In the light of this thesis, which focuses on small to medium sized batches, one has to note that only available machinery is considered during process planning. No new machinery is acquired for the completion of a specific order. The acquisition of dedicated or special tooling for the fabrication of a specific product can however be considered during process planning. Whether the choice for dedicated tooling is made depends on the benefits these provide in comparison with standard tooling.

Traditionally, process planning was performed by hand and involved a lot of retrieval and manipulation of information. With the rise of computers, the search for computerised solutions for process planning has been a major research subject for many researchers and was called Computer Aided Process Planning (CAPP). There are two main approaches to CAPP [Denkena et al., 2007]:

\section{Retrieval / Variant Process Planning}

Early research into CAPP mainly focussed on retrieval / variant based process planning. This approach makes use of group technology principles for classifying the parts into part families based on their geometric and manufacturing attributes. Standard process plans are prepared for a representative part in each part family and stored in a database. Planning for a new part is done by retrieving a process plan for a similar part and making necessary modifications [Boër et al., 1990].

\section{Generative Process Planning}

The generative process planning approach aims at generating an adequate process plans from scratch for every product. This approach relies on the use of complete and accurate models of the parts and processes. The constraints and interactions of these models have to be described in detail. Automated reasoning and knowledge representation are used to generate process plans from these data. An example of such a generative CAPP system is the PART system for small batch part manufacturing [Houten \& Erve, 1992]. The software architecture of PART, as displayed in figure 2.8, contains several modules of which the functional modules are subdivided into phases that are executed as part of a selected scenario.

Due to the difficulty in capturing the enormous amount of manufacturing knowledge, most

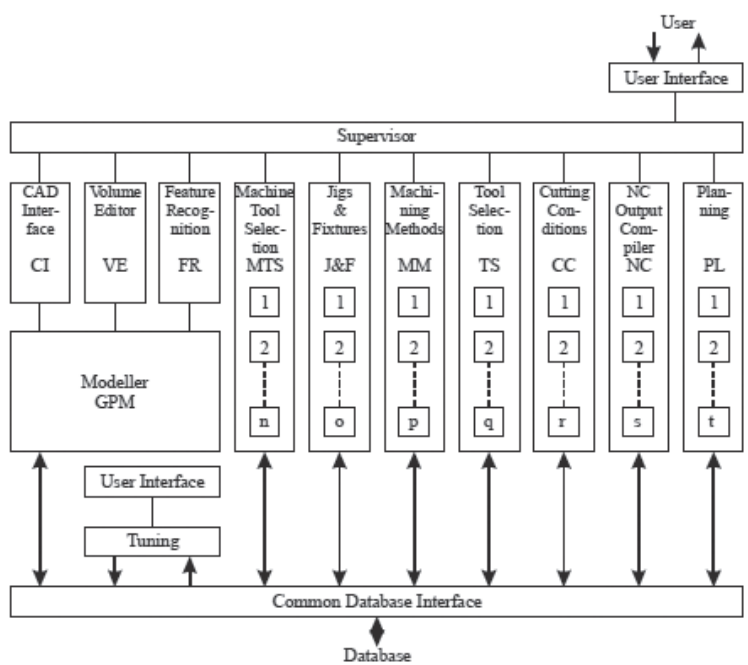

Figure 2.8 PART Architecture 
generative process planning systems are limited to single or small sets of manufacturing processes, such as milling, assembly, etc. While products become ever more complex, it seems to be too demanding to develop generative process planning systems that can deal with broad and multiple manufacturing processes. Especially the mutual influence between orders with different types of products within a generative process planning system grants problems which are difficult to overcome. Next to this, the incorporation of a rather restricted number of manufacturing features limits the applicability of several CAPP systems. Currently no complete automated process planning solution is available for small batch part production and vast product varieties. Existing solutions facilitate in-house mass production manufacturers and focus mainly on prismatic parts with minimal support for free form process planning [Denkena et al., 2007].

\section{Manufacturing processes}

Every manufacturing process has its own specific approach and difficulties associated with it. There are major differences in the process planning approaches used for each manufacturing process. This research focuses on both cutting and layered manufacturing. The differences between their common process planning approaches and their associated difficulties and research efforts are discussed in the following paragraphs.

\section{Cutting}

Process planning for machining centres is a complex process consisting of many different tasks. During this process, the product is analysed and setups, raw material dimensions and cutting methods and strategies are chosen by which the product is to be manufactured. Usually, many different combinations of solutions can be found for every product. The complexity here is to find the optimal solution, while doing justice to technologic, quality, cost and logistic criteria.. Typically, process planning is performed in a number of steps as described in figure 2.9.

The input for the process is the TPD of the product together with the requested quantities to be manufactured. During the first step, the manufacturing features are extracted from the $3 \mathrm{D}-\mathrm{CAD}$ representation of the product contained in the TPD. These manufacturing features are used by the subsequent process planning steps. A manufacturing feature in a cutting process is a volume that is removed by the cutting tool during machining. Figure 2.10 displays the basic approaches for transforming a CAD-model into a set of manufacturing features that can be used

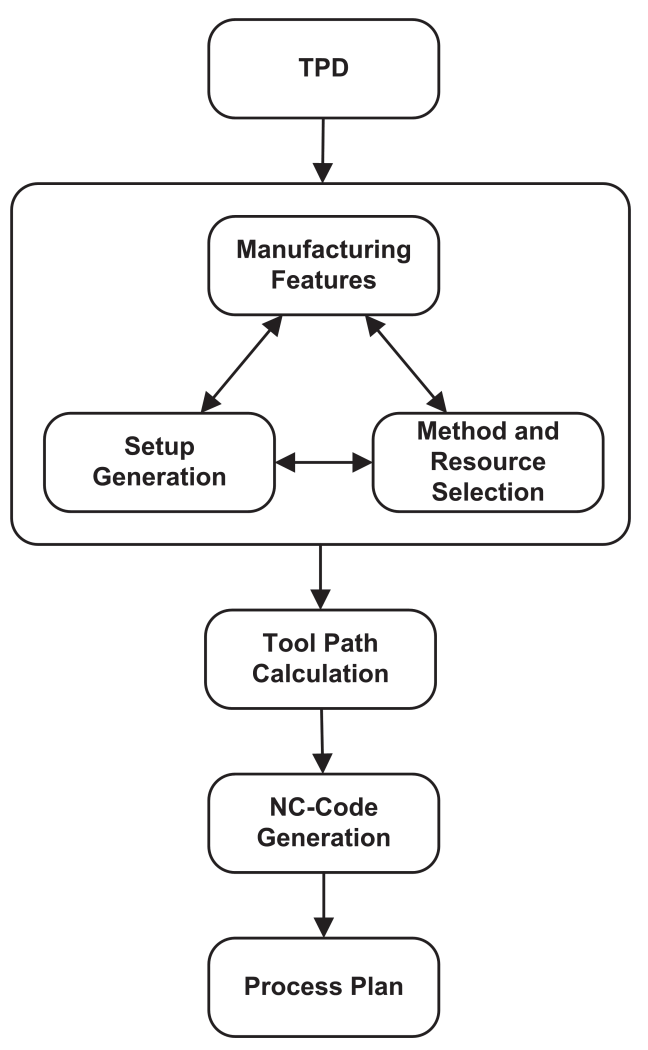

Figure 2.9 Process Planning for Cutting 


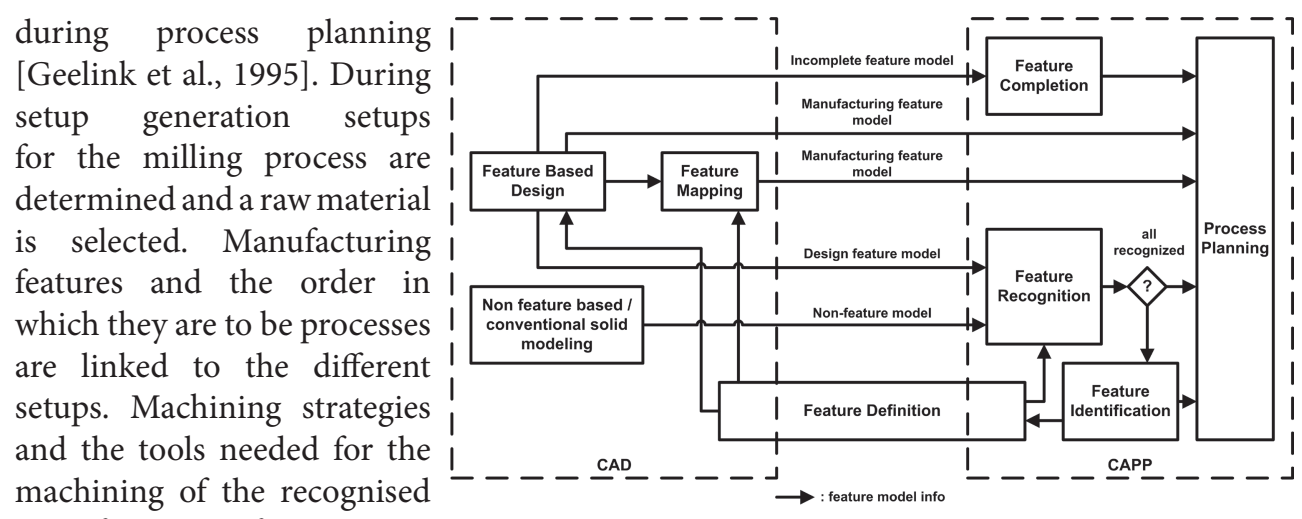
manufacturing features are selected during method and

Figure 2.10 Feature Recognition resource selection. During the next step the paths of the tools during machining are calculated and the NC-code is subsequently generated from this data. Next to the NC-code, information about the setups and raw materials to be used is contained in the process plan.

Computer aided process planning systems automate some or all of the process planning tasks described here. Here, the interaction with the user is minimised and the time required to produce process plans is reduced. CAPP optimises and computerises process planning. The process described in the previous section is, at the first glance, very straightforward and should therefore be easy to computerise and automate. However, major difficulties can be identified when looking at this process more closely. In its essence, feature recognition determines the volumes to be removed. During setup generation, the orientation and order in which these volumes are removed are determined. Method and resource selection determines the strategy and tools required to remove these volumes. The major problem here lies in the relations between these entities, because each of them is dependent on the other. Different volume shapes can be recognised based upon different orientations of the product, different strategies and tools can be used in different setups and different volumes can be removed by different methods and resources. This situation leads to a chicken and the egg problem where no deterministic starting point for the process can be found. As a result, many iterations take place between these three entities before a suitable solution is found for which tool paths can be calculated.

Process planning has been the subject of many researchers. Several have focussed their work on the overall process planning problem or on one of the specific sub-problems within the overall problem. In the following paragraphs the results and status of these researches are discussed.

\section{Manufacturing Features}

The developments of a number of laboratory prototypes in the late eighties showed that automatic process planning required a feature-based work piece description as a starting point [Tönshoff et. al., 1993]. The CAD model of the product, therefore has to be transformed into a model with manufacturing features. A feature is according to Wingard 'a generic shape that carries some engineering meaning' [Wingard, 1991]. A manufacturing feature in a cutting process is a volume that is removed by the cutting tool during machining. These manufacturing features are elemental basic shapes such as steps, slots, pockets, and holes as shown in figure 
2.11. These basic shapes can be easily machined by the available resources on the shop floor and defined machining technologies. Based on how the CAD model is built up by the engineer different approaches can be used to transform it into a manufacturing feature based model as shown in figure 2.10 [Geelink et al., 1995]. One of the approaches that is depicted in figure 2.10 is feature recognition. The basic idea of feature recognition is the discovery

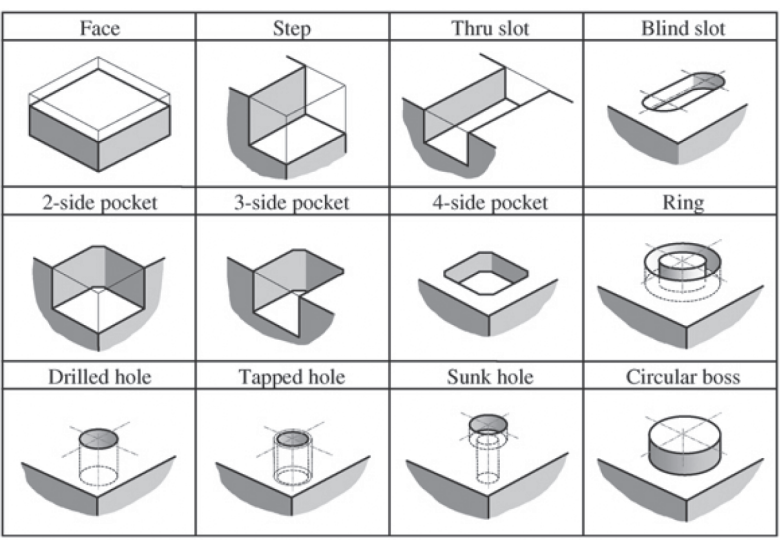

Figure 2.11 Manufacturing Features of topological and geometric patterns in 3D-CAD models and comparing these with characteristic manufacturing features. Verma discussed the different techniques and approaches for automating feature recognition [Verma \& Rajotia, 2010]. One of the most critical issues in feature recognition is the recognition of intersecting features. Currently none of the approaches is capable of handling arbitrary feature interactions. Next to this issue, nearly all research on featurebased machining of prismatic parts starts from a rectangular stock material. It is assumed that the extreme faces of the part lie on the original surfaces of the stock. This is however unrealistic, since characteristically, a flat surface is machined first to serve as a reference for machining other features accurately. Often, no region of outer surface of the stock remains in the finished part. Current research efforts mostly take a highly idealised view of machining practice [Verma \& Rajotia, 2010].

\section{Setup Generation}

The objective of setup generation is to identify the number and sequence of setups to be used when machining a part. During each setup one or more machining operations are performed on the product in a certain orientation. The orientation of the product and the sequencing of the operations performed during each setup is determined during setup generation. Next to this setup generation considers the design and configuration of the fixtures, locators, clamps and supports used in the determined setups[Yuru \& Gaoliang, 2005].

During setup generation a number of tasks have to be performed. These are:

- Raw material determination

- Feature sequencing

- Setup determination

- Fixture design

- Fixturing plan generation

During raw material determination, the dimensions and shape of the raw material are determined. As a product may contain many machining features, a proper sequence for machining these features is vital for achieving an efficient manufacturing process and a highquality product. The sequence in which features are machined is dependent on machining precedence constraints and geometric relationships between features. Handling feature 
interactions is hereby a critical issue. An interaction between features occurs when the cutting of one feature affects the subsequent machining of another feature. One or more setup orientations are determined from the feature sequences and features are allocated to these setups. The required fixture tools and the plan for fixturing the setup on the machine are also determined.

\section{Current state}

Several functioning setup generation systems have been proposed in literature. A short summary of these propositions is presented below.

Yuru and Gaoliang developed an integrated system for setup planning and fixture design. In this approach, a setup planning system is integrated with fixture design [Yuru \& Gaoliang, 2005]. Machining setups are automatically generated based upon the key factors of machining practice, tolerance requirement, and manufacturing cost. A hybrid rule based reasoning and fuzzy evaluation method is used to automatically design the fixture for the generated machining setups. Feedback from the fixture design design process is taken into account when generating machining setups. Through this approach it is ensured that feasible fixture plans are generated.

Contini proposes a system for generating setups for prismatic work pieces with $2 \frac{1}{2} \mathrm{D}$ features for machines with three, four and five axes. Setups are determined by taking into account the accessibility of the machining directions of the work piece and the technological constraints among the required operations. The technological constraints are analysed with a graphbased approach. This system however doesn't consider manufacturing features that can be produced by multiple machining directions [Contini \& Tolio, 2004].

Wang proposes a two-step adaptive setup planning approach. This approach consists out of generic setup planning and adaptive setup merging. The generic setup planning is achieved by applying machine-neutral feature-based reasoning according to the tool access directions of machining features, their tolerances, and machining technologies. Operation sequencing is also performed during generic setup planning. The final setups are determined during adaptive setup merging by focusing on the dynamic issues; machine capability, availability, and real-time scheduling requirements. An optimal setup plan is achieved by satisfying the weighted objectives including locating stability, setup number reduction, cost and make span minimisation, and maximisation of machine utilisation. Generic decisions are made in advance by the system and the machine-specific decisions can be decided at the last minute in order to accommodate possible changes on the shop floor [Wang et al., 2010].

Bansal proposes an integrated modular setup planning system. The system consists of feature recognition. setup planning, fixture planning and tolerance analysis modules. Setup plans are generated and evaluated while considering feature tolerance relationships, feature dependencies, general manufacturing rules, critical machine spatial constraints and fixturing feasibility simultaneously [Bansal et al., 2008].

Peng developed an Internet-based setup planning system. An intelligent approach of setup planning based on fuzzy set theory and Hopfield neural networks is used. In order to generate a global optimal setup plan, the system takes machining precedence, tolerance requirement, and fixturing constraints into consideration [Gaoliang et al., 2005a \& Gaoliang et al., 2005b]. 
Salehi developed an approach in which process planning is divided into preliminary planning and secondary/detailed planning. During the preliminary planning the preliminary sequences (setups) for a part based on the recognised manufacturing features and their interrelationships are determined. A genetic algorithm is used to explore the large solution space of valid operation sequences under the given constraints. The determined sequences are used in the next phase where the operations are optimised at the process level [Salehi \& TavakkoliMoghaddam, 2009].

\section{Method and Resource Selection}

The range of materials and the variety of tools that are capable of machining these materials has increased greatly over the last decades. This has complicated the work of the process planner who now has to choose from dozens of combinations. This situation has led to the development of computerised solutions for the calculation of efficient cutting parameters and the selection of tools or combination of tools for a specific operation or set of operations. Operation sequencing is also of importance during method and resource selection. Operation sequencing deals with the problem of determining in what order to perform a set of selected operations, usually within one setup. The target is to generate a feasible and optimal sequence of operations for a product based upon the technical requirements, available manufacturing resources and certain goals, such as cost and time.

\section{Current state}

Several implementations and approaches have been discussed and proposed by researchers. A selection of these are given in the following paragraphs.

Carpenter developed a decision support system for milling operations. The tool selection module of the system can select the best tool and calculate the optimised cutting data for an operation for efficient machining performance. Efficient machining performance is measured in several ways (minimum cost, maximum tool life, maximum production rate, etc.) and the selection of the preferred tools is performed by sorting a list of feasible tools by a compound objective function defined by the user [Carpenter \& Maropoulos, 2000].

D'Souza proposes and compares four different methods for finding an efficient tool sequence to machine an entire setup. These are: feature level optimisation, a composite graph method, a constrained graph method, and a sub-graph method. These methods generate the optimal solution subject to the assumptions and imposed constraints. Cost calculations are based on actual tool-path generated which gives a very accurate calculation [D’Souza, 2006].

Salehi developed as mentioned in the setup generation section of this chapter a process planning approach which is divided into preliminary planning and secondary planning. During the secondary planning of this approach the results of the first step are used to generate a detailed planning. During this step the machine tools, cutting tools and tool access directions are considered, and sequences of operations are optimised at the process level. Based upon selected criterions optimal or near-optimal process plans are generated by the developed system [Salehi \& Tavakkoli-Moghaddam, 2009].

Xu proposed a novel process planning schema. The methodology is based on process knowledge customisation, which integrates process knowledge with the manufacturing resources for process planning. The approach is a systematic methodology that addresses process reasoning 
mechanisms of process planning from the viewpoint of the manufacturing resources. Hereby the feasibility of the generated process plans is improved. Process parameters for milling are quantified and obtained by the proposed methodology [Xu et al., 2009].

\section{Interoperability}

Interoperability is the ability to exchange information seamlessly between different entities [Ray \& Jones, 2006]. Each of these information exchanges has to occur over an interface. A various and complex array of interfaces exist in the manufacturing environment [Houten, 1992]. Interoperability has an enormous impact on all entities of a supply chain. Interoperability allows companies the added ability to transfer component design, process planning and manufacturing data to not only identical duplicate plants with identical equipment, but also plants that use equivalent equipment/machine tools and controllers [Newman et al., 2008]. Next to this, interoperability will provide an enormous increase in the flexibility of production across the shop floor with parts being interchangeably manufactured and even shared across workstations with different $\mathrm{CNC}$ controllers and configurations.

As already discussed in section 2.2.1, information exchange is important to allow effective cooperation within a supply chain. The archetypical information flow for CNC manufacturing within the existing supply chain, as discussed in section 2.1.2, is shown in figure 2.12. During the engineering step at the customer a CAD system is used to generate a digital representation of the product geometry. This digital representation is stored in a CAD-file. CAD-files are often stored in proprietary formats but a number of standards make the exchange of these files among different CAD systems possible. The CAD file is forwarded to process planning. Process planning uses a CAM system to access the product geometry contained in the CAD file. Within the CAM system manufacturing information, like cutting strategies, tools and operation sequences, for the manufacture of the product is generated. This information is subsequently stored in a CAM file in a proprietary format. Process planning then utilises a postprocessor to generate the machine instructions from the CAM file. Postprocessors are setup for a specific machine configuration and outputs NC files. These NC files contain the instructions for the CNC machine and are created according to the ISO6983 standard.

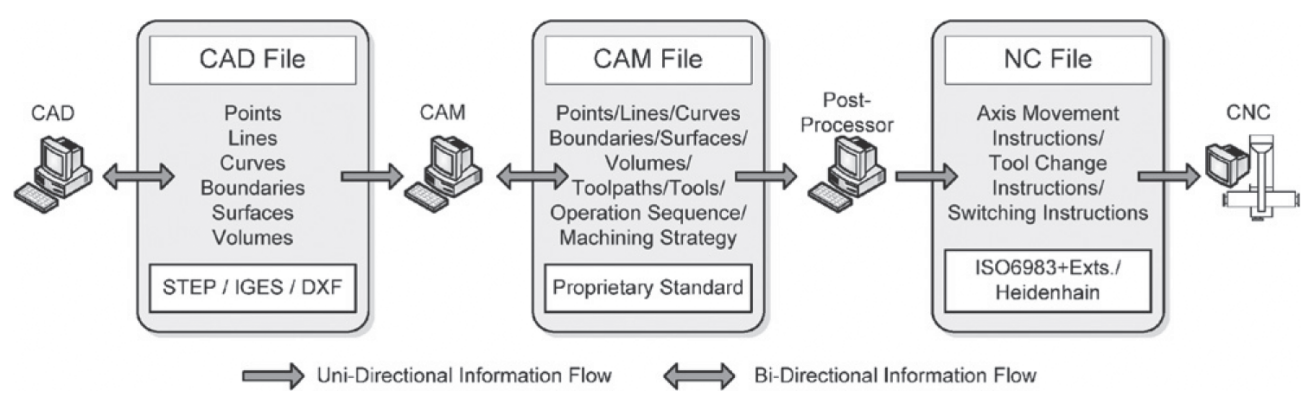

Figure 2.12 Archetypical Information flow for CNC manufacturing

During every step additional information is created and subsequently stored in a new data file. As a consequence of this, the design is basically pushed down the manufacturing chain and information is added during each successive step. The generated content during the different successive steps cannot be accessed by a previous step. Due to this one-directional information flow, it is very difficult to capture knowledge from the shop floor as modifications 
cannot be fed back up the information chain. For a supply chain to function effectively, it is imperative for the various systems used by the different entities of the supply chain to be able to exchange information in a reliable and rapid manner.

One way of exchanging information is to use a standardised format or interface. Such interfaces vary from extreme simple neutral file formats up to elaborate standards with (some) embedded intelligence. Keeping the middle between these two extremes is STEP. STEP is a collection of standards (Application Protocols) that is developed as a means to allow computer systems to exchange information with each other without using proprietary translation filters. The Express language is used for the definition of all of these STEP standards. Figure 2.13 [Newman et al., 2008] shows the manufacturing information flow in a supply chain utilising STEP. As in the existing chain, the chain starts with a CAD system that is used to create a digital representation of the product. This digital representation is stored in a feature based CAD file (STEP AP224) which in contrary to normal CAD files also stores feature information. This feature-based CAD is opened in the CAM system where manufacturing information is added. This information is stored in a AP238 STEP file which contains original geometry from the AP224 file and the manufacturing operations, manufacturing features, tools and machining strategies organised in "working steps" and "work plans". The data in these working steps are linked to the geometry of the AP224 file [Newman et al., 2008]. This file is send to an intelligent controller that is capable of interpreting the information contained in it and deriving the necessary axis movements and tool changes for the CNC machine automatically. STEP functions as an information carrier within this chain. The data flow is hereby streamlined and also becomes bi-directional. This creates the possibility to capture knowledge from the shop floor as modifications, which can be fed back up this chain.

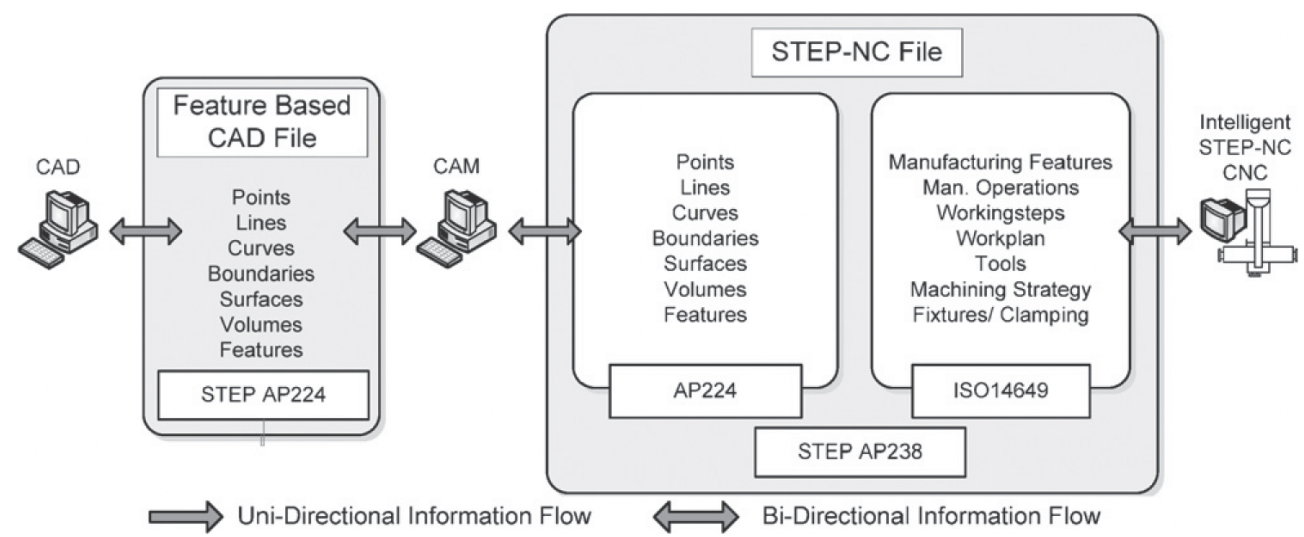

Figure 2.13 Information flow for CNC manufacturing with STEP

While several research groups have made some serious effort into creating a STEP-NC controller, none have yet been implemented commercially [Ray \& Jones, 2006]. This is perhaps due to the complexity involved in developing such a controller. In addition, as adopting AP238 would make the use of proprietary extensions to the NC code obsolete, controller manufacturers who often promote these extensions as additional functionalities have not been enthusiastic in becoming STEP-compliant as this interferes with their business concept. STEP primarily intends to offer the standardised exchange of data. The structuring of this data 
is performed in the various application protocols, which are dedicated implementations. Each of these application protocols can be interpreted as an interface that encompasses all possible information exchanges that can occur for that implementation. As a consequence of this, STEP has become overly complex.

\section{Overall CAPP solutions}

Several researchers have addressed the process planning problem as a whole by developing an overall CAPP solution.

Amaitik presented an intelligent process planning system using STEP features (ST-FeatCAPP) for prismatic parts [Amaitik \& Kilic, 2007]. ST-FeatCAPP carries out several stages of process planning utilising a hybrid approach of most recent techniques of artificial intelligence as the inference engine. Artificial neural networks have been used to select machining operations, cutting tools, and machine tools. A number of fuzzy logic models are implemented to select machining parameters for several machining operations, cutting tool materials, and work piece material combinations. Setup planning is performed based on a number of machining rules utilised by a simple setup planning algorithm. By using a hybrid approach of neural networks and fuzzy logic, a flexible CAPP system is developed that can be trained to handle new knowledge. The output of the system is a STEP-NC file that can be utilised by an intelligent controller.

Patil developed an intelligent feature-based process planning system (IFPP) that provides an integrated environment for the feature-based design and manufacture of prismatic parts [Patil \& Pande, 2002]. The system comprises of a feature based modeller (FBM) and an intelligent process planner (Autoplan). The FBM provides an environment for the design and validation of a feature-based solid part model. AutoPlan maps the feature information to the corresponding machining processes and generates the operation plan and $\mathrm{NC}$ code.

Lee proposed an integration between design and CAPP through the use of composite features. Composite features including precedence relations are recognised from the CAD data and used as input for process planning. The used feature recognition algorithm is based on orthographic projection. The process planning algorithm is based on topological sorting and breadth-first search of graphs. The system works well for parts consisting out of $2.5 \mathrm{D}$ features [Lee et al., 2007].

You proposed an interactive web-based CAPP system that consists out of three layers: client, J2EE server, and database server. The client layer provides users with a viewer to import CAD files, render 3D models, and define manufacturing features based on STEP AP224. The J2EE server layer supports the service for calculating manufacturing process planning. The database server layer handles the data models. The system is used to import the STEP file exported from CAD systems and render the 3D model, using the Java-based STEP Viewer. The features of the $3 \mathrm{D}$ models can be manually defined in the viewer. When a manufacturing process is required, the respective feature is send to a server, wrapped in a request. The response from the server is obtained and the manufacturing process information is added to the AP224 file [You \& Lin, 2005].

Wang proposed an agent-based approach for intelligent decision-making during distributed process planning [Wang \& Shen, 2003]. A two-level architecture for supervisory planning and operation planning is used and supported by agent-based decision-making. The system 
separates generic and machine specific information in process plans by assigning operation planning tasks to open-architecture CNC controllers. Wang expects that this approach can realise the dynamism and adaptiveness of process planning, and can increase the flexibility and performance on the shop floor in dynamic manufacturing environments.

\section{Overall Process Planning Evaluation}

The process planning is still a difficult topic in the manufacturing environment. Many (partial) solutions to structure and automate the process planning activities are suggested or already operational as presented in the previous paragraphs. However, difficulties still remain to be solved. The minimal support for free form process planning that is required in practice is one of these difficulties. None of the presented solutions is capable of performing this activity. Another topic of influence is the changing and wide variety of tools and machines and their capabilities that exist for cutting. The introduction of new tools and machines and the incorporation of these in the process planning activities is a constant struggle for most solutions. Next to this, a lot of effort is put in the STEP collection of standards as can be noted by the adoption of it in various solutions. Whether STEP will prove to be the solution that it is intended to be, depends on the future developments. All in all it can be concluded that considerable advances have been made in the field of process planning that have increased its efficiency and effectiveness.

\section{Layered Manufacturing}

Process planning for layered manufacturing is in its essence equal for each layered manufacturing technique. For every technique, the part needs to be oriented, nested (positioned) in the production tray and subsequently sliced. However, depending on the technique some slight differences can be noted. For some techniques like SLA and FDM supports materials or structures are required to support overhanging product features. These supports are removed after the production process. For SLS and LOM these support are not required. The basic steps used for layered manufacturing process planning are shown in figure 2.14 and discussed in the following sections.

\section{Model \& Manufacturability Check}

The input for the layered manufacturing process usually is a STL-file. The STL file approximates the shape of a product by using triangular facets. By using smaller facets a more accurate representation of the product surface can be made. This is illustrated for a sphere in figure 2.15. The STL model is first checked for correctness. Any holes or wrong facets need to be fixed before it can be used. The product represented by the STL-file is checked for suitability for the selected manufacturing technique. Manufacturability is checked on the basis of a number of product characteristics:

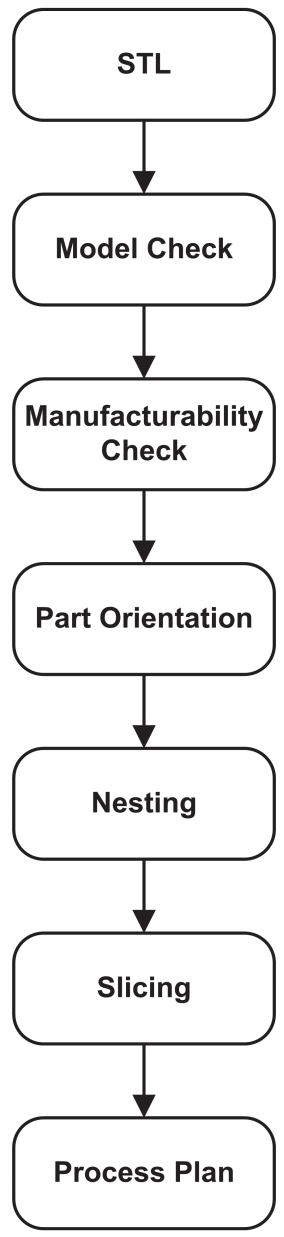

- minimum wall thickness: only products with a wall thickness Figure 2.14 Process higher than the machines capability can be taken into production. planning for layered manufacturing 
- product size: the product has to fit in the building area of the machine

- cleanability: products can be unsuitable for the cleaning process

- details: products can have a detail level in areas that surpasses the capability of the machine

Only products that pass both the model and the manufacturability check are suitable for production.

\section{Part Orientation}

Selecting the best orientation for a product is a vital part of process planning for layered manufacturing. This process is influenced by a number of factors [Lutters et al., 2012]:
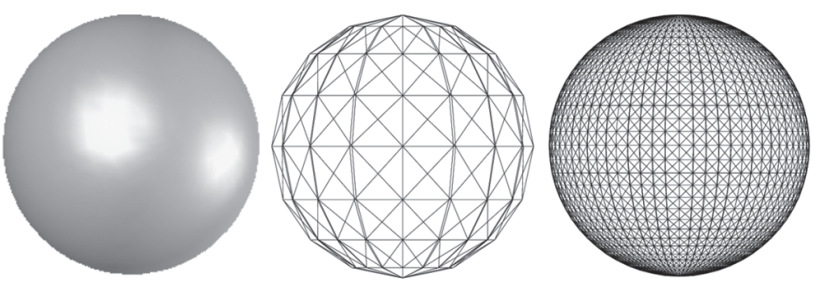

Figure 2.15 Facets of sphere

\section{Surface finish}

The orientation of a product affects the surface quality due to the so called staircase-effect. During layered manufacturing, products are constructed by placing layers on top of each other. Surfaces that are not parallel or normal to the build direction will have the staircaseeffect as shown in figure 2.16. In order to minimise the effects of this, the layer thickness can be minimised (if possible) or an orientation of the product has to be determined which minimises said effect.

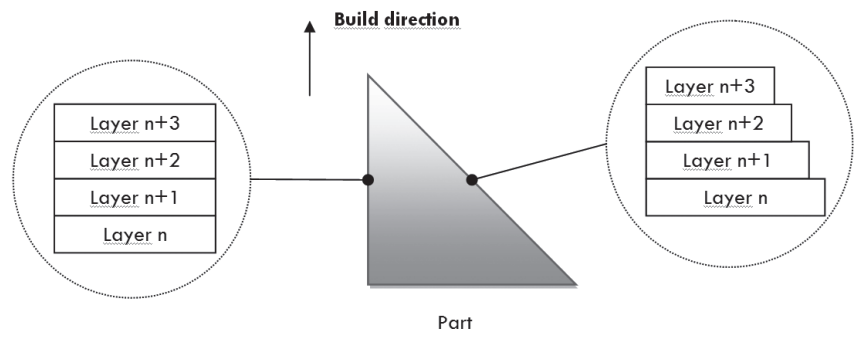

Figure 2.16 Staircase-effect

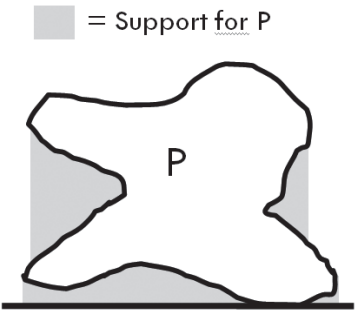

Figure 2.17 Support material

\section{Support Structures}

For some layered manufacturing techniques, support material is needed in order to be able to create cross-sections that are located at a higher position, see figure 2.17 . The amount of supports should be minimised because of cost and because it needs to be removed after production in an additional process step. It is therefore preferred that an orientation of the product is found that requires the least volume of support material.

\section{Build Time}

One of the main factors that influences the time required to manufacture a part by layered manufacturing is the model height. In order to reduce the build time an orientation of the product with the lowest height in the build direction needs to be chosen. 


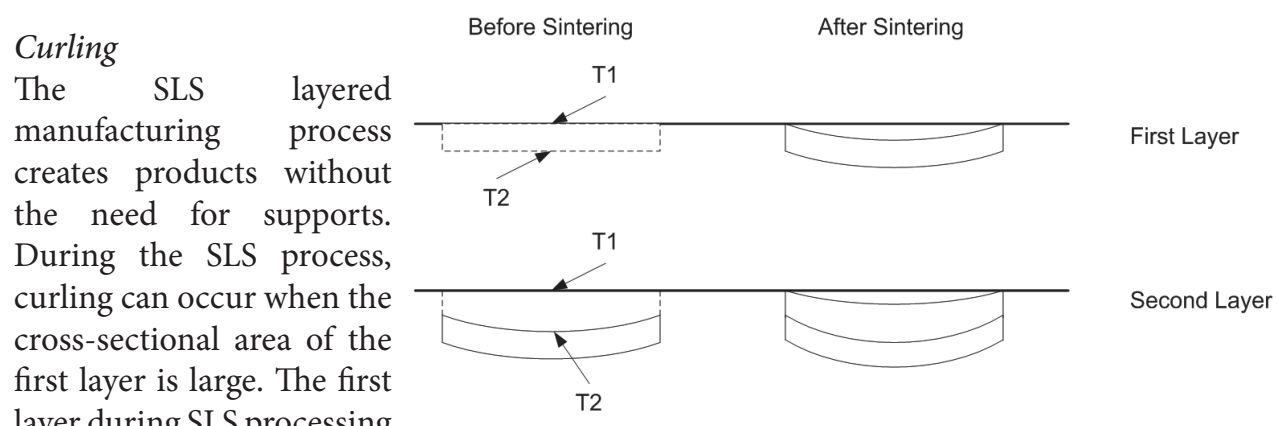
layer during SLS processing is constructed freely in

Figure 2.18 Curling space and the other layers are constructed on top of it until the product is finished. Due to nonuniform temperature differences in the tray, layers will experience different shrink rates. Due to the different shrink rates in the layer the first layer will start to curl, see figure 2.18. This curling effect can be reduced by reducing the cross-sectional area of the first layer.

\section{Orientation Methods}

Many researchers have proposed different approaches to solve the orientation problem of products for layered manufacturing. These approaches can be categorised in two groups: those focussed on optimising the fabrication time and cost and those focussed on optimising part quality and accuracy. These categorised approaches are shown in Table 2.2.

\begin{tabular}{|l|l|}
\hline Time and Cost & Quality and Accuracy \\
\hline Built time [Kim \& Lee, 2005] & Adaptive slicing [Kulkarni \& Dutta, 1993] \\
\hline $\begin{array}{l}\text { Minimal production cost [Alexander et al., } \\
1998 \text { ] }\end{array}$ & $\begin{array}{l}\text { Average weighted cusp heigth [Alexander et } \\
\text { al., 1998] }\end{array}$ \\
\hline $\begin{array}{l}\text { Minimise post-processing [Kim \& Lee, } \\
\text { 2005] }\end{array}$ & $\begin{array}{l}\text { Estimated average roughness [Pandy et al., } \\
\text { 2003 \& Pandy et al., 2004] }\end{array}$ \\
\hline $\begin{array}{l}\text { Support structure volume [Pham et al., } \\
1999 \text { ] }\end{array}$ & $\begin{array}{l}\text { Mechinical strength [Thompson \& Crawford, } \\
\text { 1995] }\end{array}$ \\
\hline & Part stability [Xu et al., 1997] \\
\hline & $\begin{array}{l}\text { Required post-machining region [Ahn et al., } \\
\text { 2007] }\end{array}$ \\
\hline & Stair stepping error [Lan et al., 1997] \\
\hline & Total overhang area [Xu et al., 1997] \\
\hline & Trapped volume error [Yew et al., 2000] \\
\hline & Volumetric error [Masood et al., 2003] \\
\hline & $\begin{array}{l}\text { Weighted average surface roughness [Byun } \\
\text { \& Lee, 2006] }\end{array}$ \\
\hline
\end{tabular}

Table 2.2 Orientation Approaches for Layered Manufacturing 


\section{Nesting}

During the nesting process the product is virtually placed in the production tray of the machine. This process is easy for trays in which only one product is placed. However the production efficiency of such trays is typically very low. To increase this efficiency more products are placed in a tray. By the introduction of more products the placement procedure becomes much more difficult. Products need to be placed close to each other in order to be able to pack as many in the tray as possible. Different nesting procedures have been described in literature. Research on this topic can be divided into two groups. The first group focuses on improving the algorithm that is used to explore the solution space and the second focuses on the actual part placement aspect of the problem.

\section{Algorithms}

The nesting process can be abstracted as an optimisation problem. It can be viewed as a generalisation of the quadratic assignment problem and therefore belongs to the class of NPhard (non-deterministic polynomial-time hard) problems. Consequently it is highly unlikely that an exact solution to the nesting problem can be obtained in a reasonable amount of time. Algorithms are typically used to generate acceptable solutions for these problems. Algorithms that have been used in literature to solve nesting problems are listed below:

- Heuristic rule-Based Approaches [George \& Robinson, 2003 \& Cagan et al., 2002]

- Genetic Algorithms (GA) [Mi et al., 2008]

- Simulated Annealing (SA) [Kirkpatrick et al., 1983]

- Extended Pattern Search Algorithms (EPS) [Yin et al., 2000]

- TABU Search Algorithm (TS) [Musliu, 2011]

- Hybrid approaches [Talbi, 2002]

\section{Placement Rule (decoder)}

In the above section, different algorithms were explained that can be used to explore the solution space of the nesting problem. However algorithms are only a tool to generate a nesting sequence whose suitability cannot be evaluated directly. A decoder is required to translate the nesting sequence into a real world nesting configuration. This nesting configuration can then subsequently be evaluated with the help of an objective function. A lot of research with respect to this placement rule has been performed in $2 \mathrm{D}$ cases. However, research on placement rules in $3 \mathrm{D}$ are rare.

\section{Deepest Bottom Left with Fill Method (DBLF)[Karabulut \& Inceoglu, 2004]}

This method is an extension to the already available $2 \mathrm{D}$ bin packing decoders and is based on the Bottom Left (BL) and Bottom Left with Fill (BLF) principles. The BL method first moves the object down as far as possible, then the object is moved to the left as far as possible and finally it is lowered so it rests on another object. The BLF algorithm keeps track of the free positions in the layout and also the size of the available area. The objects are placed into the lowest possible position that has sufficient space for an object. This ensures that the opens spaces within the layout are also filled if possible. DBLF is an extension of the BLF method to the 3D domain. DBLF first moves the part to the deepest available position ( $\mathrm{z}$ ), than it moves the part as far as possible to the bottom (y) and finally as far as possible to the left (x). The DBLF method also uses a list in which all the empty spaces are recorded. Before a new part is placed inside the tray it is first checked against the available open spaces to determine if it fits. 
After the part has been inserted into this new position the list is updated. The last step consists of sorting the list in the deepest bottom left order.

Extreme Point-Based Heuristics [Crainic et al., 2007 \& Martello et al., 2000]

The extreme point-based heuristic is an extension to the corner point method. The corner point method is basically a $2 \mathrm{D}$ method that can be extended to the $3 \mathrm{D}$ problem. The corner point method calculates new points in the tray where new parts can be packed. This drastically reduces the amount of positions at which parts can be placed. Parts are placed on these positions with their bottom left corner points. Once an item has been placed a new calculation is performed in order to determine the new corner points that have become available. This $2 \mathrm{D}$ approach is extended to the $3 \mathrm{D}$ domain by slicing the $3 \mathrm{D}$ problem in the build direction.

\section{Slicing}

Slicing is the final step of process planning for layered manufacturing. During this process the product(s) are sliced in layers. These layers are the layers by which the product(s) will be produced on the layered manufacturing machine. The result of this step is a file that describes all these layers. This file can be send to a layered manufacturing machine for production.

\section{Differences between Cutting and Layered Manufacturing}

When looking at both the process planning activities of cutting and layered manufacturing one can note that these are very different from each other. One of the most striking differences is the fact that during process planning for cutting typically one process plan is made for one specific product, while during process planning for layered manufacturing typically one process plan is made for several different products at the same time. Next to this there is a big difference in the complexity of the process planning activities between cutting and layered manufacturing. The whole product is basically re engineered during process planning for cutting. Every aspect of the product is interpreted during this process and an almost unlimited number of combinations between machines, tools, raw materials and cutting strategies can be applied for its production. With layered manufacturing this re engineering and interpretation step is not required as the geometry of the product is directly 'printed' with layered manufacturing. The complexity here merely lies in the selection of the technique and machine by which the product is produced and the subsequent orientation of the product in the production tray with eventual other products.

\subsubsection{Planning and Scheduling}

Planning and scheduling is a topic that influences both the manufacturing environment and the supply chain. It concerns the time-based allocation of orders to the available resources. This allocation is based upon the process plan as generated by process planning [see section 2.2.2] that specifies the different tasks that need to be performed for the production of an order. The matching of these tasks to the resources that are at the disposal, in detail levels ranging from coarse to very specific, is performed during planning and scheduling.

\section{Planning and Scheduling in a manufacturing environment}

Planning and scheduling is one of the entities that has great influence on the performance of a manufacturing environment. Planning and scheduling concerns the decisions about future courses of action that are mostly based on expectations (e.g. demand forecast, resource 
availability, and material supply) [Vancza et al., 2011]. Both planning and scheduling concern the same topic, a distinction can be made between them based on their detail level. Capacity planning, in a manufacture-to-order environment, comprehends the rough production planning activities in a production plant within a certain time frame. Scheduling concerns the short term allocation and the sequencing of the jobs to the resources on the manufacturing floor [Giebels, 2000]. Manufacturing resources and time are assigned to the required manufacturing processes as detailed in the process plan. The goal of scheduling is to determine the most appropriate moment to execute each operation plan, while taking into account the temporal relationships between manufacturing processes and the capacity limitations of the manufacturing resources. The optimality of the schedule is judged based on different criteria such as cost, tardiness and throughput [Wang et al., 2006].

Approaches to planning and scheduling have been widely studied due to its practical usefulness [Giebels, 2000]. The combinational aspects and the dynamic nature of the planning and scheduling subject make it a tough subject to tackle and various methods have been proposed. However, whether analytical, heuristical or meta-heuristical, these approaches encounter difficulties as they are often too inflexible, expensive and/or inefficient to be applied to real world situations as they use simplified theoretical models [Shen et al., 2006].

\section{Planning and Scheduling in a Supply Chain}

In a supply chain, planning and scheduling has a key role in the coordination of the orders and the optimal assignment of the different resources [Kovacs \& Mezgar, 1998]. As soon as a manufacturing unit tries to achieve coordination with its partners, it quickly faces difficulties associated with different operational conventions, locally specific constraints, software legacy and properties, conflicting objectives and misaligned incentives [Bruccoleri et al., 2005]. Centralised approaches can only be applied to tackle these problems if the parties are strongly tied together through the sharing of information and have a cooperative attitude [Vancza et al., 2008]. The production activities of several distributed production plants can be cooperatively planned and scheduled, this is however a difficult task [Kovacs \& Mezgar, 1998]. A planning generated on a global level for several production plants must subsequently be translated into a schedule for the local production plants [Shen et al., 2006]. In order to be able to generate an effective planning for multiple distributed production plants, it is imperative that these behave in a predictable manner. Efficient planning that results in executable, cost-efficient and stable production schedules are the key in achieving this predictable behaviour [Vancza et al., 2011]. Recently, agent-based approaches have been applied to resolve distributed planning and scheduling problems as these are capable of communicating and cooperating with other software systems in order to solve these complex problems [Wang et al., 2006]. Agent-based approaches to planning and scheduling have several advantages [Shen et al., 2006]:

- Agents allow the use of parallel computation, which may provide scheduling systems with high efficiency and robustness.

- Agent can facilitate the integration of manufacturing process planning and scheduling.

- With adequate learning, agent-based approaches make it possible to trade-off local performance to improve global performance, leading to cooperative scheduling.

- Resource agents may be connected directly to the physical devices they represent for so as to realise real-time dynamic rescheduling. It may therefore provide the manufacturing system with higher reliability and device fault tolerance. 
- Schedules are achieved by using mechanisms similar to those being used in manufacturing supply chains (i.e., negotiation rather than search). In this way, the manufacturing capabilities of manufacturers can be directly connected to each other and optimisation is possible at the supply chain level, in addition to the shop floor level and the enterprise level.

Every method that is applied to accomplish the planning and scheduling tasks within a supply chain requires information from the other entities in the supply chain. Consequently, proper supply chain information management [see section 2.2.1] is fundamental for achieving adequate planning and scheduling.

\subsubsection{Knowledge Management}

Knowledge has become an important subject in the current manufacturing environment. Knowledge can be perceived to be any idea, insight, know-what, know-how or meaningful information that can be used to achieve an objective [Wong \& Aspinwall, 2006]. In other words, it can be seen as the experience and expertise an enterprise has in achieving certain objectives, and is therefore an important strategic asset. Knowledge management (KM) is a strategy for improving organisational competitiveness and performance as it:

- reduces costs

- increases profitability

- improves products and services

- decreaces response time

KM can be understood as a formalised and active approach to manage and optimise knowledge resources in an organisation [Wong \& Aspinwall, 2006]. KM facilitates the capturing, storage, and dissemination of knowledge using information technology. It improves the effective sharing of knowledge among organisations and individuals by making the knowledge apparent to all of them with proper access control. It also enables people and organisations to share expertise and develop a learning organisation, teaching their members, and learning from experiences [Kim \& Smari, 2005]. Proper KM can propel an organisation to become more adaptive, innovative, intelligent and sustainable [Wong \& Aspinwall, 2006]. Knowledge is a broad concept and may exist in various forms such as declarative/procedural, explicit/tacit, and general/specific. To manage these various types of knowledge, a systematic approach that includes knowledge analysis, knowledge formalisation, and knowledge reasoning is desired [Lai, 2005].

Lai pointed out several major problems related to KM [Lai, 2005].

- It is difficult to pursue and integrate KM, due to a lack of systematic approaches.

- Both declarative and procedural knowledge must be captured, stored, and analysed to solve problems.

- KM must support the continuous change of knowledge.

- A common understanding of knowledge is required among knowledge workers for sharing and interoperating knowledge.

- In times of increasing information overload, finding relevant information is becoming increasingly critical. 


\section{Knowledge Management in Process Planning}

Knowledge management is applied in many parts of organisations. In the light of this thesis knowledge management applied during process planning [see section 2.2.2] is of importance. One of the important topics in a generative process planning system is the setup of a knowledge base that reflects the experience and knowledge of the expert process planners. The knowledge and experience of process planners has to be captured for the creation of such a knowledge base. By structuring and representing the captured knowledge in algebraic expressions or logical expressions, the knowledge can be utilised in a process planning system. The construction of such a knowledge base for process planning, which enables the accumulation, sharing and maintenance of knowledge and experience of process planners, is still an issue. A knowledge base has to fulfil three requirements [Park, 2003]: it needs to be transparent, support knowledge sharing and be able to adapt to changes. The knowledge contained in a knowledge base is generally used in process planning systems through the following methods [Grabowik \& Knosala, 2003]:

- Statements

- 'Sharp' and fuzzy rules

- Decision trees

- Decision tables of rules

- Frames

- Object representations

Several approaches to the extraction and structuring of knowledge for process planning purposes are recommended in literature. Ullah developed a knowledge extraction method that utilises probabilistic reasoning as well as fuzzy logical reasoning in order to extract expert machining knowledge [Ullah \& Harib, 2006]. Park developed a knowledge capturing method for process planning [Park, 2003]. It employs a three-phase modelling methodology. From the three-phase modelling methodology, four knowledge elements for process planning are derived; facts, constraints, way of thinking and rules. Facts cover all data objects, and constraints correspond to the technological requirements of process planning. The way of thinking imitates the intelligence of human experts, who are capable of quickly decreasing the solution space without losing reasonably good solutions. Rules are key parameters that control the way of thinking and can be extracted from it. The system has been applied to the process planning for machining holes.

\subsubsection{Workflow Management}

The existing supply chain as depicted in section 2.1 is a vast collection of tasks and activities that need to be completed to achieve a certain goal. The sequence in which these tasks and activities are performed is considered as a workflow. It is apparent, that the management of the creation and execution of workflows is of importance for the efficient operation of a supply chain. This section elaborates on the workflow management topic by explaining what a workflow is and how these influence the supply chain.

\section{Workflow definition}

There are different views on workflow in literature. According to Basu, a workflow is an instantiation of a process under certain conditions. The specific collection of tasks, resources and information elements involved in such an instantiation makes up a workflow [Basu \& Blanning, 2000]. In this view, workflows associated with routine processes are called 
production workflows and those associated with non-routine processes or novel situations are called ad hoc workflows. Georgakopoulos defines workflow as a collection of tasks organised to accomplish a business process. In addition to a collection of tasks, a workflow defines the order of task invocation or condition(s) under which tasks must be invoked, task synchronisation, and information flow [Georgakopoulos et al., 1995]. A more specified view is given by the Workflow Management Coalition (WFMC). According to the WFMC a workflow is defined as: "The automation of a business process, in whole or part, during which documents, information or tasks are passed from one participant to another for action, according to a set of procedural rules" [WFMC, 2008]. This is, however, a more restricted view as it assumes workflows are created to (partly) automate activities in business processes. The WFMC definition is used in this thesis as the automation of business process activities is one of the primary goals for the development of the system that is the subject of this thesis.

\section{Workflow description}

Workflow is closely related to a business process that consists of a number of tasks that need to be performed and a set of conditions or relationships that sequence these tasks in a specific execution order. A workflow description describes such a business process by identifying workflow activities, the dependence relationships between these activities and the control data required to manage this workflow. An activity within a workflow is a defined task that forms one step within a process. The relations between activities, like execution or information dependencies, are used to sequence the activities when the process is executed. The role, input / output and time duration of each activity is designated during the modelling of an activity. These are used to describe the process performed by the workflow.

\section{Workflow Management System}

Workflow management systems allow organisations to streamline and automate business processes and re-engineer their structure, as well as increase efficiency and decrease costs [Cardoso et al., 2002]. Workflow management systems are used to support different types of workflows:

- Workflows involving humans; in this type of workflow, the workflow management system is responsible for controlling and coordinating the human tasks.

- Workflows involving systems and applications; in this type of workflows the workflow management system is responsible for the control, coordination, and execution of computation-intensive operations and specialised software tasks, with little or no human intervention.

- Transactional workflows; this type of workflow involves human intervention and system orientation that is transactional-based. These workflow management systems are involved in the coordinated execution of multiple tasks that may involve humans, require access to heterogeneous, autonomous and distributed systems, and support selective use of transactional properties for individual tasks or for entire workflows.

A workflow management system provides a model and tools for specification, analysis, and execution of workflows. It forms a framework to capture the relations among the tasks and to automate the execution in such a way that it obeys the business process [Senkul \& Toroslu, 2005]. Workflow management systems are considered as efficient tools that enable the automation of organisational business processes. Workflow management systems provide an increased process efficiency through automation, process standardisation, improved information 
availability, automated assignments of tasks, and process monitoring [Xu, 2011]. A typical workflow management system consists of software components to store and interpret workflow definitions, create and manage workflow instances and control their interaction with workflow participants and applications. A workflow instance is the representation of a single enactment of a business process and is created and managed by the workflow management system. During their execution, a workflow instance can access (legacy) systems, databases, applications, and can interact with users. Workflow management systems are flow-independent, which makes applications

Build Time

Business Design

\& Definition
Business Process Analysis, modelling \& Definition Tools

independent from the underlying workflow management system [Cardoso et al., 2004]. A workflow management system usually consists out of three main parts [WFMC, 2008] as shown in figure 2.19. The build time functions are responsible for defining and managing the workflow processes. The run time functions are responsible for executing, monitoring and managing the workflow processes in an operational environment. Next to this the workflow management system interacts at runtime with human users and applications to fulfil the tasks.

Simple predictable processes within a single organisation can be designed, monitored and controlled by a single workflow management system. In practice, however, this is often not the case because of the presence of dynamically changing and complex processes in many organisations [Chung et al., 2003]. Workflows are generally rather static after their creation as they typically cannot be adapted while in operation. It is therefore difficult for a workflow to handle exceptions that are not foreseen during its development. A special kind of workflow is the adaptive workflow. These workflows aim at providing process support like normal workflow systems do, but in such a way that the system is able to deal with certain changes. These changes may range from ad hoc changes such as changing the order of two tasks for an individual case to the redesign of a workflow process. [Chung et al., 2003]

\section{Workflow Management System Implementation}

The implementation of a workflow management system can be interpreted as a bottom-up approach where the building blocks are identified first. Subsequently, a workflow is created, from the ground up, from these parts. The workflow management system is hereby customised to the business process [Cardoso, et al., 2004]. There are a number of challenges that workflow management systems need to overcome within organisation during its implementation and operation [Basu \& Kumar, 2002]: 
- processes within an organisation can span multiple, geographically distributed locations.

- workflow management systems used for sub-processes may be different and not support interoperability

- a process may span multiple organisational departments or even other members of the supply chain.

A workflow implementation typically starts with an analysis and optimisation of the as-is business process, as shown in figure 2.20. The existing (as-is) business process is analysed as input for the to-be business process that is supported by a workflow management system. During this analysis the different activities to be performed as part of the business process are identified together with their mutual relations. The integration possibilities with the workflow management system of the applications used by the different activities is also determined. The to-be business process that is supported by workflow management is subsequently modelled from this information. Based on the to-be business process a workflow scheme is created for the business process. The control and data flow requirements of each activity is determined as well as their mutual dependencies. A workflow model that can be executed by the workflow management system is created based on the workflow scheme. Next to this the applications employed by the different activities and tasks are connected with said workflow model. The workflow model is implemented in the workflow management system. The

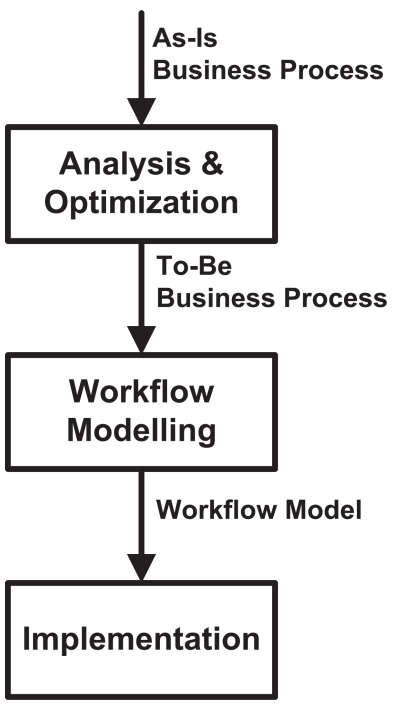

Figure 2.20 Workflow management system implementation workflow is model tested both virtually and in the field and subsequently put into operation when found suitable.

\section{Worfklow Management and ERP systems}

Workflow management systems and ERP systems [see section 2.2.1] both focus on the automation of business processes, data transfer, and information sharing across an organisation. The approach taken by both is, however, very distinct. Cardoso categorised these distinctions in tTable 2.3[Cardoso et al., 2004].

ERP systems are rather limited in their application field and are only suitable for domains for which reference models exist that suit the organisation. The main reason for this is that ERP applications are primarily function oriented and can, therefore, not be adapted easily in a changing business environment [Li \& Fan, 2003]. In a function oriented system activities are organised and managed vertically by function. This frequently results in problems occurring at the boundaries of the functional departments. In order to overcome this situation, the ERP system needs to be process oriented. In a process approach activities are organised and managed horizontally in the way they create value. Workflow management systems are the key technology for developing these process-based applications. Workflow based ERP systems show the following three advantages compared with the function based ones. 
- Flexibility. The specification of workflow relation information is separated from the specification of the logic of the application functions. The business process and the function of the ERP system can be built separately. The software component can be built according to the business process. After that, the process modeller can build the relationship between the software components and the activities in a process later. This separation allows the model of the process underlying the ERP application to change without affecting the associated activity implementations. It is the predominant reason why enterprises are investing in workflow technology today.

- Reusability. This advantage is based on the structure of the workflow-based applications themselves. Activity implementations for process models are typically flow-independent and free of assumptions about their usage. Therefore, a particular activity implementation can be used in many different process models.

- Integration capabilities. The workflow model integrates the different activities into processes by the flow relationship and information dependency. Heterogeneity information systems can be integrated into one process because the functions are encapsulated into different components.

Li and Fan put forward a workflow based ERP system to meet the requirements of flexibility and responsiveness [Li \& Fan, 2003]. On the bases of workflow management systems and component-based development, the architecture of the ERP built on components is given. Because the workflow management system support the dynamic change of the model and the workflow model and the software component are independent, the model can change in every stage of its life cycle. The model change method is shown in figure 2.21. Changes are incorporated by an administrator who can change the model. True dynamic and instantaneous model creation is, however, not achieved by this system. No automated system is in place to create new models from the created components in order to fulfil new needs; only the current model can be changed.

\begin{tabular}{|l|l|l|}
\hline \multirow{4}{*}{ Domain scope } & Workflow Management Systems & ERP Systems \\
\cline { 2 - 3 } & Customised processes & Embedded processes \\
\cline { 2 - 3 } & Domain Independence & $\begin{array}{l}\text { Domain specific (use of reference } \\
\text { models) }\end{array}$ \\
\cline { 2 - 3 } Te ch nological l & Ad-hoc and dynamic domains & Static domains \\
\cline { 2 - 3 } scope & $\begin{array}{l}\text { Pupport workflows involving } \\
\text { humans, IT applications, and } \\
\text { transactional workflows }\end{array}$ & Transactional processes \\
\cline { 2 - 3 } & $\begin{array}{l}\text { Heterogeneous and autonomous } \\
\text { environments }\end{array}$ & $\begin{array}{l}\text { Homogeneous environments with } \\
\text { common data infrastructures }\end{array}$ \\
\hline \multirow{2}{*}{$\begin{array}{l}\text { Implementation } \\
\text { s } \mathbf{m}\end{array}$} & $\begin{array}{l}\text { Acquired as ready systems; Code } \\
\text { automatically generated }\end{array}$ & $\begin{array}{l}\text { Based on pre-written 'off-the- } \\
\text { shelf' components }\end{array}$ \\
\cline { 2 - 3 } & Bottom-up approach & Top-down approach \\
\cline { 2 - 3 } & May require data conversions & Require data conversions \\
\hline
\end{tabular}

Table 2.3 Workflow Management and ERP Systems Comparison 


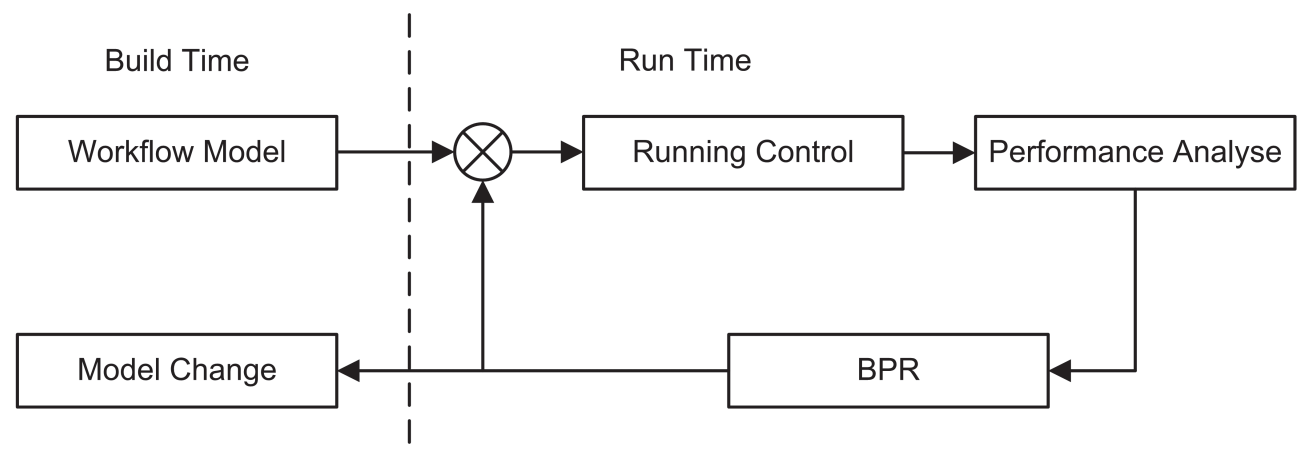

Figure 2.21 Model change method

\section{Workflow and Cost Management}

Workflow management and activity-based costing ( $\mathrm{ABC}$ ) can be used to get in insight in the cost structure of a company. $\mathrm{ABC}$ was introduced by Cooper and Caplan as an alternative to traditional costing methods [Cooper \& Kaplan, 1988]. ABC is a costing method that computes product value by allocating management resources based on the various activities in the manufacturing process. Figure 2.22 shows the general flow of $\mathrm{ABC}$. With $\mathrm{ABC}$ costs are assigned to activity centres based on their consumption of resources. Activity costs are the subsequently assigned to products or services in proportion to a selected measure of their individual workloads. Cost pools can be setup in activity centres to represent various precise business activities of a department. Hereby multilevel allocation can be performed and costing can then be analysed in detail [Watanabe \& Kaneda, 2004]. ABC can be applied naturally to a workflow by using the processes which comprise the workflow as activity centres. $\mathrm{ABC}$ management examines all processes that are relevant to the production of a product and attempts to determine exactly what portion of each resource is consumed. Hereby a realistic view of the costs is created which allows managers to make decisions based on more accurate information [Gupta \& Galloway, 2003]. By using $\mathrm{ABC}$ in combination with workflow management the effect of the use of processes on the costs can be identified and analysed. Workflows can be selected for order completion which are the most cost efficient. Next to this the processes within workflows can be identified that drive the production costs. These processes can then be selected for improvement initiatives to lower their costs.

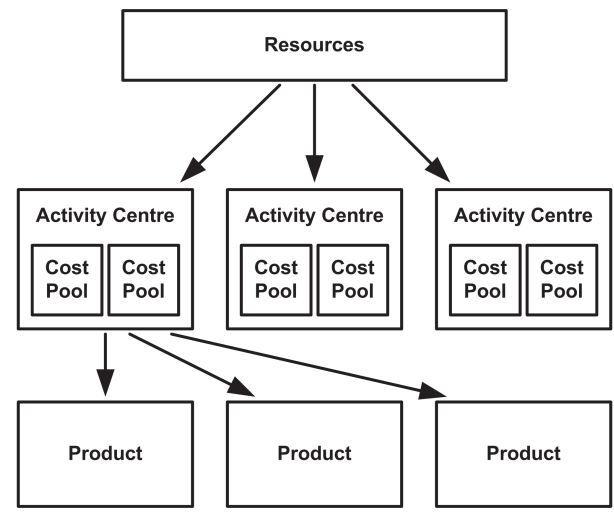

Figure 2.22 Activity based costing

\section{Workflow Management and Supply Chain Management}

Workflow management systems are important for the operation of integrated supply chains [Basu \& Kumar, 2002]. The open structure of the internet allows for flexible supply chains on the one hand and tightly integrated supply chains due the transparency offered by web-based systems on the other hand. In this environment, workflow management becomes crucial for the effective functioning of these supply chains. By having a dedicated automated system in 
place for managing business processes in the supply chain, these processes can theoretically be executed faster and more efficiently [Xu, 2011].

In the supply chain, separate workflows describe the activities performed by the different companies. Theoretically, these workflows can be integrated into an overall workflow spanning the whole supply chain and describing the interactions between the companies involved in said supply chain. With a workflow system it can then becomes easier to integrate a supply chain. A workflow management system can namely function as a bridge between two or more organisations in the supply chain. A workflow management system in the supply chain does not require radical changes to basic applications and data infrastructures of the organisations. It creates a workflow business process that can span many organisations, reflecting the supply chain [Cardoso et al., 2004]. Workflow management systems propagate information between the nodes of distributed systems and synchronise the activities of these processes [Worley et al., 2002]. The workflow management system hereby provides a means for managing distributed information systems. Workflow management system play an important role in facilitating the integration of (distributed) supply chains. Workflow technology can be employed to improve both business processes and supply chains. The increased performance due to improvements can be quantified with respect to, for example, lead time, wait time, service time, and utilisation of resources.

\subsubsection{Quality Management}

In this section, the quality entity of the triangle of constraints [see section 2.1.1] is discussed. First, an introduction to the topic quality is given and this subject is subsequently extended to quality management. The relation between quality management and supply chain management is elaborated upon, next after which several relevant implementations are presented.

\section{Introduction to quality}

Quality is an important factor in the current manufacturing climate. A positive perception of a company's product quality can lead to its long-term survival. A negative perception can result in an erosion of trust, whereby the viability of the company is damaged seriously. Companies that successfully focus on quality from a strategic viewpoint will develop a competitive advantage over their competitors. Quality is a perceptual, conditional and somewhat subjective attribute and may be understood differently from different perspectives. From a customer perspective, it focuses more on the specifications of a product and how these compare to those of competing products. In other words, for a business, quality is all about meeting the needs and expectations of the customer. From a manufacturers perspective quality focuses on the degree to which a product was produced correctly.

\section{Quality Management}

Customers recognise that quality is an important attribute in products and services. Suppliers recognise that quality can be an important differentiator between their own offerings and those of competitors. This quality differentiation is also popularly called the quality gap. Supplier realise that they need to manage quality in order to remain competitive. Quality management is comprised of all the activities that organisations use to direct, control, and coordinate quality. The ISO 9000 series of standards are probably the best known International standards for quality management. 
Recently, a number of themes have become more significant including quality culture, the importance of knowledge management, and the role of leadership in promoting and achieving high quality. Approaches like systems thinking are bringing more holistic approaches to quality. As a consequence, people, processes and products are considered together rather than as independent factors in quality management. The influence of quality thinking has spread to non traditional applications outside the walls of manufacturing, extending into service sectors and into areas such as sales, marketing and customer service.

In manufacturing, quality management and control is fundamental to ascertain conformance of processes and the products manufactured by it. It plays an important role in deciding whether parts are being manufactured according to the design specifications and whether the manufacturing processes are functioning properly. The recent progress in developing new, automated production and measuring instruments has led to $100 \%$ real-time inspection, where critical dimensions are measured and verified while parts are being produced. The immediate benefit from this approach is the reduction of manufacturing costs by preventing further processing of defective parts along the manufacturing phases [Kwon \& Rauniar, 2007].

\section{Quality Management Practices}

There are many different quality management practices, a number of these practices are discussed in the following sections.

\section{Kaizen}

Kaizen is the Japanese word for continuous improvement. The philosophy of Kaizen revolves around the involvement of all the stakeholders in the improvement process. Kaizen is a low cost, low risk incremental quality approach [Rowlands \& Richards, 2002]. Kaizen focuses on the elimination of waste (muda) and the standardisation of operational procedures. Kaizen usually delivers small improvements, these small improvements combined with continual improvement culture and standardisation yields large results in the form of compound productivity improvements. A typical kaizen activity cycle contains the following steps:

- Standardise an operation or activity

- Measure the standardised operation

- Gauge measurements against requirements

- Innovate to meet requirements and increase productivity

- Standardise the new, improved operations

- Continue the cycle

This cycle is also known as the Plan-Do-Check-Act (PDCA) circle of continual improvement.

\section{Quality Function Deployment}

Quality function deployment (QFD) is a structured method in which customer requirements are translated into appropriate technical requirements for each stage of product development and production [Hong \& Huo, 2010]. QFD was originally proposed, through collecting and analysing the voice of the customer, to develop products with higher quality to meet or surpass customer's needs. Thus, the primary functions of QFD are product development, quality management, and customer needs analysis. Later, QFD's functions has been expanded to wider fields such as design, planning, decision-making, engineering, management, teamwork, timing, and costing. Essentially, there are no definite boundaries for QFD's potential fields of 
application. Early QFD applications focused on industries as automobiles, electronics, and software. The fast development of QFD has resulted in its applications to many manufacturing industries. Eventually, QFD has also been introduced to the service sector such as government, banking and accounting, health care, education and research. The ultimate benefits of QFD applications are reported to be tangible benefits and intangible benefits. Tangible benefits include "improvement in reliability", "reduction in the number of project changes", "reduction in project time and costs". Intangible benefits include

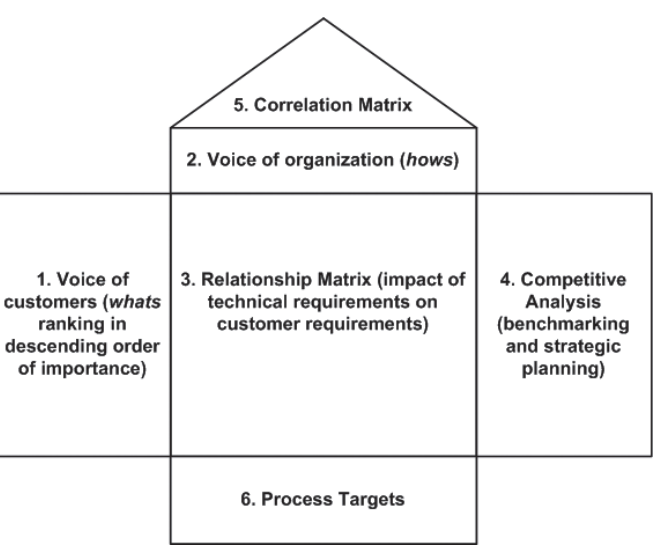

Figure 2.23 House of quality "creating multifunctional teams", "increasing and preserving the company's knowledge", "increased customer satisfaction" and so on.

A complete QFD procedure uses a series of matrices to express linkages between the inputs and outputs of the different stages of development [Hong \& Huo, 2010]. The matrix known as the House of Quality is shown in figure 2.23. As it is seen in the figure, building of the house of quality demands six stages, which are explained by the following elaborations:

- Stage 1: Customer Requirements; One of the objectives of QFD is to make sure that all customer requirements are met; therefore it is crucial to identify the customer.

- Stage 2: Technical Requirements; Once the whats have been defined, it is necessary to answer the question, "How is the organisation going to meet the customer needs." What steps/actions/goods/services are needed to ensure that all the whats are met.

- Stage 3: Relationship Matrix; As the whats and hows might not be independent, and a how might affect more than one what, it is necessary to evaluate the relationship among the whats and hows.

- Stage 4: Competitive Analysis; Customer requirements are studied by methodologies like benchmarking and strategic planning.

- Stage 5: Correlation Matrix; It is sometimes called the "roof' of the House of Quality, and it provides a means of capturing information about hows that might interact with one another; either in a positive, or negative way.

- Stage 6: Process Targets; The stage involves calculation of the importance of the hows (technical requirements) based on its impact to fulfil the whats. The importance of the hows corresponds to the sum of products between the importance of the whats and the relationship among the whats and the hows.

The House of Quality helps in translating the customer requirements into concrete operating or engineering goals. The important product characteristics and goals for improvement are detailed in the matrix. The creation of the matrix helps in focussing on producing a product that satisfies the customer.

\section{Lean Manufacturing}

Lean manufacturing is a management philosophy that focuses on the elimination of waste. It considers every expenditure of resources for any goal other than the creation of value for the 
customer as waste. It requires the manufacturer to examine all its activities from the viewpoint of the customer and to optimise processes to maximise added value. Consequently, the focus of lean manufacturing is on the whole process flow and not just on the improvement of one or more individual operations. The lean manufacturing concept can be summarised as follows [Tompkins et al.,2003]:

- Eliminate or minimise non-value-adding activities

- Produce only what is demanded

- Minimise the use of time and space resources

- Manufacture in the shortest cycle time possible

\section{Six Sigma}

Six Sigma refers to the philosophy and methods used to eliminate defects in products and processes. Each process step or activity represents an opportunity for defects to occur. Six Sigma seeks to reduce the variation in processes that lead to these effects [Chase et al., 2004]. Six Sigma is a comprehensive and flexible system for achieving, sustaining and maximising business success. It focuses on the understanding of the customers' needs, which is coupled with a structured approach through the use of data and statistical analysis [Rowlands \& Richards, 2002]. The six sigma approach has two aspects: management and methods \& tools. Application begins with a management initiative that recognises the goal as breakthrough and achieving great improvements. This involves a systematic and focussed approach and its success depends on selecting the projects that support the strategic goals of the company. Six sigma methods and tools stem from the common quality practices. Six sigma begins with process thinking and one of its main goals is process improvements that improve the bottom line and global competitiveness. It depends on data-based decisions and uses standard quality tools and statistical tools. These are integrated into a standard methodology called DMAIC which stands for:

- Define customers and requirements

- Measure things critical to quality

- Analyse baseline, opportunities, objectives, and root causes

- Improve the process

- Control the process

This methodology hereby provides a structured approach that focuses on solving practical problems through the use of statistics.

\section{TQM}

Total Quality Management (TQM) considers that quality management should cover both the entire enterprise and product life cycle. According to this view, the management of quality should be coherent with the enterprise environment and should be integrated with all the functions and processes that are required for bringing a product to the market. TQM is a philosophy from a systems point of view that focuses on continuous improvement within the enterprise in order to provide superior value to the customer [Li et al., 2008]. Enterprises employing TQM continuously seek improvement in all their activities, functions and processes. To achieve this, TQM embraces change along several dimensions [Bessant et al., 1994]: 
- in the processes and procedures in use within organisations

a in the tools and skills that it uses to assure and improve quality

- in the organisational structures that permit quality to be built in and maintained in product and service generation and delivery

- in the underlying pattern of values and behaviour, i.e. the culture of the organisation. The central theme of TQM stresses three principles, i.e. customer satisfaction, employee involvement and process improvement. One of the central themes of TQM is business process re-engineering and reflects the design and improvement of a business process to support the business operations of an organisation. Quality practices as discussed in the previous paragraphs such as Kaizen, Six Sigma and QFD can all be employed as part of an overall TQM approach.

\section{ISO 9000 Family of Standards}

ISO 9000 standards originated in 1987 with a bulletin from the International Organisation for Standardisation (ISO). Its purpose was to provide a series of international standards dealing with quality systems that could be used for external quality purposes. Another important consideration was the desire to provide information to organisations about how to design their own quality systems based on individual company marketplace needs. The standards in the ISO 9000 series intend to be generic standards for quality management and quality assurance. The standards are to be applied to any type of organisations; independent to the size of the organisations or the kind of products manufactured or services provided, in private and public organisations, including government services.

The ISO 9000:2005 family of standards is the current baseline for the definition and the requirements of quality management systems. This international standard encourages the adoption of the process approach to the management of an organisation [ISO, 2005]. The process approach is an approach whereby activities are organised and managed horizontally according to the way they create value. In a functional approach these activities are organised and managed vertically by function. This results in quality problems frequently occurring at the boundaries of the functional departments. The process approach is referred to, by the standard, as the systematic identification and management of the processes employed within an organisation and particularly the interactions between those processes. In this context, a process is defined as any activity or set of activities that uses resources to transform inputs to outputs. The process-based QMS approach divides the quality management system (QMS) into four main processes: management responsibility; resource management; product realisation and measurement, analysis and improvement. Figure 2.24 shows the continual improvement of the process-based quality management approach. In fact, in order to maximise the customers' satisfaction and the efficiency of the organisation, this system considers the customers requirements as input for product realisation process and their expectations as input for management responsibility. Then, a measure of their satisfaction and of the effectiveness and the efficiency of the organisation will be considered as input for the measurement analysis and improvement process in order to ensure the continual improvement of the quality management system.

The ISO 9000 family distinguishes between requirements for QMSs and requirements for products. Requirements for QMSs are specified in ISO 9001. Requirements for QMSs are generic and applicable to organisations in any industry or economic sector, regardless of the offered product category. ISO 9001 itself does not establish requirements for products. 


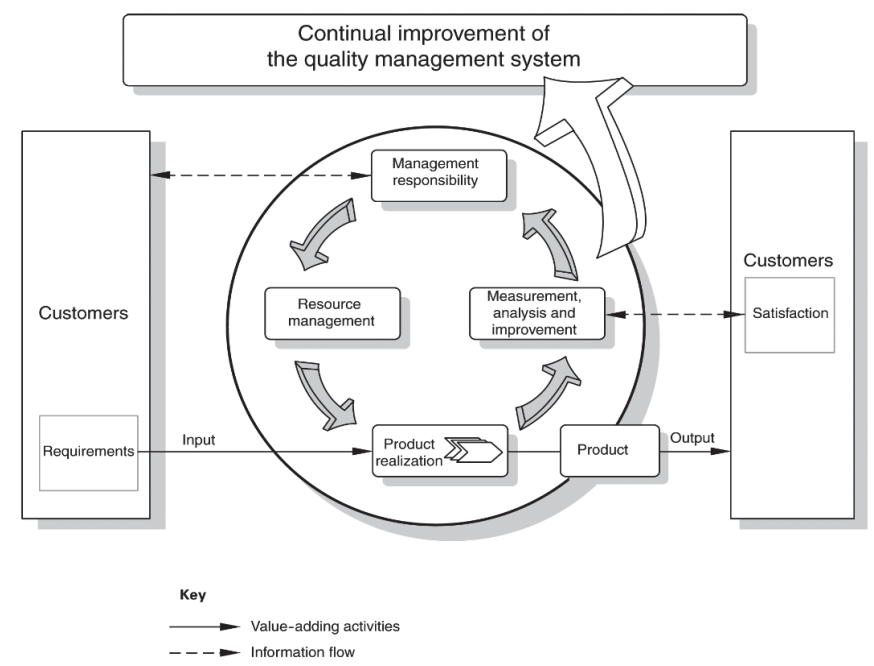

Figure 2.24 Process based quality management approach

Delivering a product that meets user requirements involves a dual approach. On the one hand, a product must often conform to specified technical specifications that address certain attributes related to product performance and characteristics. On the other hand, the organisation must ensure that these attributes are consistently built into or incorporated in the product. This dual approach is depicted in figure 2.25 .

The ISO 9000 standard is based on 8 quality principles that emphasise the core values and

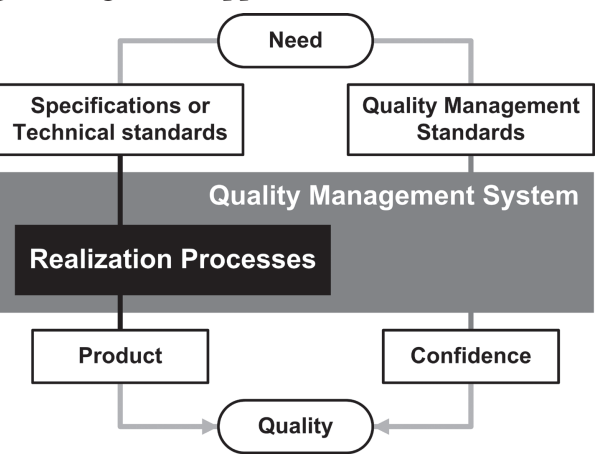

Figure 2.25 Dual quality approach concepts of quality management:

- Customer focus: Organisations depend on their customers and therefore should understand current and future customer needs, meet customer requirements, and strive to exceed customer expectations.

- Leadership: Leaders establish unity of purpose and the direction of the organisation. They should create and maintain an internal environment in which people can become fully involved in achieving the organisation's objectives.

- Involvement of people: People at all levels are the essence of an organisation, and their full involvement enables their abilities to be used for the organisation's benefit.

- Process approach: A desired result is achieved more efficiently when related resources and activities are managed as a process.

- System approach to management: Identifying, understanding, and managing a system of interrelated processes for a given objective improves the organisation's effectiveness and efficiency.

- Continual improvement: Continual improvement should be a permanent objective of the organisation. 
- Factual approach to decision-making: Effective decisions are based on the analysis of data and information.

- Mutually beneficial supplier relationships: An organisation and its suppliers are interdependent, and a mutually beneficial relationship enhances the ability of both to create value.

Although ISO 9000:2000 is an established general QMS, it has faced criticism from business professionals and academics for its implementation costs, documentation requirements, bureaucracy development risks and the possibility of failing to obtain registration. These authors concluded that despite several criticisms of ISO 9000, companies that followed the standard and fully integrated QMS with their business significantly improved both their internal systems, and their external dealings with customers and suppliers [Sroufe \& Curkovic, 2008].

\section{Quality Management and Supply Chain Management}

Quality management in a global supply chain environment is difficult due to issues with e.g. geographical distribution, functional distribution and cultural gaps between the partners in supply chains [Chin et al., 2006]. Successful supply chain management depends on how well quality and technology are introduced and managed within the framework of a supply chain [Kuei et al., 2002]. Supply chain management and quality management have commonalities as well as differences. Figure 2.26 presents the underlying assumptions of both SCM and QM and highlights the linking pin of the two fields [Foster Jr., 2008]. Some general differences can be detected between SCM and QM. QM can be viewed to encompass both internal and external operations that need to be taken into account in order to guarantee high quality services and products. SCM is a more external operation which largely aims at upstream activities. There are however a lot of commonalities between the two entities.

- both are under the domain of operations management functions;

- both are complementary and closely interconnected

- both emphasise the importance of system-based view to operations

- both can be regarded as a major means of attaining competitive advantage

- the effectiveness of both SCM and QM requires a high degree of coordination among all organisational levels, people and activities

- both emphasise or start and end with the customer

Fulfilling and meeting customer needs can be regarded as the interface or linking pin between both QM and SCM. Integrating the customers and suppliers into the supply chain process improves the performance of the supply chain by directly impacting input and product

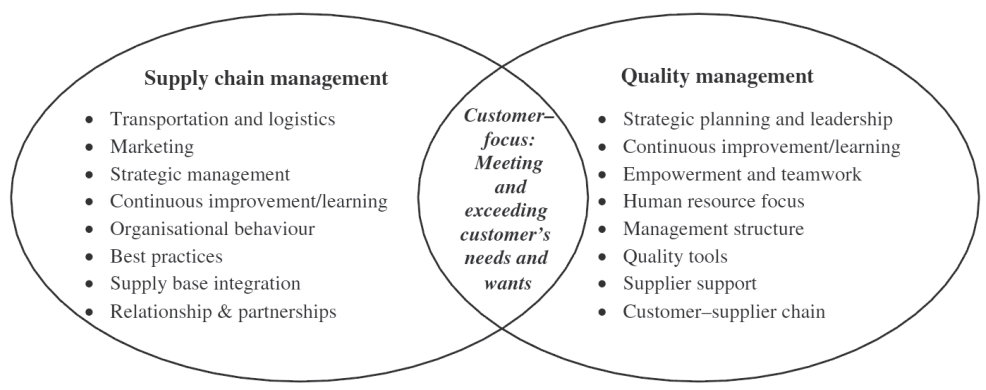

Figure 2.26 SCM \& QM commonalities and difference 
processing quality [Das, 2011]. Currently, organisations integrate quality management (QM) and supply chain management (SCM) and extend their vision beyond their own organisation into the supply chain in order to manage quality. This integration and co-ordination is called supply chain quality management (SCQM) [Soltani et al., 2011]. SCQM is defined as the systems-based approach to performance improvement that leverages opportunities created by upstream and downstream linkages with suppliers and customers [Foster Jr., 2008].

Despite the challenges posed by complex global and logistics factors, ensuring quality from the start to the end of a supply chain is a basic but also crucial requirement for all entities in a supply chain [Das, 2011]. Ensuring quality coherently across the entire supply chain is only possible by an integration of supply chain management and quality management. A common approach to ensuring the quality at input points is evaluating each supplier using quality management based attributes. To ensure required performance supply chain management can set threshold values for these attributes. In addition to these quality attributes, criticalto-quality and critical-to-business factors and relevant performance requirements can be defined in order to be able to check the suitability of each supplier. A similar approach can be applied to ensure the quality at the shipment points.

Predicting and controlling quality factors in a supply chain is difficult without the provision of correct information. Subsequently, information technology is identified as one of the main critical areas of opportunity in order to improve supply chain quality management. Information technology enables effective supply chain quality management as information sharing is crucial for timely quality management and control [Xu, 2011].

Integrating quality and supply chain management can provide many positive outcomes for both organisations and supply chains. It can lead to decreased production lead times, reduced costs, faster product development and increased quality. Working with customers and suppliers while implementing quality management practices along the supply chain can lead to dramatic improvements in quality and to reduced costs [Forster Jr. \& Ogden, 2008].

Chin [Chin et al., 2006] presented the concept of global quality chain management (GQCM), which is shown in figure 2.27. GQCM treats quality management from a global supply chain viewpoint. It aims to establish an interlinked quality chain instead of the traditional 'checkbased' relationships between the entities of the supply chain. This concept brings the following benefits to the quality management within the supply chain:

- the right quality information is available at the right time and right location in the supply chain.

- the voice of the customer can be effectively integrated in the product and processes of the supply chain

- quality problems found in one location can be communicated to the other entities of the supply chain on time, so that appropriate actions can be taken along the supply chain.

- quality improvement can be executed on a supply chain level, to optimise the product and manufacturing process as a whole.

Bessant identified seven components and their functions that need to be managed in order to be able to sustain supply chain quality [Bessant et al., 1994]: 


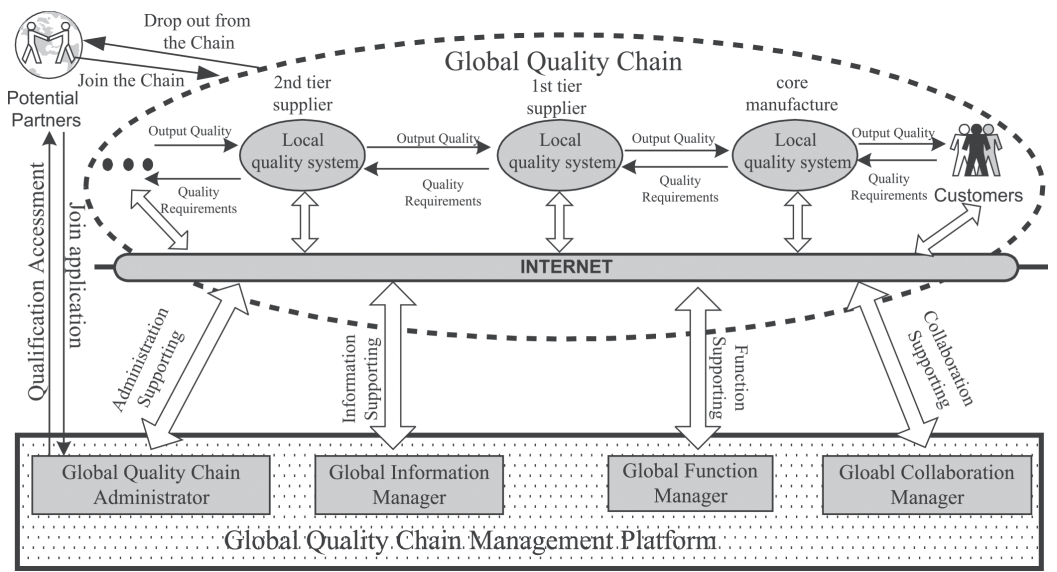

Figure 2.27 Global quality chain management concept

- strategy; defines a purpose and a development direction

- boundary definition; defines the supply chain and the connected organisations

- monitoring and measuring performance; guides and monitors the progress of the supply chain

- developing and managing culture with the supply chain; establishes and develops the behavioural norms governing the way in which the supply chain functions

- people and structures; identifies / defines the people, structure and systems that enable the supply chain to function and grow

- processes and coordination; defines the way in which the supply chain operates

- continuous improvement; ensures long-term development and learning within the supply chain

\section{Cost of Quality}

Cost of quality is a term that is widely used and represents the cost of creating a product or service that is nonconforming [Campanella, 1999]. Every time work is redone, the cost of quality increases. Any cost that would not have been expended if quality were perfect contributes to the cost of quality. Quality costs are a measure of the costs specifically associated with the achievement or non-achievement of product or service quality. It is important to get a thorough insight in the quality costs within a company. Campanella defines quality costs as the total of the cost incurred by [Campanella, 1999]:

- prevention costs; the costs of activities to prevent poor quality in products or services

- appraisal costs; the costs associated with measuring, evaluating or auditing products or services to assure conformance to quality standards and performance requirements.

- failure costs; the costs resulting from product or services not conforming the requirements or customer needs

Many of these quality costs can be categorised as non-value added costs and are therefore hard to quantify to a product with traditional cost accounting methods. ABC management [see section 2.2.5] can be used to quantify these costs of quality [Gupta \& Galloway, 2003]. Next to these costs, there are also 'hidden' costs that should also be appointed to the cost of quality. Yang [Yang, 2008] divides these 'hidden' costs into two categories. The first category is 'extra resultant costs' and consist of the items caused by failures or errors. These costs can be traced and counted because it refers to the costs of materials and the cost of reworks that 
can be analysed and quantified. These are all extra costs, because they are all caused by one operational error and are therefore defined as 'extra resultant costs.' The second category is 'estimated hidden costs' and included many cost items that are difficult to analyse and quantify. An example is lost sales as a result of poor quality in the past. These costs can be quantified by analysing the consequential losses caused by critical failures. These costs can be estimated on the basis of an analysis of losses from the past records and information.

A thorough insight in quality costs benefits the management of a company on a number of aspects [Campanella, 1999 \& Yang, 2008]. Overall quality costs will point out potential improvement areas, and will also assist management in measuring the accomplished improvements. It can therefore be seen as an indicator for the quality effectiveness within a company. Next to this, quality cost numbers are an important asset in prioritising the needs for corrective action. Quality costs show the payoff for potential corrective actions, and with this underpins their accomplishment. The proper management of quality cost raises the companies competitive advantage through higher quality and lower costs.

$\mathrm{ABC}$ management can play a significant role in the priorisation and cost justification of quality improvement projects. ABC management includes non-value added activities in the costs and can hereby provide the information needed to determine the impact of an improvement project [Campanella, 1999].

\section{Quality Management and Information Management}

Many manufacturing enterprises use both operational and quality management system functions at different departments. Often a number of these quality management system functions are implemented at different settings within an enterprise. However, the data generated by these systems is often only available on the setting where it is implemented. This is sufficient for making quality decisions on that particular process level. However, when making enterprise level quality decisions, the information from these individual systems must be combined and integrated into meaning full information [Klenz \& Fulenwider, 1999]. Information management can facilitate the application of quality management systems functions such as statistical process control (SPC), design of experiments (DOE), failure mode and effect analysis (FMEA), and quality function deployment (QFD) [Dewhurst et al., 1999]. Next to this, information management is vital for combining the data generated from these and other quality system functions and presenting it in terms of customer satisfaction, internal process controls, critical business systems, and other measurement systems that are necessary for quality management at enterprise level. Information management plays a key role in the quality management of an enterprise as the provisions of quality information is an important resource for successful quality management. A properly integrated information management system with quality management should be able to provide the enterprise with the capability to send the right quality information to the right point at the right time.

\section{Quality Management Systems and Implementations}

Several quality management systems and implementations are described in literature. In the following sections those systems and implementations with relevance to this thesis are discussed. 


\section{QQ-Enterprise}

QQ-Enterprise is a framework for the development of integrated quality information systems (IQIS). It assists manufacturing enterprises in managing their quality data in a more efficient way, and supports the implementation of quality management systems [Tang \& Duan, 2006]. The framework of QQ-Enterprise is composed of thee platforms and is shown in figure 2.28. The infrastructure platform embodies the hardware, operating system and database management system and serves as a supporting platform in the system. The basic data platform provides a uniformed management service of the basic enterprise information and the application information produced by the functional modules and serves as a uniform information 'base plate' of these functional modules. This also is the integration platform of the whole system. The application platform contains a series of modularised and reusable functional module, which cover all the quality managing processes and activities in the product life cycle. This modularisation ensures a high flexibility of the system. The QQ-Enterprise has proven to be a feasible and effective framework for implementing integrated quality management systems in the manufacturing environment [Tang et al., 2007].

\section{IEI-QIS}

Tang proposes a net-based quality information management system (IEI-QIS) that can process and integrate the internal quality management information for an expanded enterprise [Tang \& Lu, 2002]. For a geographically dispersed enterprise, IEI-QIS is able to break through the regional limitations and collect, deliver and feedback quality information from and to different locations for enterprise quality management operations. IEI-QIS enables timely, sufficient and effective quality information communication

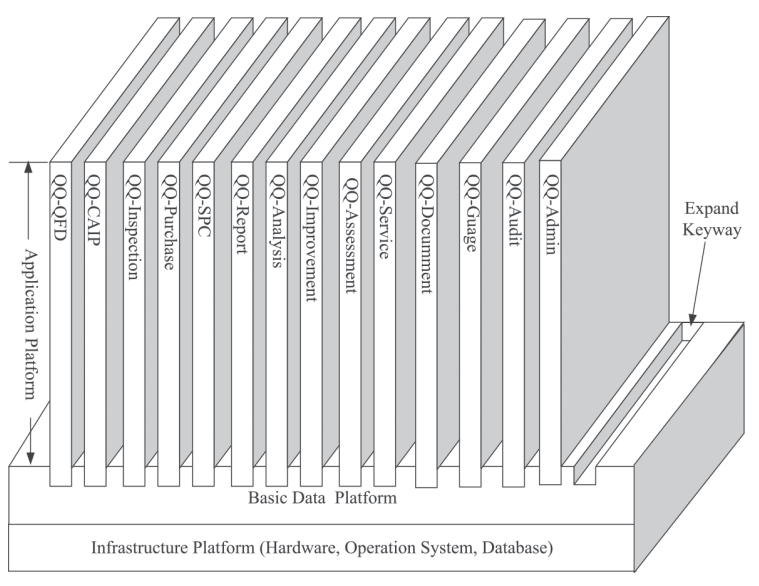

Figure 2.28 QQ-Enterprise framework within the enterprise and with its suppliers and customers. The proposed functional model of IEI-QIS is given in figure 2.29 and described in the following paragraphs.

Quality Planning Management supports enterprise-wide quality management by managing processes and documents, by creating quality policy, goals, plans, etc., and by bringing these into effect.

Quality Improvement Management supports the collection of quality failure data and information, reviews the data and reports, traces and analyses the causes of failure, makes the correcting action, and records the effectiveness of each corrective action for managing the modification of the process.

Quality Control supports the product life cycle in the aspects of design, production and usage. In the design process, this module includes functions for: quality goal decomposition and management of the design process, evaluation of design quality, inspection and test planning. For the production process, the module includes functions such as: production 
data collection, statistical process control, materials quality control, non-conformance management, and failure and problem feedback. In the usage process, the module includes functions such as: packaging and delivery, customer satisfaction and complaint analysis, after sales service management, maintenance management.

The modules implemented in Supporting Quality Management

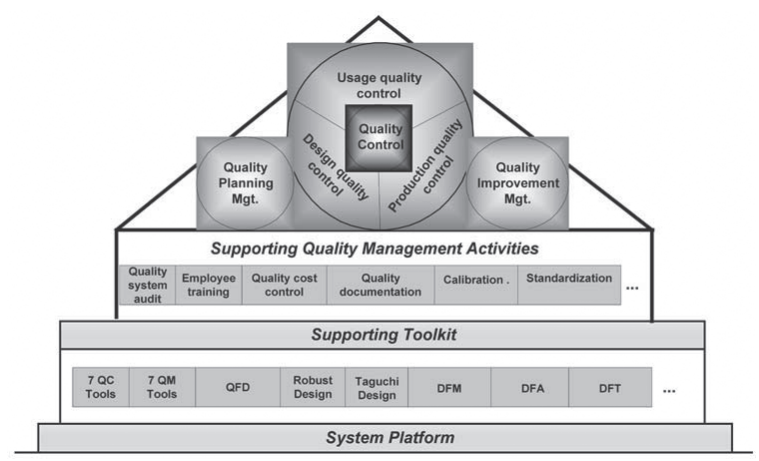

Figure 2.29 Functional modules of IEI-QIS Activities include activities such as quality system audit, employee training, quality document management, calibration, standardisation and specifications management and quality cost control.

The Supporting Toolkit provides a variety of computer-aided quality tools to implement quality management functions.

A System Platform is setup to run in Intranet/Extranet/Internet applications. It provides a database management system, web-based information process tools, network communication tools, report creating tools, network meeting tools, e-mail tools, e-fax tools, etc. Additionally the System Platform implements authorisation management and monitoring of system operation, configures system applications of the users, and manages the systems interfaces between an enterprise and customers or suppliers. The System Platform ensures that IEIQIS is distributed, flexible, extendable and has web-based characteristics.

An enterprise-wide quality management system can be setup based on IEI-QIS. This quality management system can collaborate closely and easily with both suppliers and customers to make the quality management system more effective.

\section{EQM}

Drexel University proposed an internet based quality control scheme called 'e-quality for manufacturing' (EQM) and is shown in figure 2.30. The network-sensor-based quality control systems are integrated with internet-based productions systems in this proposal [Kwon \& Rauniar, 2007]. EQM refers to the holistic approach to design and to embed efficient quality control systems with the use of advanced sensor technology to achieve real time, fully automated quality inspection, which is better suited for the modern production environment. Strong emphasis is given in this approach to the application of internet-based technologies into comprehensive quality control through the Web. Hereby the benefits of integrating preventive quality control with the information management networks can be realised.

\section{Quality Work Flow}

$\mathrm{Li}$ [Cheng et al., 2008] presented the concept of the Quality Work Flow (QWF). The QWF is a quality process control method that can systematically identify quality activities, processes and the interactions among these according to the requirements of the process approach. It performs quality process control based on workflow technology. Based upon the QWF, 


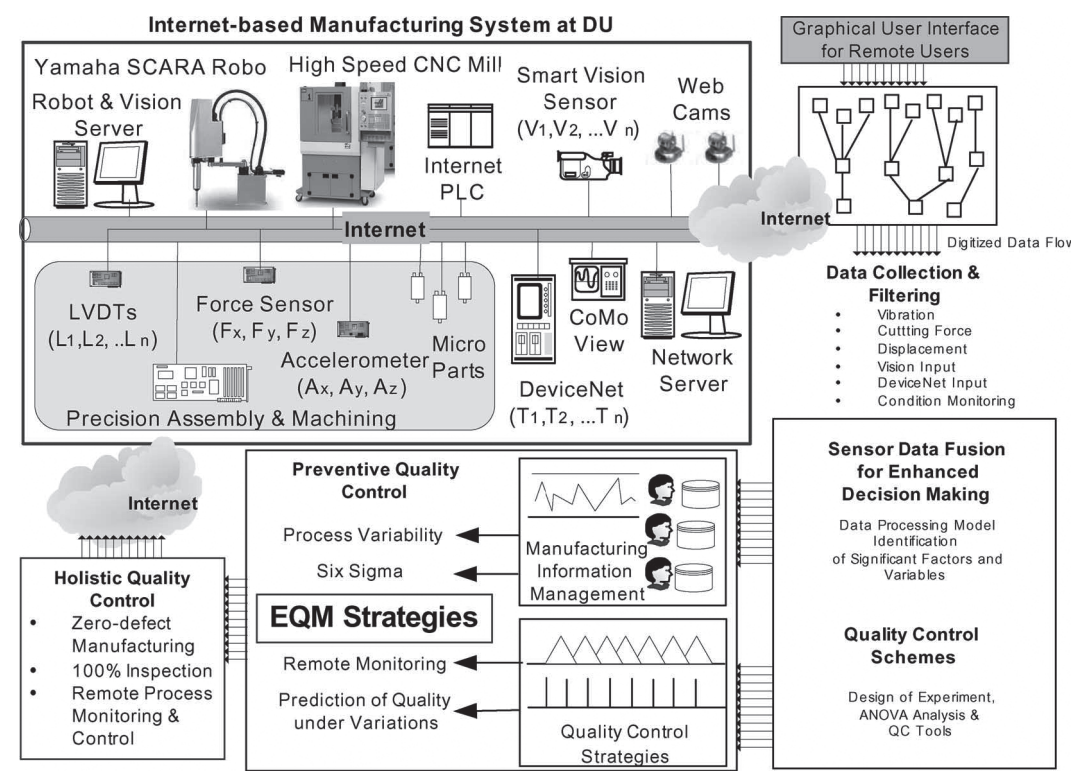

Figure 2.30 e-quality for manufacturing

Li developed an architecture for an integrated quality system. This architecture is flexible, because it divides the system into an enabling platform and an application platform. However, this architecture can only be implemented in a single manufacturing facility. The QWF concept is implemented as follows:

3. Perform the quality business discretisation: According to the requirements described in ISO9000/2000 the quality activities, processes and the interactions among them are identified. There is the strict difference between quality activities and processes. A quality process is a quality business process which passes different participants. These are described by process logic and managed by QWF. A quality activity is the quality business processing process fulfilled once by a participant, which is described by business logic.

4. Develop the quality business components: the quality business components are developed through the use of information technologies

5. Create the QWF: workflow middle ware is used to create the QWF from the quality process logic and the developed quality business components.

It can be seen as the core of QWF is to realise the separation of process logic and business logic. The process logic corresponds to the quality reference model and the business logic corresponds to the quality component. This can be clearly seen in the system structure of the QWF shown in figure 2.31. Quality workflow organises the different quality activities together in a loose coupling manner to form a specific quality process, where the quality process and the quality activities are under control and implemented in prescriptive logic. Hereby, the right information is passed to the right person at the right time.

\subsubsection{Networked Manufacturing}

A development in the continuing cooperative trend in the manufacturing industry is the formation of manufacturing networks, sometimes called production networks [Wiendahl, 
2002]. The main idea behind manufacturing networks is the mutual use of resources and the joint planning of the value-added processes. Companies participating in these networks communicate intensively with each other and data is exchanged between them. This data may consist of the actual and future load of machines, the availability of resources, order volumes or future and planned demands, and the order progress along the value added chain. This data is required to be able to accurately plan the activities in the network and to adjust the capacities effectively. It is important that this data

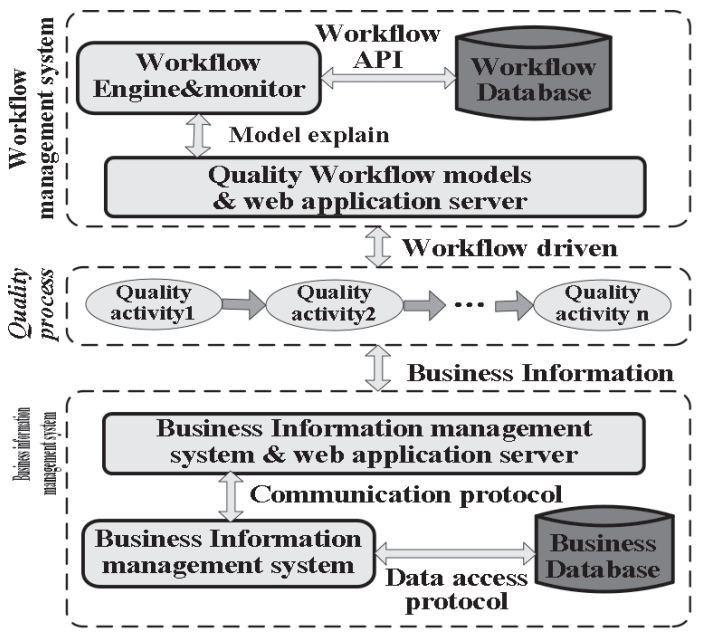

Figure 2.31 QWF system structure is exchanged as early as possible in order to be able to respond quickly and adequately to changes.

As a result of this, companies can hardly be seen as single entities anymore, as they have become nodes in networks. SMEs seem to be the appropriate units to behave like network nodes because of their lean structure, adaptability to market evolution, active involvement of versatile human resources, ability to establish sub-contracting relations and good technological level of their products [Mezgár et al., 2000]. A disadvantage in this can be the traditional individualistic attitude of SMEs. This attitude leaves each enterprise self-reliant in facing marketing, purchasing, design, engineering and technological innovation problems. In addition, problems arise from historical distrust between enterprises traditionally in competition with each other.

Different types of networks can be identified based on their strategic goals. Mazzola identified three different network typologies that are named below together with their goals [Mazzola et al., 2009]:

1. Efficiency: cost reduction, lead time reduction, time to market reduction, economies of scale, learning economies, product or process standardisation and risk reduction (financial perspective)

2. Globalisation: market and production globalisation, production off-shoring and new markets penetration.

3. Knowledge: know-how and skills acquisition, quality improvement, risk reduction (opportunistic behaviour perspective), resource pooling and market share increase.

The organisation of manufacturing networks involves the selection of suppliers, the assignment of products to suppliers, the location of production nodes as well as the design of the distribution system. All these decisions set the channels for the flow of materials, information and financial assets. Organisation of these networks is however often difficult due to the lack of any central agency or a dominating partner within the network [Vanzca et al., 2011]. 


\section{Networked Manufacturing Initiatives and Projects}

Manufacturing networks have been the subject of many research projects. Many approaches consider entire enterprises as the nodes of the manufacturing networks. The shortcoming of this approach lies in the fact that such a node is an autonomous, but complex hierarchical structure, which, as a rule, withstands effective communication and decision making and is reluctant to be subjected to control. Thus, the complexity of a network increases with the number of involved partners [Butala \& Sluga, 2006]. The effective coordination of the tasks executed within a manufacturing network is also a challenge due to its distributed entities. In the following sections several of projects and initiatives are discussed that try to structure and manage the complexity of manufacturing networks and coordinate the activities that are executed within it.

\section{TeleManufacturing}

TeleManufacturing is an early attempt at the creation a distributed manufacturing network. It is a concept proposed by Layed and comprises of a structure where a company outsources several of its production and design activities through the Internet [Malek et al., 1998]. This structure increases the flexibility of manufacturing enterprises and especially SMEs. The TeleManufacturing structure,

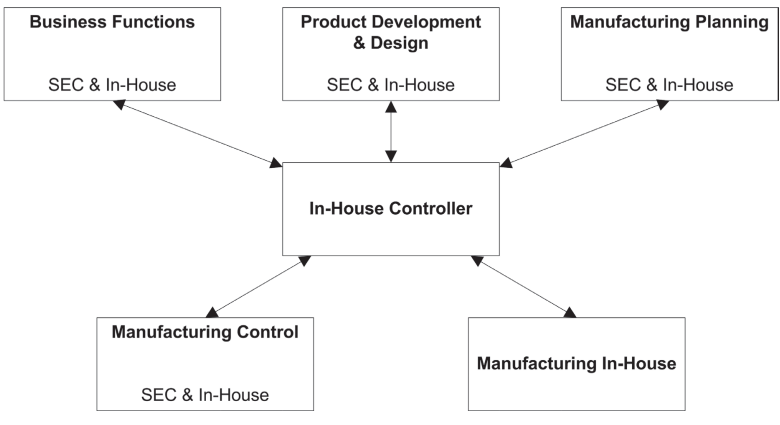

Figure 2.32 TeleManufacturing structure as shown in figure 2.32, is based on the existence of two basic components. The first is the availability of service providers through the internet which are called 'specialised expert centres' (SEC). To the SEC's functions are out sourced such as product development and design, process planning, scheduling, etc. The second component is the existence of an inhouse control (IHC) system. The IHC system orchestrates the activities and the functions, acts like the brain of the system and has the final central authority prior to task execution. TeleManufacturing enhances the flexibility of a company as it gives it the option of selecting service providers among available SEC's. This encourages competition among the SEC's and, as a consequence, the continuous improvement of their capabilities is stimulated.

\section{Hungarian Network}

The Hungarian Network $(\mathrm{HN})$ is a cooperative manufacturing model that is proposed by Mezgár [Mezgár et al., 2000]. It is used for coordinating the production of Small- and Mediumsized Enterprises (SMEs), based on a holonic paradigm. The holonic production system is a system of cooperating holons that are organised to achieve a production goal. The system integrates the whole range of activities from booking the orders through design, production and marketing in order to form an autonomous and decentralised production organisation.

The functional description of the Hungarian SME network is shown in figure 2.33. The HN is a real-time, on-line network with three basic functions. The local planning module, the coordination modules and the performance evaluation module are the three software units that cover the functions. 


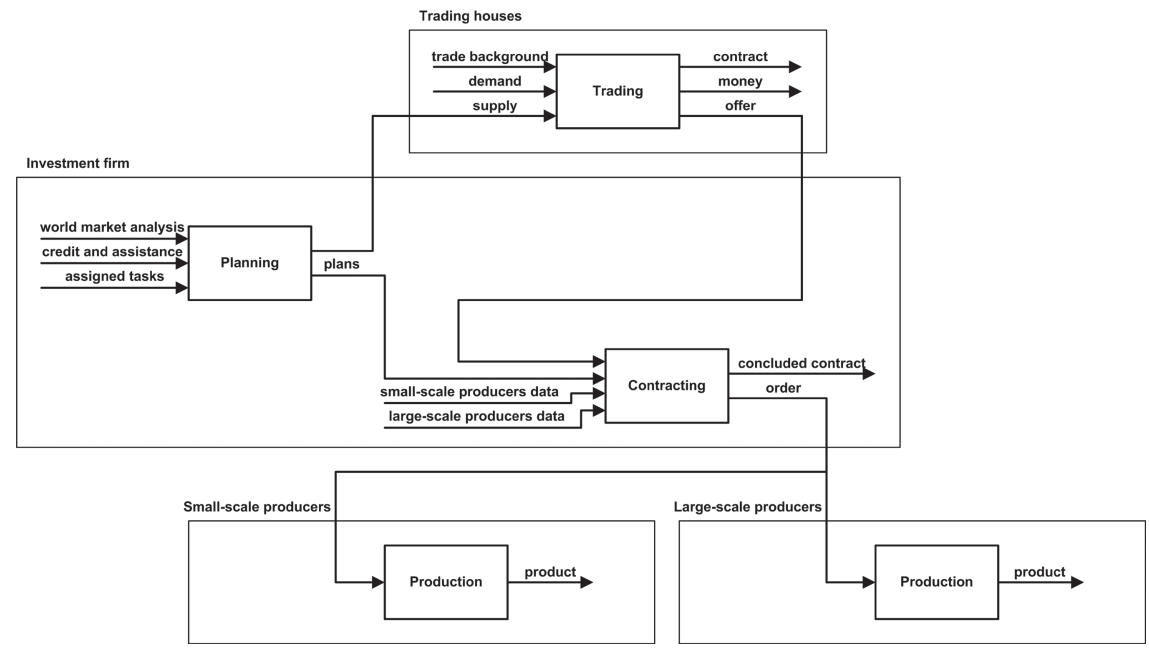

Figure 2.33 Functional description Hungarion SME network

- The coordination module manages the network planning policy. This module is responsible for controlling the connections outside of the network, for keeping contact with customers, for selecting the proper nodes (production units) and for distributing production tasks to these nodes.

- The local planning module supports the network related activities of each node. It aims at managing and communicating delivery plans and delivery conditions with the coordination module and the supplier and client nodes. The local planning modules realise the network controlling tasks of the node, in order to fulfil the goals of the management and communication, and deliver the status information of the node for the other nodes.

- The performance evaluation modules are used by the coordinating modules to calculate node reliability and network reaction capability by simulating possible scenarios. The performance evaluation module supports the work of the coordination module in selecting the best node for fulfilling a task. This module generates different measures, statistics, estimates based on the past behaviour of the nodes.

The HN has the following general advantages:

- complex and technologically advanced products can be realised by connecting/ integrating the skills and capabilities of the different network nodes.

- high manufacturing volumes can be obtained by cumulating node capacities, especially if two or more nodes concur in performing the same manufacturing phases.

- fluctuations of market demand volumes can be handled better by sharing workload peaks and shortages among the network nodes.

- limited resources of each SME can be better spent on technological innovation and process re-engineering rather than in hard competition with other SMEs.

The main advantages of the HN are the more effective usage of each SMEs resources, the faster reaction to market demands while keeping the individual characteristic of each node. Through coordinating the production in a very unstable, unreliable production field, the agricultural production can become more reliable, more safe both for the customer and the 
SME's who are members of the network. The reliability results in more orders, stabilised and higher income, less costs, i.e. more profit. The expected costs of the network investment are low. The $\mathrm{HN}$ is implemented and used in Hungary in the agricultural industry.

\section{B2MN}

In order to manage the structural complexity of a manufacturing network, the business-to-manufacturing network (B2MN) approach, based on the market mechanism, is proposed by Butala, see figure 2.34 [Butala \& Sluga, 2006]. The link between the business and manufacturing environments of the manufacturing network is provided by a marketplace. The marketplace governs the distribution of different project tasks to members of the manufacturing environment. The complex structure of the manufacturing network is decomposed into a number of self-sufficient functional entities, that are capable of performing certain functions autonomously within the network. These functional entities are called Autonomous Work Systems (AWS). The network nodes

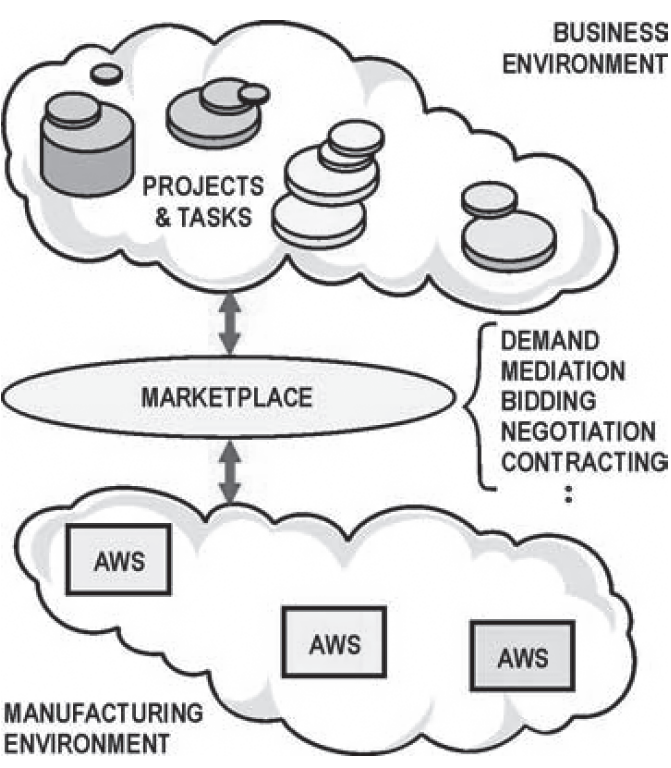

Figure 2.34 B2MN approach are represented by AWS's. Each AWS encapsulates functionalities and competences related to its management and manufacturing operations, as well as its autonomous information system, which supports autonomous decision-making and cooperation in the network.

Figure 2.35 shows the base level diagram of such an AWS. The basic AWS functionality is the transformation of inputs into outputs. Elements of the AWS are resources and human subjects. These elements constitute the functional competence of AWS, which is required to transform the input into an output. Besides these two elements, each AWS is supported by services providing additional expertise for effective operation of the AWS. The management of AWS covers management and control of the internal operations as well as the external coordination on the network. Both stakeholder and network controls influence the behaviour and level of autonomy of an AWS. The stakeholder control controls the economic and organisational objectives and constraints of the AWS. These controls motivate the self-interest of the AWS to act cooperatively and/or competitively in the network. The network controls, are defined on the network level and assure consistent and effective network operations. These controls define for example the rules of behaviour, protocols for communication, syntax and semantics for information exchange, contract

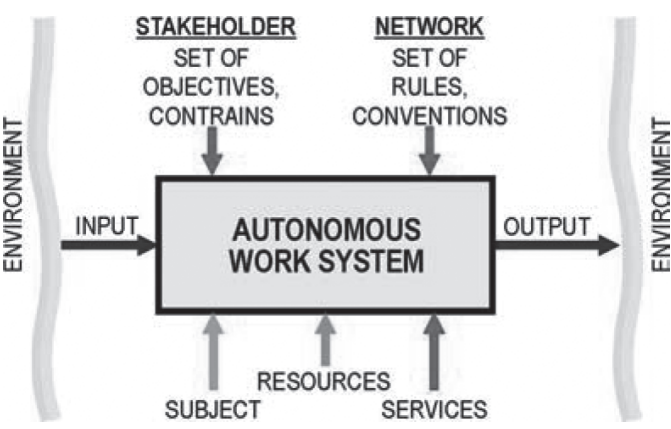

Figure 2.35 Autonomous work system diagram 
templates etc. Implicitly, the structure of the AWS strongly resembles the structured approach used in Idef0 [see section 4.5.1].

The advantage of $\mathrm{B} 2 \mathrm{MN}$ is that it links the business and manufacturing environments together through the use of a digital marketplace. Next to that, it manages to lower the structural complexity of a distributed manufacturing network through a logical decomposition of its constituents.

\section{e2-MES}

e2-MES is the prototype of an e-service-driven networked manufacturing platform based on application server providers (ASP) [Jiang et al., 2007]. An ASP digitally sells or rents an application in a one-to-multiple sharing mode to its customers. The developed platform can efficiently and effectively schedule and control the execution of manufacturing tasks in a range of extended enterprises. The platform also facilitates information

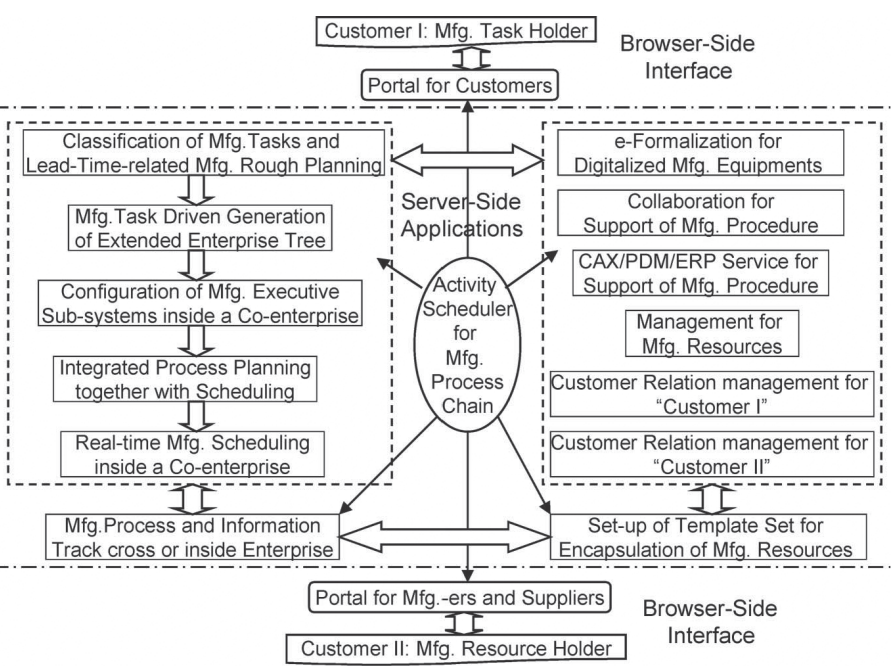

Figure 2.36 e2-MES implementation architecture provision and exchange between the extended enterprises. The implementation architecture of e2-MES is illustrated in figure 2.36. It is based on a three-tier networked information infrastructure (browser/server/database). The system serves two kinds of objects: task holders and resource holders. The task holder refers to customers that act as service receivers that submit manufacturing tasks. The resource holder refers to manufacturers or suppliers that posses manufacturing resources and act as service providers. The architecture consists of a series of collaborating functional modules, customer-oriented portals, manufacturer/ supplier-oriented portals, activity schedulers and ASP-based enabling tools.

The running procedure of e2-MES is shown in and is described as follows:

- The customers submit their manufacturing tasks to the platform.

- The core enterprise classifies these manufacturing tasks into different types of inhouse machining, out-house machining, and outsourcing sub manufacturing tasks.

- The core enterprise allocates these sub manufacturing tasks to the co-enterprises, like manufacturers or suppliers. Hereby the extended enterprise tree is created.

- Each co-enterprise dynamically allocates its assigned manufacturing tasks based on process plans generated by the integrated CAPP/scheduling system.

- Finally, the manufacturing tasks are implemented. 


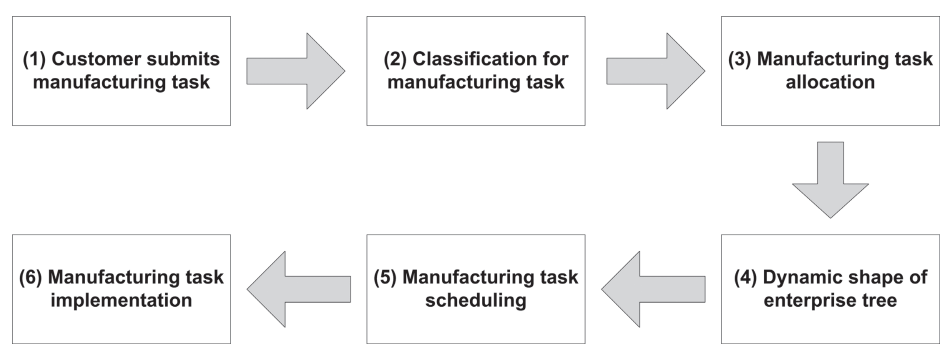

e2-MES running procedure

e2-MES evaluates the manufacturing capabilities of the different providers and makes a selection based on a comparison of the machining costs and times. The quality performance of the different providers is however not considered, which conflicts with the triangle of constraints.

\section{WebMAS}

Web-based multi-agent system (WebMAS) is a framework proposed to facilitate collaborative product development and production among geographically distributed functional agents using digitalised information [Mahesh et al., 2007]. Each agent possesses unique capabilities and a knowledge base for performing different activities like manufacturing evaluation; process planning, scheduling and real-time production monitoring. An overview of the framework is shown in figure 2.37. A manufacturing managing agent acts as the centre of the system and coordinates the activities of the participating agents while ensuring a seamless workflow and collaboration. This approach facilitates optimisation

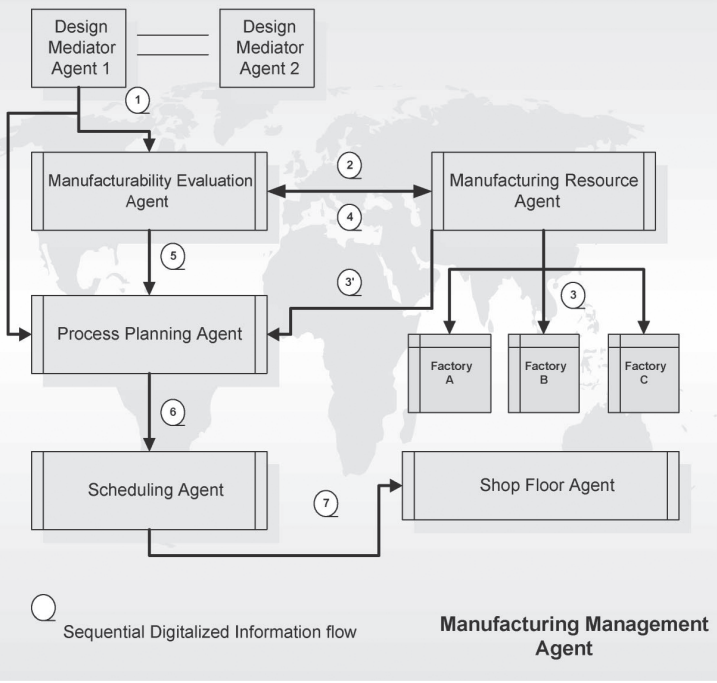

Figure 2.37 WebMAS framework of the part production cycle from product design to final manufacturing because all the production procedures are related and are considered to be logically connected. The agents communicate through the knowledge query manipulation language, which includes many predefined performatives to aid the participating agents in carrying out their tasks intelligently by interpreting commands from one another. In addition, the structure of the distributed task operation and central management makes the system flexible.

\subsection{1. e-Business and Manufacturing}

Next to the development of manufacturing networks, several researchers and companies have focussed their efforts on the employment of e-Business in a manufacturing environment. 
Every day new companies enter the field of e-Business to broaden their market reach and to enter the 24/7 economy with their business. E-Business involves the application of information and communication technology in support of all activities of a business.

\section{e-Commerce}

The manufacturing industry is changing rapidly and the growing emphasis is on electronic commerce (e-commerce). E-Commerce is the external component of e-Business and focuses on the employment of information technology in support of the external activities and relationships of the company with customers and other companies. E-Commerce enables organisation to carry out transactions on the web, which include advertising, training, buying and selling of products and services. The key component in e-Commerce is the Internet, that allows organisations to access information all the time. There are a number of different e-Commerce types, all of them having their own characteristics:

- Business-to-business (B2B) is electronic commerce between businesses. B2B portals link buyers and sellers together for the exchange of goods and services. In manufacturing, B2B allows for the direct handling of purchase orders, receiving and invoices. It allows business partners to benefit from a better response time, removal of non-value added inventories and reduction of the overall inventory level in the supply chain by managing the information flow among the business partners [Butala \& Sluga, 2006].

- Business-to-consumers (B2C) is electronic commerce conducted between businesses and consumers. In B2C the buyer orders its products directly on the sellers Internet site. Amazon.com is an example of such a company where the wholesale and purchase transaction is completed electronically.

- Consumer-to-consumer (C2C) is electronic commerce conducted between consumers and through the use of an intermediate. eBay.com is an example of such an intermediate where consumers buy and sell their products from and to each other. To many SMEs, e-Commerce seems to be a prospective alternative to the way they currently conduct business. E-commerce allows them to easily extend their reach to potential customers and suppliers world-wide. e-Commerce provides both SMEs and customers with the chance to compare buyer offerings and compare seller prices instantly in a real-time manner [Chan \& Chung, 2002].

\section{c-Commerce}

Collaborative environments are environments in which organisations and individuals can work together, share information, and collaborate on activities and projects efficiently and effectively. Through the introduction of e-Commerce technologies in these environments collaborative commerce (c-Commerce) is created. Where e-Commerce mainly emphasises on the trading activities, c-Commerce also emphasises the importance of exchanging information and collaboration between users on a common objective [Kim \&

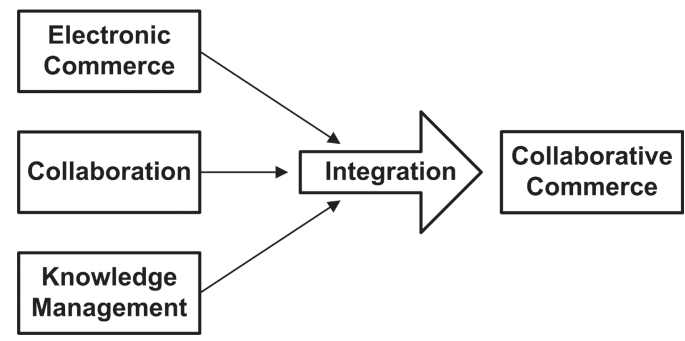

Figure 2.38 Collaborative commerce components 
Smari, 2005]. C-Commerce can help companies gain competitive advantages by [Chen et al., 2007]:

- connecting and automating processes with their partners, customers, and suppliers.

- reducing processing latencies

- developing new capabilities that improve service levels while reducing costs

- making planning, design, and operational decisions dynamically based on real-time information.

Figure 2.38 shows the three main components of a collaborative commerce system and illustrates their integration into such a system [Kim \& Smari, 2005]. The component e-Commerce is discussed in the previous section and the component Knowledge Management is discussed in [ref to knowledge management]. Collaboration plays a major role in c-Commerce systems. Pushed by the mega-trends and pulled by pragmatic industrial demands, collaboration has become an imperative, as well as an asset in all levels and domains [Horváth, 2012]. Adding collaboration in a system facilitates interactions and teamwork, and enables synchronous and asynchronous communication among the users.

\section{Cloud Manufacturing}

Cloud manufacturing is an emerging topic in the manufacturing environment and was introduced in 2010 by $\mathrm{Li}$ [ $\mathrm{Li}$ et al., 2010]. Cloud manufacturing mixes network-based manufacturing and service technology with cloud computing [Ning et al., 2011]. It is a promising strategy for large-scale distributed manufacturing system cooperation and integration. Cloud manufacturing provides users with various types of demand-oriented manufacturing services. Xu defines cloud manufacturing as a model for enabling ubiquitous, convenient, on-demand network access to a shared pool of configurable manufacturing resources that can rapidly be provisioned and released with minimal management effort or service provider interaction [Xu, 2012]. The distributed resources are encapsulated into cloud services and managed in a centralised way. These cloud services can be used by users according to their requirements. Cloud manufacturing connect providers and users as is shown in figure 2.39 [Xu, 2012]. Providers input their manufacturing resources and capacities. The platform turns these providers into a large virtual resource pool. Upon the request of a user a manufacturing service is quickly created and outputted to the user. Hereby users can utilise manufacturing resources and capacities on demand without concern about their specific location or condition.

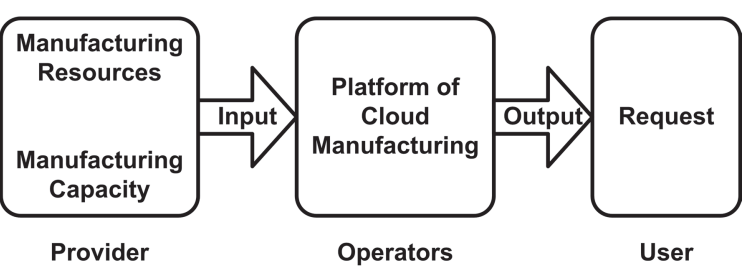

Figure 2.39 Cloud manufacturing

Implementations and Initiatives in the Manufacturing Industry

A number of implementations and initiatives exist which show the use of e- and c-Commerce in the manufacturing industry. These are discussed in the following sections.

\section{WebMachining}

WebMachining is a Brazilian initiative that aims at integrating CAD/CAPP/CAM for the remote manufacturing of feature-based cylindrical parts with symmetrical and asymmetrical 
features through the Internet, using an approach based on multi-agent systems as shown in figure 2.40 [Alvares \& Ferreira, 2008]. The WebMachining virtual company consists of three distributed manufacturing systems, which are all located in different cities in Brazil. In order to execute operations and processes to design and manufacture parts, the customer can use the manufacturing services based on Service Oriented Applications (SOA) through the Internet. The methodology integrates both
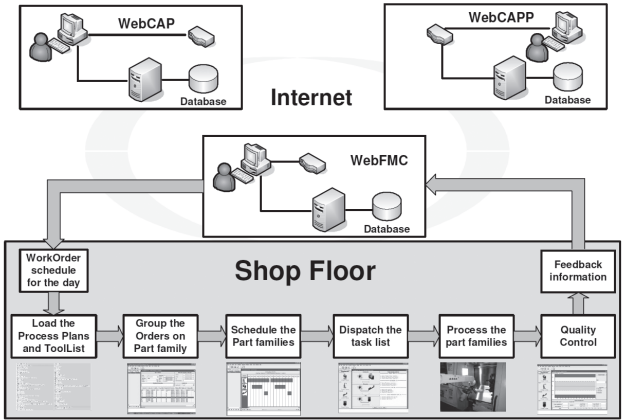

Figure 2.40 WebMachining engineering and manufacturing management through the use of ERP software. This software decides which of the three systems will produce the ordered part, based on parameters related to each of the three systems. After this decision, the ERP system will generate the production schedule.

Figure 2.41 presents part of the IDEF0 model of the WebMachining system which is divided into three basic activities: collaborative product modelling, generative CAPP and CAM. [Alvares \& Ferreira, 2008]

\section{TeleRP}

TeleRP is a Java-enabled solution using WWW techniques [Jiang \& Fukuda, 2001]. TeleRP makes is possible to implement a personal virtual factory by using the developed web server. TeleRP is based on a server-centred infrastructure which deals with five aspects (see figure 2.42):

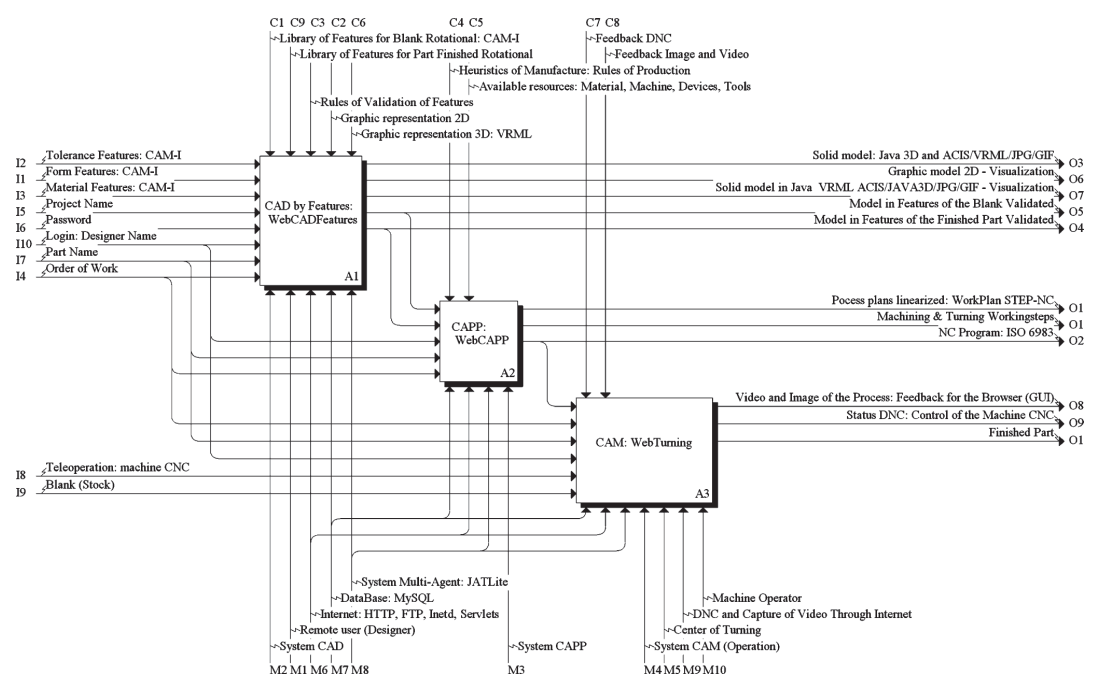

Figure 2.41 IDEF0 model WebMachining 
- applets are used as executable objects in order to create the browser-interface for users and manufacturers, and to implement the client-side computing. Corresponding main functions include submitting and queuing a part, monitoring a manufacturing site, maintaining queues, managing manufacturing sites, and running a collaborative activity if necessary. These functions are under the control of competence management of access permission.

- servlets are the core for the server-side computing. As soon as they are triggered by applets, functions, e.g. checking the access privileges, showing dynamic pages back, operating data and images, broadcasting messages, etc. can be finished.

- In the third aspect, the media for connecting applets and servlets, and for providing interfaces to users and manufacturers are given. They include a Java-enabled web server, web camera if selected, HTML pages and the corresponding dynamic data area, and Java-enabled browsers.

- In the fourth aspect, a group of users who are distributed in different geographical places may work for their tele-manufacturing tasks that are submitted via the browser.

- Manufacturers can also manage tele-manufacturing tasks via the browser as soon as their manufacturing sites are configured.

TeleRP has the following advantages:

- using the unified programming language for developing client- and server-side applications

- maintaining the remote server and resources with unified user interfaces in the platform-independent mode, from any place by the user, the manufacturer, and the webmaster under the control of access permissions

- operating multiple manufacturing sites and the correspondent queues inside one web server

- realising all the functions in different computer platforms only by reconfiguring this set of running environments and re/ installing 'TeleRP' without modifying the source codes.

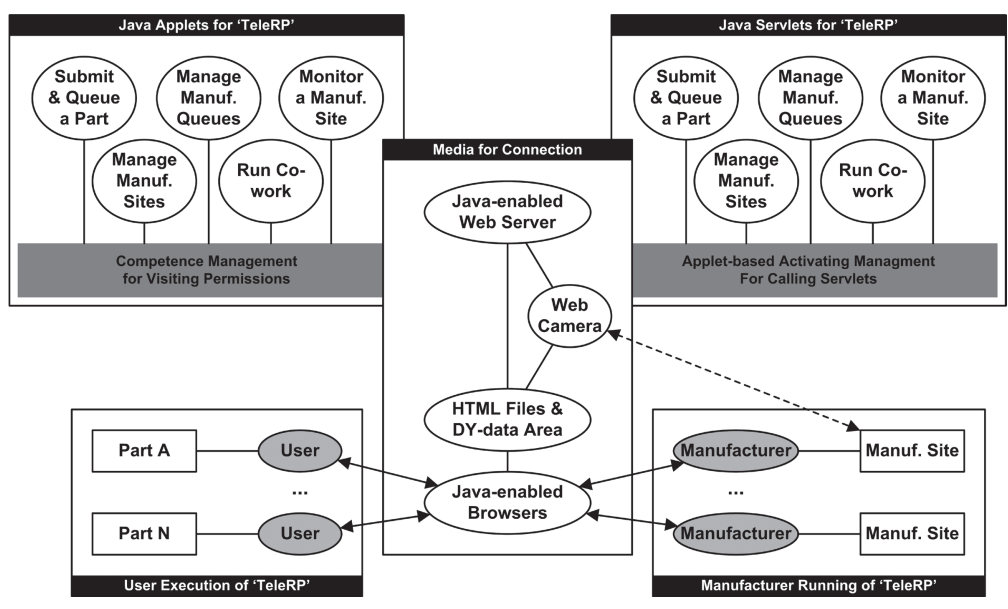

Figure 2.42 TeleRP overview 


\section{Agent-based service-oriented integration architecture}

The agent-based service-oriented architecture for manufacturing enterprise collaboration proposed by Shen is shown in figure 2.43 [Shen et al., 2007]. In this system, each enterprise provides a number of web services using agents. Through the agents, enterprises are provided with the ability to negotiate bids with upper mediating agents. The upper mediating agents are implemented as a network on the Internet. The major components of the system are described below.

The Web Portal is a web interface that is designed for users to access and manage related information. From the web portal, the customers register their profiles, place orders, select bids, and manage the contract information.

The workflow planner is a software agent that is responsible for coordinating the workflow process. The workflow planner includes a workflow engine. When a workflow process is triggered, the workflow planner selects a related workflow definition. According to this definition, the workflow engine finds

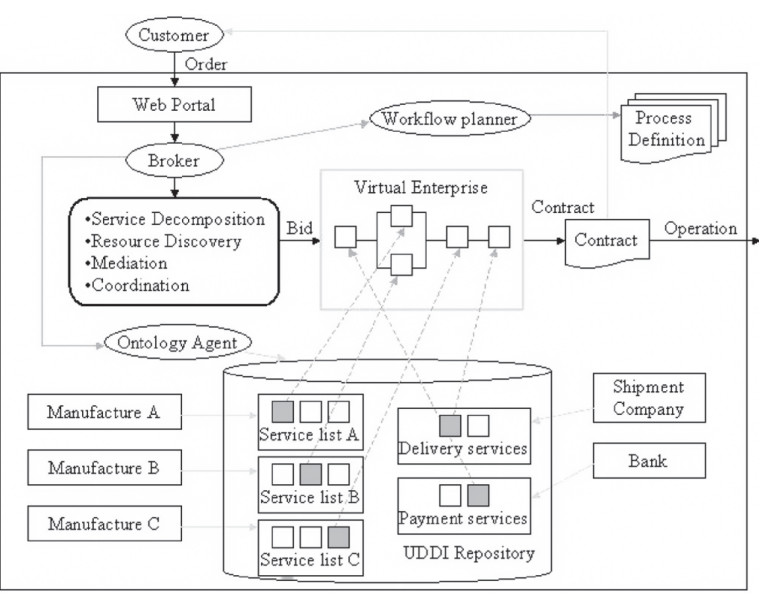

Figure 2.43 Architecture for manufacturing enterprise collaboration an execution task and sends it to the broker agent for task allocation.

\section{Web-based ERP system}

Tarantillis developed a web-based ERP system that is built around a workflow business process mechanism and an enterprise resource management engine, see figure 2.44 [Tarantilis et al., 2008]. Users log into the system via a web application portal. Through an information flow engine, the user can navigate past the independent system's functionalities. Each web-based component is autonomous and is easily pluggable even across applications. The accessibility of the data as well as the initiation of business processes is controlled by web-based components. The proposed Web-based ERP system is able to through the integration of both workflow and resource planning processes to overcome several supply chain problems. The system is applied and tested in several companies and showed the following benefits:

- Streamlining, improvement and control of business processes

- Cost-reductions and time-savings

- Management of service related personnel and costs

- Integration with Quality Management System

- Flexible and efficient production planning.

- Provision of critical information in the company. 


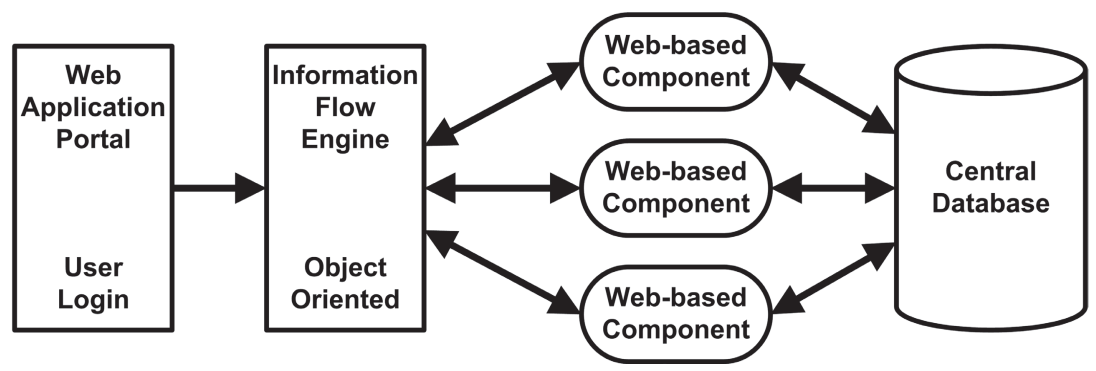

Figure 2.44 Web-based ERP system

\section{TailorSteel.com}

247TailorSteel.com is a company that provides customers with an online tool to instantly order custom sheetmetal parts [247tailorsteel, 2011]. The ordering process of the 247TailorSteel. com is illustrated in figure 2.45 .

Customers can upload their drawings to 247TailorSteel.com through an application and request a quotation for it. A quotation is then provided within 2 minutes by the application to the customer. The quotation provides both an accurate cost calculation as well as a delivery date based upon the situation in the production environment. Submitted orders are produced in an unmanned production environment. AVGs (automatically guided vehicles) in combination with automated production processes provide for a cost efficient production environment that operates 247 .

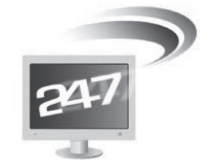

1. Install 247 CAD Tool on Computer

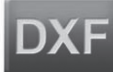

2. Upload DXF-file of the product. Choose material, thickness, surface-finish and quantity.

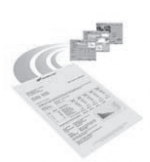

3. Submit the request. A quotation is presented within 2 minutes.

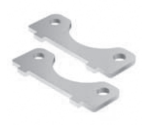

4. Submit the order. The product is manufactured and delivered.

Figure 2.45 247TailorSteel

\section{CyberCut}

CyberCut is a prototype of a CNC-milling c-Commerce implementation in the manufacturing industry developed by Smith and Wright [Smith \& Wright, 1996]. CyberCut is a web-based design-to-manufacturing system. Users of CyberCut can access a CAD interface through the Internet. By providing access to this CAD interface, any engineer can become a user of this online rapid prototyping tool. A user can upload a CAD file in a specified universal exchange format to the CyberCut server, which in turn executes the necessary process planning and generates the appropriate NC code for milling. The part can then be manufactured and subsequently shipped to the designer. The engineer can have a fully functional prototype within days at a fraction of the cost of in-house manufacturing.

\section{eMachineShop}

eMachineShop is an online machine shop that enables any company, organisation or individual to design, quote, and instantly order custom mechanical parts [Emachineshop, 2011]. In 
order to be able to order products by eMachineShop, a CAD modeller has to be downloaded. Only parts designed in this modeller can be ordered on the online machine shop. Quotations are generated automatically by a module contained in the CAD modeller. Process plans for the submitted parts are generated with a high degree of automation and the parts are immediately scheduled for production. This commercial system is very similar to the CyberCut prototype. Both use a dedicated CAD modeller as input for their system. However, eMachineShop provides for more manufacturing

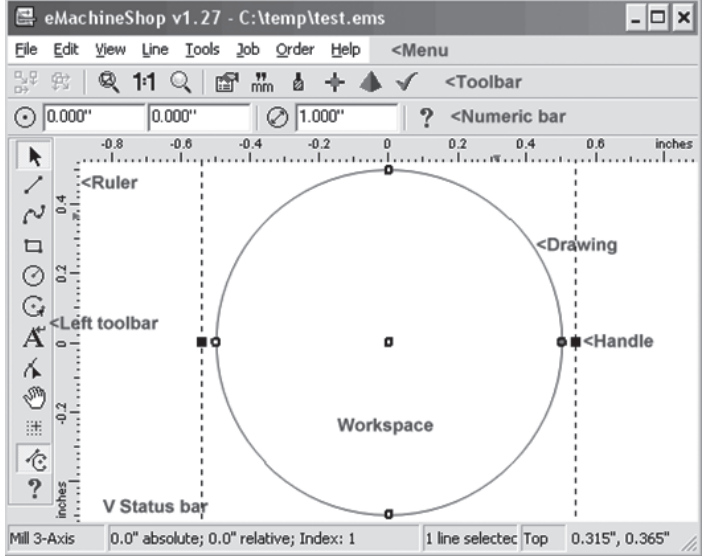

Figure 2.46 eMachineshop techniques than just CNC-milling as is the case with CyberCut. With eMachineShop parts produced by almost every conventional manufacturing technique (from bending to extrusion and from casting to laser cutting) can be ordered.

\section{Shapeways}

Shapeways is an online rapid prototyping company that focuses on the consumer market [Shapeways, 2011]. Shapeways offers the service of uploading your designs and prototyping them on order. Designs can be stored online so they can be reordered at any time, or a personal shop can be opened where others can view and order your designs. A view of such a personal shop on the Shapeways site is given in figure 2.47. Shapeways support several file formats, allowing for the use of virtually any 3D CAD software. Once a design has been uploaded, the model is checked for errors to be fixed by an online tool. When the uploaded model is approved, it can be ordered. The price is calculated through the size of the model and the material used. The model is then produced on the rapid prototyping machines of Shapeways and are subsequently send to the customer. The designs are produced in several manufacturing sites distributed over the globe, which are linked to the Shapeways site.

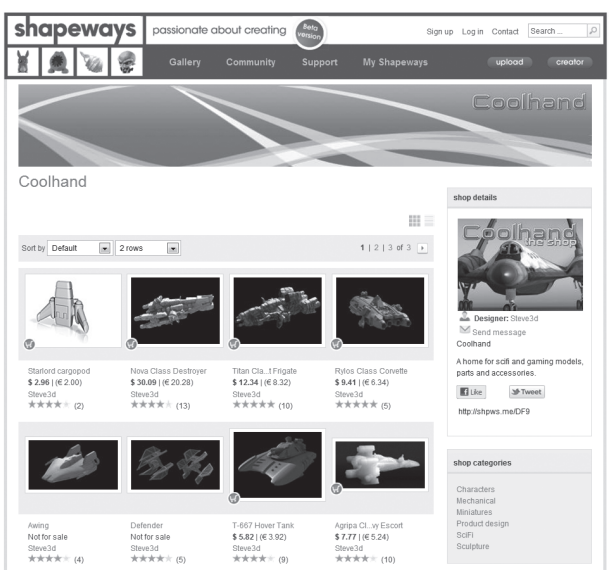

Figure 2.47 Shapeways website

\section{Materialise OnSite}

Materialise OnSite offers a similar rapid prototyping service as Shapeways but focussed on the business market [Materialiseonsite, 2011]. Materialise OnSite is an online service that allows engineers to quote and order prototypes 24/7. The products ordered on via OnSite are all produced in the manufacturing plant of Materialise located in Leuven (Belgium). 


\section{Comparison of the initiatives with CNC}

Worknet.

As can be seen in the previous sections, e-commerce opportunities in the manufacturing industry are being explored and have been implemented successfully. In the machining industry the concept of e-commerce is rather new. When comparing these implementations with the CNC Worknet business model some differences can be noted. Current implementations revolve around the use of a client-side software package that is used to transfer the TPD or manufacturing data to the manufacturing site in a structured way. This is advantageous for

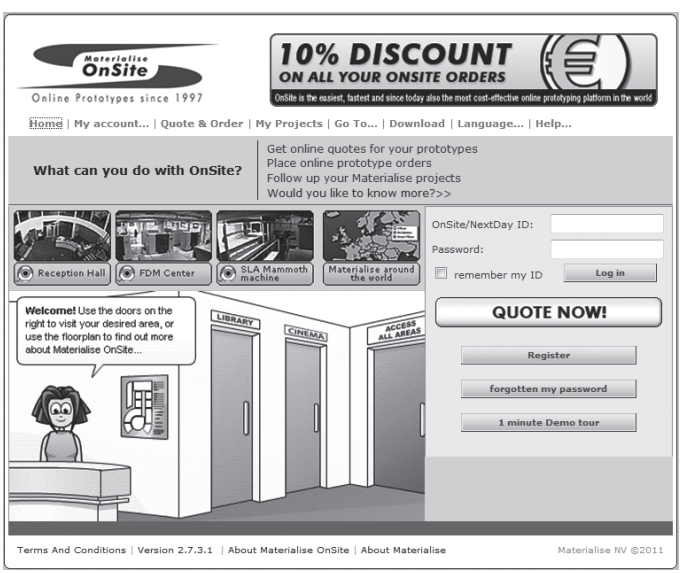

Figure 2.48 Materialise Onsite the system but hinders the customer. Sometimes the product has to be converted or regenerated again in the client-side software package by the customer. Next to this, the current available implementation are generally only dedicated to one machining technology, like turning for WebMachining and sheet metal for 247Tailorsteel.com. CNC Worknet is initially also focussed on only two technologies, but it is foreseen that this is expanded, which is a novelty in the current manufacturing environment.

\subsection{Recapitulation}

In retrospect, several remarks emerge if looking at the discussion of both the existing supply chain and the different disciplines and processes that it is comprised of. First, an overview of the different discussed disciplines and processes is given and then the challenges that arise in the existing supply chain are discussed in relation to this overview.

\subsubsection{Difficulties and Disadvantages}

The existing supply chain described in section 2.1.2 is capable of dealing with almost any task given to it. However, there are a number of challenges that can be identified in this said supply chain. Due to these challenges, it can be stated that the existing supply chain performs rather inefficiently. This is due to the way the supply chain is geared to dealing with even the most complex products and circumstances. Moreover, all inefficiencies in the individual links in the chain tend to add up in the overall chain. This causes unnecessary waiting time as well as unnecessary buffer time [Goldrath, 1999]. Figure 2.49 displays a selection of the identified difficulties and disadvantages that challenge the efficiency of the supply chain. These difficulties and disadvantages are subsequently discussed in the following paragraphs.

\section{Complex workflow with many links}

The described supply chain contains many different departments and parties. This directly results in a complex workflow with many links. Every link between entities is a potential source for miscommunication that can result in difficulties, both up- and downstream. These 


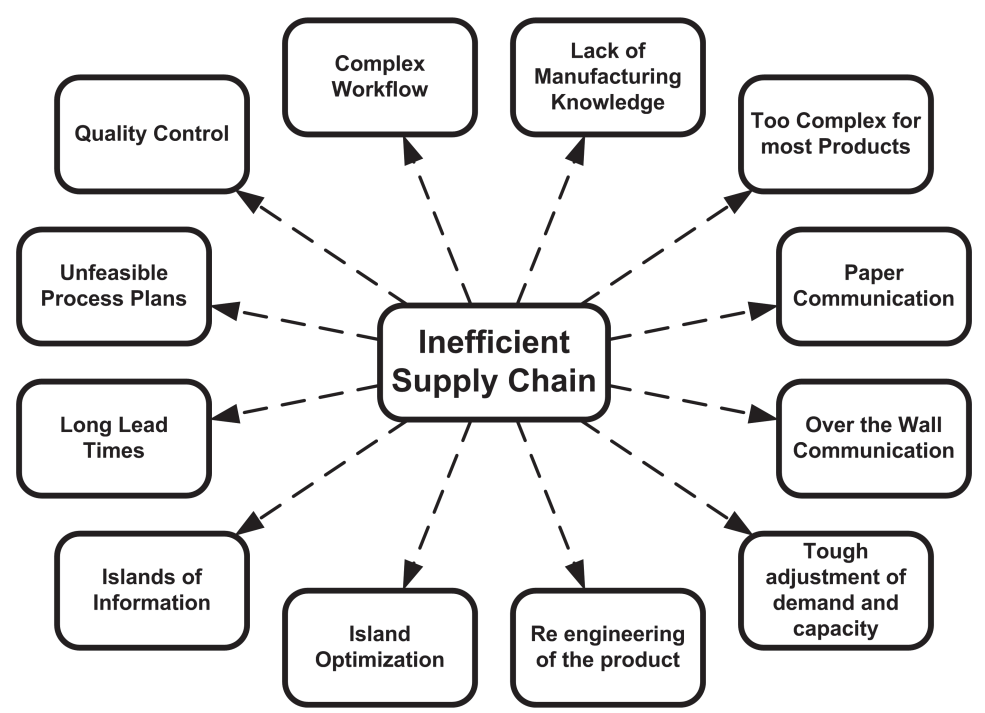

Figure 2.49 Difficulties supply chain

difficulties relate directly to both the workflow and the information management entities of the supply chain.

\section{Lack of Manufacturing Knowledge}

The decisions that engender $80 \%$ of the costs of a product are taken during the initial design steps in the engineering department of the customer. Due to a lack of (usage of) manufacturing knowledge, often products are designed that could have been produced against a much lower cost when the engineer had (access to) more knowledge of the manufacturing capabilities on the shop floor where the product is to be manufactured. The same situation occurs in the calculation department. The experts that perform the calculations on which the quotations are based are in general not the employees who prepare the process plan. Therefore, also these employees do not always have (access to) the manufacturing knowledge that is required for adequate process planning. As a consequence, the accuracy of the established quotations can be questioned. This can result in refusals from customers when the calculated price is too high or in losses for the company when the calculated price is too low. From this, it is clear that significant steps are required in the field of knowledge management to overcome these difficulties.

\section{Too complex for most of the products}

It is a general observation that in the existing supply chain $20 \%$ of all the products cause $80 \%$ of the problems. The supply chain is set up to be able to handle all requests; consequently it has to provide solutions for the problems stemming from even the niche products. As a consequence, the supply chain has become too complex for the major part of the products that are manufactured by it. 


\section{Paper communication}

The different departments in the supply chain generally communicate with each other through conventional 'paper' means and meetings. The currently available digital means of communication are not exploited to their fullest extent within the supply chain.

\section{Over the wall communication}

Each entity within the supply chain focuses on performing its own tasks within the time frame set for completing it. When the task is complete, the result is passed on down the chain. This way of working is typically known as 'over the wall communication.' No reflection on the results or feedback is flowing up the chain. Things that go wrong downstream due to decisions taken earlier in the chain will go wrong the next time because the source of the mistake is not identified. An illustrative example is that process plans are often changed or adjusted on the shop floor, without notifying the process planning department of the change. Moreover, hardly ever the reasons for these changes are communicated back to the process planners, thus these mistakes may therefore happen again, resulting in even more delays and errors.

\section{Re-engineering of the product}

Each product is usually 'engineered' twice during its flow through the supply chain. Generally, the engineering of the product is initially performed by the customer; a second time by the process planner during the translation of the product drawings into a fabrication plan. Consequently, quite some time is lost between the initial purchasing step of the customer and the start of the actual manufacturing. This loss is directly linked to the process planning as well as the interoperability topics [see section 2.2.2], both proposing ways in which these reengineering activities can be avoided. However, as the suggestions regarding these solutions are still too immature to be implemented, these options are still extremely occasional in industrial supply chains.

\section{Island optimisation}

Another disadvantage of existing supply chains is that optimisation of the various departments and processes usually does not involve the departments or processes with which they interact. Therefore, several islands of optimisation are created, which, over the entire process chain, generally result in a lower efficiency. The local goals of departments tend to prevail over the global goals of the company. It is not uncommon that several dedicated systems, with their own databases, are set up for these islands. Although these dedicated systems enable improved decision making within a specific department, they lack functional integration and make communication and cooperation with other departments and processes exceedingly difficult. This results in problems like data redundancy, information inconsistency and/or inaccuracy, and high system maintenance costs. Consequently, a company as a whole may lose its competitive advantage because it is not able to realise its full potential.

\section{Islands of information}

The existing supply chain is comprised out of many entities and departments. It is not uncommon for every department or entity to have its own information system. As a result of this, it is very difficult to synchronise all the data and information along the supply chain. Research has pointed out that this fragmentation of information is one the primary reasons for information delays and distortions in the supply chain [Mc Afee, 2002]. For example, information delay and distortion thereof are the major causes of the bullwhip effect in a 
supply chain. Proper implementations of both ERP and information management in the supply chain are required to prevent these problems.

\section{Long lead times}

The time between the initial request for quotation and the actual start of the production of the order can be very long. This is mainly due to the customer himself, because he waits for the return of all the quotations from the different companies where a quotation is requested. The time it takes for a manufacturing company to generate a quotation is rather long because the company, in its turn, has to wait for the return of the quotations from the (different) suppliers. Consequently, the majority of time is lost in waiting for the response of other companies or departments in the supply chain.

\section{Unfeasible Process Plans}

Process plans are generally prepared well in advance of their execution in order to prevent machine idle time. During process planning, usually infinite machine capability of the manufacturing resources is assumed by the process planners. Based on this assumption and certain economical/technical criteria, the process planners make the decision to choose the best routing of operations on corresponding resources from all technically feasible alternatives. They also embed the use of these resources in the corresponding process plan. It is, however, very likely that process plans prepared well in advance become infeasible at the time they are to be executed, due to the unavailability of certain resources [Xu \& Li, 2008].

\section{Quality Control}

The quality of the products manufactured by the existing supply chain is typically checked at the end of the manufacturing process. Products that do not comply with the quality requirements are either reworked or remanufactured after detection. This extra work can result in a delay of the delivery date of the order and it can also interfere with the manufacturing process of other orders currently in production.

\section{Tough adjustment of demand and capacity}

Due to the uncertainty of quotation acceptance by the customer and the long waiting times before responses are received, it is very difficult to schedule and plan the production. During the generation of the quotation, production time may be reserved for the potential order. In order to take into account a potential rejection of a quotation, multiple quotations are allotted the same time slots. The difficulty in this situation lies in the fact that sometimes orders will claim the same time slot and that sometimes no order will claim the time slot. Due to this, it is very difficult to adjust the production capacity to the expected requests. Next to this, the information that is available for drawing up the capacity plans is not planned in detail by process planning yet. Therefore, one has not only to deal with the uncertainty that results from the stochastic characteristics of manufacturing (randomness, such as machine breakdowns), but also with the uncertainty that results from the rough status of the technological plans [Giebels, 2000]. This all adds to the difficulty of adjusting the demand to the available production capacity. Advancements are to be made to overcome these difficulties in the application of both ERP and planning and scheduling in the current supply chain. 


\section{Reference Model}

The entities of the manufacturing environment, as described in the previous chapter, influence the manufacturing environment from many different directions. Due to these different directions it is difficult to predict the influence or effect of an entity on another entity or the manufacturing environment as a whole. A reference model outlines the relations between the different entities of the manufacturing environment. Through the use of a reference model the different views can be unified [Arentsen, 1995].

\subsection{Manufacturing Engineering Reference Model}

A manufacturing engineering reference model that is capable of supporting the entire manufacturing environment is developed by Lutters and shown in figure 3.1 [Lutters et al., 1999]. It addresses the products and the accompanying processes and resources through the entire manufacturing cycle, emphasising on the equivalent importance of products, orders and resources. The reference model creates a flexible environment in which tasks can be executed, either automatically or by human interaction.

\subsection{Reference Model Entities \& Interactions}

The reference model as shown in figure 3.1, displays several entities that together form the reference model. These entities and their interactions are discussed in the following sections.

\subsubsection{Company Management}

Company Management is placed at the top of the reference model, dealing with the strategic decisions concerning the range of products, long-term resource investments, marketing and sales strategies. The tactical and operational decisions are dealt with by the next three functions: Product Engineering, Resource Engineering and Order Engineering. In the figure, these functions are represented by the vertical pillars.

\subsubsection{Product Engineering}

Product Engineering refers to all the engineering activities related to the product life cycle of a specific type of product. It is concerned with the design and development of a product and its variants, starting from functional requirements up to the final recycling or disposal of the product.

\subsubsection{Order Engineering}

All the production activities as well as the supporting activities necessary to make the products are planned and controlled by Order Engineering. Typical tasks are internal due date setting, determination of batch sizes and resource allocation. Next to controlling the activities that are performed internally in the company, Order Engineering also deals with the external life cycle of the orders. This task involves the communication with the external stakeholders (e.g. customers, suppliers) of the company. 


\subsubsection{Resource Engineering}

Resource Engineering deals with all the life cycle aspects of the resources in relation to the execution of the production tasks. It therefore includes the specification, design, development, acquisition, preparation, use and maintenance of all the resources of a company.

\subsubsection{Information Management}

Information Management is the central pillar in the Manufacturing Engineering Reference Model. Information Management provides for all information processing requirements of the engineering tasks. The manufacturing information is represented in three information structures,

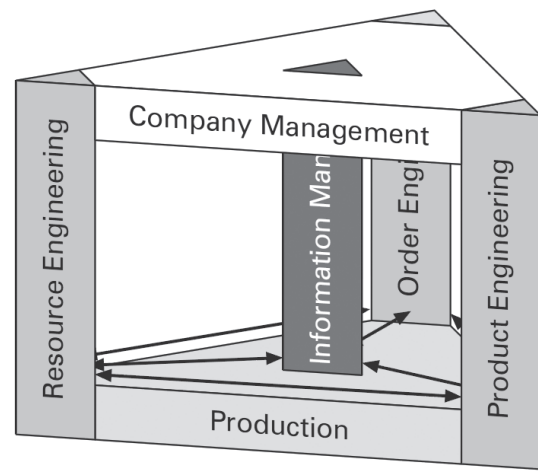

Figure 3.1 Manufacturing Engineering Reference Model dealing with product-, order- and resource information, respectively. Each of the structures supports the tasks of the corresponding engineering pillar.

\subsubsection{Production}

Production is concerned with the actual execution of the plans generated by the engineering tasks. From production, information is fed back to the engineering tasks.

\subsubsection{Interactions in the reference model}

The engineering tasks of Product, Order and Resource Engineering substantially influence each other. These interactions are mainly realised by information that is generated by the engineering tasks. Through the use of Information Management, this information can be exchanged between the different tasks. This information exchange can be registered and serve as the basis for the control of the engineering tasks. Consequently, the arrows between Information Management and each of the engineering tasks represent the exchange of both required and generated information and the exchange of control information. These arrows between Information Management and the engineering tasks relate to short term interactions. The arrows between the engineering tasks themselves address the interaction between them in the long term. Examples of this type of interaction are the conveyance of knowledge, context information and procedural commitment. The transfer of knowledge and context information can be regarded as a type of interdepartmental education in the manufacturing environment. Procedural commitment is transferred to regulate and govern the workflow dependent on constraints imposed by Company Management.

The Manufacturing Engineering Reference Model encompasses all manufacturing planning tasks that are to be performed in a manufacture-to-order environment. It does not focus on either the technological or logistic planning tasks, and it makes no distinction between these planning tasks. Information Management serves as the kernel in the reference model to streamline the concurrent generation of the product-, order-, and resource information. 


\section{CNC Worknet}

This chapter introduces CNC Worknet and its business model of CNC Worknet is presented in the first section. The envisaged environment and supply chain, that are the result of this business model, are discussed in the following sections and they are compared to the existing supply chain. These three parts form the input for the specifications of the envisaged $\mathrm{CNC}$ Worknet supply chain as presented in figure 4.1.

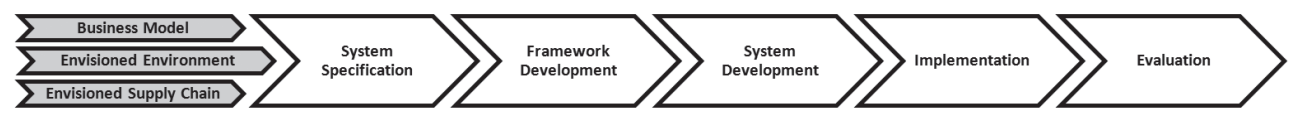

Figure 4.1 Research Approach

The specifications of the envisaged CNC Worknet supply chain are presented through functional descriptions of the entities of CNC Worknet and the requirements thereof in the final section of this chapter.

\subsection{CNC Worknet Business Model}

CNC Worknet introduces a business model that interprets the manufacturing engineering reference model [see section 3.1] in a specific way. The existing supply chain, as explained in [see section 2.1.2], is by far too complex for the majority of the products manufactured by it. The business model of CNC Worknet focuses on the manufacturing of relative simple products that generate less problems within the supply chain [Dam et al., 2009]. By focussing only on the manufacturing of these specific products in small numbers, the entities of the reference model are simplified and the relations between the different entities becomes more clear and direct. The supply chain resulting from this situation is both more streamlined and responsive when compared with the existing supply chain.

The CNC Worknet business model revolves around an Internet portal through which customers can request quotations and place orders for the manufacture of simple products. This Internet portal is connected to a network of manufacturing plants in which the ordered products are manufactured. The manufacturing plants that are connected to the portal are operated within a franchise model. This business model is illustrated in figure 4.2. The goal of CNC Worknet is to provide the customer access to a univocal, direct and easily accessible global manufacturing network that consistently manufactures products according to the needs and specifications of the customer.

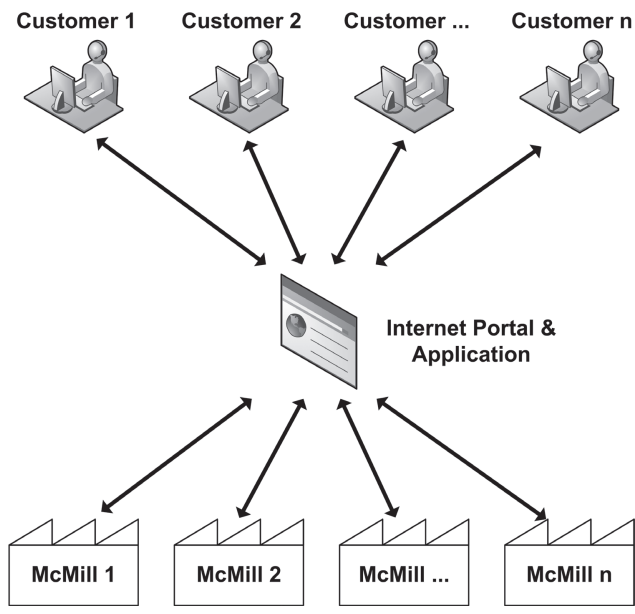

Figure 4.2 CNC Worknet Business Model 


\subsection{Envisaged Environment}

Within the business model introduced for CNC Worknet, two distinct environments can be identified; a portal environment and a production environment. The portal environment provides access to all those manufacturing activities that occur before production and that can be handled centrally. In the context of this thesis, these centralised manufacturing activities are referred to as pre-production activities. Alternatively, the production environment contains those manufacturing activities that cannot be handled centrally, i.e. the activities that take place in the production plants. The centralisation of pre-production activities is enabled through thorough and far-reaching standardisation of the production environment. Due to both the standardisation and centralisation, products can be produced in any production environment connected to the portal environment. A short explanation and a description of the primary functions of these two environments are given in the following sections.

\section{Portal Environment:}

The Internet portal acts as the mediator between the customers and the production environments. Additionally, the portal environment integrates, centralises and automates all the preproduction activities for all the production environments connected to it. These centralised processes include for example planning and scheduling, process planning operations, purchasing activities and sales operations. One of the main functions of the portal environment is the quick quotation process, which envisages to present a quotation to the customer within one day.

\section{Production Environment:}

The production environments are connected to the portal environment through the Internet. In order to be able to centralise all the pre-production activities for all these environments, all these environments have to comply to a blue print. This blue print specifies all the hardware, software and working principles employed within these production environments. Next to this, the production environments share information with the portal environment regarding the status of the different operations on the shop floor. The production locations have a high degree of automation that allows for $24 / 7$ production.

\section{Franchise Organisation}

CNC Worknet does not strive to own many production environments themselves. The production environments are therefore setup as part of a franchise organisation that is managed and controlled by CNC Worknet. Companies can join the CNC Worknet franchise organisation if they comply to the blue print. Hereby a manufacturing network of franchisees is created that focuses on both globalisation and efficiency. As a result of the combination of the global presence of the franchise organisation, the use of the blue print and the centralised preproduction processes, technical reasons no longer play a role in deciding in which environment a product is manufactured. The process plan for the production of the part can be executed at every production location that complies to the blue print. Therefore, the decision where a product is manufactured can become primarily a logistic choice instead of an technical choice. The production costs at all production locations will be comparable due to the use of the blue print. Thus, the differences between the locations will primarily stem from the delivery times, transportation costs and the local procurement costs. This described approach allows for extremely flexible planning and scheduling. Production can be planned 
and scheduled based on the actual situation on the shop floor of the different production environments, also giving the ability to quickly reschedule or re-assign orders to another production location when problems occur.

\section{Modularity and Continuous Improvement}

The production environments connected to the portal environment are, as a result of the use of the blue print, envisaged to be large modular entities. It is envisaged by CNC Worknet that modularity also exists on a more detailed level within the different entities of CNC Worknet. This vision finds its footing in the envisaged setup of the $\mathrm{CNC}$ Worknet system. CNC Worknet is a small company with a limited budget. As a consequence of that, it is envisaged that the system is initially setup in a rudimentary fashion through the use of modular entities. These modular entities are subsequently steadily improved or replaced by an continuous improvement approach. This approach identifies and prioritises the development activities for the further development of the different entities of CNC Worknet. The combination of the modular setup and the continuous improvement approach allows CNC Worknet to be initially setup in a rudimentary fashion, that is subsequently steadily improved.

\section{Quality Control and Standardisation}

In the existing supply chain, quality of both products and the processes themselves is mostly handled implicitly. Within CNC Worknet, quality needs to be controlled explicitly in order to make sure that the quality of the products and the processes is of a sufficient level throughout the entire supply chain. As a consequence, an environment is envisaged in which the quality of the product is taken into account from the moment a customer submits an enquiry until the actual delivery of the order.

Due to standardisation, the functioning of the different entities and the entire CNC Worknet supply chain becomes more structured and therefore more predictable. Machines, tools, processes and working methods employed within CNC Worknet are all standardised and have proven their functionality. Consequently, these should behave in a predictable manner. This predictability is of great benefit for assuring the quality of the resulting product but also of the processes used to manufacture it.

\subsection{Envisaged Supply Chain}

Based on the CNC Worknet business model and the described environments, a scenario can be used to describe how the production environments, within the context of the business model, ideally act in a supply chain. An illustration of this envisaged supply chain is given in figure 4.3. The different activities and processes employed at the different stages of this supply chain are explained in the following sections.

\section{Scenario - step 1: Engineering at the customer}

The product is engineered by the customer, as is the case in the existing supply chain, [see section 2.1.2]. However, the difference with the existing supply chain is that only a singe data package is created. The basis of this data package is the 3D CAD model of the desired product that describes all its specifications including the dimensions and tolerances. No 2D drawings of the product are therefore created anymore. 

the Internet portal. The 3D CAD models of the products are uploaded and a request for quotation (RFQ) is created via the portal after submitting, for example, the requested product quantities. A quotation is presented to the customer within 24 hours on the internet portal. The customer accepts or rejects the quotation. When the quotation is accepted, the customer is kept up-to-date on the portal about the status of the order throughout the entire production process.

\section{Scenario - step 3: Portal Environment}

The RFQ is processed by the automated processes of the portal environment. First, a process plan is generated based upon the $3 \mathrm{D}$ CAD model. Subsequently, this process plan is used for the calculations required for the quotation. Based upon the actual situation on the shop floor and the lead times of the suppliers a delivery date is calculated. The quotation is presented to the customer on the Internet portal. When the quotation is accepted, the order is scheduled immediately at a production location that has the required time and capacity to produce the order and also meets other logistic criteria. Purchase orders are send to the supplier for the delivery of the required materials at the production location. The production package containing all the data required for the manufacture and inspection of the order is send to the production location. The status of the order is presented on the Internet portal throughout the entire production process. Next to the technical side of the supply chain the portal environment also manages the financial transactions between the CNC Worknet and its customers and suppliers.

\section{Scenario - step 4: Production Environment}

The production package is received from the portal and the instructions contained in it are distributed to the points of use. The delivery of the material supplier is received and registered after inspection according to the instructions. The requirements for the production are prepared in order for the production to start in accordance with to the schedule.

CNC Worknet

\section{Engineering}

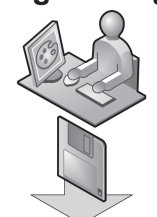

Purchasing

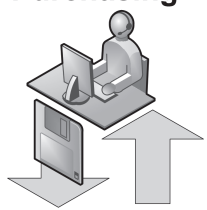

CNC Worknet Portal
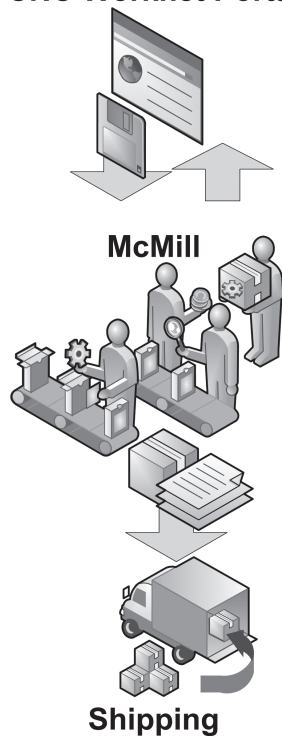

Figure 4.3 Envisaged

Supply Chain The production environment executes the production according to the instructions provided in the production package. Inspections are carried out during and after the production to verify the specifications of the products. When the specifications are met, the products are prepared for shipping. All the required shipping documentation is bundled, including inspection data, and attached to the shipment. The prepared shipment is subsequently handed over to the expedition for the actual delivery to the customer.

\section{Scenario - step 5: Expedition}

The prepared shipment is picked up by an external transportation company. The shipment is subsequently delivered to the customer. 


\subsection{Supply Chain Comparison}

The existing supply chain and the envisaged supply chain for CNC Worknet described in the previous section differ considerably. These differences and their implications are discussed in the following sections.

\section{Quick and accurate quotation process}

First of all, the quotation process of the envisaged supply chain is much quicker due to the high level of automation and integration of the preproduction processes. Next to this, the quotations that are generated by this system are more accurate. The main reason for this improved accuracy is that the quotations are based on the actual process plan that is going to be used during production. A disadvantage of the quick quotation process is that the customer may use it next to the existing supply chain. The customer will then wait for the quotations from the current supply chain in order to compare them with the quotation from the envisaged supply chain. Obviously, this nullifies the effect of the quick quotation process.

\section{Short throughput time}

Next to the quick and accurate quotation process, the through put time of the envisaged supply chain is much shorter than it would be in the existing supply chain. One of the main reasons for this is that the production processes can be started immediately after the quotation is accepted by the customer. The process plan is already finished and the necessary materials and supplies can be ordered directly at the supplier. In the existing supply chain the process plan typically still has to be generated as a rough process plan is used during the calculation of the quotation process. The generation of the actual process plan is in the existing supply chain initiated upon the order is granted to the company. This takes time and increases the through put time of the supply chain.

\section{Product types}

The envisaged supply chain focuses only on a certain types of products. Only products that are fully defined and specified are suitable. Products that verge on the limits of the process, machine and tool capabilities are not considered. When focusing on the resulting types of products, the main challenges in the production environments will be logistic in nature. This implies that technical challenges do hardly occur on the shop floor, thus limiting the risk of having to make complex decisions too late in the supply chain. The result will be a production environment that is stable, flexible and predictable. All other product types are assumed to fall back on the existing supply chain.

\section{Order size}

Next to the product type the envisaged supply chain also limits its focus on products that are ordered in small to medium batch sizes. In order to be able to standardise the production environment, only orders in small to medium sized batches can be considered. Larger batches require specialisation in tools and equipment in order to be competitive. The required standardisation of the production environments would be violated by such adaptations. The flexibility of the production capacity would also decrease due to the introduction of large batches. 


\section{Technical Product Data}

The technical product data (TPD) received from the customer in the envisaged supply chain is completely based on a single $3 \mathrm{D}$ CAD file. This CAD file describes the entire product, including all dimensions and tolerances. Each process within the supply chain uses the same 3D CAD representation of the product. The use of $2 \mathrm{D}$ drawings is avoided. Due to this change, a lot of data redundancy (multiple 2D drawings and 3D models of the same product) and time consuming processes ( $2 \mathrm{D}$ drawing creation and translation) are excluded from the supply chain.

\section{Complexity}

The complexity of the envisaged supply chain is much lower than that of the existing supply chain. Because all the processes that are required to handle complex products are omitted, the supply chain contains less iterations and loops to solve the problems associated with these complex products. The envisaged supply chain contains less dependencies between processes and is therefore not as complex as the existing supply chain and more straightforward.

\section{Load balancing capabilities}

The envisaged supply chain can perform load balancing between the different production environments connected to it. Production peaks and lulls are shared between the different locations. Moreover, in the envisaged supply chain, the difference between scheduling and capacity planning becomes less important, because of the resource sharing in the supply chain. This situation does not occur in the existing supply chain where different production locations compete with each other.

\section{Digital process flow}

The communication between the different departments in the existing supply chain heavily relies on paper means and meetings. This makes the communication in this supply chain sluggish and prone to errors due to items getting lost or misunderstood. In the envisaged supply chain, the communication is heavily digitalised and focus is on using unequivocal information. A digital process flow is created by that allows for full tracking and tracing during the entire process, from the initial request for quotation until the actual delivery.

\section{Reduced costs}

Due to the high level of standardisation the equipment costs in the envisaged supply chain will be much lower then in the existing supply chain. Next to this the storage costs of unused tools will be lower as well. All the tools in use in the production environment are also actively used. In the existing supply chain a lot of specialised tools are purchased for one specific order and subsequently stored so that it might be used again. This situation results in high storage costs and a lot of unused equipment.

\section{Logistic consequences}

Due to the network of standardised production environments connected to the portal environment, the logistic consequences of altering the production from one location to another are low. In the existing supply chain, the alteration of the production location is difficult and will have major consequences. For example, process plans will have to be changed and new suppliers will need to be found. Both of these activities require a lot of time and may result in delays of the delivery of the order. 


\section{Quality}

Quality control is one of the final steps in the existing supply chain: therefore it is a very reactive process by definition. The quality control process in the envisaged supply chain is much more pro-active as it is used to manage and control the quality of the products throughout the entire production process. Quality deficiencies are detected early in the process which results in less rework and a more stable production process. Moreover, by focusing on quality throughout the entire supply chain, a much better integration between workflow and quality can be established.

\subsection{CNC Worknet Specification}

In this section, the business model, its corresponding envisaged environment and supply chain are translated into a specification that contains both functional descriptions as well as requirements for the different entities of CNC Worknet. Initially the envisaged system is subdivided in three main entities based on the strategic, tactical and operational aggregation levels [Giebels, 2000] of CNC Worknet. Subsequently, functional descriptions of the constituents of these three main entities are given. Based on these functional descriptions and the result of the previous chapter, the requirements for CNC Worknet are specified. The functional descriptions and the requirements together form a thorough basis, which is used during the development of CNC Worknet.

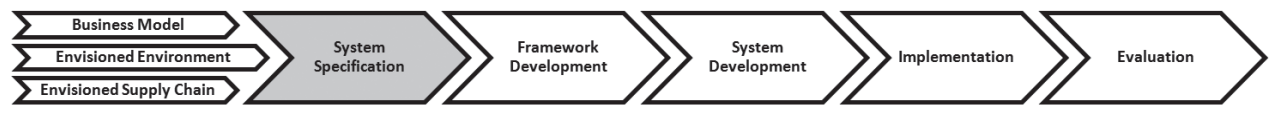

Figure 4.4 Research Approach

\subsubsection{Functional Description}

CNC Worknet can be decomposed into a set of functional descriptions. These functional descriptions form the basis for the development of the different parts of the CNC Worknet system. The functional descriptions are derived from the envisaged CNC Worknet environment and supply chain, by carefully following the workflows that exist within $\mathrm{CNC}$ Worknet. Hereby, the different functions that need to be accomplished are identified and subsequently described. To establish the functional descriptions in a structured manner, IDEF0 is used. IDEF0 is a method designed to model the decisions, actions, and activities of an organisation or system. IDEF0 was developed to model a variety of systems to provide a consistent approach for systems and enterprise requirements specification along with the functional relationships of data to facilitate the integration of these functions [Rowlands \& Richards, 2002]. The first scheme, given in figure 4.5, shows the interactions of the CNC Worknet system with its environment. These interactions can be divided into four main groups:

- customer interaction related to orders.

- supplier interaction related to purchases.

a interaction with potential franchisees.

- technology interaction for the improvement and incorporation of new technology. 
Figure 4.6 gives an overview of the CNC Worknet system. The figure illustrates the subdivision into the three main entities that correspond with

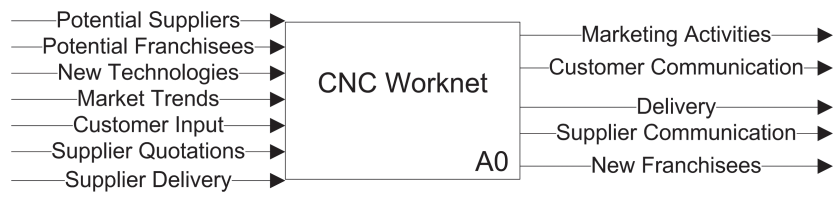
the three aggregation levels of CNC Worknet. The strategic Figure 4.5 Interactions of CNC Worknet entity focuses on the long term

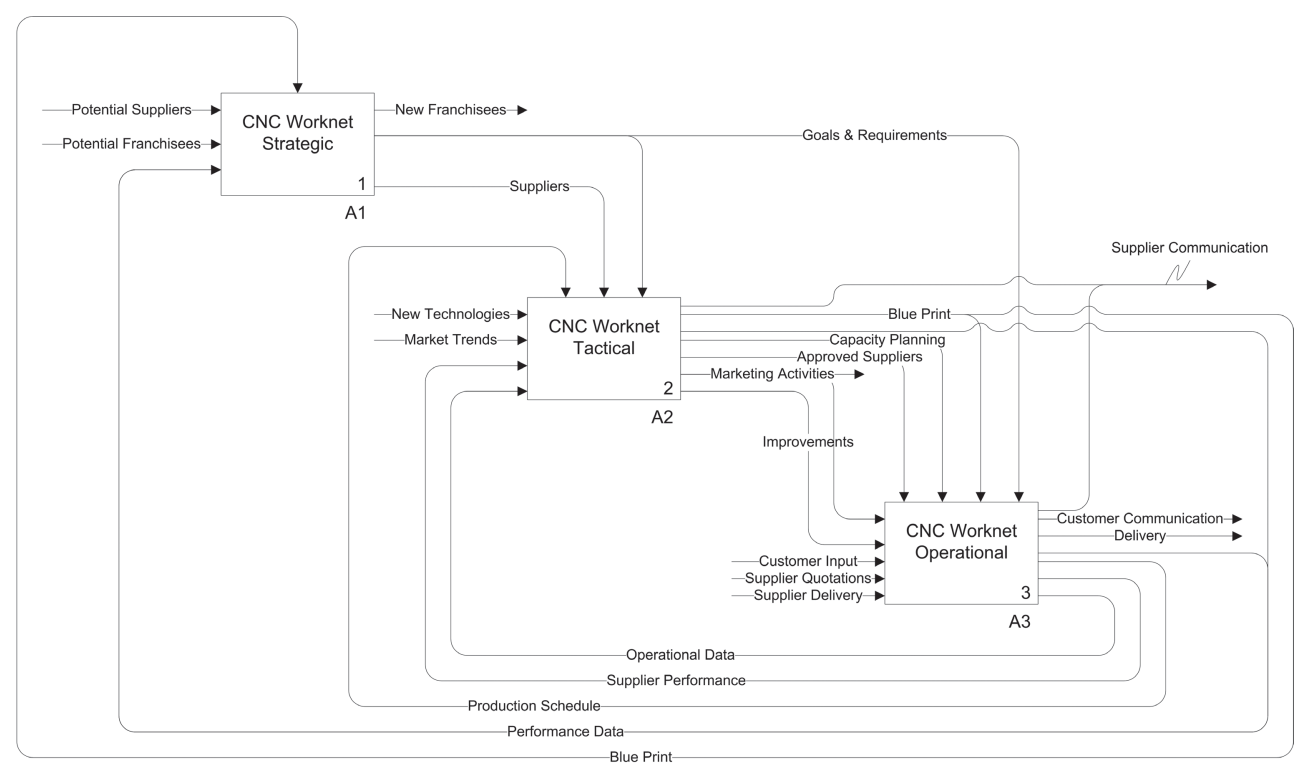

Figure 4.6 Overview CNC Worknet System

commitments and functions of the company, the tactical entity on the mid-term functions and the operational entity on the daily operations. All entities have a number of mutual connections and connections with the outside world. The contents and relations of the three entities are discussed in the following sections.

\section{CNC Worknet Strategic}

The functions on the strategic aggregation level of the system govern and manage the longterm goals and commitments of the company. An IDEF0-style scheme of these entities on the strategic level is shown in figure 4.7. Three entities operate on the strategic aggregation level of the system. The business model focuses on the overall strategy and goals of the company, strategic purchasing negotiates long term relationships with the suppliers and franchise management manages the franchise organisation of CNC Worknet.

\section{Business Strategy}

This entity manages the long term strategy of the company together with the business model. This strategy and business model are translated into goals and requirements for the different entities of the system. These goals and requirements result from reviewing and balancing them against the triangle of constraints as discussed in [see section 2.1.1]. The performance 


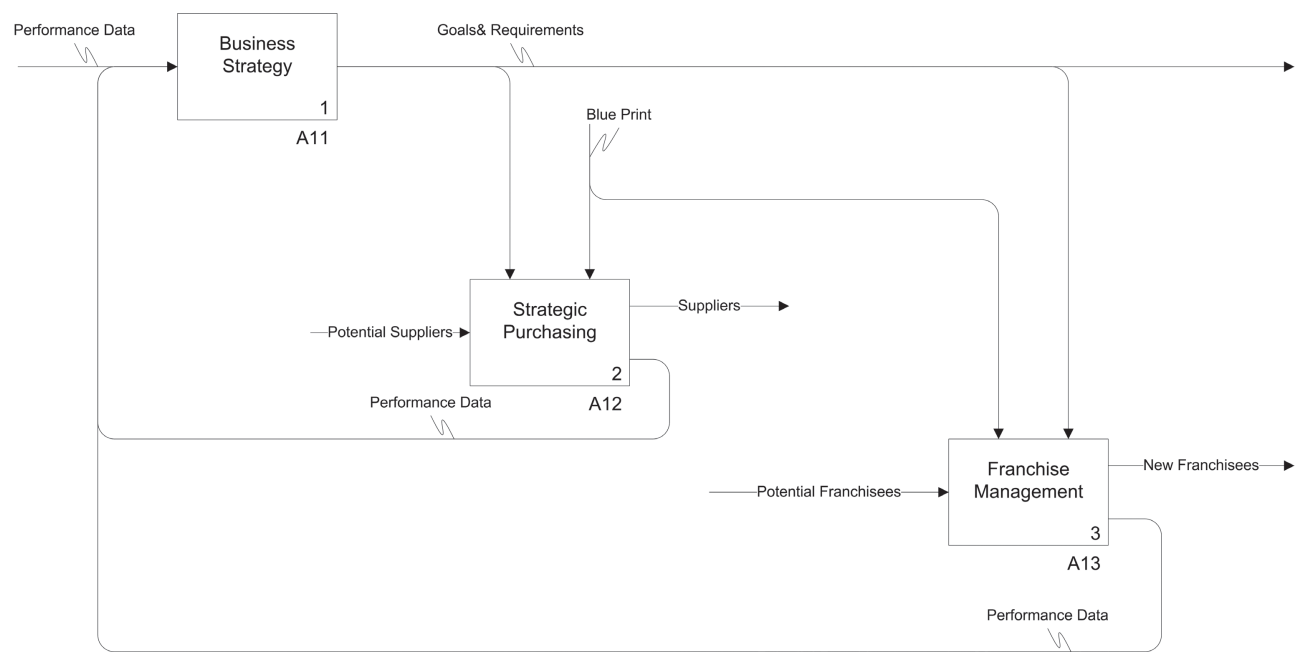

Figure 4.7 Strategic Level

of the other entities of the system is fed back to this entity in order to review whether the goals and requirements set for them are met and/or need to be adjusted.

\section{Strategic Purchasing}

The strategic purchasing entity governs the long-term relationships of CNC Worknet with its suppliers. Its primary function is negotiating with the suppliers about pricing and delivery agreements and their integration in the CNC Worknet system. The results of these negotiations are used by the operational entities of the system. Geographically dispersed suppliers are required in order to be able to support all the franchisees connected to the system. Strategic purchasing seeks and selects new and capable suppliers that meet the requirements of $\mathrm{CNC}$ Worknet for these franchisees.

\section{Franchise Management}

Franchise management actively seeks, evaluates and selects potential new franchisees needed for the expansion of the franchise organisation. Furthermore, the operation of the franchise organisation is also managed by this entity. The functioning of all the franchisees is monitored; when needed, franchisees are assisted in increasing their performance to the appropriate level.

\section{CNC Worknet Tactical}

The tactical aggregation level of CNC Worknet governs goals on the medium term of the company. Four entities are located on this level; marketing, continuous improvement, capacity planning and supplier monitoring. These entities and their connection are shown in figure 4.8.

\section{Marketing}

The marketing tasks of the company and its franchisees are executed and managed by this entity. Its primary role is to determine the customers' needs in relation to the functioning of CNC Worknet and to determine whether these needs are met and how this can be improved. Next to this, activities are employed to attract people to submit orders to CNC Worknet. Based upon these activities and upon operational data sales expectancies are determined 


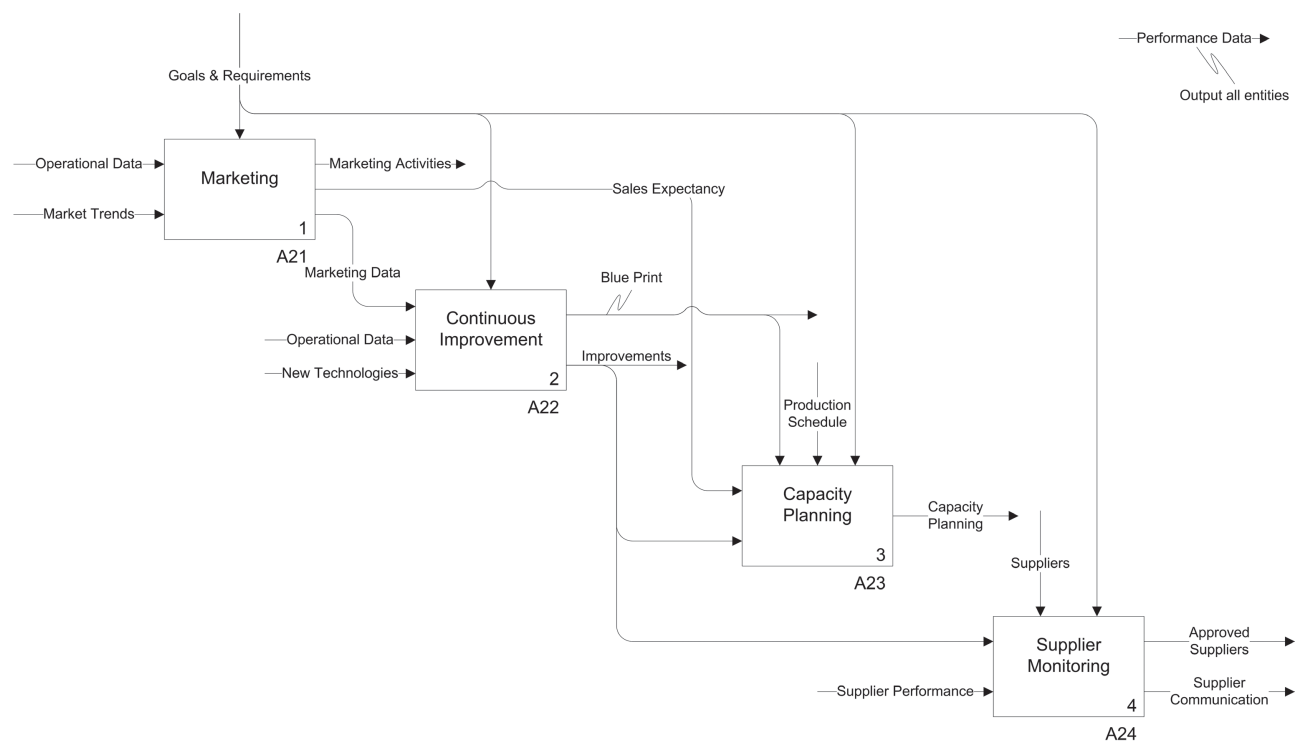

Figure 4.8 Tactical Level

by this entity. This information can subsequently be used by the capacity planning entity. Management of the CNC Worknet brand is another task that is performed by this entity.

\section{Continuous Improvement}

In order to remain competitive in the current market, the continuous improvement of the process of CNC Worknet is important. For this purpose, the continuous improvement entity is introduced on the tactical aggregation level. This entity receives processing data from the different entities of the system. This data is analysed and possible improvements are identified and implemented. Only improvements are suggested that comply with requirements set for the triangle of constraints by the business strategy entity on the strategic aggregation level [see section 2.1.1]. In addition, the performance in the overall system is reviewed in order to guarantee that the improvement actually results in an overall better solution. Examples of possible improvements are updated operating procedures or improved algorithms. Moreover, this entity maintains the blue print of the standardised production location. New technologies and equipment are evaluated and when found suitable they can be implemented in the blue print. An example of this process is the maintenance and updating of the standardised toolset as it is used in the milling implementation of this system. This toolset is monitored; based on operational data and the availability of new tools on the market this standard tool set is adjusted. All changes are incorporated in the blueprint and also (when needed) in the algorithms used for the selection of these tools during process planning.

\section{Capacity Planning}

This entity performs based on the current and expected sales in the longer term capacity planning of the production locations connected to the network. The information is used on the operational aggregation level of the system in order to be able to adequately react on peaks and lulls in the production volumes. 


\section{Supplier Monitoring}

The Supplier Monitoring entity aligns the performance of the suppliers with the requirements of CNC Worknet. Therefore, the performance of the suppliers is continuously monitored. Factors like on-time delivery performance and product quality are all measured and logged. Action is taken when the performance of a supplier drops below the requirements of CNC Worknet. Consequently, the performance of the suppliers is aligned with CNC Worknet and both will function more cohesively.

\section{CNC Worknet Operational}

On the operational aggregation level, the system is divided into three main entities, shown in

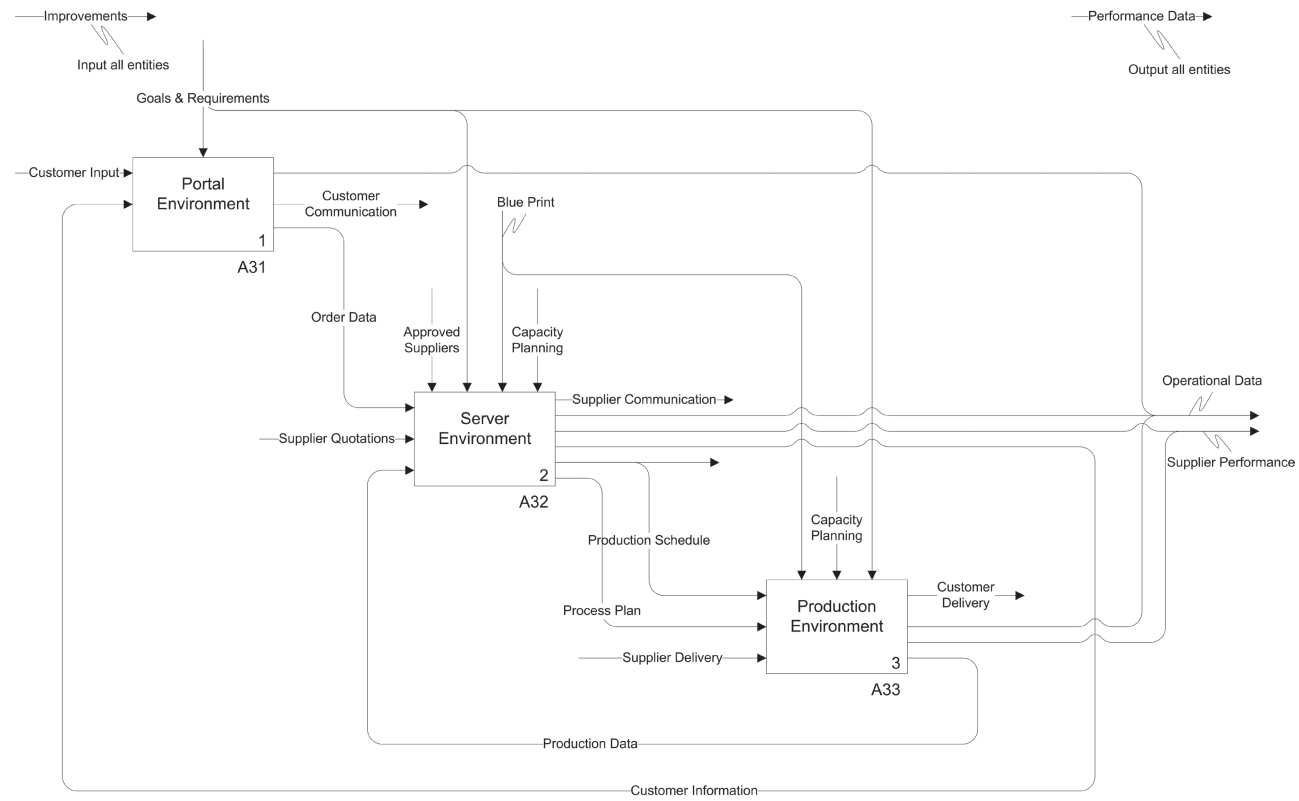

Figure 4.9 Operational Level

Figure 4.9. The first entity is the Portal Environment that governs all communications with the customers. The second entity is the Server Environment that handles all the preproduction steps and the third entity is the Production Environment that is the physical executing entity of the whole system.

\section{Portal Environment}

On the operational level of the system, the portal environment is used as an interface between the entire system and the customer. In a portal environment, the customer can place requests for quotations by submitting the order related data:

- Technical product data

- Order quantities

- Quality requirements

- Shipping information 
The order related data has to comply with a number of requirements set by CNC Worknet as further described in section 4.5.2. The customer can review the quotation generated by the system in this environment and accept or deny it. After acceptance, the customer can review the order status and the order progress on the portal environment. Next to this, the portal is also used to attract customers through the use of marketing activities as suggested by the Marketing entity located on the tactical aggregation level of the system.

\section{Production Environment}

The production environment manufactures the product according to the process plan and production schedule provided by the server environment. The production environment can be viewed as an franchisee of the franchise organisation.

\section{Server Environment}

As can be seen from figure 4.9 the server environment is the mediator between the portal and the production environments. All customer requests are processed within the server environment. Quotations and order status information are communicated to the customer through the portal environment. The activities in the production environment are controlled by the server environment. The required materials and tools are purchased at the suppliers within the server environment. The server environment is sub-divided into four different entities that each have their own tasks and functionalities. A detailed view of these entities of the server environment and the connections between them is shown in figure 4.10.

\section{Sales}

The sales entity is responsible for the sales related functions of the system. Quotations for the customer are generated based on information provided by the process planning, planning \& scheduling and purchasing entities that are also located on this aggregation level. Next to this, the order progress is monitored and communicated through the portal environment to the customer.

\section{Process Planning}

The technical analysis of the products is performed by the process planning entity. Based on the submitted TPD, the product is analysed for its suitability for the CNC Worknet manufacturing processes. Process plans are subsequently generated for the suitable products. As a result of the use of the blue print [see section 4.5.2], this entity generates process plans that can be executed within each connected production environment. Information from the generated process plans serves as input for the other entities of the server environment.

\section{Planning \& Scheduling}

The Planning \& Scheduling entity schedules the production in the production environments and provides purchasing with information on when materials and tools required for the production are requested at the production location.

\section{Purchasing}

The purchasing entity communicates with the suppliers and orders materials and tools based upon the input it gets from the other entities. The focus lies here on the managing the provision of the material and tool needs of the production environments. 


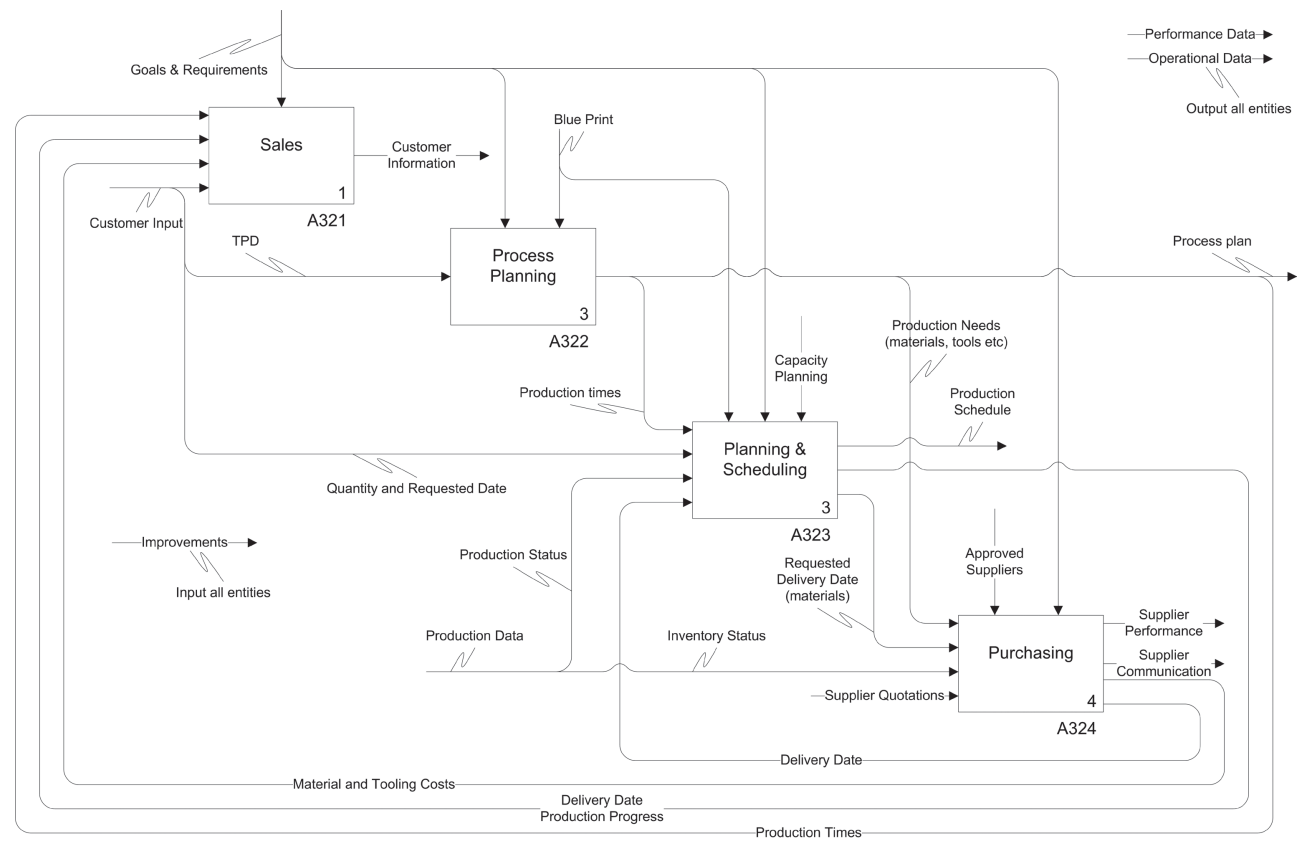

Figure 4.10 Server Environment

\subsubsection{CNC Worknet Requirements}

Based on the functional descriptions and the business model with its envisaged environment and supply chain a set of requirements is determined for the CNC Worknet system. These requirements can be sub-divided into a number of main topics and these will be discussed separately in the following sections.

\section{Environment}

In order for the system to function as it is envisaged in the business model, the system and the environment in which it operates impose a number of (mutual) requirements. These requirements, which regard the environment of CNC Worknet, can be sub-divided into four categories as shown in figure 4.11. These categories are discussed in the following sections.

\section{Customer Requirements}

The customer plays an important role in the business model of CNC Worknet. As CNC Worknet uses a new methodology for acquiring and processing their orders, as described in the business model, the customer should be willing to use it. Customers are already accustomed to ordering off the shelf products through an internet portal, like books on Amazon.com. This is however not so common for built to print orders [see section 2.3.1].

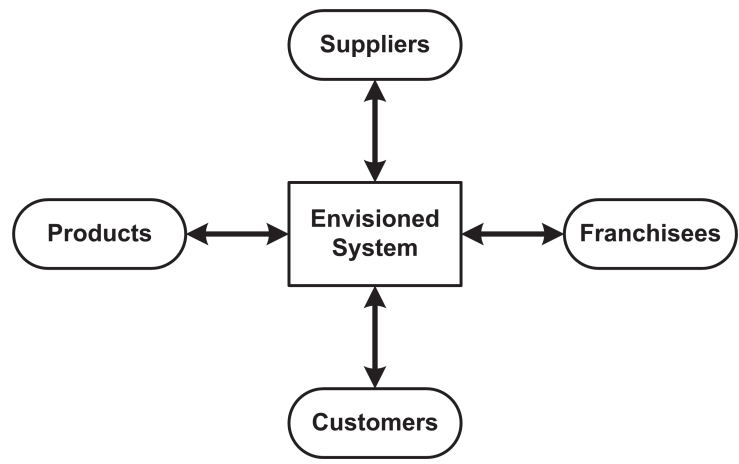

Figure 4.11 CNC Worknet Environment 
In order to get customers to use the system, it should fulfil a number of requirements. First of all the customer should trust CNC Worknet, this implies that business is conducted in a secure Internet environment where the customers' data is protected. Next to this, CNC Worknet should be reliable and predictable. This means that once a customer places his order he is assured that he gets his desired product on time and with the correct quality. Another important requirement revolves around the communication with the customer. As all communication is conducted through the Internet portal and email this communication is to be clear, to the point and direct.

\section{Product and Order Requirements}

One of the most important requirements for the development of the system refers to the type of products and orders that are to be manufactured by it. The requirements related to this topic are discussed below.

\section{Product requirements}

As described in the business model, CNC Worknet focuses on the manufacture of those products that are expected to cause hardly any problems in the supply chain [see section 4.1]. This focus implies that these products need to be fully defined and specified. Next to this, the processes needed for the manufacture of these products should also not verge on its limits in terms of the machine and tool capabilities. In order to guarantee a stable production and manufacturing environment only these products are considered for production. Products on the verge or outside of these limitations can result in unstable situations and disturbances which will lead to a decrease in quality of the system, processes and the products manufactured by it.

\section{Order size requirements}

As CNC Worknet focuses on the standardisation of its production processes, only products ordered in small to medium sized batches are considered. Generally, products ordered in larger quantities cannot be manufactured competitively in a standardised manufacturing environment as these are generally produced with specialised tools and equipment in order to increase the efficiency of the production process. The specialisation that is required to remain competitive when producing large product quantities therefore conflicts with the envisaged standardisation efforts within CNC Worknet.

\section{TPD requirements}

The only communication with the customer regarding the product is conducted over the Internet portal through the submitted technical product data (TPD). Consequently, all communication is therefore digitalised. CNC Worknet envisages that a single $3 \mathrm{D}$ CAD representation is used as the core of all activities throughout the entire supply chain. Therefore, the TPD should be based on a single 3D CAD representation to which all the additional product related data is attached. When required, $2 \mathrm{D}$ drawings of the product can be added to the $3 \mathrm{D}$ CAD representation, but always with the $3 \mathrm{D}$ model as the basis. The customer is therefore required to create and submit the TPD according to these requirements. The format of the submitted TPD should be compatible with the software used by the system. 


\section{Supplier Requirements}

It is envisaged that quotations are generated quickly and accurately; next to this the different production locations are managed centrally by the portal environment. This can only be achieved by closely cooperating with the suppliers. Suppliers should therefore provide the system with a full and detailed listing of their product range and specifications. Additionally, arrangements between CNC Worknet and the suppliers should be made about pricing, delivery time spans and delivery guarantees. All this information must be available instantaneously when generating an accurate quotation or overall production plan of several locations in a short time span. The suppliers should be challenged to provide this information to the system and keep this information up-to-date.

\section{Franchisee Requirements}

Franchisees play an important role in the business model of CNC Worknet, as CNC Worknet does not strive to operate and own many production environments. Without franchisees no global manufacturing network can be established. As described in the business model, all activities to be performed in the production environments are centrally planned in the server environment. In order to allow for this centralisation, the franchisees have to setup their company according to the requirements specified in the blue print and operate it accordingly.

\section{Blue Print}

One of the aspects of the CNC Worknet business model is the centralisation of the preproduction activities in the server environment. The effective coordination of activities is only possible when detailed information is available at the server environment about the capabilities and capacities of the different connected production environments. Uncontrolled diversity of the capabilities and capacities of the different production environments makes this task very difficult. Consequently, this topic has been addressed by many researchers [see section 2.5.1]. CNC Worknet aims to address the diversity problem by means of a blue print. The blue print specifies the requirements and minimum specifications of the machines, tools and processes employed at the production location. The basic assumption is that all production environments connected to the server environment are setup to comply with the specifications of the blue print. Consequently, all production environments can be virtually treated as identical. As a result, process plans generated within the server environment can be executed in every production environment. With this, the choice of where to produce an order is simplified to a logistic decision instead of a combined technical/logistic decision. As it is envisaged that different production techniques are employed within the CNC Worknet business model, the blue print will contain both specific and generic elements. Specific elements are dedicated to a certain production technique and generic elements apply to all production environments. The generic and specific elements are identified by comparing the functional descriptions of the generic system (in IDEF0 style) with the functional description of the system setup for a specific production technique. Commonalities and differences between these versions can be identified and subsequently incorporated into the blue print. The definition and management of the blue print is one of the most important activities of the CNC Worknet as almost every entity of the system has a relation with it. The contents of blue print will over the course of time evolve due to the introduction of for example new and improved machines, tools and working principles. These changes are managed by the continuous improvement entity located on the tactical aggregation level of CNC Worknet. This entity thoroughly verifies and improves the contents of the blue print. During this improvement process the consequences 
of these improvements are evaluated for both current and future production environments. A more detailed look at the specifications and descriptions described in the blue print is given in the following sections.

\section{Machinery}

One of the main features of the blue print is the specifications of the machine tools that are available in the production environments. By means of this specification it is ensured that each production environment has comparable capabilities in terms of machinery. An evolution of this specification as part of the continuous improvement process has major consequences for existing production environments. An improvement of this specification might require the replacement of the machinery in existing production environments. Due to the large amounts capital invested in machinery, these improvements and their consequences need to be evaluated carefully before they are implemented.

\section{Tooling}

The tooling used on and around the machine tools is also specified in the blue print. CNC Worknet strives to use a standardised tool set by which most operations can be performed. Due to the order size, no specialised equipment is considered as this would interfere with the purpose of the blue print.

\section{Working principles}

The blue print also provides the production environments with work instructions and procedures in order to guide and structure the activities that occur within this environment. Because of the fact that these work instructions and procedures are standardised, all activities are bound to be executed in the same manner in every production environment, rendering equivalent results and predictable outcomes.

\section{Personnel qualifications and skills}

The machine tools, tooling and working principles described in the previous sections cannot be operated adequately without qualified and skilled personnel. The blue print therefore specifies the required qualifications and skills of the personnel employed in the production environment.

\section{Automation}

One of the main requirements of CNC Worknet is a short through put time for both the quotation process and the entire order completion process. The business model [see section 4.1] foresees that quotations are presented to the customer within 24 hours; production should commence within days after order acceptance. This requirement implies that a high level of automation is required for all entities that operate in both the server and production environments. Effective and efficient triggering, diagnostics and monitoring is essential for the adequate functioning of an automated system. This is for CNC Worknet however, complicated by the high variety of products, that are manufactured in low volumes with a low repeating frequency. This variance results in challenges for the coordination of the logistic flow through CNC Worknet. To guarantee both the in-time completion of the production orders as well as an efficient use of the resources, an adequate control concept is required [Arentsen et al., 1996]. Requirements for control are predictive behaviour and reactive behaviour of entities in the system to disturbances. Arentsen developed a control functions 


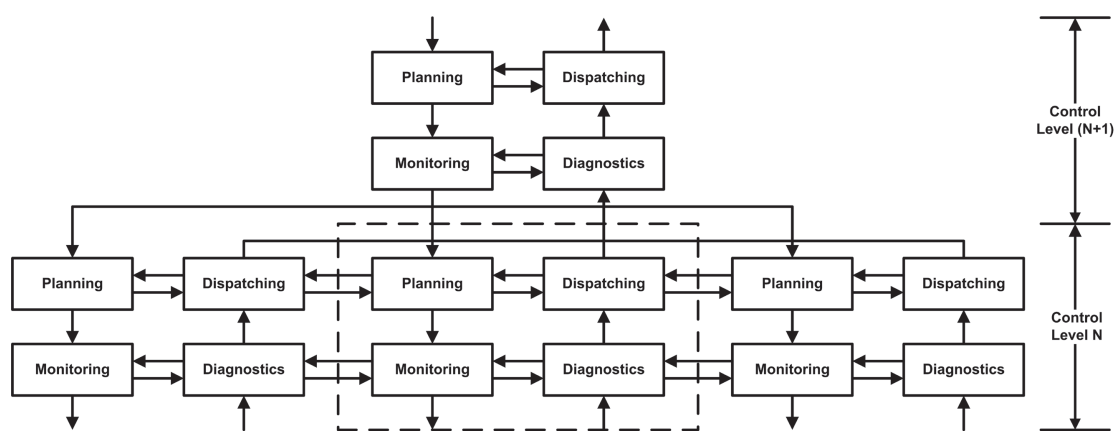

Figure 4.12 Control Functions Block

block that meets these requirements as shown in figure 4.12. The control functions block contains four entities that together control a certain entity. The function block can be applied to entities on all hierarchical levels of a system. By combining these control functions blocks for different entities and on different hierarchical levels, autonomous operation of the control function is enabled on all levels of the system [Arentsen, 1995]. Workflow management [see section 2.2.5] synchronises the execution of all the processes to be performed within a system and therefore plays a pivotal role in developing and operating CNC Worknet. Additionally, the processes have to be suitable for operation in an automated environment. Therefore, these processes need to function predictable and reliable, and the quality of their results and outcomes needs to be guaranteed. If this is not the case, the overall performance of the system might suffer greatly.

\section{Modularity}

The system should embed and allow for a considerable amount of modularity. This modularity is required on different detail levels and for several reasons that are discussed in the following sections.

\section{Franchise Organisation}

One of the most obvious modular entities of CNC Worknet is the production environments. Each production environment can be seen as a modular entity that can be easily attached and detached. Through the use of the franchise organisation and its modular features the production capacity of the overall system can be extended with ease. Also, production environments that do not function according to the requirements set by CNC Worknet can be easily detached from the overall system until these issues have been cleared.

\section{Maintainability and Step-wise Automation}

In order to increase the effectivity and efficiency with which the entire system can be kept up-to-date or can be improved, it is advantageous to be able to adjust or exchange distinct parts of the system. According to the rules of robust design, the implementation of individual modules can be considered to be relatively independent of the implementation of the overall system, thus avoiding redesign needs at system level. As a consequence, maintainability and continuous improvement in them self are already sufficient underpinning to a modular system. This modularity also brings advantages for the development and implementation of the overall system. As discussed in the business model [see section 4.1], the system operates on a high level of automation. A direct turn-key implementation of such a system is difficult 
and not without risk. With a modular setup the system can initially be established in a basic manner. Following the continuous improvement principle, modules can gradually be exchanged for newly developed and implemented modules.

\section{Production Technique}

The primary focus for the development of the system is on a milling and a layered manufacturing implementation. However, it is not unforeseen that in the future additional production techniques are implemented. A modular setup of the system allows for easy re-use of certain general parts of the system. These re-used modules can then be implemented next to newly developed modules that are specific for the added production technique. With this, a system can quickly be assembled out of re-used and new modules that are dedicated to the added production technique.

\section{Quality}

The supply chain envisaged by CNC Worknet cannot function properly without an adequate quality management system [see section 2.2.6]. The requirements for this quality management system are discussed below on the three different detail levels of the system.

\section{Products}

The products manufactured by the system need to comply with the requirements set by the customer. The quality of products is largely determined by the manner in which [Brombacher et al., 2001]:

- the customer requirements are translated into product specifications

- the product specifications are translated into process specifications

- the product and process specifications are realised

- the product realises the customer requirements

In order to achieve this, it is required that quality it to controlled and monitored during the entire manufacturing process and not only at the end-stage as is often the case in the current supply chain [see section 2.1.2]. Quality issues should be detected at the earliest possible stage in order to be able to act quickly on these issues and to prevent the issue from interfering with other production orders. The quality inspection and control activities required to manufacture products conform to their requirements should therefore be integrated in the supply chain.

\section{Processes}

The envisaged high level of automation sets demands for the quality of the processes of the system. In a highly automated system the quality of the individual processes is of great importance. First of all, the individual processes need to be capable of performing the task assigned to them. Next to this, the individual processes have to run efficiently, effectively and reliably, in order for the overall system to function properly. When this is not the case, product quality and the performance of the overall system will suffer greatly or not even function at all. Quality management is therefore an important topic when automating the processes of CNC Worknet and should be closely regarded during its development and operation.

\section{Supply Chain}

The product and process quality requirements discussed above cannot be uncoupled. In order to assure a stable and controlled system, which consistently manufactures products 
in compliance with the requirements set by the customer, an overall quality focus should exist in the whole supply chain. Quality should therefore, be inherent in every step and at every level within the supply chain. As part of the quality management system, a continuous improvement environment should exist in the entire supply chain. Solutions for quality issues are in such an environment implemented constantly in order to prevent their reoccurrence and improve the effectiveness of the whole supply chain. 


\section{Workflow and Quality Integration}

CNC Worknet strives to realise its envisaged business model by focussing on the integration of workflow and quality management. The joint implementation, cooperation and operation of these two entities will form the heart of the development of CNC Worknet.

\subsection{Workflow and Quality Management Importance}

When reviewing the specifications in the previous chapter, one can identify that the strive for a high level of automation is one of the most important requirements for CNC Worknet. Consequently, both quality and workflow management become two important topics for achieving this requirement. Workflow and quality management influence the overall performance and functioning of CNC Worknet. Together these entities play a central role in the processes employed by CNC Worknet, as is visualised in figure 5.1. In this figure workflow and quality management are the central entities around which the other entities of CNC Worknet are situated. Both workflow and quality management have strong relations with each of these entities and bound them together. Workflow and quality management can be considered as the beating heart of $\mathrm{CNC}$ Worknet. It is apparent that workflow and quality management should be both considered and matched during the development of $\mathrm{CNC}$ Worknet. An integrated quality and workflow management approach is therefore vital in order to assure that both these entities are developed and implemented coherently. By choosing an integrated approach the quality requirements of the workflows and the individual processes contained within them will be considered from

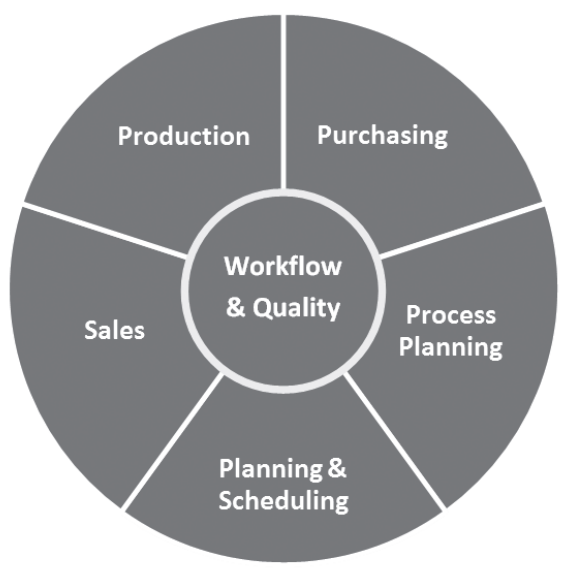

Figure 5.1 Workflow \& Quality Importance the earliest development phase till its actual execution.

\section{Reflection on Triangle of Constraints}

As discussed in section 2.1.1, every supply chain operates under a number of constraints, which are depicted by the triangle of constraints as shown in figure 2.2. Every supply chain strives to achieve the optimal combination of these constraints within this ToC. CNC Worknet also has to find an optimal solution in this triangle. In comparing the statements on quality management and workflow management to the discussion on the ToC, the first observation is that, unlike workflow management, quality management is represented directly in the triangle. The reason for this is that, during its engendering, workflow management is time and resource independent. Conversely, time and resource are a consequence of the specific implementation of a workflow instance. In other words, workflow can be expressed in terms of time and cost. In these terms, quality, time and cost are together covered by quality 
management and workflow management, and -as such- the latter are the apposite driving entities for the development and operation of CNC Worknet.

\subsection{CNC Worknet Workflow Management}

Every process to be performed by CNC Worknet can be captured in one or more workflows. Together, these workflows connect all the tasks to be performed by the different entities of CNC Worknet. Through the employment of workflow management it is guaranteed that all tasks within a workflow are executed in the correct order, at the right time and with the required information and resources needed. All the entities of CNC Worknet are through the use of workflow management integrated into one overall system. CNC Worknet can be interpreted in a sequence of interpretations and connections on different aggregation levels. This is visualised in a chain and presented in figure 5.2. Workflow management can through these interpretations be seen as the integrator

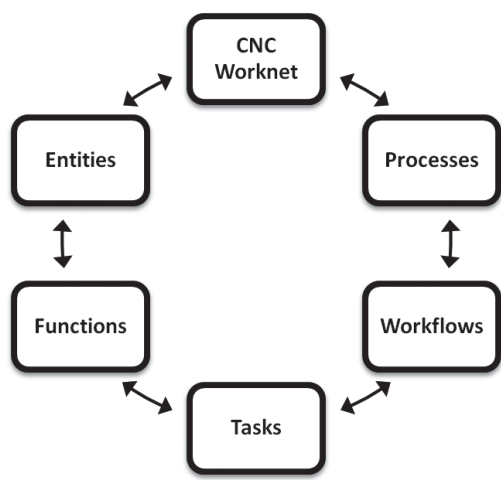

Figure 5.2 CNC Worknet Interpretations of CNC Worknet.

\section{ERP and Workflow Management Consideration}

Both workflow management systems and ERP systems focus on the automation of business processes, data transfer, and information sharing across an organisation. Many of the processes to be employed by CNC Worknet are of a transactional nature, especially those employed by the sales and purchasing entities. This nature makes them suitable to be performed within an ERP system. ERP systems are, as discussed in section 2.2.1 and section 2.2.5, commonly used to facilitate processes with these transactional characteristics. When looking pragmatic to CNC Worknet in relation to ERP systems one can conclude that an ERP system is a database with an interface and rules based on best practices. ERP systems are in their essence created by centralising the databases and building-in data analysis capabilities. CNC Worknet most definitely requires the competencies of an ERP system. However, the required flexibility of the overall system will conflict with these interests, as an ERP system imposes a lot of restrictions and obligations on this overall system of CNC Worknet. Therefore, a solution needs to be created that combines the capabilities of an ERP system in a flexible environment. This can be achieved through workflow management, as this can be employed to fulfil these capabilities and requirements. From an integration point-of-view, workflow management is also more beneficial as it can also be employed for the integration of the overall system, and is therefore considered as a better solution for CNC Worknet.

\subsection{CNC Worknet Quality Management}

As depicted in the requirements of $\mathrm{CNC}$ Worknet, quality and the management thereof plays an important role on all the aggregation levels of CNC Worknet [see section 4.5.2]. The quality of the products manufactured by CNC Worknet is dependent upon all the entities that comprise it. For example the quality of the products produced by layered manufacturing 
is dependent on the choices made during the preproduction stage. Quality characteristics like surface quality, dimensional accuracy and mechanical strength are dependent upon the building orientation of the product during its manufacturing. In order to be able to incorporate these quality characteristics into the product these have to be identified. Process planning can determine an appropriate building orientation for the product based upon the identified characteristics. Subsequently, a product that satisfies the identified quality characteristics is produced in the standardised manufacturing environment. Quality, as can be seen in this example, needs to be considered and coordinated throughout the whole manufacturing chain from the initial enquiry to the actual delivery of the order. All the quality efforts of the different entities within CNC Worknet have to cooperate to achieve this common goal. Though the incorporation of this quality consideration throughout the whole system, it is possible to consistently manufacture products, that are conforming to the needs of both the customer and CNC Worknet.

\section{Quality Management System Implementation}

The quality management system of CNC Worknet will be complaint to the current baseline of QMS's (ISO9001) [see section 2.2.4]. It is foreseen, by CNC Worknet, that their customers will prescribe the implementation of such a QMS. Typically, a QMS is formally designed and implemented when a company is fully operational and already operating for some time. This approach usually results into major process modifications in order to make the QMS effective and compliant to a certain quality management standard. Next to this, certification bodies define a mandatory QMS operation period prior to an certification. It is therefore apparent, that the requirements for the QMS of CNC Worknet should be considered from the early stages of development. This assures an effective and efficient QMS implementation and certification, without the need for major modifications at a later stage.

\section{Quality Management and the Standardised Manufacturing Environment}

The standardised manufacturing environments play an important role in the business model of CNC Worknet [see section 4.1]. These environments need to operate in a consistent and reliable manner, in order for CNC Worknet to achieve its envisaged global manufacturing network. Every standardised manufacturing environment connected to the server environment, therefore, has to operate on a certain baseline. Quality management plays an important role in achieving this goal. The quality management system of $\mathrm{CNC}$ Worknet needs to monitor, adjust and improve the performance of each of the manufacturing environments connected to it. Quality management hereby assures that these environments operate on an equal level and that environments that under perform are timely identified and being acted upon. This approach can be seen as a form of supplier quality monitoring, in which the quality management entity of the portal environment monitors the quality performance of its suppliers, i.e. the standardised manufacturing environments. The portal environment as a whole will hereby function as a supply chain (quality) manager for CNC Worknet. Consequently, it should not matter in which manufacturing environment an order is produced, as these perform all on an equal footing. 


\subsection{CNC Worknet Workflow and Quality Integration}

The integration of workflow and quality management in CNC Worknet will result in a system that consistently considers quality throughout the different manufacturing stages. Quality tasks are in this system identified and incorporated in the workflows in order to make sure that they are properly executed. Through this integration an order will have a quality focus during its progression through the whole system. The quality requirements of the order are identified, incorporated and verified from the moment a request is submitted until the actual delivery.

CNC Worknet can be reviewed and evaluated on different aggregation levels [see section 4.5.1]. On each aggregation level different functions exist which interact and cooperate with other functions. These functions but also their interaction and cooperation with other functions can be evaluated in terms of quality. The combination of these functions and their interactions and cooperations can be viewed as a workflow that spans the functions required to fulfil a request. These workflows can subsequently, also be interpreted in terms of quality. Consequently, quality management can be employed to assemble, evaluate and adjust the workflows required to fulfil a request. Hereby, quality and workflow management are aligned and utilised in such a way that total quality is considered during all manufacturing stages. A thorough quality focus and thinking is hereby introduced on all aggregation levels of CNC Worknet.

Through this integration of quality and workflow management, an environment is created in which quality management assembles the workflows to fulfil a request, and hereby assures that the correct quality related measures are taken. These workflows are assembled by quality management by combining elemental tasks from which the (quality) performance is known. This workflow is subsequently executed by workflow management. Quality management is actively involved in the execution of the workflow, by monitoring the progress and adjusting the workflow where needed to assure all quality requirements are realised.

\section{Activity Based Costing}

The way in which quality management assembles, evaluates and adjust the workflows in terms of quality is in its essence quite similar to activity based costing [see section 2.2.5]. Based on this similarity, it is obvious that $\mathrm{ABC}$ is effective tool to compare the costing aspects of the different assembled workflows. The $\mathrm{ABC}$ characteristics for the different tasks to be performed within a workflow can be determined. The calculation process hereby becomes very insightful. The $\mathrm{ABC}$ characteristics of the different tasks can be continuously improved by comparing the predictions with the results from the calculations. Based on evaluations of these comparisons the $\mathrm{ABC}$ characteristics can be adjusted, resulting in an even more accurate calculation process. 


\section{CNC Worknet Development}

In this chapter the outline of CNC Worknet is developed that is based upon an information management architecture that is adapted along the guidelines of workflow and quality integration. Hereby a system is developed that is used for the implementation of CNC Worknet as shown in Figure 6.1. This chapter elaborates on the used architecture and discusses the setup and development of the basic CNC Worknet system.

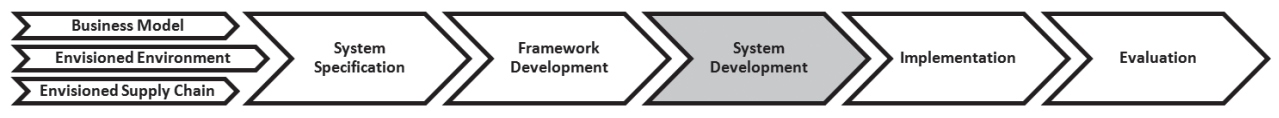

Figure 6.1 Research Approach

\subsection{Architecture development}

The integration of workflow and quality management, as described in the previous chapter, forms the focus point for the implementation of CNC Worknet. However, workflow and quality management cannot be implemented as such. For a structured and effective implementation of CNC Worknet, an architecture is required. This architecture should adhere to the requirements set for CNC Worknet and facilitate the integration of workflow and quality management.

\subsubsection{Reference Models and Architectures}

An architecture is a specification of the functions of a system and the interactions between these functions in terms of input and output, as observed by the user. Architectures [Lutters, 2001] are an indispensable tool in translating the abstract theories, methodologies and operating procedures into a system that is applicable in everyday practice. Architectures are created to support the effective and efficient implementation of a manufacturing system. An architecture can be applied as the basis for the implementation and realisation of the intended functionality of a system. A reference model is required in order to be able to deal with different views on a manufacturing system. A reference model describes a complex system as a configuration of components that each execute their own, globally defined tasks. These components interact to realise the task of the system as a whole. Based on a reference model, an architecture can be developed. Mili describes how reference models are distinguished from reference architectures [Mili et al., 2002]. As reference architectures are the result of mapping a reference model (domain model) into an architecture style, see Figure 6.2. Reference architectures constitute the blueprint for architectural-level enterprise frameworks. Concrete realisations of the architecturallevel components may include the specification of components of the architecture in terms of an interface definition language and some form of documentation that describes the functionalities of the components, and their variants.

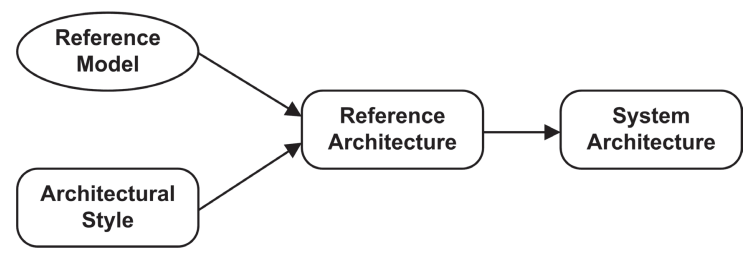

Figure 6.2 From Reference to System Architecture 
The manufacturing engineering reference model [see section 3.1] forms the basis for the development of CNC Worknet. It is able to deal with all the views on a manufacturing system, as it addresses the products and the accompanying processes and resources through the entire manufacturing cycle. It emphasises on the equivalent importance of products, orders and resources and hereby creates a flexible environment that is suitable for the development of CNC Worknet.

\subsubsection{Architecture Based on Information Management}

In order to establish the functionalities as described in the manufacturing engineering reference model it is concluded that different architectures are required. Both an architecture for the engineering processes as an architecture for information management is required to accomplish this. Lutters developed an information management architecture that in itself can constitute the footing for architectures that outline the engineering processes [Lutters, 2001]. An information management architecture forms a kernel onto which other architectures can be founded which represent the different functions to be fulfilled. The main role of the information management architecture is to accommodate all functionality concerned with information processing to the architectures built upon it. The architecture deals with information concerning products as well as resources and orders and no distinction is made between these different information types. Users can interact with the system through interfaces which are constructed in the applications built upon the information management kernel. The details of the information management kernel are described in the following section.

\section{Information Management Kernel}

The main role of the information management architecture is to accommodate all functionalities concerned with information processing related to the architectures that are built upon it. To accomplish this, the kernel is built up out of different function blocks as shown in Figure 6.3. A description of the different constituents of the information management architecture is given in the following paragraphs.

\section{User}

The user is a system that is based upon the information management kernel. Access to information can only be performed through a system that is built upon this kernel. If a human for example wishes to access product information, this has to be done through a

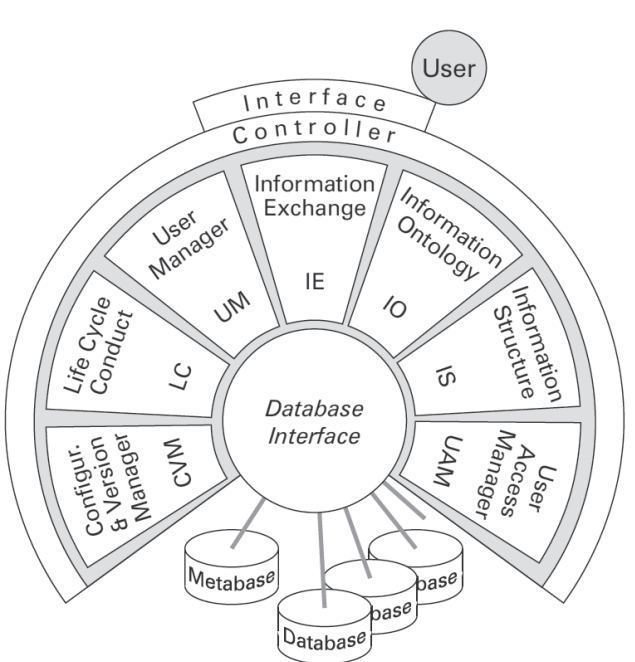

Figure 6.3 Information Management Kernel system on top of the kernel.

\section{Interface}

Users access the information management kernel through an interface. The interface accommodates the exchange of information between the kernel and the system on top of it. 


\section{Controller}

The controller translates exchanged information into actions. These actions can concern actions within the information management kernel but also action of other users.

The interaction between the user, the controller and the interface directs the activities of the kernel and hereby also the execution of processes of the architectures built on it. The complexity of the interaction may vary depending the detail level of the information that is to be provided. The controller can initiate actions due to the exchange of information and/or as the result of exchanged information. These actions can in turn initiate e.g. search, storage or retrieval procedures within the kernel, but also initiate actions for the users to be carried out. Examples of such user actions are specific requests for information, or the notification of a change that influences the actions of other users.

\section{Database Interface and Databases}

The information management kernel in itself does not store information in a central database. The kernel redirects information to and from databases owned by the different users. This redirecting of information is performed by the database interface. It provides low level access to different types of physical databases. The meta-information on an order is provided in the metabase. The function blocks of the kernel rely upon the database interface for the transfer of information. The information management kernel virtually integrates all the databases from the different users connected to it.

\section{Information Exchange}

The main function block in the architecture is Information Exchange. The task of this module is to translate the incoming information request from the users into actions that can be performed by the other modules.

\section{Information Ontology}

In order to be able to process information requests, it is essential to understand the content of these requests. An ontological specification of the information is used for this purpose. The ontological specification is also used for translating a request into actions.

\section{Information Structure}

All information accessible through the information management kernel is structured in order to allow for adequate information flows. These information structures are established and maintained by this function block.

\section{User Access Manager}

This function block validates all user requests to access information as not every user has access and the rights to view and/or alter all types of information. These user rights are managed by the user manager.

\section{User Manager}

This function block acts as an account manager. It specifies user access rights to the structure, database tables and user groups of the kernel. 


\section{Configuration \& Version Manager}

This function block acts performs the version control and configuration management activities of the architecture. Another function of this block is the control of information integrity and transparency.

\section{Life Cycle Conduct}

This function block is concerned with the ontology of the manufacturing process. It specifies the required types of information and their mutual dependencies. Moreover it is used to navigate the manufacturing process based on the information content. The need for information can be determined by comparing the current ontology of a product with the ontology describing the entire product life cycle.

\section{Kernel application}

The application of the information management kernel as the basis for the architectures of other processes is illustrated in Figure 6.4. The interaction between the various processes is enabled by the information management kernel. Due to this arrangement the need to predefine separate architectures of different processes is no longer present. Co-operating modules containing the functionality of processes can as a consequence be formed. Each module performs specific tasks and is deployable whenever needed. Customised systems can as a result of this be composed from the available modules.

\section{Developed Applications}

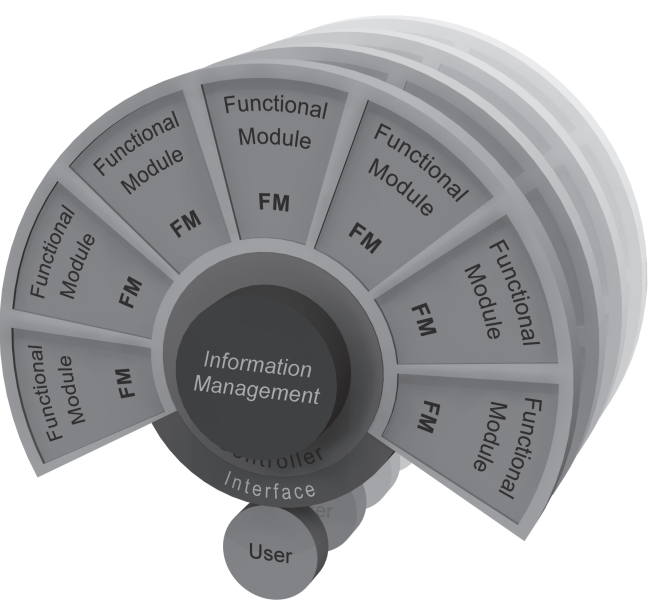

Figure 6.4 Kernel Application

Several researchers have used the information management architecture as the basis for the development of different applications. These applications and their architectures are discussed in the following paragraphs.

\section{Sheet Metal Process Planning}

Lutters developed a sheet metal process planning application based on the information management kernel [Lutters et al., 1999]. The application is developed on an architecture which contains seven functional modules which together provide all the process planning functionalities required for sheet metal, see Figure 6.5.

\section{Cost Control}

An application for the generation of cost estimates, and that is capable of determining the cost consequences of decisions made in design and engineering applications has been developed by Ten Brinke [Brinke, 2002]. The application is based on a cost estimation architecture, see Figure 6.5. The cost estimation architecture contains six functional modules, which are arranged around the Information Management kernel. The six modules together contain and fulfil all the functional specifications of the developed cost estimation system. The cost 

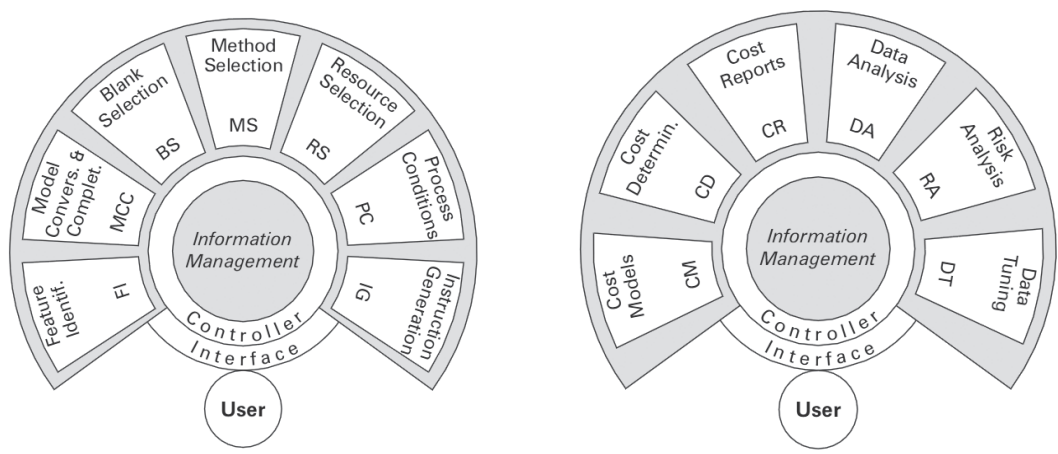

Figure 6.5 Sheet Metal (L) and Cost Control (R) Applications

estimation architecture can be integrated in any manufacturing process that is based on the information management kernel.

\section{Order Planning}

Giebels developed the EtoPlan system which is based on the information management philosophy of Lutters [Giebels, 2000]. EtoPlan is a decision support system for integrating order planning. It covers the higher aggregation levels onto which both macro process planning and capacity planning are executed.

\section{Reasoning}

The information management architecture developed by Lutters is selected to form the basis for the CNC Worknet system. The reasoning for doing so are discussed in the following sections.

\section{Facilitate integration of workflow and quality management}

The integration of workflow and quality management is the main focus for the development of CNC Worknet [see section 5.4]. Both workflow and quality management rely on information management for their effective and efficient functioning. Quality management requires many different information types from many sources in order to be able to monitor and improve the quality of the system, processes and products of CNC Worknet. Workflow management as a whole relies on information management for the provision of information on the status of the different workflow instantiations. Also the individual workflow tasks themselves rely on information management, as they require information input and generate information that needs to be stored and made available to other tasks and functions. Without the fulfilment of these two information requirements, workflow management cannot function properly. The information management architecture supports both of these requirements and hereby facilitates the integration of workflow and quality management.

\section{Generic}

$\mathrm{CNC}$ Worknet is envisaged to eventually be comprised out of a wide range of manufacturing techniques. The generic nature of the information management architecture and the possibility to reuse modules from previous implementations is therefore of benefit to CNC Worknet. A system based on the information management architecture is generic enough to be able 
to cope with the introduction of additional manufacturing techniques. The adding of these additional manufacturing techniques should therefore not pose any problems in the future.

\section{Modularity}

The information management architecture is modular which makes it very suitable for $\mathrm{CNC}$ Worknet. Modularity is required on a number of aggregation levels of the CNC Worknet system. First of all the incorporation of the different standardised production locations should be handled in a modular way to facility the connecting and disconnecting of these locations to the overall network of CNC Worknet. Secondly, updating and replacing software packages within the CNC Worknet system should not impact the functioning of surrounding processes to a large extent. A modular approach to implementing these packages prevents these negative effects. Both these two forms of modularity are supported by the information management architecture.

\section{Platform independence}

The information management architecture facilitates platform independence. Hereby the architecture will support all the platforms in use by CNC Worknet. The platform independence of the architecture allows applications to interact with other applications that are embedded in the architecture. Also replacing applications with updated or new versions like discussed in the previous modularity section is facilitated by this. All in all, this results in an environment with a high level of interoperability where applications exchange information quickly and seamlessly.

\section{Proven Functionality}

For CNC Worknet it is important that its foundation is sound and functional. The focus of the development should be on setting up a working system and not on developing or experimenting with a new architecture. Examples of implementations of the information management architecture are already present as described earlier. These implementations can be used as a reference and provide an example of the computational infrastructure of the architecture. Components which are already worked out for these applications can, when found suitable, be reused for CNC Worknet.

\subsection{Architecture Application}

As described in the previous section, the information management architecture is selected to form the basis onto which the different applications of CNC Worknet are developed. The architecture has to be setup to the requirements of CNC Worknet before the actual implementation process can commence. CNC Worknet is therefore first decomposed into its elemental functions. The interfaces of each elemental function with the other functions are determined in the next step. Based on this information, the individual functional modules are created. These functional modules are then grouped into different application discs, which together will form the CNC Worknet system. This whole process is visualised in Figure 6.6 and described in the following sections. 


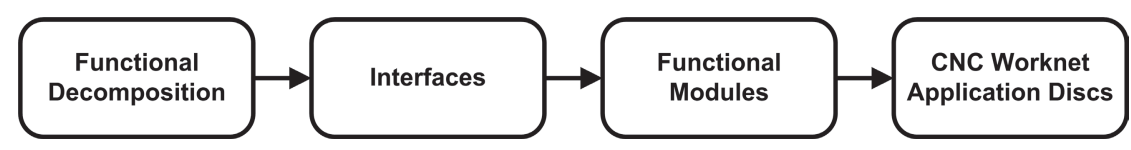

Figure 6.6 Architecture Application

\subsubsection{Functional Modules}

The information management architecture is built up out of different functional modules which are grouped on application discs. A functional module contains the functionality of a process which can be used to perform specific tasks. In order to generate these modules all the tasks to be performed by CNC Worknet have to be identified first. This is performed by decomposing CNC Worknet into its elemental functional elements.

\section{Functional Decomposition}

By approaching CNC Worknet from different directions all the tasks to be performed by CNC Worknet are identified. As CNC Worknet is setup from scratch, it is impossible to identify every single function to be performed before hand. Due to the information management architecture this is however not a problem, as functional modules can be added to the system at a later stadium. The directions used for identifying the different tasks and functions are discussed in the following paragraphs.

\section{Functional descriptions}

The functional description [see section 4.5.1] is used as the starting point for the functional decomposition of CNC Worknet. The functional description gives a break up of the CNC Worknet system into larger chunks on the different aggregation levels. The elemental functions to be performed by these larger chunks are then extracted. Hereby a good initial overview of the elemental functions of CNC Worknet is created. To assure that most functions are identified, two different methods are also applied to identify the elemental functions of CNC Worknet

\section{Quality management system functions}

The quality management system forms an integral part of CNC Worknet. Therefore, the functions to be performed as part of the QMS need to be identified. As the QMS is to be compliant to ISO 9001 [see section 5.3], the functions to be performed by the QMS can be extracted from this standard. Hereby, it is assured that all the functional requirements of the QMS are incorporated in the CNC Worknet system, assuring an effective and efficient QMS implementation and certification.

\section{Workflow Scenarios}

Workflow scenarios are also employed to identify the elemental functions of CNC Worknet These scenarios describe the activities to be performed when a certain requirement has to be fulfilled by CNC Worknet. Examples from these scenarios are; customers submitting a request for quotation for a certain product, or the tasks to be performed when conducting maintenance to the machinery of CNC Worknet. Within these workflow scenarios, the elemental functions of CNC Worknet can be identified. 


\section{Interfaces}

The interfaces of each identified function are subsequently determined. These interfaces describe the in- and outputs of a function, that are required for its proper execution. These interfaces contain both physical entities (for example resources) as informational entities (for example TPD).

\section{Functional Module}

Based upon the functional decomposition and the interfaces, the functional modules of CNC Worknet are constructed. The identified elemental function form the basis for the different functional modules, and their function is subsequently described in detail. The interface information is used to determine the information management requirements of the module and the possible physical relations of the module with other modules. The result of this step are the functional modules or fundamental building blocks out of which CNC Worknet is constructed.

\subsubsection{Application Discs}

Application discs are created by grouping the different functional modules. Grouping is performed based on a common factor that the functional modules share. These common factors focus, for CNC Worknet, mainly on the stage of the manufacturing process in which the functional modules operates or with which other functional modules they communicate in general. The functional modules that focus on the purchasing operations of the system and the communication with the suppliers are for example all grouped on a Purchasing application disc. Eight different application discs are created for CNC Worknet as a result of this grouping. A more detailed description of the contents of the application discs is given in the appendix 2.

\section{Sales}

The Sales application disc contains all the functional modules that are associated with the sales processes of CNC Worknet. Functional modules used for quote generation, order processing and customer relations management are all located on this disc. The main task of the Quote Management functional module is to transform the Request for a Quote (RFQ) from a customer into a quotation. Different calculation methods can be used to generate quotations and these methods are all managed and executed within this functional module. The information required for performing these calculations is collected and requested from the functional modules located on the Process Planning, Purchasing and the Logistics application discs through the Information Management kernel. Quotations generated by the quote generation module and accepted by the customer are assessed and processed by the Order Management functional module. Upon registering an order, other processes within the architecture are triggered in order to start the fulfilment of the order. Customer relations are managed by this Customer Relations Management (CRM) functional module. The CRM module manages the customer data so that these are kept up-to-date. The communication between a customer and the company which is performed outside of the Internet portal is also tracked and registered by this module.

\section{Purchasing}

The Purchasing application disc is responsible for the supplier communication and the purchasing operations of CNC Worknet. It contains the functional modules for supplier 
relations management and for both strategic and operational purchasing. The main task of the Strategic Purchasing module is to negotiate pricing and delivery agreements with existing and new suppliers of CNC Worknet. The Operational Purchasing functional module handles the purchasing requirements which are needed to fulfil an order submitted to the system. The requirements for purchases are determined based on the information generated by the Process Planning and Logistics discs and provided through the Information Management kernel. Supplier relations are managed by the Supplier Relations Management functional module. This module manages and aligns the interactions between CNC Worknet and its suppliers. The performance of the suppliers is also monitored and acted upon by this module.

\section{Process Planning}

The technical analysis of the products submitted to CNC Worknet is performed by the Process Planning application disc. The main task of this application is the generation of the process plan that is required for the manufacture of the product. Functional modules for model conversion, feature recognition, setup generation, method selection, resource selection and instruction generation are located on this disc. Together, these modules analyse the submitted products on their manufacturability and suitability for the processes of CNC Worknet. Process plans required for the fabrication of these products are generated based on the methods and resources available in the standardised manufacturing plants connected to the network. Every manufacturing technology employed by the system has its own dedicated process planning application disc with its own set of functional modules. The appropriate production technique will be selected by the workflow based upon a quick review of the characteristics of the product. When multiple appropriate production techniques are found a process plan will be generated for each of these techniques. The definitive selection is then made by the quotation module based on a comparison of the costs, quality and production times of the different suitable production techniques.

\section{Logistics}

The functional modules for the planning and scheduling of the production orders are located on the Logistics disc. Next to this, a workflow management functional module is also present on this application disc. The Capacity Planning module handles the capacity planning of the different standardised production plants that are connected to CNC Worknet. The Capacity Planning module uses methods for distributed production planning to distribute the workload over the connected standardised production environments. To fulfil this task the module requires accurate and constantly updated information on the production progress, capacity and performance of each standardised manufacturing plant. Upon request by Quote Management this module also provides the estimated delivery time spans for quotations. The detailed scheduling of production orders on the machines (or cells) located in the standardised production plants is taken care of by the Scheduling functional module. This planning is a detailing of the capacity planning into the operational level of CNC Worknet, i.e. the standardised production plants. The receiving of supplier deliveries and the delivery of products (incl. transportation) to customers or suppliers is also planned by this functional module.

The tasks and functions of the Workflow Management functional module are described in section 6.3.2. 


\section{Quality Management}

The quality management entities of CNC Worknet are grouped on the Quality Management application disc. Together, the functional modules contained on the disc manage the QMS and monitor the quality performance and efficiency of the processes and products manufactured by CNC Worknet. A more detailed description of the functioning of the quality management disc will be given in section 6.3.1.

\section{Manufacturing}

The physical executing functionalities of $\mathrm{CNC}$ Worknet are located on the Manufacturing disc. There are multiple Manufacturing application discs connected to the Information Management kernel. Each application disc represents a standardised manufacturing environment that is connected to the network. The disc receives its work orders and production schedule through the central information management kernel. The functional modules for tooling, inspection, internal logistics, dispatching and production are all located on this application disc. The Inspection functional module acts as a quality inspector and performs inspections according to the inspection plans generated by the Quality Management application disc. The Production module represents the actual production activities inside the standardised production plant. The production is performed according the instructions and schedule generated by the other applications of the architecture. The receiving, dispatching and movement of goods and products in the manufacturing facilities is handled by the Receiving, Dispatching and Internal Logistics functional module. The Tooling module is responsible for the management of the tools inside the standardised production plant. The preparation and disassembling of production setups is also performed by this functional module. The Maintenance module acts as a manager for the different maintenance oriented tasks in the standardised production plant. Examples of these tasks are the daily, weekly and monthly maintenance checks. Large maintenance operations are planned in conjunction with the Order Scheduling and Quality Control Processes modules.

\section{Business Administration}

The functional modules that focus on the administrative and financial tasks of CNC Worknet are located on the Business Administration application disc. The management of the financial traffic of CNC Worknet is performed by the Accounting functional module. The Financial Control functional module monitors and registers the financial state of the company. It is used by top management to get an insight into the liquidity and financial balance of CNC Worknet. Human resources oriented tasks are performed by the Human Resource Management functional module, which is also located on the Business Administration application disc.

\section{Franchise and Marketing}

The Franchise and Marketing application disc contains the modules that fulfil the franchise and marketing requirements of CNC Worknet. The Franchising module analyses the overall performance of the standardised manufacturing environments connected to the network and scouts for, and analyses opportunities for expanding the franchise organisation through opening new, or increasing the capacity of existing, standardised manufacturing environments. The marketing and branding modules are used to attract potential customers and present a single, consistent face to the customer. 


\section{Internet Portal}

The internet portal as discussed in section 4.1 has a prominent place in the envisaged $\mathrm{CNC}$ Worknet system. The internet portal functions as an interface of CNC Worknet with its users and is therefore not directly represented by a separate functional module in the architecture. Coherently with the functioning of the information management architecture the internet portal is contained in the interfaces of the different application discs.

\subsection{Workflow and Quality Management Role}

The integration of workflow and quality management plays an important role in CNC Worknet. Within the architecture of CNC Worknet the functions of the quality management have all been bundled into a quality management application disc. The workflow management functions have been bundled in a functional module which is located on the logistics application disc. Both these two entities are described in more detail in the following sections as well as their relations and collaborative functioning.

\subsubsection{Quality Management Disc}

The Quality Management application disc handles all the functions pertaining to quality within CNC Worknet and can therefore be interpreted as the quality management system of CNC Worknet. The quality control functions of CNC Worknet are grouped into four functional modules which operate on the aggregation levels of CNC Worknet. These aggregation levels are; product, process, workflow, and standardised manufacturing environment as shown in figure 6.7. Next to the quality control modules a functional module is created that governs the overall quality strategy and objectives of CNC Worknet. A complete quality management system is hereby created on the Quality Management application disc. A figure of the resulting Quality

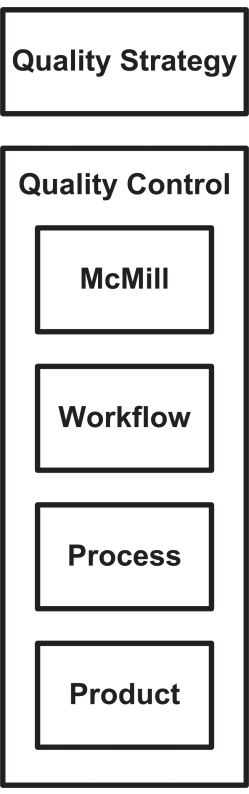
Management application disc which is used in the architecture is presented in figure 6.8. The different functional modules of the Quality Management disc are discussed in the following paragraphs.

\section{Quality Control Product (QCPd)}

The Quality Control Product functional module operates on the product aggregation level and focuses on the quality of the products that are manufactured by $\mathrm{CNC}$ Worknet. The quality requirements of the products, submitted through the Internet portal, are determined and evaluated for suitability for the CNC Worknet processes. The requirements of the products are

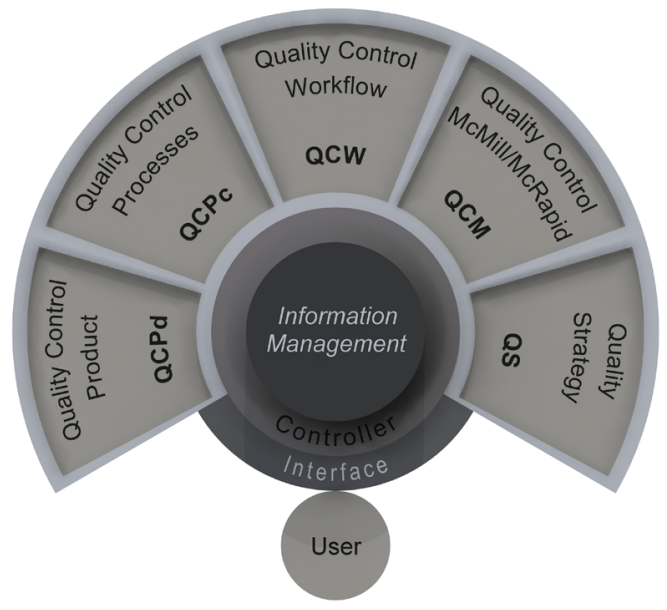

Figure 6.8 Quality Management Disc 
determined and translated into inspection plans and instructions to be used during the different production stages. The generated inspection plans and instructions are stored in the Information Management kernel and executed by the Inspection module located on the Manufacturing application disc. The inspection results are submitted by the Inspection module to the Information management kernel and subsequently analysed by the Quality Control Product module. Based upon this analysis, the products are either released for delivery or submitted to non-conforming product control, which is also a function performed by this functional module. Next to these more physical product control aspects, this module is also responsible for verifying the quality of the process plans generated by the portal environment before they are released to the manufacturing environment.

\section{Quality Control Processes (QCP)}

The Quality Control Processes functional module operates on the process aggregation level of CNC Worknet. This functional module monitors and controls the processes within the various functional modules of the architecture. The major activity of this module is the creation and maintenance of the operating procedures and job descriptions that are required to execute the different tasks within CNC Worknet. These procedures and descriptions prescribe the inputs, requirements for the task or task sequence and how these need to be processed into an output. This module hereby generates sets of operating procedures and job descriptions which correspond with the different modules contained in the architecture. Through the use of these procedures and descriptions the different processes of CNC Worknet are executed all equally. Both generic and dedicated operating procedures and job descriptions are created; generic versions for the repetitive and administrative tasks and dedicated versions to meet the specific requirements. Next to this the module monitors the quality of the inputs and outputs of the various functional modules. The module hereby verifies whether the processes run both correctly and efficiently, and to assure that the quality requirements of both the customer and CNC Worknet are met. This module also validates processes before they are implemented into CNC Worknet, in order to make sure they will function correctly and can be incorporated correctly. The control of the processes through, for example, SPC (Statistical Process Control) for the production processes is also a typical function performed by this functional module.

\section{Quality Control Workflow (QCW)}

The main assignment of this functional module is to determine the workflow which is required for the product to meet the quality and product requirements that are identified by the QCPd module. The process plans generated by the Process Planning application disc are also utilised for generating these workflows. Next to generating the workflows, the QCW functional module also monitors the execution of the workflows by the Workflow Management functional module located on the Logistics disc. Hereby, this functional module assures that all the processes required for meeting the customer requirements are identified and executed in a correct and efficient manner.

\section{Quality Control ME (QCM)}

The monitoring of the quality performance of the standardised manufacturing environments (ME) that are part of the franchise is performed by the Quality Control ME functional module. The overall quality performance of these environments is monitored through the use of key performance indicators. Next to this, audits are performed by entities from this 
module to assure and confirm that both operations and processes are performed according to the regulations of both the QMS and CNC Worknet.

\section{Quality Strategy (QS)}

Quality strategy is the top level functional module of the QMS and the Quality Management disc. Its main task is to manage the operation of the QMS of CNC Worknet. Functions contained within this module determine and set the quality policy and translate this policy into quality objectives for the various entities. Quality performance is analysed at intervals set by this functional module in order to determine whether the objectives are met and whether they need to be adjusted. Through the initiation of corrective and preventive action initiatives, continuous improvement of the QMS and CNC Worknet as a whole is achieved.

\subsubsection{Workflow Management Functional Module}

A Workflow Management functional module is located on the Logistics application disc. The main task of this module is the execution of the workflows which are generated by the QCW module. It therefore triggers and monitors the execution of the different tasks of the functional modules required to fulfil a request. The module executes both static and dynamic workflows. Static workflows are used for procedures and task sequences which are equal for all requests. Dynamic workflows are workflows whose path is determined by the outcome of the already executed tasks. The decisions on which path to follow during the execution of dynamic workflows are taken in close conjunction with the QCW module. A more thorough explanation on how the workflow and quality management modules cooperate in $\mathrm{CNC}$ Worknet is given in the following section.

\subsection{Functioning}

As discussed earlier, operating procedures and job descriptions for the different tasks to be performed by the functional modules are generated by the QCP module. These procedures and descriptions can be formed into workflows by connecting their in- and outputs together. For its execution, each task requires certain elements (informational or physical demands) that need to be provided and each task also generates outputs. These outputs can subsequently be used as input for other tasks, whereby a chain or workflow is created. Next to this, the process plan generated by Process Planning also contains a workflow consisting out of different procedures and descriptions that is dedicated to the production of a certain product. By constructing the workflows based on the actual outputs of the tasks an adaptive workflow is created. This workflow actively seeks its own way through the CNC Worknet system. When reflecting this situation on the architecture, one can understand that each functional module is represented within CNC Worknet by its own set of operating procedures and job descriptions.

Two major workflows can be identified when reviewing the business model of CNC Worknet. One major workflow is comprised of the processes which are executed in the server environment and can be called the preproduction workflow. A second major workflow can be identified inside the standardised production environment. This workflow is can be viewed as the physical production workflow whereby the customer order is completed. 
The process plan generated in the server environment forms the basis for the workflow in the production environment. This process plan can therefore be seen as the linking pin between these two workflows. The initial version of the process plan is generic and suitable for all standardised production environments connected to CNC Worknet. Through the addition of more detailed information from purchasing, planning \& scheduling and process planning the process plan is further detailed until it can be executed in a specific production entity. Based on this information it is apparent that care

\subsubsection{Example}

The functioning of the system is best explained through the example which is shown in figure 6.9. The figure shows an overview of the layered manufacturing process. The figure is broken up in four mayor lanes. The first three lanes represent the different environments of CNC Worknet; i.e. the portal, server and production environments [see section 4.5.1]. Within these three lanes the main functional modules or whole application discs of the architecture are displayed, that are required to process a customer order. These modules and discs are

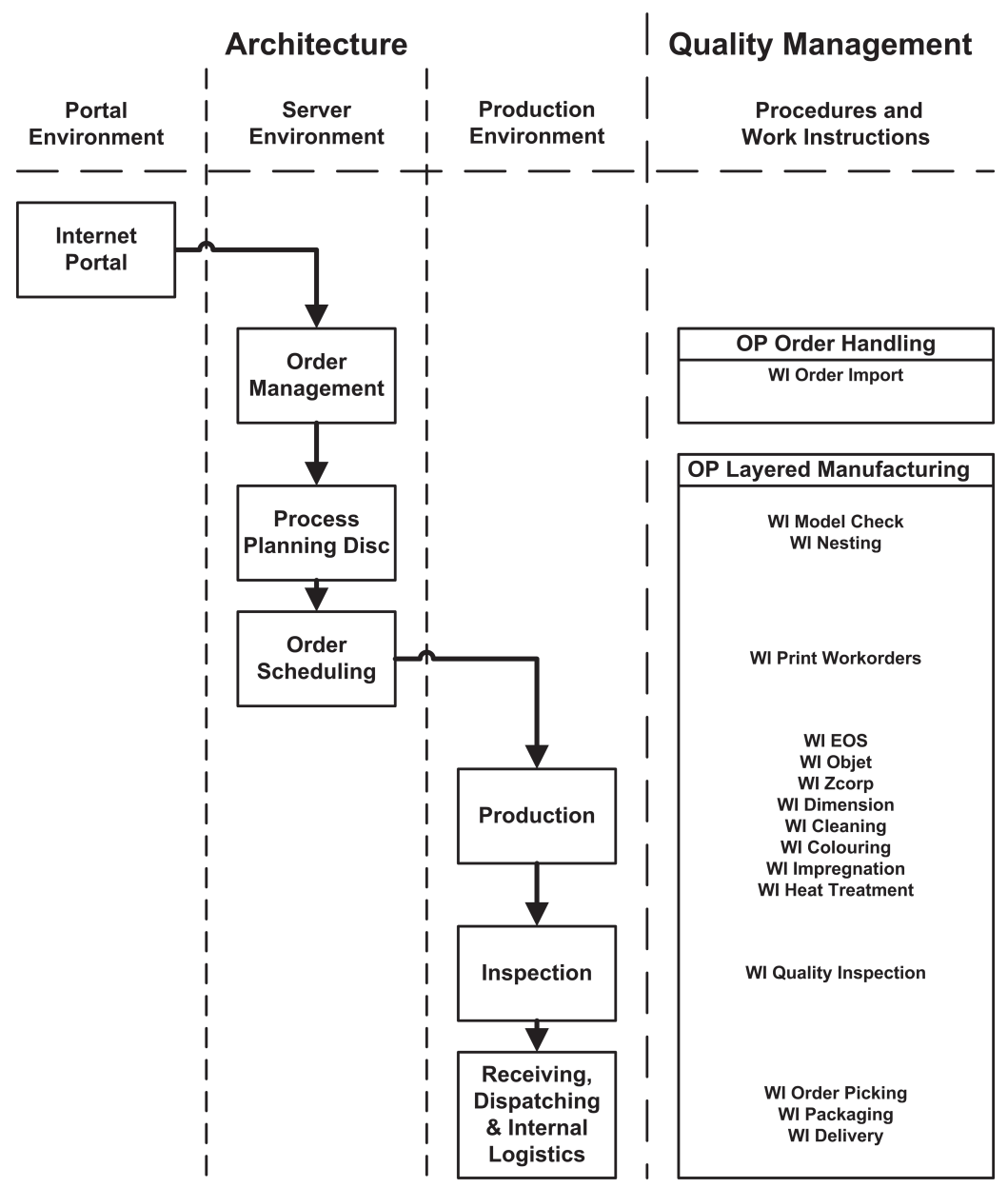

Figure 6.9 Overview Layered Manufacturing Process 
displayed in a sequential manner from top to bottom based on when they are executed, hereby the main constituents of the workflow become visible. On the right side the operating procedures and work instructions which correspond with the activities of the modules of the first three lanes are shown. Workflow management triggers upon the submission of an order by a customer the Order Management module. This functional module subsequently retrieves and verifies the contents of the order. All order data is stored in the information management kernel of the architecture. The functional modules of the Process Planning application disc are then triggered to verify the manufacturability of the submitted products and to create a production plan. Process planning subsequently nests a batch of products that require the same layered manufacturing technique into a production tray. This tray is subsequently scheduled for production. Based upon the production plan the procedures and work instructions are triggered that are required for producing the order. Before the products are handed over to dispatching a final inspection is conducted. The orders are then picked, packaged and send to the customer. Due to the low product diversity this whole system is built up out of predefined procedures and work instructions. Dedicated instructions can be generated for specific products when the need arises. The adaptive behaviour of the workflow becomes visible during the finishing operations that need to be performed on a product. Based on the identified product requirements, work instructions are triggered for finishing the product according to the needs of the customer. These specific products are segregated from the general workflow, whereby it is assured that they receive their specific treatments. 


\section{Implementation}

The implementation of the developed system as depicted in the previous chapter is described in this chapter. To demonstrate the functionalities of CNC Worknet, a production environment connected to a portal environment is setup. The production environment functions as a prototype of the standardised manufacturing environments as envisaged in the CNC Worknet concept [see section 4.1]. Two implementations of the system are realised for two different manufacturing techniques, i.e. milling and layered manufacturing. The functioning, similarities and differences of both implementations are discussed in the following sections.

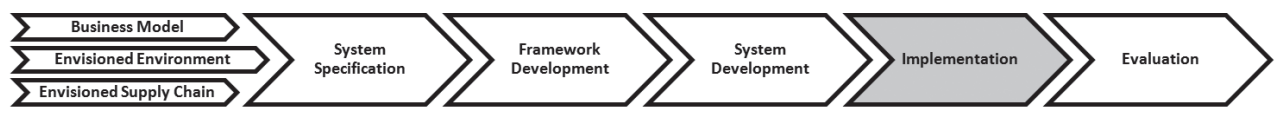

Figure 7.1 Research Approach

\subsection{CNC Worknet - Milling}

The first implementation is realised at the CNC Worknet company in Ede (The Netherlands). This implementation focuses on the manufacturing of milled products in a standardised manufacturing environment. Because of the prototype character of the environment, a number of concessions to the pure CNC Worknet principle had to be made. Next to producing the type of products as envisaged in the CNC Worknet business model, the environment also engenders products for the aerospace industry. The two product types and their consequences on the development and implementation of the CNC Worknet system are discussed below.

\section{Envisaged Products}

As discussed in section 4.5.2, CNC Worknet's main target group contains common builtto-order products for the manufacturing industry. These products are assumed to hardly cause problems in the supply chain and can be produced in the standardised manufacturing environments of CNC Worknet.

\section{Aerospace Products}

Next to the manufacture of common products the system is also setup to be able to manufacture products that are built-to-order for the aerospace industry. These aerospace products are introduced due to a request from a local aerospace manufacturer and the economic value they present for the company. The characteristics of these products are equal to the envisaged products. However, the inclusion of these aerospace products has several consequences for quality management system of the milling implementation.

\section{EN9100}

In order to be allowed to produce aerospace products the quality management system has to comply with the EN9100 quality management standard. EN9100 is based on the ISO9001 standard. EN9100 sets additional requirements to the ISO9001 standard that are specific for the aerospace industry. 
First of all, EN9100 specifies First Article Inspections (FAI). A FAI is a complete, independent, and documented physical and functional inspection process. Its goal is to verify that prescribed production methods have produced an item that is acceptable in terms of the specification by engineering drawings, planning, purchase order, engineering specifications, and/or other applicable design documents. Conducting a FAI is a labour-intensive activity that requires an extensive amount of time and money. The manufacturing process for aerospace products differs, due to the FAI requirement, from that for the common products. The general process flow for the manufacture of products for the aerospace industry by CNC Worknet is shown in figure 7.2.

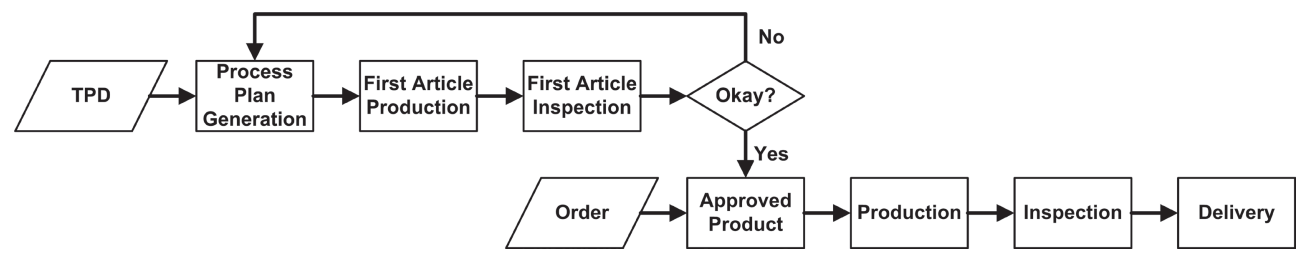

Figure 7.2 Process Flow for Aerospace Products

Based on the provided TPD, a process plan is generated for the manufacture of the product. A first article is produced according to this process plan and subsequently inspected, whereby every characteristic of the product is inspected and verified for conformance. The first article is rejected when non-conformances are identified. The process plan is adjusted when needed and a new first article is produced and inspected. The process plan is approved for production when the first article is accepted without non-conformances. Orders for the product can now be manufactured according to the approved process plan and subsequently delivered to the customer. When the contractor wants to reorder the product on a later moment, the product has to be made according to exactly the same process plan. Alterations of the approved process plan can only be accepted after conducting a new FAI. Because of this, companies are very hesitant to alter the process plan to incorporate the capabilities of new machines, tools and/ or cutting strategies. The product will be made by the same process plan over and over again. This process actually directly conflicts with the business model of CNC Worknet in which the optimal process plan at the moment of ordering is used. This optimal process plan takes the current and available machines, tools and cutting strategies into account.

EN9100 also imposes additional requirements on configuration management. The configuration of aerospace products needs to be accounted for at each production stage. A change in the configuration of the process plan has to be communicated to all the parties involved.

Throughout the complete life cycle of the product, the identification and traceability of the product has to be maintained. This means that during production all (semi-) finished products need to be identifiable and that records have to be kept that describe the origins of the raw materials, the process plans, machines and tools used to manufacture the product.

The non-conformance control entities of EN9100 are much stricter than formulated in ISO9001. Moreover, the level of supplier control is much higher in the EN9100 standard. The performance of all critical suppliers is required to be monitored. Only products from suppliers with a satisfactory performance may be utilised. Supplier Corrective Action Requests (SCAR) 
can be issued to suppliers in order to correct detected shortcomings and to increase the performance of the supplier(s).

\section{Common and Aerospace Products Mixed}

As discussed above, significant differences exist between the manufacturing processes for envisaged and for aerospace products. Both product types are manufactured in the standardised manufacturing environment with the same resources. Through the cooperation between workflow and quality management it is assured that the requirements for both these product types are met. Quality management ensures for both types that all the quality related characteristics and requirements are identified and verified and workflow management subsequently ensures that all processes needed to meet these characteristics and requirements are executed.

\subsubsection{Implementation Priorities}

Due to the prototype character of the initial implementation, the primary focus is on creating a functioning manufacturing environment. Consequently, the main focus initially lies on the development of the server and manufacturing environment, i.e. the back-end of the milling application.

Due to the limited resources that are available and the short time span of 6 months before the first $\mathrm{CNC}$ milling machines had to become operational, it is obvious that a pragmatic approach is required for the implementation of the architecture. This pragmatic approach focuses on selecting and implementing available solutions or initiating new developments that are required for creating an operational manufacturing environment that adheres to the envisaged CNC Worknet system. An example of this pragmatic approach can be seen in the accounting and financial control functional modules of the business administration application disc. These are operated within an off-the-shelf accounting application that was already operational within the company.

\section{Information Management}

The core of the CNC Worknet architecture is the information management kernel. A pragmatic solution is chosen here, as no full-blown information management kernel can be set up in the allotted time, i.e. before the system needs to go operational. Therefore, a standard ERP solution, called JobDispo [JobDispo, 2009], is implemented. While operating this commercial ERP system, experience is gathered that will be used for developing a dedicated application that suits the requirements of the envisaged CNC Worknet system. The implementation of an ERP system can be interpreted as a concession to the quality and workflow integration focus [see section 5.4], that states the benefits of workflows in comparison to ERP systems for the envisaged CNC Worknet system. With the future change in mind the ERP system is not embedded deeply in the systems of CNC Worknet. The ERP system is mainly employed as an available database that registers quotations, orders and supplier related data. Due to the experienced low order load, initially the scheduling needs of CNC Worknet are rather limited, thus elaborating on this functionality did not have priority. The scheduling capabilities of the ERP system are consequently merely used to register the on-going production and adding new production orders. The workflows of CNC Worknet, all work around this database, requesting data for the execution of their tasks. The interfaces of the workflow tasks with the 
database are therefore important as these specify the requirements for the dedicated solution exactly.

\section{Process Planning}

A crucial topic is the implementation of the Process Planning application disc of the architecture. Its primary role is the translation of the provided TPD into a process plan that can be executed in the Manufacturing Environment. The Process Planning application disc for the envisaged CNC Worknet system consists out of six functional modules [see Appendix 2].

\section{Implementation}

The ultimate goal is to develop and integrate an automated process planning system for CNC Worknet. However, due to the current state of automated process planning and the unavailability of such a fully automated system to CNC Worknet, the decision was made to implement a conventional process planning system. The Esprit software package [Esprit, 2009] forms the basis for all process planning activities; with this software, process planning is performed interactively. The workflow system, therefore, only communicates with the process planning application disc and not with any modules contained on it. The process planning application disc is therefore initially implemented as a black box, as visualised in figure 7.3. In practice, the efficiency of this implementation is steadily increased, through the development and implementation of dedicated CNC Worknet extensions. These developed extensions correspond with the functional modules of the process planning application disc. By steadily improving these extensions, a more efficient and effective process planning functionality is created. Based on the knowledge and experience gained from developing these extensions, an automated version of the process planning application disc can be developed and implemented at a

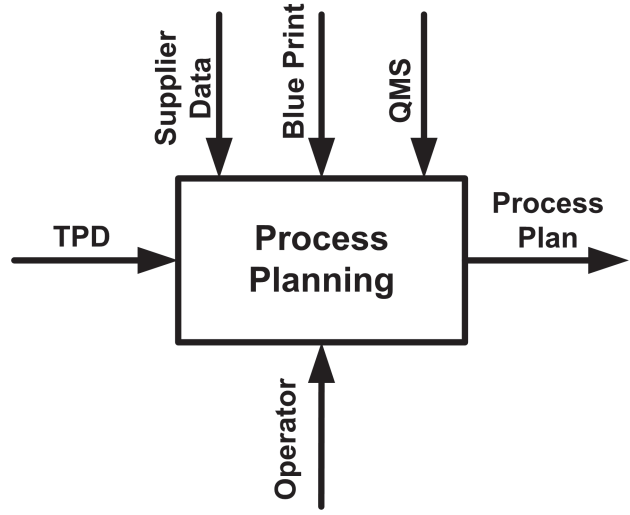

Figure 7.3 Process Planning Black Box later stage.

\section{Process Plan Verification \& Simulation}

Every NC-code generated by process planning is verified through a simulation before it is released to the manufacturing environment, i.e. the factory floor. These simulations are performed to detect errors in the NC-code. By detecting these errors before they actually happen, production delays and potential damage to the expensive CNC machines is prevented. This verification and simulation process is part of the Quality Control Processes functional module located on the Quality Management application disc. Detected errors are repaired after which the NC-code is verified again and subsequently released for production.

\section{Feedback from factory floor}

Once the process plan has been released, no alterations are allowed by entities outside of the process planning application disc. Alterations have to be requested after which these 
are evaluated and, when beneficial, implemented. Hereby, it is guaranteed that feedback, especially from the manufacturing floor, is fed back to process planning. This feedback can subsequently be incorporated into the process planning knowledge. This will improve the effectiveness and quality of the process planning activities.

\section{Portal Environment}

Having the back-end adequately in place, in a more or less automatic manner yields the requirement specification for the portal environment. Based on the experience gained in setting up the server and manufacturing environment, the requirements imposed on the portal environment are rather straightforward. However, as for many customers the interaction based on only $3 \mathrm{D}$ models is relatively new, and presents them with some challenges, it was decided by CNC Worknet to provisionally interact with the customers in a more traditional manner, thus initially sidestepping the portal environment. A prototype of a portal environment for CNC Worknet was tested with a few close customers. In its essence this portal environment functioned, customers could submit TPD and order data to CNC Worknet and download quotations and order confirmation documents in pdf-form from the portal. All data was received or uploaded manually by $\mathrm{CNC}$ Worknet operators. Due to the bare bones character of the portal and bugs that were still present, it was concluded that more time was required before a definitive portal environment could be implemented.

\section{Quality and Workflow Management}

With both the information management functionality and the process planning application disc in place, the focus of the implementation shifts to quality and workflow management. Together, these two entities are responsible for bringing the system to life. As mentioned, both envisaged and aerospace products are manufactured by the CNC Worknet milling implementation. The workflow and quality management entities are crucial in ensuring that these products are manufactured correctly. This is achieved by setting up a workflow and quality management system that is based upon well-defined operating procedures and job descriptions. Both generic and dedicated operating procedures and job descriptions are generated for the tasks to be performed within both the server and manufacturing environment. Generic procedures and description are created for the tasks that are equal for both envisaged and aerospace products. Dedicated versions are created for those tasks that are only required for aerospace products or that need extra clarification when compared to envisaged products. The process plan itself is also a dedicated operating procedure with job descriptions for manufacturing a certain product. All these procedures and job descriptions together form the different workflows to be executed within the server and manufacturing environments. Every workflow for the fulfilment of a request is initiated by a generic operating procedure. This procedure is first used to register the request and secondly to identify the characteristics and requirements of the request. Based on the identified characteristics and requirements, the workflow then branches off along a path of operating procedures and job descriptions to meet these characteristics and requirements. The manufacturing environment executes the process plan, as generated by the server environment, that describes the detailed and dedicated product workflow.

The differences in the quality and workflow management requirements of the envisaged and aerospace products are tackled with relative ease. Within the server environment, the extra requirements for the aerospace products are in some cases implemented for all 
products. Configuration management, for example, is easily achieved due to the high level of digitalisation and also directly benefits the envisaged products. The stricter supplier control entities for aerospace products are covered within the ERP system. Raw materials for aerospace and envisaged products can only be acquired from specific and approved suppliers. Suppliers are closely monitored by the quality management entities and corrective actions are taken against detected non-conforming suppliers. Within the manufacturing environment, the aerospace and envisaged products are differentiated by their workflows as described in their respective process plans. Fulfilling the FAI requirement for aerospace products is merely a scheduling and administrative restraint, as it requires the production of the first article and the detailed inspection afterwards. Production of the order is subsequently started when the FAI is approved. One of the big differences, however, is the disposal of non-conforming aerospace products. These non-conforming products are separated from the correct products with great care. When the investigation into the nature of the non-conformance is completed, these non-conforming products are disposed of by rendering them utterly useless through a cutting process.

CNC Worknet aims to certify the QMS of CNC Worknet according to both the ISO 9001 and EN9100 standards. Certification is to be performed in two steps. First, the whole system is certified according to the ISO 9001 standard, after which the set of entities of the system responsible for the aerospace products are also certified according to the EN9100 standard. This approach is chosen as EN9100 in its essence is equal to ISO 9001 and only imposes additional demands on certain specific elements. By first certifying the whole system to ISO 9001, it is assured that the baseline of the aerospace implementation is compliant.

\subsubsection{Functioning}

The functioning of the CNC Worknet milling implementation is described along the three environments as depicted in the functional description of CNC Worknet [see section 4.5.1]. As CNC Worknet is currently located in one facility, all entities are also located in the same building. This would indicate that the activities of both the server and manufacturing environment would be very entwined and difficult to distinguish and therefore not in line with the CNC Worknet concept. This, however, is explicitly not the case as the elements of the server and manufacturing environments are situated in different parts of the building and function completely independent of each other, thus stressing the fact that they can operate in the envisaged franchise model.

\section{Portal Environment}

Due to the choice to sidestep the portal environment, currently, order information from the customer is submitted into the ERP system manually. Communication with the customer is conducted over the telephone and e-mail. During the operation of the milling case it was noticed that direct communication with the customer is required from time to time, as the engineering intent of certain product features cannot always be interpreted by the process planner directly due to improper or unclear specifications in the TPD package.

\section{Server Environment}

The server environment is responsible for all the preproduction activities of CNC Worknet. A high-level view of these activities is presented in figure 7.4. Requests for quotations are processed by the Quote Generation Module of the Sales application disc. Quotations are 


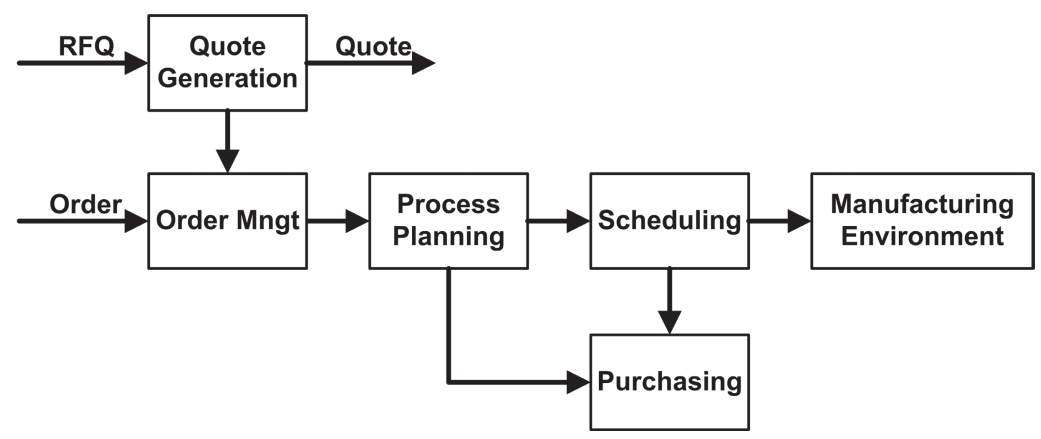

Figure 7.4 Server Environment Process Flow

generated based on a rough process plan that is generated by the process planning application disc, information from purchasing and the capacity planning entities. Orders, resulting from quotations, are registered by the Order Management module, which triggers the process planning application disc. The process planning application disc generates an elaborate process plan that is used by Scheduling and Purchasing. Scheduling uses the process planning information to schedule the production in the manufacturing environment. Purchasing uses this information together with the production schedule to order the materials required for producing the order. A manufacturing package is constituted from all the information generated in the server environment; subsequently, it is send to the manufacturing environment. The manufacturing package contains all the information required to manufacture the order; i.e. setup plan, inspection plan, NC-files etc.

\section{Manufacturing Environment}

The manufacturing environment is focussed around the operation of four 5-axis $\mathrm{CNC}$ milling machines. Two of these machines are situated in a manufacturing cell with a storage magazine and a loading robot, as shown in figure 7.5. Next to this, magazines for storage purposes and tooling benches are present in the manufacturing environment. Inspection equipment in the form of a CMM, callipers and gauges are also present in the manufacturing environment.

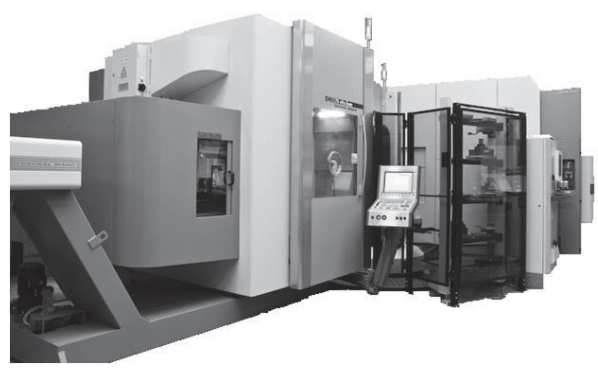

Figure 7.5 Manufacturing Cell

The processes within the manufacturing environment of the milling implementation as well as their correspondence with the functional modules of the Manufacturing application disc [see Appendix 2] are shown in figure 7.6. During pre-production, the required tools and production setup are assembled and mounted in the milling machine. Next to this, the proper NC-program is uploaded to the machine, after which the milling process is started.

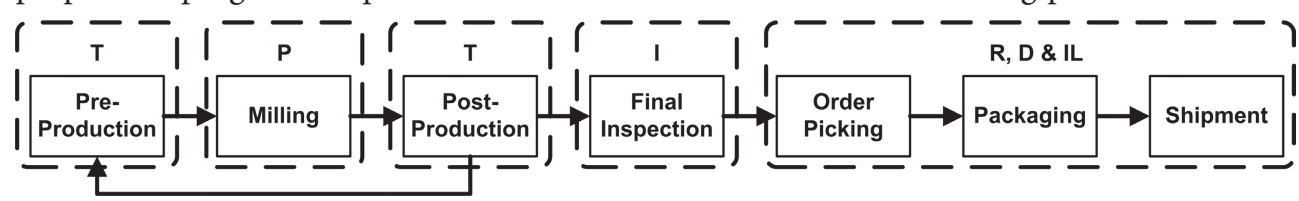

Figure 7.6 Manufacturing Environment Process Flow 
While the setup is mounted on the machine, measurements can be performed as part of the inspection plan and to adjust the NC-program in order to machine tight tolerances. After completion of the milling process, the setup is dismounted during the post-production step and disassembled. When additional setups are required to manufacture the product, the semifinished product is send to pre-production again to be prepared for the subsequent setup. The product is send to final inspection when it is finished. During final inspection the product is inspected according to the provided inspection plan. Action is taken on encountering non-conformances. Completed orders are packaged and subsequently send to the customer together with any required accompanying documentation.

\subsubsection{Evaluation}

Operation and development on the milling implementation came to an abrupt end with the declaration of bankruptcy of CNC Worknet in 2010. Due to the economic crisis at that time and the resulting low order load the company failed to remain profitable. Even though operation and development was seized after the declaration of bankruptcy, several results have been accomplished. CNC Worknet displayed, at first sight, not many differences from a conventional milling implementation at the time of the bankruptcy. Many of the activities within CNC Worknet were still performed in a manner similar to that in a conventional implementation. However, when looking more closely, it is evident that the different elements of the architecture have been implemented and have started to function according to specification.

\section{Quality and Workflow Integration}

The integration of workflow and quality centred around the creation, implementation and operation of the operating procedures and job descriptions. Together, these gave the entities of CNC Worknet more structure and also resulted in structured and insightful order process and production processes. The integration of quality and workflow management resulted in a manufacturing environment, in which workflows are created, executed and managed based on the identification and monitoring of the quality requirements of an order. This environment was able to manufacture both common and aerospace products. The QMS of CNC Worknet was not yet certified to ISO9001 and EN9100 at the time of bankruptcy, but already functioned according to the requirements of these standards.

\section{Continuous Improvement}

As the system was developed and implemented while also being operational it is understandable that not everything was functioning optimally and harmoniously from the start and that a lot of teething troubles existed. However, once the structure of the architecture was implemented and the quality management system started operating, these problems could be isolated and could be overcome through continuous improvement activities, without disturbing the other functionalities. Especially the process planning application disc was the subject of many improvement activities, as it was initially executed in a very basic manner. The effectiveness and efficiency of the process planning activities was increased through the development and introduction of various applications. These improvements were introduced as part of the functional modules of the architecture and displayed the modular capabilities of the $\mathrm{CNC}$ Worknet architecture. 


\section{Blue Print Development}

The manufacturing environment of the production location in Ede is setup as a prototype of an envisaged standardised manufacturing environment. The findings of CNC Worknet milling in respect to the blue print for the standardised manufacturing facility can be divided into two general topics; hardware and operating procedures. The requirements of the hardware are prescribed so the production locations are capable of machining the same types of products. The way in which the hardware is to be utilised is prescribed in operating procedures that make sure that the working standards are of the same level across the different production locations.

\section{Hardware}

Three general purpose 5-axis NC milling machines (DML Evo) and one more accurate 5-axis NC milling machine (Matsuura) are installed at the production location in Ede. Together, these machines are technically capable of manufacturing the envisaged product-mix with ease. This combination of general and a more accurate machine is therefore incorporated in the blue print of the standardised manufacturing environment.

The machines are only one part of the hardware as described in the blue print. The tools that are required when machining a product on a milling machine are equally important, if not more important. CNC Worknet operates with a limited toolset. This means that no dedicated tools are acquired for the machining of products. The tools in the limited toolset together should be capable of machining well-nigh all of the milling features present in the envisaged product-mix. Dedicated tools are generally more efficient when machining the product for which they are acquired. However, many tools are acquired by this process as these tools still represent some value after the product is machined. These tools are therefore stored and take up more and more storage space and make the tool inventory not very insightful nor cheap. To counter this problem, a limited tool set is employed by CNC Worknet. This tool set will be less efficient on a product-to-product basis when compared with dedicated tools but is more efficient when viewed at from a broader perspective. Less storage space required and the inventory is easily tracked. Next to this, the process planning activities also benefit from this situation, as standardised milling operations can be created for the milling of different features. With this, the efficiency of the process planning is increased. Next to the tooling set, a universal clamping system is utilised for fixturing the raw materials on the milling machines.

\section{Operating Procedures}

The most important part of the blue print is how the hardware is utilised within the manufacturing environment. In order to make sure that the hardware is utilised in the same manner at each location, operation procedures and job descriptions are incorporated in the blue print. Every activity and task to be performed within the manufacturing environment is described by operating procedures and job descriptions. When properly implemented, a consistent manufacturing process is established at each production location on an equal working standard. The proper implementation of the procedures is monitored through audits performed by the Quality Control ME functional module of the Quality Management application disc. 


\section{Case Conclusion}

Even though the CNC Worknet -Milling case was not a financial success, the technical implementation of the different entities of the system showed the potential of the envisaged system as is discussed in the evaluation of this case. In the state at the time of the bankruptcy CNC Worknet - Milling performed equally to conventional milling implementations. However, this situation would have significantly improved as the different elements of the architecture have become functional and the continuous improvement activities started to increase the efficiency and effectiveness of the CNC Worknet. Next to this, the workflow and quality integration focus proved to be an effective approach to setup and operate $\mathrm{CNC}$ Worknet. Because of this, it was decided to continue the development of CNC Worknet in a second implementation.

\subsection{CNC Worknet - Layered Manufacturing}

The second implementation, which focuses on the employment of layered manufacturing production techniques, is also realised at the production location in Ede. This layered manufacturing implementation was initially operated alongside the milling implementation, but after the bankruptcy of CNC Worknet, the layered manufacturing implementation continued independently as a company named 3D Worknet. For reasons of clarity, the layered manufacturing implementation will be referred to as CNC Worknet - Layered Manufacturing.

Three different layered manufacturing techniques are employed within this implementation; Selective Laser Sintering (SLS), two Ink-Jet Based techniques and Fused Deposit Modeling (FDM) [see Appendix 1]. The main focus of this implementation is on the SLS technique as $80 \%$ of the manufactured products by CNC Worknet are produced with this technique.

The layered manufacturing implementation was initially setup on a small scale as a test case for the logistics application disc and information management kernel. However, the focus shifted to a full implementation of the CNC Worknet system for layered manufacturing. The main difference between the layered manufacturing and milling implementation is the manner and grouping in which the products are manufactured. With milling, one product is manufactured within one setup, so there is always a one-to-one relationship between the machine and product that is to be manufactured on it. However, this is not the case with layered manufacturing. Generally speaking, layered manufacturing is a batch manufacturing process where several (different) products are manufactured on the same machine in the same production setup (batch or production tray). This difference has consequences for the functional modules contained on the Logistics, Process Planning and Manufacturing application discs.

\subsubsection{Implementation Priorities}

The experience gathered while implementing and operating the milling implementation was of great benefit for the layered manufacturing implementation. The architecture and quality and workflow entities of the system could be implemented with relative ease due to its generic nature and the experience gathered during the development and operation of the milling implementation. 


\section{Information Management}

The information management kernel forms the basis for all the applications of the architecture. Unlike the milling implementation that utilised a commercial ERP system, the information management needs of the layered manufacturing implementation are fulfilled through a dedicated solution. Based on the experience gathered while operating the milling implementing, which gave a detailed insight in the information management requirements of the system, a database is developed and implemented. On top of this database, interfaces with the different application discs and functional modules are created.

\section{Quality and Workflow Management}

The quality and workflow management entities of the layered manufacturing implementation function in the same manner as the milling implementation. Several operating procedures and job descriptions of the milling implementation are reused and/or adapted where possible in the layered manufacturing implementation. New operating procedures and job descriptions are created for new tasks dedicated to layered manufacturing. The QMS is setup conform the requirements of ISO9001. This implementation is not focussed on the production of aerospace products, like the milling implementation, and the requirements of EN9100 are therefore not implemented. Initially a paper based workflow and quality management system was created that functions comparable to the milling implementation. Many of the operating procedures and job descriptions are generic, as the layered manufacturing process is more deterministic in its outcomes when compared to the milling process. A more structured approach to the generation, implementation and operation of the quality and workflow management system could therefore be employed.

The paper based workflow and quality management system utilised in the server environment was replaced in a test environment by a digitalised workflow management system. However, only functioning within a test environment this workflow management system already showed its possibilities. It resulted in faster and more structured processes and a more structured data exchange and processing within the server environment. As the interfaces of the workflow management system only present the necessary data to the user, the tasks to be performed are simplified and human errors are less prevalent [Nijholt, 2010]. The workflow management

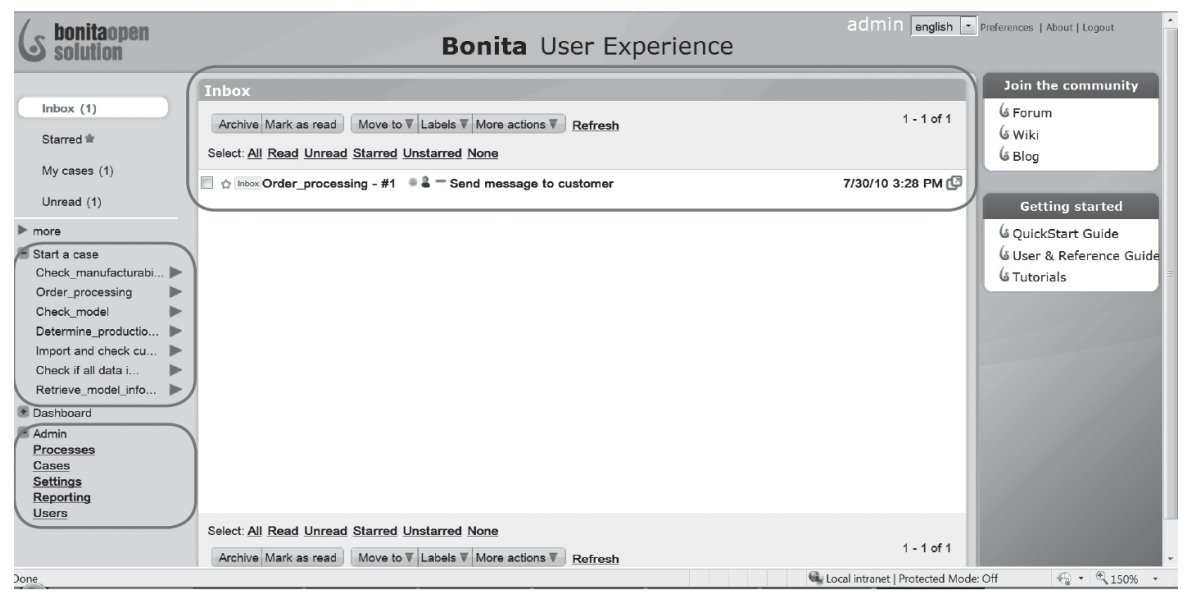

Figure 7.7 Interface Workflow Management System 
system digitalised the operating procedures and job descriptions of the server environment as many of these descriptions can be displayed, when needed, within the interfaces of the workflow management system. The workflow management system allowed the tracking and tracing of the progress of the contents of an order through the whole system of CNC Worknet. Another benefit of the workflow management system is that it forces the employees to follow the prescribed procedures and hereby prevents its circumvention. Consequently bottlenecks or bad connections in the workflows are identified instantly. The major downside of the tested workflow management system was that using it sometimes resulted in very cumbersome operations by the user. The workflow management system revolves around an email inbox styled interface, in which new assignments for the user appear, as shown in figure 7.7. This resulted in situations where users had to spend a considerable amount of time opening and closing these assignments. This is however merely an interface problem that is easily fixed in an improved implementation of the workflow management system. The financial situation of $\mathrm{CNC}$ Worknet however, did not permit the utilisation of the resources needed to implement these changes, within the time frame of this research.

\section{Process Planning}

The process planning application disc required a large adaption when compared to the milling implementation. Although the layout of the process planning application disc is equal to that of the milling implementation, the contents of several functional modules is, however, fully dedicated to layered manufacturing. The primary priority during the implementation was to adapt the functional modules in such a way, that they are capable of facilitating process planning for layered manufacturing. The efficiency and effectiveness of this initial implementation is then, through continuous improvement activities, steadily improved. The main challenges for process planning for layered manufacturing are determining if a product is suitable for a certain technique and generating the optimal nesting for a group of products. A short description of two functional modules that are responsible for fulfilling these tasks is given in the following two sections.

\section{Feature Identification}

Essentially, layered manufacturing is the 'printing' of geometry; consequently feature information can be considered as unnecessary. However, the product may contain characteristics that are of influence on the layered manufacturing process. This module is used to identify these characteristics within the provided product models. One of the key characteristics that is checked by this module, is the wall thickness of each model. Every layered manufacturing technique is only able to produce parts with walls of a certain minimum thickness. By detecting the smallest wall thickness within a model, the suitability of the model for a layered manufacturing technique is verified. This module is also used to recognise characteristics that indicate a suitable or preferred orientation of the product during printing. These identified characteristics are used by the Setup Generation module during nesting.

\section{Setup Generation}

The Setup Generation module is responsible for orienting and nesting the products in the build volume of the layered manufacturing machine. It determines suitable orientations of the product based upon the recognised characteristics by the feature identification functional module. The products are subsequently nested in the production tray based upon these suitable 
orientations. During this step, products from different orders are optimally placed within the confined building space (tray) of the machine. An optimal tray has a high production volume density and, for logistic reasons, has a production time of about 23 hours.

\section{Portal Environment}

The Portal Environment is realised in three different stages for CNC Worknet. Initially, communication with the customer was conducted through a conventional order processing system as used in the milling implementation. Next to this conventional order processing system a secondary order processing system was setup dedicated to a single customer, Shapeways [see also section 2.3.1]. CNC Worknet was selected by Shapeways as one of the sites for the manufacture of customised products, which consumers order through the Internet portal of Shapeways. This secondary order processing system was later also connected to the Internet Portal of CNC Worknet. Within this Internet portal customers can request quotations and review and track their submitted orders. With the introduction of this Internet Portal the conventional order processing system became obsolete.

\subsubsection{Functioning}

As with the milling implementation, a distinction is made between the Portal, Server and Manufacturing Environments. Due to the respective locations of the server and manufacturing environments in the CNC Worknet building, a distinct and physical boundary between them is created. All the entities of the manufacturing environment are realised at the ground level of the building. The entities of the server environment are all located on the second floor. Communication between the two entities is realised through team meetings, database interfaces and tray production orders. The functioning of the three environments is discussed in the following sections.

\section{Portal Environment}

Customers and request quotations or submit orders through the Internet Portal. The data from these requests and orders is registered in the databases of CNC Worknet and subsequently processed by the server environment. Quotations are presented to the customer on the Internet Portal, as well as the current status of any submitted orders. Next to this, every working day an order batch is submitted to CNC Worknet for production. The orders are broken up in different order lines, and stl-files. Together these describe the model, amount, material and requested treatment of each order as well as the shipping details.

\section{Server Environment}

The application discs that govern the functioning of the server environment are basically equal to the CNC Worknet implementation. A high level view of the preproduction activities

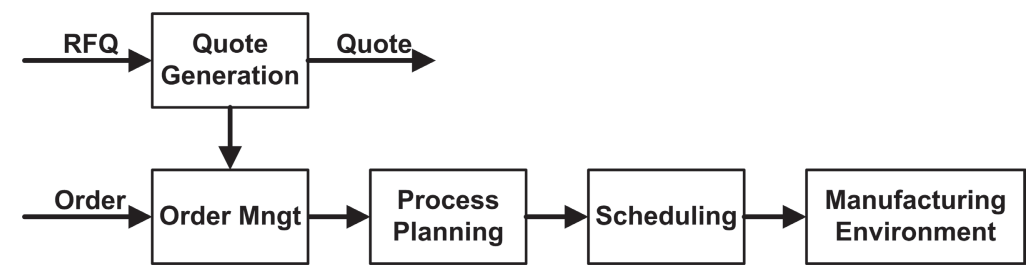

Figure 7.8 Server Environment Process Flow 
of the server environment is given in figure 7.8. The similarities with the server environment of the milling implementation [see section 7.1.2] are obvious. RFQ's are processed by Quote Generation that functions very straightforward due to a number of reasons. First of all, CNC Worknet uses a fixed order lead time of 8 days upon order acceptance. Next to this, CNC Worknet accepts every model during the quotation process, thus making the customer responsible for the quality and suitability of the stl-model. During process planning, the model is checked for its suitability for the selected layered manufacturing technique, the model can however at this stage still be rejected (i.e. the order is rejected). Therefore, the Quote Generation process only has to calculate the pricing element of the quotation. The price of a product is calculated based on the selected material and the model characteristics of the product. These model characteristics like volume, density and dimensions of the product are extracted from the stl-file that is submitted by the customer.

Orders are registered and reviewed by Order Management and process planning is subsequently triggered. Process planning first checks the products for suitability and then nests the products from several orders in production trays. The nesting and slicing activities are performed within applications dedicated to a certain machine make. All these applications function manually or semi-automatically under the guidance of process planners. For SLS (which makes up $80 \%$ of total order volume), operators select the products and, when needed, lock them into certain orientations within the nesting application. The nesting is subsequently performed by the application after which the created nest is manually checked for nesting errors. Correctly nested trays are then sliced by a dedicated application.

Scheduling the production within the layered manufacturing facility is straightforward, as the production sequence of the different trays is determined based upon the earliest due date of the products contained within a tray. For scheduling purposes, process planning strives to create trays which take 23 hours to produce. With one hour for tray removal and machine preparation, this setup allows for steady and repetitive 24/7 production. The Scheduling module also preselects the products that are allocated to trays for nesting. This preselection is made based on a combination of the due date and the bounding box volume of the product. This preselection is performed once a day for multiple trays at the same time. The scheduling of the daily production activities within the facility is performed by the scheduling functional module. When more standardised manufacturing environments are connected to the server environment, the role of scheduling during preselection becomes also more important as the products from one order should ideally be produced in one and the same manufacturing environment for shipping purposes. This extra dimension gives an additional constraint when appointing products to trays, which can be easily incorporated when the need arises. Capacity planning of the layered manufacturing facility can be viewed as volume based planning. Typically each tray takes about 24 hours to be produced on a layered manufacturing machine (SLS). Next to this, the average product volume density of the trays is also known. Based on the expected sales volume, the capacity planning of the layered manufacturing plant can hereby be easily performed. A shortage in the production capacity can be overcome through incidentally producing a number of trays during the weekend or -when structural- by an expansion of the production capacity through the introduction of additional equipment.

The purchasing entity has been removed from this order activity flow as the layered manufacturing process does not require a direct, order related purchasing process. Raw 
material is purchased in bulk from fixed suppliers and replenished when the inventory gets below a certain level.

\section{Manufacturing Environment}

Like the milling implementation, the manufacturing environment of thelayered manufacturing implementation resembles a standardised manufacturing facility as envisaged in the CNC Worknet business model [see section 4.1]. The manufacturing environment consists of the production processes and several supporting processes like maintenance and storage. Its main constituents are located on the Manufacturing application disc.

The manufacturing environment is comprised out of four different areas. The first area is used for the actual layered manufacturing process. Four machine makes are employed there, which comprise three different layered manufacturing techniques: SLS (EOS), FDM (Dimension) and Ink-Jet Based(ZCorp and Objet). Initially, CNC Worknet employed two machines for the SLS production, but this number was steadily increased to six machines during the course of two years. Next to the layered manufacturing machines, an product cleaning area was setup with blasting chambers and powder recollection areas where the products are manually cleaned. A finishing area was setup with the equipment used for colouring, baking and impregnating the products. The last area is used for order picking, inspection and packaging; for this purpose it contains a lot of tables and storage room.

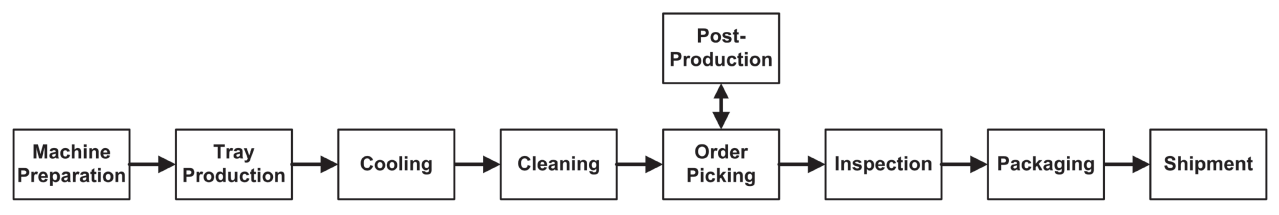

Figure 7.9 Manufacturing Environment Process Flow

The processes of the manufacturing environment as employed for the layered manufacturing implementation, as well as their correspondence with the Manufacturing application disc [see Appendix 2] are shown in figure 7.9. The manufacturing process is started with the preparation of the machine. The machine is cleaned and checked after the previous production run. A new production tray is mounted in the machine and when needed, the powder reservoir is refilled or the cartridges for the material are replaced. The production-data file for the tray is uploaded to the machine and the tray production process is subsequently started. After production, the tray is put in a rack for cooling. After cooling, the products are separated from the unsintered powder at the start of the cleaning process. Through a combination of brushing, air blasting and powder blasting the products are cleaned. During the order picking process, the individual products are identified and collected per order in small containers. During order picking, products that require an extra production step are also identified and subsequently send to this step. These extra production steps comprise of processes like colouring, impregnation and/or a heat treatment. After the extra production steps, these products are returned to order picking. Order Picking can be viewed as the spider in the web of CNC Worknet. All products from the different production trays and layered manufacturing techniques come together during this stage as the different elements of the 
orders are collected here. Before order picking, the products are identified in groups through their tray identification number and after order picking, products are identified through their specific order number. Containers that contain complete orders are forwarded to inspection. During inspection, the contents of the order is thoroughly checked for completeness and correctness. Non-conformances are reported and necessary activities to correct them are initiated. Completed orders are subsequently packaged and send to the customer.

\subsubsection{Evaluation}

The CNC Worknet - Layered Manufacturing achieved several positive results. These achieved results are shortly discussed in the following paragraphs.

\section{Architecture and Workflow and Quality Management Application}

The architecture and quality and workflow management system developed for the milling implementation were adjusted and applied with relative ease to the layered manufacturing implementation. These adaptations demonstrate the generic applicability of both the architecture and quality and workflow management to different manufacturing techniques. Through the tests with the wall thickness and automated nesting applications, the modularity of the architecture is demonstrated through the use of the functional modules in which these applications are encapsulated. Next to this, these test demonstrated that the workflows through the system are not dependent on how the different tasks of the functional modules are executed, as the overall workflow is not changed due to the implementation of new applications or improvements.

\section{Continuous Improvement}

The initial layered manufacturing implementation consisted out of many processes and tasks which were not very efficient and/or effective. However during its operation, several elements were improved, tested and implemented which increased the efficiency and automation of the overall system considerably. These improvements can be categorised into several topics which are discussed below.

\section{Database Interface Improvements}

The operation of CNC Worknet revolves around several databases (i.e. the Information Management Kernel) that have interfaces to the different functional modules of the architecture. Initially, one and the same interface was used by several entities of the architecture This gave every entity access to the same data with the same rights. This situation resulted in an information overload for the user, who has to seek for the required specific information. Moreover, users could adjust data they are not allowed to. Through the development of dedicated interfaces for the different entities, these problems were overcome, resulting in a more effective and efficient process.

\section{Automation of administrative Tasks}

In the initial implementation the order intake into the databases of CNC Worknet was performed manually. Especially the intake of the order batches of Shapeways required a great deal of manual manipulation of data and was a very tedious administrative task. Through the introduction of several algorithms within the different functional modules of the server environment, many of these administrative tasks have been automated. 


\section{Automated Workflow Management System}

As discussed earlier, parallel to the CNC Worknet system, a shadow system was setup that was used to test a more digitised version of the server environment. This digitalisation revolved around a workflow management system that automated the assignment and distribution of the different tasks to be performed within the server environment and structured their execution. This shadow system was extensively tested, with good results [Nijholt, 2010]. The implementation in the test environment showed that the digitalisation of the operating procedures and job descriptions within the workflow management system resulted in a more structured and transparent process consisting of many simplified activities which are less error-prone. Implementation of an improved version within the server environment is however postponed due to a lack of resources.

\section{Wall thickness check}

One time consuming activity within the server environment is the manual verification of each newly submitted model. During this verification, the wall thickness of each model is manually checked for suitability for the layered manufacturing process. This wall thickness check is a tedious task, where mistakes are easily made. As part of the feature identification module an application is developed by ontologics that verifies the wall thickness of a stlmodel. The program identifies areas with small thicknesses within a model and presents them to the process planner for a final judgement. This application is easily integrated within the operating procedures and workflows of the server environment and increases the efficiency and effectiveness of the process planning activities.

\section{Automated nesting application}

One of the most critical and time consuming tasks of the server environment is the nesting activity performed by the Feature Identification and Setup Generation modules of the process planning application disc. This activity is in practice performed semi-automatically by the process planners of CNC Worknet. In order to increase the efficiency and effectiveness of this activity two applications have been developed and tested [Faneker, 2011 \& Lutters et al., 2012]. The first application is part of the Feature Identification module and determines the optimal orientation of the product for nesting. A second application belonging to the Setup Generation module is also developed; this application automatically nests the adequately oriented models in a tray. The application can very quickly generate an initial nest, which is then steadily improved as long as time is available. This initial nest is not the most optimal nest in terms of building volume density, but it can be used immediately when needed. The initial nest is improved through applying the 'Brazil Nut' effect on the models contained in it. This improvement process can be terminated at any moment and will always result in a suitable nest. Therefore, the application is capable of generating a nest at any given time. This is not the case in the current implementation, which is more a time consuming trial and error process. Currently, it takes a lot of time to generate a nest and the resulting nest needs to be checked thoroughly as it regularly contains errors. From a workflow point-of-view, the tested application is beneficial to CNC Worknet as it removes the bottleneck from the nesting activity, where the layered manufacturing process often had to wait for the nesting process to be finished. In the workflow with the new application, this will not be the case anymore. The nesting activity can be used in this new workflow as a 'buffer' for the layered manufacturing process from which trays can be taken when needed. 


\section{Order Volume}

One of the most striking results is that the order volume that is processed by CNC Worknet has risen considerably without a need for more personnel. Thanks to the different improvements applied to the different entities of CNC Worknet, the efficiency and effectiveness of the overall system is increased considerably. Especially the administrative tasks within both the server and manufacturing environment benefited from these improvements.

\section{Blue Print Development}

The actual implementation resembles a manufacturing entity for layered manufacturing of the envisaged concept very closely. As described in the milling implementation, the findings of the layered manufacturing implementation in regard to the blue print is described according to two general topics; hardware and operating procedures.

\section{Hardware}

The machines from EOS, ZCorp, Objet and Dimension that are installed in the manufacturing environment are capable of performing the most common layered manufacturing techniques at this moment. The process planning for the different machines types is equal per make, therefore the machine types (version) may differ between the manufacturing environments. The tray size and the machine make are the entities that should be known to the server environment. Next to the layered manufacturing machines, the equipment used for the different post-production activities is prescribed in the blue print. Given the nature of these activities, the required capabilities or minimum specifications of these is the only prescribed entity present in the blue print.

\section{Operating Procedures}

The main focus of the blue print, as with the milling implementation, is on the operating procedures and work instructions. These describe and prescribe the working standards and ways by which the equipment present in the manufacturing environment is to be utilised. Especially the post-processing activities like cleaning and colouring, for example, require a certain way of working that is described in detail in their respective operating procedures and work instructions. When these are followed correctly, the products should be cleaned and coloured equally independent of the production location.

\section{Case Conclusion}

CNC Worknet - Layered Manufacturing is in its current state an effective and efficient system for the manufacture of layered manufacturing products. It demonstrates all the elements of the envisaged CNC Worknet business model. An Internet Portal is present for the communication with the customer in relation to quotations and orders. All the pre-production activities are performed within the Server Environment. A Manufacturing Environment is setup that produces the products according to the plans provided by the Server Environment. The only element that is not present in this case, is the presence of multiple manufacturing environments as part of the envisaged franchise organisation. The effectiveness and efficiency of the implementation has been steadily improved through the employment of continuous improvement activities and it is foreseen that this process is continued after this research. It can therefore be concluded that the implementation and operation of CNC Worknet - Layered Manufacturing is a success. 


\section{Future Vision}

When anticipating possible evolvements in manufacturing that are relevant in the context of this thesis, three distinct tracks can be discerned, being technology, organisation and business respectively. First the development of manufacturing technologies employed in future will be discussed. Secondly, the organisation of manufacturing environment of the future is discussed. The way in which these organisations are employed in future business models is discussed in the closing section of this chapter.

\subsection{Future of technology}

One of the most important developments of the last decade is the evolution of layered manufacturing techniques and machines. Initially, these devices had high cycle times and only a small building volume, thus limiting the size of the products. This resulted in a process that was slow and limited in its application, and that was in general only suitable for prototypes. It was by far not a competitor for the more conventional manufacturing techniques. In the last decade, layered manufacturing evolved into techniques and machines that, for certain types of products, can indeed compete with conventional manufacturing. This trend will continue in the future; therefore layered manufacturing will become a real competitor or even surpass the capabilities of conventional manufacturing. Engineers will have to learn how to employ layered manufacturing to its full potential, as many products that are currently produced by this technique are originally engineered with a conventional manufacturing state of mind. The almost complete freedom of geometry available in layered manufacturing does provide engineers with new possibilities to shape their products. These new possibilities are currently (gradually) explored and will become common knowledge in the future, resulting in products that are actually designed and developed for the production means of layered manufacturing.

Next to this, the machine tools employed in layered manufacturing are evolving rapidly into two different directions. On the one hand, these machines are becoming capable of producing larger products at increasing production speeds. On the other hand, these machines have also become smaller and more affordable. This is a development that can be compared to the evolution of the now common printer. Initially, these were only available in an industrial context; through the introduction of print shops, printing became available for the customer. Currently, almost every home has a printer connected to a computer by which consumers can print their own documents. This evolution was made possible because printers became smaller and therefore suited for home use and also affordable due to mass production. Layered manufacturing is already following the same route. Recently, layered manufacturing has become directly available for consumers. Companies like Shapeways have given consumers direct access to layered manufacturing techniques with which they can produce and sell their own designed products. It is foreseeable that with the growing affordability of the layered manufacturing machines, it is only a question of time until these make their entrance into the consumer's home. The layered manufacturing implementation [see section 7.2] is already used by consumers to explore the possibilities and capabilities of layered manufacturing. For which products these machines will be employed by consumers is also an interesting question. 
Currently, most products submitted to CNC Worknet for manufacturing are scale models, jewellery and gadgets. It is expected that this will expand to other product types as well.

In machining, most of the processes have been subject to on-going optimisation over the years. Moveover, in machining, less technological revolutions have occurred over the last decade as compared to layered manufacturing. It is therefore expected that the principle of machining will not change significantly in the near future. The capabilities of the hardware (tools and machines) employed in machining will be improved. Faster and more durable tools and machines will be developed that are either capable of machining a specific machining operation very efficient or are capable of performing a range of machining operations. The main developments in the field of machining will occur in the process planning activities. Process planning has, over the last decades, come close to achieving fully automated process planning. The final steps needed in the fields of feature recognition and the overall management of process planning will be taken in the near future. Manufacturing systems will consequently be employed like CNC Worknet - Milling [see section 7.1] that will incorporate this technology in the operation of streamlined supply chains.

\subsection{Future of Organisation}

The current market is demanding more and more customised products and this trend will continue. The manufacturing environment will therefore steadily change from one that is focussed on producing products in large quantities and at low costs to one that is able to produce customised products at low costs in small batches. The benefits of manufacturing products with mass production techniques is consequently decreasing, as centralising all production activities in one location will increase the transportation costs and lead time. The focus is therefore shifting towards distributed manufacturing. In terms of the triangle of constraints [see section 2.1.1] producers have to adopt more to the vision of the customer; in other words, they have to focus more on the product they produce than on the processes they employ. By distributed manufacturing, products can be manufactured closer to the delivery location, thus considerably lowering the costs of transportation. The factories within these distributed manufacturing networks will be capable of producing a wide range of products. The strict requirements for the factories connected to these distributed manufacturing networks as described in the franchise model of CNC Worknet will not be required anymore in the future. Due to advancements in information management and process planning, the need to centrally manage or prescribe the capabilities of the different entities in the network will decrease. The information of the different factories will be instantly available to process planning, which will use this information to generate a process plan for that specific factory with its own specific equipment.

\subsection{Future of Business}

The successful management of information has become one of the main decisive factors for the competitiveness of companies. The availability of adequate information in the supply chain at the right time is vital for its successful operation. Through the development of e-business applications, companies are increasingly able to instantaneously share information throughout the supply chain. This massive load of information, that has become available in the supply chain, is becoming difficult to manage and to process efficiently. The system 
proposed in this research enables the management and processing of this information more efficiently. Consequently, it makes the supply chain more responsive to changes. In the future companies will be able to instantaneously share, structure and process this information efficiently throughout the supply chain. Therefore, the supply chain will be able to respond adequately to disturbances or customer requests.

The Internet and e-business are increasingly being employed to facilitate and structure the communication between the different entities in a supply chain. Initiatives like CNC Worknet, Shapeways, eMachineShop and 247TailorSteel have shown that e-business can successfully be employed for the manufacturing of products in small batches. These initiatives are currently acquiring a market share and will expand and grow in the future. The combination of e-business in a distributed manufacturing environment for products in small numbers can be considered as an ideal combination. The employment of e-business will allow all entities in the supply chain to respond directly to a customer request, as information will be shared instantly throughout the entire supply chain. The information exchange in current e-business initiatives is currently commonly structured through the employment of an application in which the customer specifies its product. This restricts the customer in its freedom and should guarantee a structured information exchange; moreover, these companies are designing their own information exchange standards. The system proposed in this research does not employ such a client-side application in order to give the customer complete freedom and relies on native CAD-data for the provision of the necessary TPD. The emphasis will in the future lie on the direct exchange of information between the customer and the manufacturer without the need for client-side applications.

New business models will be developed with the introduction of layered manufacturing machines into the homes of consumers. Business models where consumers, for example, purchase a license of a product design and subsequently produce it on their own machine can become reality. Other possibilities are that customers purchase the core module of the product and are subsequently able to customise and produce the exterior of the product on their own. Customers can then adjust the looks of their product to their own liking. As can be noted from these initiatives, consumers increasingly want to be involved actively in the manufacturing process of their products. An example of this active involvement is car manufacturer Audi where customers are invited to the actual car factory to start and pick up their new car from the 'end' of the assembly line. This experience is currently only a marketing trick, but might become reality in the future. The experience to be involved in the creation of their own product fascinates consumers and will become even more real with the increased application of layered manufacturing. Consequently, traditional manufacturing is slowly but surely moving to an environment that can be described as 'personal manufacturing.' In this environment, consumers have a high influence on the decisions relating to which product is produced when and how. In their considerations, consumers will unremittingly address the elements quality, costs and lead time in all their considerations. The element that is not of interest of the customer is the production location; logically, production location, with the consequential logistic cost, will become the obvious means for companies to compete on when acquiring orders. 


\section{Conclusions and Recommendations}

Based on a generic and modular architecture, a system is proposed for the distributed manufacturing of products in small batches. This system has been implemented in two cases; milling and layered manufacturing. The system revolves around the integration of quality and workflow management, leading to a manufacturing environment that is focussed on both the quality of the product and the quality of the processes throughout the entire supply chain.

\subsection{Generic System}

The conclusions concerning the generic proposed system are discussed in three sections, first the integration of quality and workflow is discussed, then the capabilities of the architecture and finally the distributed manufacturing capabilities of the proposed system are discussed.

\subsubsection{Workflow and Quality Integration}

As a result of the focus on the integration of workflow management and quality management, an environment has been established in which the workflows for the completion of an order determine their own way through the system. The milling implementation demonstrates the adaptive capabilities of the workflow for products with different quality requirements, as next to the envisaged products also aerospace products were produced by this implementation. Within the layered manufacturing implementation these capabilities were employed to differentiate between the different techniques for layered manufacturing and to execute additional finishing processes for certain products. As a result of the integration of workflow management and quality management, the system is capable of manufacturing products in a controlled and predictable environment.

\subsubsection{Generic and Modular Architecture}

The information management architecture of the proposed system demonstrates its potential in both case studies. Its generic and modular capabilities were stressed during the transition of the milling case into the layered manufacturing case. This transition was facilitated by the architecture with relative ease. A considerable number of modules that had initially been developed for the milling architecture could, due to the generic nature of the architecture, be reused for the layered manufacturing implementation. Consequently, both the cases operate on the same architecture and only differ in the specific implementation of some modules of the application discs. The overall structure of the application discs is identical for both case studies and a considerable number of discs is equal for both cases. Consequently, it is stated that, based on the provided architecture, an extension to other manufacturing techniques is attainable with relative ease. The modular capabilities of the architecture are also demonstrated during various improvements that led to the replacement of modules in the architecture with more efficient and effective counterparts. These -frequent- updates/upgrades are performed as a consequence of the various continuous improvement initiatives. 


\subsubsection{Distributed Manufacturing}

The production activities of the proposed system are employed within a distributed manufacturing network. In theory, the management of these distributed entities should be transparent and straightforward, due to the use of the blue print that prescribes the contents and working methods to be employed. Although the organisational impacts of the implementation of this type of distributed manufacturing have not been studied explicitly in this project, no sighs were encountered that undermine the claims on the effectivity of the system in a distributed manufacturing mode.

\subsection{CNC Worknet}

The company CNC Worknet has implemented the proposed system for milling and layered manufacturing. When comparing the envisaged supply chain of CNC Worknet with the realised supply chain it is concluded that not all goals have been reached. The financial climate has been harsh on CNC Worknet and it considerably hindered its successful development - to say the least. Most notable in this context is the bankruptcy of CNC Worknet, and the subsequent discontinuation of the milling implementation. However, when looking more closely at both implementations, it is evident that the outlines of the envisaged system are visible and that CNC Worknet has started to function according to specification and expectation. The focus on the integration of quality and workflow management has enabled CNC Worknet in closely approximating the envisaged supply chain. The gap that still exists between the envisaged supply chain and the current implementation mainly relates to the level of automation that is required to respond with a quotation to a customer request within a day. This is mainly due to the fact that the automation of workflow management has not been realised yet. Moreover, the state-of-the-art in process planning technology has not reached its full potential for the production techniques employed by CNC Worknet. These are however temporary setbacks as these difficulties will be removed in the future when the technology of process planning has progressed sufficiently. Next to this the franchising and networked manufacturing aspects of the envisaged supply chain have not been fully implemented. The achievements and shortcomings of the main constituents of the CNC Worknet business model, i.e. the Portal, Server and Production environments, are discussed in the following sections.

\subsubsection{Portal Environment}

The portal environment has been established for the layered manufacturing implementation as envisaged in the business model. With the milling implementation communication with the customer was conducted through conventional means. The experience gathered with the portal and the conventional method proved that communication related to products with low complexity is suitable to be conducted over an Internet portal. When the complexity increases or when the provided TPD cannot be interpreted correctly by process planning in an autonomous manner, direct communication with the customer is required. Especially with the milling implementation these direct communications with the customer often appeared necessary. This is, however, not the case with the layered manufacturing case, as the process planning components in the workflow give less rise to uncertainties or incompleteness. Consequently, an Internet portal has proven to be a suitable means for communicating with the customer if the products concerned have a low complexity; otherwise conventional or additional means of communication need to be employed. 


\subsubsection{Server Environment}

The CNC Worknet server environment heavily relies on the automation of the business processes contained in it. This required amount of automation has not yet been reached by CNC Worknet. Many of the processes within CNC Worknet were initially performed manually. However, as a result of the steady elimination and replacement of these processes with more automated versions, the level of automation of CNC Worknet increased considerably. This is especially the case for the layered manufacturing implementation, as the processes related to this manufacturing technique are better suited for automation. A complete unmanned operation of both the server and production environments is, however, utopian as human control will always be required/desirable during certain stages in the supply chain. The bottleneck in the automation of the server environment clearly is process planning. For both milling and layered manufacturing no solution is currently available that meets the requirements of CNC Worknet in relation to automation and maintainability.

\subsubsection{Production Environment}

A production environment as envisaged in the CNC Worknet business model is setup and operated. The production environment complies with the blue print that specifies the equipment, tooling and operating procedures and instruction to be used. The operating procedures and instructions are all prescribed by the quality management system of CNC Worknet. The equipment and tooling prescriptions are primarily of importance to facilitate the distributed manufacturing capabilities of CNC Worknet. The operating procedures and instructions are, once the production environment has been established, of a greater importance as they prescribe how the equipment is operated. In other words, they directly influence the quality performance of CNC Worknet. Only a single implementation of the production environment is realised in both cases. Consequently, the functioning of the network of production locations operated within a franchise model as foreseen in the business model could not be tested. The production location of both implementations has been setup with a clear separation between the functionalities of both the server and production environments. Therefore, no consequential pitfalls are expected in the expansion to the full franchise model.

\subsubsection{Overall}

The focus on the integration of quality and workflow management has enabled CNC Worknet to come close to the envisaged supply chain. Unfortunately, only the layered manufacturing implementation is still operational at the writing of this conclusion. The integration of quality and workflow management, together with the information management architecture has, however, proven itself to be a sound foundation for the development and operation of CNC Worknet and any other manufacturing system that is based on it.

\subsection{Recommendations}

The system as proposed and developed in this research is not yet in a state where it is complete, impeccable and ready for commercial resale; further research and development activities are required. The recommendations are split up in two sections; one for the generic system (design) and one for the CNC Worknet implementation. 


\subsubsection{Generic system}

The recommendations for the generic system can be subdivided into two main topics; distributed manufacturing and quality and workflow management.

\section{Distributed Manufacturing}

One of the key aspects that has not been elaborated and tested in this research project is the distributed networked manufacturing capability of the proposed system. The primary focus during the development has been the creation of a functional manufacturing environment. The server and production environments of both case studies have, however, been established separately from each other, indicating the possibility to operate independently from each other without the need for direct mutual influence. However, the practical distributed networked aspects of the implementation still have to be established and tested. The main requirements for approaching this aspect lie in addressing additional production environments as well as in the operation of the applications discs for Planning and Scheduling, and Purchasing. The functionalities of the planning and scheduling functional modules require updating to allow for addressing multiple production locations. The purchasing application disc requires an update in order to incorporate the local procurement possibilities for each production location. For layered manufacturing, this hardly is an impediment in implementation and testing. The only explicit potential issue in layered manufacturing is adjusting the planning and scheduling functional module to serve multiple production locations. Due to the fact that no direct purchasing is required for the production of a printed product, there no need to closely co-operate with local suppliers. Milling could pose more difficulties as the operation of an additional production location is also dependent on the local procurement possibilities for raw materials. Close cooperations with suppliers may prevent from needless indistinctnesses.

\section{Quality and Workflow Integration}

Obviously, additional improvements can be made in the integration of quality and workflow management of the system. In its current actualisation, the workflows are captured in the operating procedures and work instructions infused by quality management. The workflows are flexible and adaptive but these capabilities can be improved by (further) digitalising the workflow management system. The workflows and their sequencing can then be adapted more easily and an environment can be realised where quality management directly constructs the workflow for order completion based on its quality requirements, instead of in the traditional prescribed and predefined manner.

\subsubsection{CNC Worknet}

In order to close or reduce the gap that still exist between the envisaged supply chain and the present mode of conduct in $\mathrm{CNC}$ Worknet emphasis should be given to the following topics.

\section{Continuous Improvement}

The continuous improvement activities employed as part of the system within CNC Worknet should be continued. Even more, attention should shift from setting up the system to accepting the current system as the basis for future development. Through continuous improvement activities CNC Worknet identifies its opportunities for improvement, consequently the overall functioning of CNC Worknet will become more efficient and effective, resulting in a system that gets more competitive. Additionally, continuous improvement is an excellent manner 
of unremittingly assessing the current working methods, thus staying alert as concerns inconsistencies, loopholes and shortcomings.

Workflow Management

The workflows within CNC Worknet are currently managed through the employment of paper based operating procedures and work instructions. The drawback of this is that operators are able to circumvent and decelerate these procedures. A prototype implementation of a digitalised workflow management system was tested for the layered manufacturing implementation [see section 7.2.1]. Implementing this workflow management system and aligning the user interface with the functional requirements imposed by the system will result in a more structured and transparent process consisting of many simplified activities that are less error-prone. Consequently, the processes of CNC Worknet will operate more predictable and effective.

\section{Franchise Organisation}

Until now, no formal franchising organisation has emerged for CNC Worknet as part of the distributed manufacturing network. All required expansions of the production capacity has been achieved through the acquisition of additional production equipment. However, to better serve its international customers, it is definitely recommended that CNC Worknet expands its production capacity through the inclusion of additional production locations. Whether these are initiated from within CNC Worknet, or join the franchise from an external position is open for discussion. The franchise model allows CNC Worknet to penetrate the market faster and improve the logistics without the need for large investments; however CNC Worknet will have to closely guard the contents of their business model to prevent the education of its competitors.

\section{Business Administration}

The functional modules of the business administration application disc related to accounting and financial control are responsible for the administrative and financial activities of $\mathrm{CNC}$ Worknet [see section 6.2.2]. Currently, they are operated in an off-the-shelf administrative application. Its operation requires a lot of manual manipulation of data as the interfaces are not yet fully integrated in the architecture of CNC Worknet. A considerable increase in efficiency can be achieved by properly realising this interface. This is considered to be a straightforward and uncomplicated task; however; as it does not directly contribute to the research in this project, no extensive efforts have been invested in this direction.

\section{Manufacturing Techniques}

Currently, CNC Worknet merely employs layered manufacturing for the production of its products. The milling implementation of CNC Worknet was seized after the bankruptcy. It is foreseen that CNC Worknet will eventually expand its range of manufacturing techniques again. However, before this expansion, it is recommended that CNC Worknet first matures its current layered manufacturing implementation, both as concerns organisational controllability and reproducibility of the workflow(s). Once this implementation is working entirely according to the envisaged supply chain, it will be straightforward to expand and implement it for additional manufacturing techniques. The main requirement for such an 
expansion is that the process planning functionality of the manufacturing technique can be incorporated in the architecture.

\subsection{Closing Remarks}

In short, the design and implementation of the manufacturing system that has been realised for CNC Worknet has shown the feasibility to meet the essential needs that were imposed at the beginning of this project. In addition, the process of developing the manufacturing system has in itself contributed to much more insight in the essence of the system and the related system requirements. As a result, many functionalities, understandings and approaches have been developed that together surpass the initial problem formulation, resulting in a system that does justice to the theoretical ambition that initiated the research project on the supply chain that underlies CNC Worknet. As mentioned, not all functionalities have been realised to their fullest extent, but the structure and architecture of the system have shown their aptness, flexibility and responsiveness in industrial practice. While there is ample room for improvements and extensions, the developed manufacturing system meets the (un) foreseen eventualities in practice. As such, the result is considered to be a sound basis for wellstructured, effective and efficient extension of the system, both as concerns the embedded functionality as well as concerns the industrial environment and types of production processes that are addressed. 


\section{References}

[247tailorsteel, 2011]

Retrieved 22 Augustus, 2011, from www.247tailorsteel.com

\section{[Ahn et al., 2007]}

Ahn, D., Kim, H., Lee, S. (2007). "Fabrication direction optimization to minimize postmachining in layered manufacturing." International Journal of Machine Tools and Manufacture, Vol.47(3-4): 593-606

\section{[Akkermans et al., 2003]}

Akkermans, H.A., Bogerd, P., Yücesan, E., Wassenhove, L.N. van (2003). “The impact of ERP on supply chain management: Exploratory findings from a European Delphi study." European Journal of Operational Research, 146: 284-301

\section{[Alexander et al., 1998]}

Alexander, P., Allen, S., Dutta, D. (1998). "Part orientation and build cost determination in layered manufacturing." Computer-Aided Design, Vol.30(5): 343-356

\section{[Alvares \& Ferreira, 2008]}

Alvares, A.J., Ferreira, J.C.E. (2008). "A system for the design and manufacture of feature-based parts through the Internet." International Journal of Advanced Manufacturing Technology, Vol.35: 646-664

\section{[Amaitik \& Kilic, 2007]}

Amaitik, S.M., Kilic, S.E. (2007). "An intelligent process planning system for prismatic parts using STEP features.” International Journal of Advanced Manufacturing Technology, Vol.31: 978-993

\section{[Arentsen et al., 1996]}

Arentsen, A.L. (1996). "The integration of quality control and shop floor control." International Journal of Computer Integrated Manufacturing, Vol.9(2): 113-130

\section{[Arentsen, 1995]}

Arentsen, A.L. (1995). “A generic architecture for factory activity control.” PhD. Thesis, University of Twente, Enschede, ISBN 9090086609

\section{[Bansal et al., 2008]}

Bansal, S., Nagarajan, S., Reddy, V.N. (2008). "An integrated fixture planning system for minimum tolerances." International Journal of Advanced Manufacturing Technology, Vol.38: 501-513

\section{[Basu \& Blanning, 2000]}

Basu, A., Blanning, R.W. (2000). “A Formal Approach to Workflow Analysis” Information Systems Research, Vol.11(1): 17-36

\section{[Basu \& Kumar, 2002]}

Basu, A., Kumar, A. (2002). "Research Commentary: Workflow Management Issues in eBusiness” Information Systems Research, Vol.13(1): 1-14 
[Bessant et al., 1994]

Bessant, J., Levy, P., Sang, B., Lamming, R. (1994). "Managing successful total quality relationships in the supply chain" European Journal of Purchasing and Supply Management, Vol.1(1): 7-17

\section{[Boër et al., 1990]}

Boër, C.R., Petitti, M., Lombardi, F., Simon, J.-P. (1990). “A CAPP/CAM Expert System for a High Productivity, High Flexibility CNC Turning Center." CIRP Annals - Manufacturing Technology, Vol.39(1): 481-483

\section{[Brinke, 2002]}

Brinke, E. (2002). "Costing support and costing control in manufacturing." PhD. Thesis, University of Twente, Enschede; ISBN 9036517265

\section{[Brombacher et al., 2001]}

Brombacher, A.C. Graef, M.R. De; Ouden, E. Den; Minderhoud, S., Lu, Y. (2001). "Invloed van trends op productontwikkeling en op bedrijfszekerheid." Stichting Toekomst Beeld der Techniek, STT64: 54-71

\section{[Bruccoleri et al., 2005]}

Bruccoleri, M., Lo Nigro, G., Perrone, G., Renna, P., Noto La Diega, S. (2005). "Production planning in reconfigurable enterprises and reconfigurable production systems." CIRP Annals - Manufacturing Technology, Vol.54(1): 433-436

\section{[Butala \& Sluga, 2006]}

Butala, P., Sluga, A. (2006) "Autonomous Work Systems in Manufacturing Networks" CIRP Annals - Manufacturing Technology, Vol.55(1): 521-524

\section{[Byun \& Lee, 2006]}

Byun, H.-S., Lee, K.H. (2006). "Determination of the optimal build direction for different rapid prototyping processes using multi-criterion decision making." Robotics and Computer-Integrated Manufacturing, Vol.22(1): 69-80

\section{[Cagan et al., 2002]}

Cagan, J., Shimada, K., Yin, S. (2002). "A survey of computational appraoches to threedimensional layout problems." Computer-Aided Design, Vol.34(8): 597-611

\section{[Campanella, 1999]}

Campanella, J. (1999). “Principles of Quality Costs.” ASQ Quality Press, Milwaukee; ISBN: 087389443x

\section{[Candido et al., 2009]}

Candido, G., Barata, J., Colombo, A.W., Jammes, F. (2009). "SOA in reconfigurable supply chains: A research roadmap." Engineering Applications of Artificial Intelligence, Vol.22(6): 939-949

\section{[Cardoso et al., 2002]}

Cardoso, J., Sheth, A., Kochut, K. (2002) "Implementing QoS Management for Workflow Systems” Technical Report, UGA-CS-TR-02-003

\section{[Cardoso et al., 2004]}

Cardoso, J., Bostrom, R.P., Sheth, A. (2004). "Workflow Management Systems and ERP Systems: Differences, Commonalities, and Applications." Information Technology and Management, Vol.5(3-4): 319-338 
[Carpenter \& Maropoulos, 2000]

Carpenter, I.D., Maropoulos, P.G. (2000). "A flexible tool selection decision support system for milling operations.” Journal of Materials Processing Technology, Vol.107(1-3): $143-152$

\section{[Chan \& Chung, 2002]}

Chan, M.F.S., Chung, W.W.C. (2002). "A framework to develop an enterprise information portal for contract manufacturing." International Journal of Production Economics, Vol.75(1-2): 113-126

\section{[Chapman \& Petersen, 2000]}

Chapman, L., Petersen, M. (2000). "Demand Activated Manufacturing Architecture (DAMA). Model for supply chain Collaboration." International Conference on Modeling and Analysis of Semiconductor Manufacturing

[Chase et al., 2004]

Chase, R.B., Jacobs, F.R., Aquilano, N.J. (2004). “Operations Management for Competitive Advantage.” McGraw - Hill, New York, ISBN 0072506369

\section{[Chen et al., 2007]}

Chen, M., Zhang, D., Zhou, L. (2007). "Empowering collaborative commerce with web services enabled business process management systems." Decision Support Systems, Vol.43(2): 530-546

\section{[Cheng et al., 2008]}

Li, C., Gao, J.-M., Chen, F.-M. (2008). "Integrated quality system based on quality workflow for equipment manufacturing enterprise." International Conference on Information and Automation

\section{[Chin et al., 2006]}

Chin, K.-S., Duan, G., Tang, X. (2006). “A computer-integrated framework for global quality chain management." International Journal of Advanced Manufacturing Technology, Vol.27(5-6): 547-560

\section{[Chisholm, 1990]}

Chisholm, A.W.J. (1990). "Nomenclature and definitions for manufacturing systems." Annals of the CIRP, Vol.39(2): 735-742

\section{[Christopher, 2000]}

Christopher, M. (2000). “The Agile Supply Chain: Competing in Volatile Markets.” Industrial Marketing Management, Vol.29(1): 37-44

[Chung et al., 2003]

Chung, P.W.H., Cheung, L., Stader, J., Jarvis, P., Moore, J., Macintosh, A. (2003). "Knowledge-based process management -an approach to handling adaptive workflow." Knowledge-Based Systems, Vol.16: 149-160

\section{[Contini \& Tolio, 2004]}

Contini, P., Tolio, T. (2004). “Computer-aided set-up planning for machining centres configuration.” International Journal of Production Research, Vol.42(17): 3473-3491

\section{[Cooper \& Kaplan, 1988]}

Cooper, R., Kaplan, R.S. (1988). “Measure Costs Right: Make the Right Decisions.” Harvard Business Review, September 1988 
[Crainic et al., 2007]

Crainic, T.G., Perboli, G., Tadei, R. (2008). "Extreme Point-Based Heuristics for ThreeDimensional Bin Packing." INFORMS Journal on Computing, Vol.20(3): 368-384

[CSCMP, 2010]

Retrieved 11 October, 2011, from http://cscmp.org/aboutcscmp/definitions.asp

[Dam \& Lutters, 2010]

Dam, D.C. Ten; Lutters, D. (2010). "An Approach to Workflow Based Quality Management.” 43rd CIRP Conference on Manufacturing Systems

[Dam et al, 2009]

Dam, D.C. Ten; Anema, H.F.A., Houten, F.J.A.M. Van; Lutters, D. (2009). “CNC Worknet: a network of flexible production plants." 42nd CIRP Conference on Manufacturing Systems

\section{[Das, 2011]}

Das, K. (2011). "A quality integrated strategic level global supply chain model.” International Journal of Production Research, Vol.49(1): 5-31

\section{[Denkena et al., 2007]}

Denkena, B., Shpitalni, M., Kowalski, P., Molcho, G., Zipori, Y. (2007). “Knowledge management in process planning. " CIRP Annals - Manufacturing Technology, Vol.56(1): 175180

\section{[Dewhurst et al., 1999]}

Dewhurst, F., Lorente, A.R.M., Dale, B.G. (1999). “Total quality management and information technologies: an exploration of the issues." International Journal of Quality \& Reliability Management, Vol.16(4): 392-405

\section{[D'Souza, 2006]}

D’Souza, R.M. (2006). “On setup level tool sequence selection for 2.5-D pocket machining." Robotics and Computer-Integrated Manufacturing, Vol.22: 256-266

\section{[Emachineshop, 2011]}

Retrieved 11 November, 2011, from www.emachineshop.com

\section{[Esprit, 2009]}

Retrieved Feb 1, 2009, from www.dptechnology.com

[Fan et al., 2005]

Fan, Y., Huang, C., Wang, Y., Zhang, L. (2005). "Architecture and operational mechanisms of networked manufactuirng integration platform." International Journal of Production Research, Vol.43(12): 2615-2629

\section{[Faneker, 2011]}

Faneker, T. (2011). "Nesting of 3D complex shaped objects." Master Thesis, University of Twente

\section{[Fisher, 1997]}

Fisher, M.L. (1997). "What is the right supply chain for your product?” Harvard Business Review 
[Foster Jr. \& Ogden, 2008]

Foster JR, S.T., Ogden, J. (2008). "On differences in how operations and supply chain managers approach quality management." Internation Journal of Production Research, Vol.46(24): 6945-6961

[Foster Jr., 2008]

Foster JR, S.T. (2008). “Towards an understanding of supply chain quality management.” Journal of Operations Management, Vol.26: 461-467

[Gaoliang et al., 2005a]

Gaoliang, P., Wenjian, L., Yanhai, C. (2005). “An intelligent system of setup planning on Internet for metal cutting." IEEE International Conference on Mechatronics

[Gaoliang et al., 2005b]

Gaoliang, P., Wenjian, L., Zhang, X. (2005). "An Internet-Based System for Setup Planning in Machining Operations." IEEE International Conference on Engineering of Complex Computer Systems

\section{[Geelink et al., 1995]}

Geelink, R., Salomons, O.W., Slooten, F., Houten F.J.H. Van; Kals, H.J.J. (1995). “Unified feature definition for feature based design and feature based manufacturing." ASME Conference on Computers in Engineering

\section{[Georgakopoulos et al., 1995]}

Georgakopoulos, D., Hornick, M., Sheth, A. (1995). “An Overview of Workflow Management: From Process Modeling to Workflow Automation Infrastructure." Distributed and Parallel Databases, Vol.3: 119-153

[George \& Robinson, 2003]

George, J.A., Robinson, D.F. (1980). "A heuristic for packing boxes into a container." Computers \& Operations Research, Vol.7(3): 147-156

[Giebels, 2000]

Giebels, M.M.T. (2000). "EtoPlan; a concept for concurrent manufacturing planning and control.” Phd. Thesis, University of Twente, Enschede, ISBN 9036514533

[Goldrath, 1999]

Goldratt, E.M. (1999). “De zwakste schakel." Uitgeverij het Spectrum, Utrecht, ISBN 9789027466549

[Grabowik \& Knosala, 2003]

Grabowik, C., Knosala, R. (2003). "The method of knowledge representation for a CAPP system.” Journal of Materials Processing Technology, Vol.133: 90-98

\section{[Gunasekaran etal., 2008]}

Gunasekaran, A., Lai, K.-H., Cheng, T.C.E. (2008). "Responsive supply chain: A competitive strategy in a networked economy." Omega, Vol.36(4): 549-564

\section{[Gupta \& Galloway, 2003]}

Gupta, M., Galloway, K. (2003). "Activity-based costing/management and its implications for operations management.” Technovation, Vol.23: 131-138 
[Gupta \& Kohli, 2006]

Gupta, M., Kohli, A. (2006). "Enterprise resource planning systems and its implications for operations function.” Technovation, Vol.26: 687-696

\section{[Hong \& Huo, 2010]}

Hong, Z.-S., Huo, J.-Z. (2010). “Applying quality function deployment to qualilty management of product service system." IEEE International Conference on Industrial Engineering and Engineering Management

\section{[Horváth, 2012]}

Horvath, I. (2012). "Recent developments in computer supported cooperative work in design: From group collaboration through global connectivity to informing apobetics." IEEE 16th International Conference on Computer Supported Cooperative Work in Design

\section{[Houten \& Erve, 1992]}

Houten, F.J.A.M. van; Erve, A.H. van 't (1992) "PART, a feature based computer aided process planning system" International Journal of CAD/CAM and Computer Graphics, Vol.7(3): 335-368

\section{[Houten, 1992 ]}

Houten, F.J.A.M. Van. (1992). "Manufacturing Interfaces." Annals of the CIRP, Vol.41(2): 699-710

\section{[Hussain et al., 2009]}

Hussain, Z., Barber, K., Hussain, N. (2009). "An Intranet based system as an enabler in effective project management and implementation of quality standards: A case study." Journal of Engineering and Technology Management, Vol.26: 196-210

[ISO, 2005]

ISO. (2005). "Quality Management Systems - Fundamentals and vocubulary." www.iso.org

\section{ISO, 2011]}

Retrieved 31 October, 2011 from www.ISO.org

\section{[Jiang \& Fukuda, 2001]}

Jiang, P.-Y., Fukuda, S. (2001). “TeleRP -an Internet web-based solution for remote rapid prototyping service and maintenance." Interational Journal of Computer Integrated Manufacturing, Vol.14(1): 83-94

[Jiang et al., 2007]

Jiang, P.-Y., Zhou, G.-H., Zhao, G., Zhang, Y.-F., Sun, H.-B. (2007). "e2-MES: an e-servicedriven networked manufacturing platform for extended enterprises." International Journal of Computer Integrated Manufacturing, Vol.20(2-3): 127-142

\section{[JobDispo, 2009]}

Retriebed 20 October, 2011, from www.jobdispo.de

\section{[Kalpakjian \& Schmid, 2006]}

Kalpakjian, S., Schmid, S.R. (2006). "Manufacturing Engineering and Technology." Pearson Prentice Hall, Upper Saddle River, ISBN 0131489658

\section{[Karabulut \& Inceoglu, 2004]}

Karabulut, K., Inceoglu, M.M. (2004). "A hybrid genetic algorithm for packing in 3d with deepest bottom left with fill method." International Conference on Advances in Information Systems 
[Kim \& Lee, 2005]

Kim, H.-C., Lee, S.-H. (2005). "Reduction of post-processing of stereolithography systems by fabrication-direction optimization." Computer-Aided Design, Vol.37(7): 711-725

[Kim \& Smari, 2005]

Kim, S., Smari, W.W. (2005). "On a collaborative commerce framework and architecture for next generation commerce." International Symposium on Collaborative Technologies and Systems

\section{[Kirkpatrick et al., 1983]}

Kirkpatrick, S., Gelatt, C.D., Vecchi, M.P. (1983). “Optimization by Simulated Annealing.” Science, Vol.220(4598)

[Klenz \& Fulenwider, 1999]

Klenz, B.W., Fulenwider, D.O. (1999). “The Quality Data Warehouse: Solving Problems for the Enterprise.” SUGI Proceedings, Paper 142

\section{[Kovacs \& Mezgar, 1998]}

Kovacs, G.L., Mezgar, I. (1998). "A distributed planning network for manufacturing systems management." IEEE International Conference on Robotics and Automation

\section{[Kuei et al., 2002]}

Kuei, C.-H., Madu, C.N., Lin, C., Chow, W.S. (2002). “Developing supply chain strategies based on the survey of supply chain quality and technology management." International Journal of Quality \& Reliability Management, Vol.19(2): 889-901

\section{[Kulkarni \& Dutta, 1993]}

Kulkarni, P., Dutta, D. (1996). "An accurate slicing procedure for layered manufacturing." Computer-Aided Design, Vol.28(9): 683-697

\section{[Kwon \& Rauniar, 2007]}

Kwon, Y., Rauniar, S. (2007). "E-Quality for Manufacturing (EQM) Within the Framework of Internet-Based Systems." IEEE Transactions on Systems, Man, and Cybernetics, Part C: Applications and Reviews, Vol.37(6): 1365-1372

\section{[Laframboise \& Reyes, 2005]}

Laframboise, K., Reyes, Felipe. (2005). “Gaining Competitive Advantage From Integrating Enterprise Resource Planning and Total Quality Management.” The Journal of Supply Chain Management, Summer 2005: 49-64

[Lai, 2005]

Lai, L.F. (2007). “A knowledge engineering approach to knowledge management." Information Sciences, Vol.177: 4072-4094

\section{[Lan et al., 1997]}

Lan, P.-T., Chou, S.-Y., Chen L.-L., Gemmill, D. (1997). “Determining fabrication orientations for rapid prototyping with Stereolithography apparatus." Computer-Aided Design, Vol.29(1): 53-62

\section{[Lee \& Lee, 2007]}

Lee, Y.-C., Lee, S.-K. (2007). “Capabilities, Processes, and Performance of Knowledge Management: A Structural Approach." Human Factors and Ergonomics in Manufacturing, Vol.17(1): 21-41 
[Lee et al., 2007]

Lee, H.C., Jhee, W.C., Park, H.-S. (2007). “Generative CAPP through projective feature recognition.” Computers \& Industrial Engineering, Vol.53: 241-246

[Lee, 2003]

Lee, C.Y. (2003). “Total manufacturing information system: a conceptual model of a strategic tool for competitive advantage." Integrated Manufacturing Systems, Vol.14(2): 114122

[Li \& Fan, 2003]

Li, W., Fan, Y. (2003). "Development of ERP systems based on workflow management system." Proceedings of the Third International Conference on Electronic Commerce, 981-984

[Li et al., 2008]

Li, L., Markowski, C., Xu, L., Markowski, E. (2008). “TQM -A predecessor of ERP implementation.” International Journal of Production Economics, Vol.115: 569-580

[Li et al., 2010]

Li, B.-H., Zhang, L., Wang, S.-L., Tao, F., Cao, J.-W., Jiang, X.-D., Song, X, Chai, X.-D. (2010). "Cloud manufacturing: a new service oriented networked manufacturing model." Computer Integrated Manufacturing Systems

[Lutters et al., 1999]

Lutters, D., Wijnker, T.C., Kals, H.J.J. (1999). "Information Management in Process Planning." CIRP Annals, Vol.48(1): 385-388

[Lutters et al., 2012]

Lutters, D., Dam, D.C. Ten; Faneker, T. (2012). “3D nesting of complex shapes." 45th CIRP Conference on Manufacturing Systems

\section{[Lutters, 2001]}

Lutters, D. (2001). "Manufacturing integration based on information management." PhD. Thesis, University of Twente, Enschede, ISBN 9036515831

[Mahesh et al., 2007]

Mahesh, M., Ong, S.K., Nee, A.Y.C. (2007). “A web-based multi-agent system for distributed digital manufacturing." International Journal of Computer Integrated Manufacturing, Vol.20(1): 11-27

[Malek et al., 1998]

Abdel-Malek, L.L., Wolf, C., Guyot, P.D. (1998). “Telemanufacturing: A flexible manufacturing solution.” International Journal of Production Economics, Vol.56-57: 1-12

\section{[Martello et al., 2000]}

Martello, S., Pisinger, D., Vigo, D. (2000). “The Three-Dimensional Bin Packing Problem.” Operations Research, Vol.48(2): 256-267

[Martins et al., 2004]

Martins, A., Ferreira, J.J.P., Mendonça, J.M. (2004). "Quality management and certification in the virtual enterprise." International Journal of Computer Integrated Manufacturing, Vol.17(3): 212-223 
[Masood et al., 2003]

Masood, S.H., Rattanawong, W., Iovenitti, P. (2003. "A generic algorithm for a best part orientation system for complex parts in rapid prototyping." Journal of Materials Processing Technology, Vol.139(1-3): 110-116

[Materialiseonsite, 2011]

Retrieved Nov 22, 2011, from www.materialiseonsite.com

\section{[Mazzola et al., 2009]}

Mazzola, E., Bruccoleri, M., Perrone, G. (2009). "A strategic framework for firm networks in manufacturing industry: An empirical survey." CIRP Annals - Manufacturing Technology, Vol.58: 387-390

[Mc Afee, 2002]

McAfee, A. (2002). “The impact of enterprise information technology adoption on operational performance: an empirical investigation." Production and Operations Management, Vol.11(1): 33-53

\section{[Mezgár et al., 2000]}

Mezgár, I., Kovács, G.L., Paganelli, P. (2000). “Co-operative production planning for small- and medium-sized enterprises." International Journal of Production Economics, Vol.64: 37-48

\section{[Mi et al., 2008]}

Mi, X., Zhao, X., Zhao, W., Fan, W. (2008). "Case Study on Optimization of Rectangular Object Layout by Genetic Algorithm.” Computer Supported Cooperative Work in Design IV, Vol.5236: 608-619

[Mili et al., 2002]

Mili, H., Fayad, M., Brugali, D., Hamu, D., Dori, D. (2002). “Enterprise frameworks: issues and research directions." Software -Practice and Experience, Vol.32: 801-831

[Mourtzis, 2011]

Mourtzis, D. (2011). "Internet based collaboration in the manufacturing supply chain." CIRP Journal of Manufacturing Science and Technology, Vol.4(3): 296-304

\section{[Musliu, 2011]}

Retrieved Nov 29, 2011, from http://www.dbai.tuwien.ac.at/staff/musliu/ProblemSolvingAI/Class7TabuSearch.pdf

[Newman et al., 2008]

Newman, S.T., Nassehi, A., Xu, X.W., Rosso Jr., R.S.U., Wang, L., Yusof, Y., Ali, L., Liu, R., Zheng, L.Y., Kumar, S., Vichare, P., Dhokia, V. (2008). "Strategic advantages of interoperability for global manufacturing using CNC technology." Robotics and ComputerIntegrated Manufacturing, Vol.24: 699-708

\section{[Nijholt, 2010]}

Nijholt, J. (2010). "Workflow modeling for business process automation." Master Thesis, University of Twente

\section{[Ning et al., 2011]}

Ning, F., Zhou, W., Zhang, F., Yin, Q., Ni, X. (2011). “The architecture of cloud manufacturing and its key technologies research.” IEEE International Conference on Cloud Computing and Intelligence Systems 
[Pandy et al., 2003]

Pandey, P.M., Reddy, N.V., Dhande, S.G. (2003). "Improvement of surface finish by staircase machining in fused deposition modeling." Journal of Materials Processing Technology, Vol.132(1-3): 323-331

[Pandy et al., 2004]

Pandey, P.M., Thrimurthulu, K., Reddy, N.V. (2004). “Optimal part deposition orientation in FDM by using a multicriteria genetic algorithm." International Journal of Production Research, Vol.42(19): 4069-4089

[Park, 2003]

Park, S.C. (2003). "Knowledge capturing methodology in process planning." ComputerAided Design, Vol.35: 1109-1117

[Patil \& Pande, 2002]

Patil, L., Pande, S.S. (2002). "An intelligent feature-based process planning system for prismatic parts." International Journal of Production Research, Vol.40(17): 4431-4447

[Pham et al., 1999]

Pham, D.T., Dimov, S.S., Gault, R.S. (1999). "Part Orientation in Stereolithography." The International Journal of Advanced Manufacturing Technology, Vol.15(9): 674-682

[Ray \& Jones, 2006]

Ray, S.R., Jones, A.T. (2006). "Manufacturing interoperability." Journal of Intelligent Manufacturing, Vol.17: 681-688

[Ribeiro et al., 2009]

Ribeiro, L., Barata, J., Colombo, A. (2009). "Supporting agile supply chains using a serviceoriented shop floor." Engineering Applications of Artificial Intelligence, Vol.22: 950-960

\section{[Rowlands \& Richards, 2002]}

Rowlands, H., Richards, C. (2002). "Modelling of an integrated quality system using IDEF0.” IEEE International Symposium on Industrial Electronics

[Sadiq et al., 2001]

Sadiq, S., Sadiq, W., Orlowska, M. (2001). "Pockets of Flexibility in Workflow Specification.” Conceptual Modeling - ER2001: 513-526

\section{[Salehi \& Tavakkoli-Moghaddam, 2009]}

Salehi, M., Tavakkoli-Moghaddam, R. (2009). "Application of genetic algorithm to computer-aided process planning in preliminary and detailed planning." Engineering Applications of Artificial Intelligence, Vol.22: 1179-1187

[Scholz-Reiter et al., 2010]

Scholz-Reiter, B., Frazzon, E.M., Makuschewitz, T. (2010). "Integrating manufacturing and logistic systems along global supply chains." CIRP Journal of Manufacturing Science and Technology, Vol.2(3): 216-223

[Senkul \& Toroslu, 2005]

Senkul, P., Toroslu, I.H. (2005). "An architecture for workflow scheduling under resouce allocation constraints." Information Systems, Vol.30: 399-422

[Shapeways, 2011]

Retrieved Nov 8, 2011, from www.shapeways.com 
[Shen et al., 2006]

Shen, W., Wang, L., Hao, Q. (2006). “Agent-Based Distributed Manufacturing Process Planning and Scheduling: A State-of-the-Art Survey." IEEE Transactions on Systems, Man, and Cybernetics, Part C: Applications and Reviews, Vol.36: 563-577

[Shen et al., 2007]

Shen, W., Hao, Q., Wang, S., Li, Y., Ghenniwa, H. (2007). “An agent-based service-oriented integration architecture for collaborative intelligent manufacturing." Robotics and Computer-Integrated Manufacturing, Vol.23: 315-325

\section{[Smith \& Wright, 1996]}

Smith, C.S., Wright, P.K. (1996). “CyberCut: A World Wide Web Based Design-to-Fabrication Tool.” Journal of Manufacturing Systems, Vol.15(6): 432-442

[Soltani et al., 2011]

Soltani, E., Azadegan, A., Liao, Y.-Y., Phillips, P. (2011). “Quality performance in a global supply chain: finding out the weak link." International Jounal of Production Research, Vol.49(1): 269-293

\section{[Sroufe \& Curkovic, 2008]}

Sroufe, R., Curkovic, S. (2008). "An examination of ISO 9000:2000 and supply chain quality assurance." Journal of Operations Management, Vol.26: 503-520

\section{[Swafford et al., 2008]}

Swafford, P.M., Ghosh, S., Murthy, N. (2008). "Achieving supply chain agility through IT integration and flexibility." International Journal of Production Economics, Vol.116(2): 288-297

[Talbi, 2002]

Talbi, E.-G. (1999). “A Taxonomy of Hybrid Metaheuristics.” Journal of Heuristics, Vol.8: 541-564

\section{[Tang \& Duan, 2006]}

Tang, X., Duan, G. (2006). "Integrated Quality Information System and China Experience." Knowledge Enterprise: Intelligent Strategies in Product Design, Manufacturing, and Management, Vol.207: 54-61

\section{[Tang \& Lu, 2002]}

Tang, X.-Q., Lu, Q.-L. (2002). “Intranet/Extranet/Internet-Based Quality Information Management System in Expanded Enterprises.” International Journal of Advanced Manufacturing Technology, Vol.20: 853-858

[Tang et al., 2007]

Tang, X., Duan, G., Chin, K.-S. (2007). "Development and implementation of an integrated quality information system -a China experience.” International Journal of Advanced Manufacturing Technology, Vol.32: 608-616

\section{[Tarantilis et al., 2008]}

Tarantilis, C.D., Kiranoudis, C.T., Theodorakopoulos, N.D. (2008). “A Web-based ERP system for business services and supply chain management: Application to real-world process scheduling." European Journal of Operational Research, Vol.187: 1310-1326 
[Thompson \& Crawford, 1995]

Thompson, D.C., Crawford, R.H. (1995). “Optimizing part quality with orientation.” 6th Solid Free Form Symposium

[Tompkins et al., 2003]

Tompkins, J.A., White, J.A., Bozer, Y.A., Tanchoco, J.M.A. (2003). "Facilities Planning." John Wiley \& Sons, Inc., Hoboken, ISBN 0471413895

[Tönshoff et. Al., 1993]

Tönshoff, H.K., Kreutzfeldt, J., Hofschneider, D. (1993). “Concurrent process planning and workshop control in batch production - load oriented process planning." Manufacturing Systems, Vol.22(3): 231-241

[Ugarte et al., 2009]

Ugarte, B.S. De; Artiba, A., Pellerin, R. (2009). "Manufacturing execution system - a literature review." Production Planning \& Control: The Management of Operations, Vol.20(6): 525-539

\section{[Ullah \& Harib, 2006]}

Ullah, A.M.M.S., Harib, K.H. (2006). "A human-assisted knowledge extraction method for machining operations." Advanced Engineering Informatics, Vol.20: 335-350

[Vancza et al., 2008]

Váncza, J., Egri, P., Monostori, L. (2008). “A coordination mechanism for rolling horizon planning in supply networks." CIRP Annals - Manufacturing Technology, Vol.57: 455-458

[Vancza et al., 2011]

Váncza, J., Monostori, L., Lutters, D., Kumara, S.R., Tseng, M., Valckenaers, P., Brussel, H. Van. (2011). "Cooperative and responsive manufacturing enterprises." CIRP Annals, Vol.60(2): 797-820

\section{[Verma \& Rajotia, 2010]}

Verma, A.K., Rajotia, S. (2010). "A review of machining feature recognition methodologies." International Journal of Computer Integrated Manufacturing, Vol.23(4): 353-368

[Wallace \& Kremzar, 2001]

Wallace, T.F., Kremzar, M.H. (2001). “ERP: Making it happen: The implementers' guide to success with enterprise resource planning." Wiley, ISBN 0471392014

[Wang \& Shen, 2003]

Wang, L., Shen, W. (2003). "DPP: An agent-based approach for distributed process planning." Journal of Intelligent Manufacturing, Vol.14: 429-439

\section{[Wang et al., 2006]}

Wang, L., Shen, W., Hao, Q. (2006). “An overview of distributed process planning and its integration with scheduling." International Journal of Computer Applications in Technology, Vol.26(1/2): 3-14

[Wang et al., 2010]

Wang, L., Cai, N., Feng, H.-Y., Ma, J. (2010). "ASP: An Adaptive Setup Planning Approach for Dynamic Machine Assignments." IEEE Transactions on Automation Science and Engineering, Vol.7(1): 2-14 
[Watanabe \& Kaneda, 2004]

Watanabe, S., Kaneda, S. (2004). "Workflow Analysis Method Using Activity-Based Costing Management with Information Allocation." Electronics and Communications in Japan, Vol.87(8): 55-65

[WFMC, 2008 ]

orkflow Management Coalition. (2008). "WFMC-TC-1011 Ver 3 Terminology and Glossary English.”

\section{[Wiendahl, 2002]}

Wiendahl, H.-P., Lutz, S. (2002). "Production in Networks.” CIRP Annals - Manufacturing Technology, Vol.51(2): 573-586

[Wiendahl, 2009]

Wiendahl, H.-P., Elmaraghy, H.A., Nyhuis, P., Zäh, M.F., Wiendahl, H.-H., Duffie, N., Brieke, M. (2007). "Changeable Manufacturing - Classification, Design and Operation." CIRP Annals - Manufacturing Technology, Vol.56(2): 783-809

\section{[Wingard, 1991]}

Wingard, L. (1991). "Introducing form features in product models, a step towards cadcam with engineering technology." Licenciate thesis, Royal insitute of technology, Stockholm

\section{[Wong \& Aspinwall, 2006]}

Wong, K.Y., Aspinwall, E. (2006). "Development of a knowledge management initiative and system: A case study." Expert Systems with Applications, Vol.30: 633-641

[Worley et al., 2002]

Worley, J.H., Castillo, G.R., Geneste, L., Grabot, B. (2002). "Adding decision support to workflow systems by reusable standard software components." Computers in Industry, Vol.49: 123-140

\section{[Xu \& Li, 2008]}

Xu, H.-M., Li, B.-B. (2008). “A meta-modeling paradigm of the manufacturing resources using mathematical logic for process planning." International Journal of Manufacturing Technology, Vol.36: 1022-1031

\section{[Xu et al., 1997]}

Xu, F., Wong, Y.S., Loh, H.T., Fuh, J.Y.H., Miyazawa, T. (1997). “Optimal orientation with variable slicing in stereolithography.” Rapid Prototyping Journal, Vol.3(3): 76-88

\section{[Xu et al., 2009]}

Xu, H.-M., Yuan, M.-H., Li, D.-B. (2009). "A novel process planning schema based on process knowledge customization." International Journal of Manufacturing Technology, Vol.44: 161-172

\section{[Xu, 2011]}

Xu, L.D. (2011). “Information architecture for supply chain quality management.” International Journal of Production Research, Vol.49(1): 183-198

[Xu, 2012]

$\mathrm{Xu}, \mathrm{X}$. (2012). "From cloud computing to cloud manufacturing." Robotics and ComputerIntegrated Manufacturing, Vol.28: 75-86 
[Yang, 2008]

Yang, C.-C. (2008). "Improving the definition and quantification of quality costs." Total Quality Management \& Business Excellence, Vol.19(3): 175-191

[Yew et al., 2000]

Yew, A.B., Kai, C.C., Zhaohui, D. (2000). "Development of an Advisory System for Trapped Material in Rapid Prototyping Parts." The International Journal of Advanced Manufacturing Technology, Vol.16(10): 733-738

\section{[Yin et al., 2000]}

Yin, S., Cagan, J. (2000). “An extended pattern search algorithm for three-dimensional component layout.” Journal of Mechanical Design, Vol.122: 102-108

[You \& Lin, 2005]

You, C.-F., Lin, C.-H. (2005). “Java-based computer-aided process planning." International Journal of Manufacturing Technology, Vol.26: 1063-1070

\section{[Yuru \& Gaoliang, 2005]}

Yuru, Z., Gaoliang, P. (2005). "Development of an integrated system for setup planning and fixture design in CAPP." IEEE/ASME International Conference on Advanced Intelligent Mechatronics 


\section{Appendix 1. Layered Manufacturing Techniques}

\section{SLA}

SLA stands for Stereolithography. This technique makes use of a vat filled with a photosensitive liquid polymer and a moving platform, see figure 11.1. The part under construction is supported by the platform that moves downward by a layer thickness (typically about $0.1 \mathrm{~mm}$ ) for each layer. A laser beam traces out the shape of each layer and hardens the photosensitive resin. After the products are complete they are post-cured to fully cure the resin. Typical for the SLA process is that the finished products show the stepping effect, which means that the building layers stay visible on the parts. Afterwards this can be grinded so that a smooth surface is created. Another characteristic of the SLA process is that supports are needed to make sure the products stays intact. This is because, when the first layers of an overhang of the product are printed, the liquid cannot support these layers. So supports have to be printed starting from the building platform to the desired height.

\section{SLS}

SLS stands for Selective Laser Sintering. In this process a thin layer of powder is placed on top of a moving platform. The powder and the moving platform are positioned in a chamber that is preheated to just below the melt temperature of the powder. A laser melts is used to locally heat the powder to its melt temperature. Hereby the powder is melted together to construct one layer of the product. The platform is then lowered one layer thickness and the whole process is

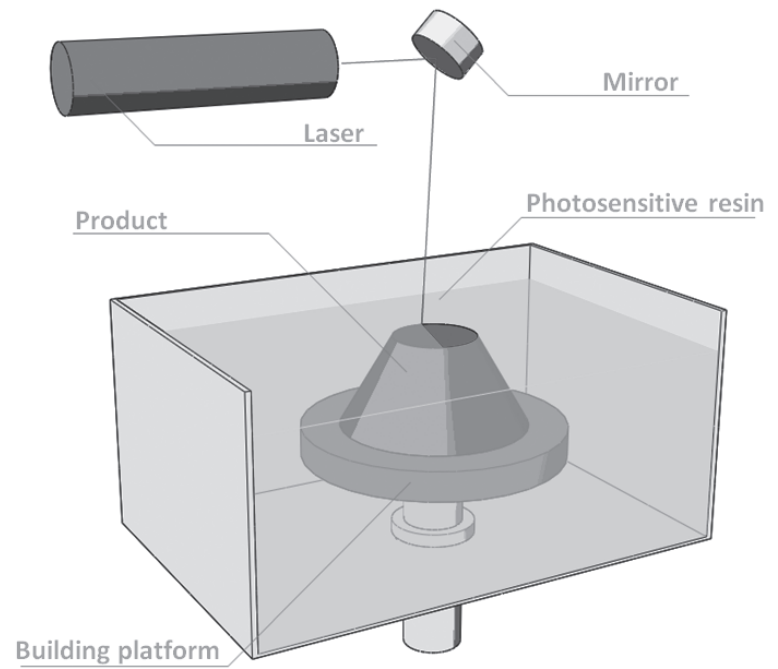

Figure 11.1 SLA Technique

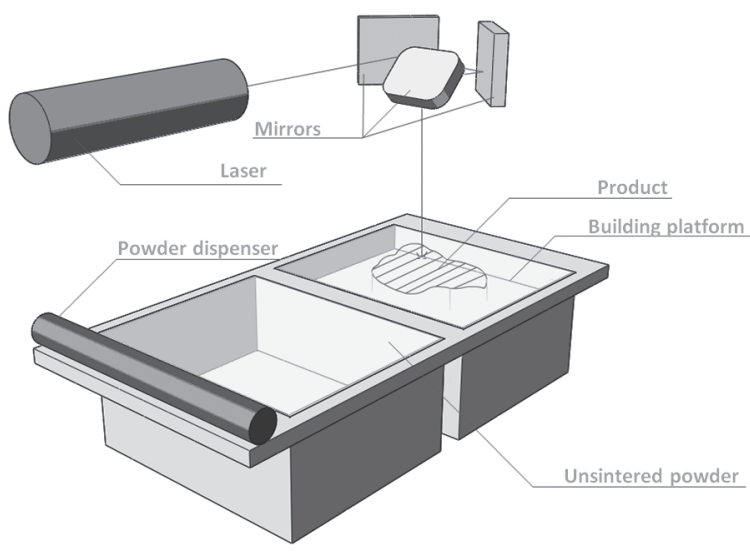

Figure 11.2 SLS Technique 
repeated again. Hereby the product is constructed layer-by-layer. Figure 11.2 illustrates this process. After the built is complete, the powder needs to cool down to become a stable solid product. Unlike SLA, products made by SLS do not have to be post-cured. The products are immediately finished when the tray has cooled down. Another advantage over SLA is that products made by SLS do not need any supports. This is because the unsintered powder on the moving platform acts as a support for the products.

\section{LOM}

LOM is short for Laminated Object Manufacturing. The principle of LOM is to glue layers of material (mostly paper) on top of each other. Before the layer is glued, the sheet which will form the next layer is adhered with a heated roller to ensure it is free of ripples. In the next step, a laser or knife cuts out the contour of the product. Unused areas are crosshatched to be easily removed afterwards. Once the cutting is done the platform, on which the products are build,

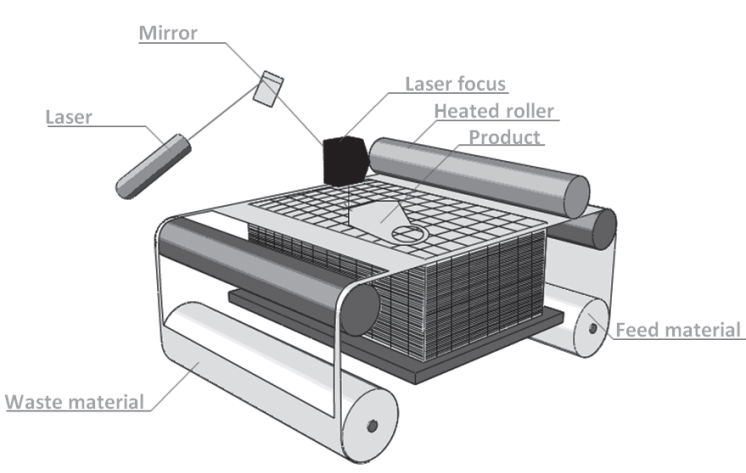

Figure 11.3 LOM Technique is moved down again so that a new layer can be formed. This process is repeated until the products are completed. Figure 11.3 gives an overview of this process. As with SLS, products made by LOM do not need any supports. However, the amount of waste material is high compared to SLA and SLS. It is also very difficult to remove the waste material from cavities within products made by LOM, because of this the design freedom is limited.

\section{FDM}

FDM or Fused Deposition Modeling, consists of heating a filament of thermoplastic polymer and squeezing it out a nozzle to form a layers. The materials include polyester, ABS, elastomers, and investment casting wax. Figure 11.4 illustrates the overall arrangement of the process. Within this process supports are required. Planes can become skewed due to non uniform layer deposition. This layered manufacturing technique is therefore not as accurate as for example SLA or SLS.

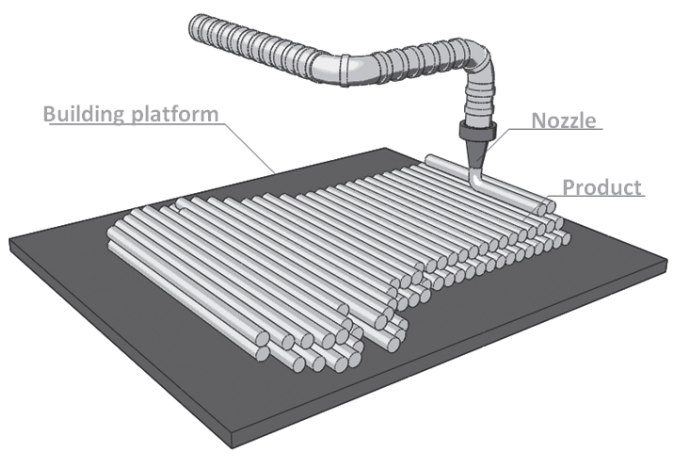

Figure 11.4 FDM Technique 


\section{Ink Jet Printing techniques}

With this layered manufacturing technique ink jet technology is utilised, as used in the printer and plotting industry. Small droplets of liquid-tosolid compound are shot on a surface to form a layer when ink jet printing. This surface is lowered after which the process is repeated again until the product is formed. Figure 11.5 gives an example of an ink jet printing technique. In the figure ink is shot at powder to become a solid. Because of the small droplet size, high accuracy in the parts can be

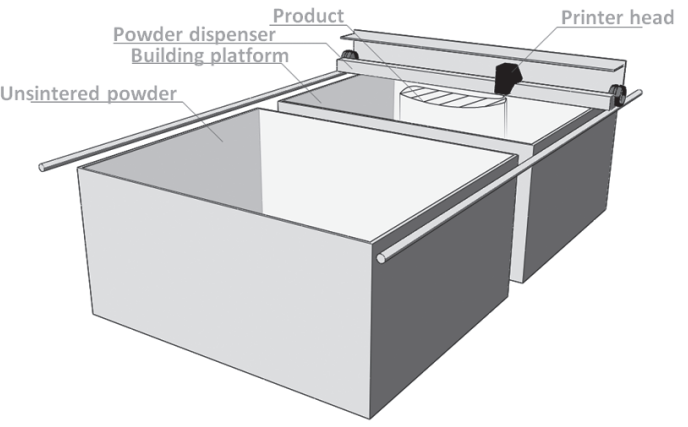

Figure 11.5 Ink Jet Printing Technique established with this technique. However support material is required to support the parts when needed. 


\section{Appendix 2. Application Discs}

\section{Sales Application Disc}

The Sales application disc contains the functional modules that are associated to the sales processes of the CNC Worknet system. Functional modules used for order processing, quote generation and customer relations management are located on this application disc. An overview of the contents of this application disc is given in figure 11.6.

\section{Order Management}

Quotations accepted by the customer are processed by the Order Management functional module. This module initially reviews the quotation accepted by the customer to make sure the contents of the quotation are still valid. Upon acceptance, the

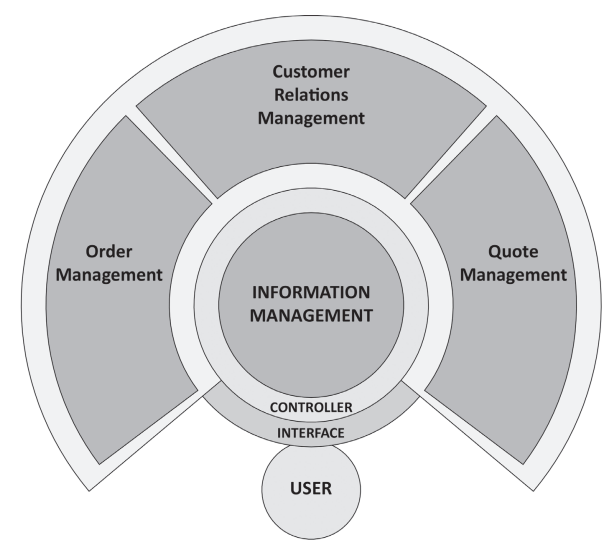

Figure 11.6 Sales Application Disc quotation is registered as an order and an order confirmation is generated and presented to the customer.

Main Functions:

- Order Review

- Order Acceptance

- Order Registration

- Order Confirmation

\section{Customer Relations Management}

Customer relations are managed by this functional module. CRM is the combination of policies, processes, and strategies implemented by CNC Worknet that unify its customer interaction. The CRM module manages the customer data so that these are up-to-date. CRM also checks the creditworthiness of the customers of CNC Worknet. The communication between a customer and CNC Worknet which is performed outside of the portal is tracked and registered by this module.

Main Functions:

- Management of customer data

- Checking customer creditworthiness

- Tracking communication between the system and customer outside portal

- Registering communication between the system and customer outside portal 


\section{Quote Management}

In this functional module the Request for a Quote (RFQ) is transformed into a quotation. The submitted RFQ data is checked for completeness and registered. Different calculation methods are used to generate the quotation. These methods are managed and executed by this functional module. Information needed for performing the methods in Quote Management is collected and requested from the Process Planning, Purchasing and Logistics discs through the Information Management kernel. Upon the generation of a quotation, it is registered and presented to the customer. The reaction of the customer is monitored by the quotation followup function of this module.

Main Functions:

- Check RFQ completeness

- Register RFQ's

- Generate quotations

- Register Quotes

- Manage quote calculation methods

- Quotation follow-up

\section{Process Planning Application Disc (Milling)}

The technical analysis of the submitted products is performed by the Process Planning application disc. Functional modules for model conversion, feature recognition, setup generation, method selection and instruction generation are located on this disc. Together, these modules analyse the submitted products on manufacturability and generate the process plans required for the fabrication of these products in the production environments connected to the network. An overview of the contents of this application disc is given in figure 11.7

\section{Model Conversion \& Completion}

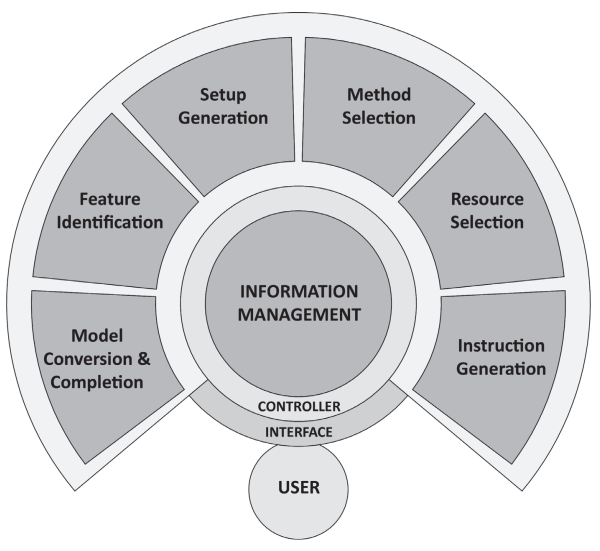

Figure 11.7 Process Planning Application Disc

This function block converts, when needed, the 3D model provided by the customer to a format appropriate and detects and/or corrects any errors in the model. In the case that a customer is not able to provide a $3 \mathrm{D}$ model of the part this functional module will generate (manually) a 3D model.

Main Functions:

- Conversion of TPD to appropriate format

- Detection of model errors

- Correction of model errors

- Creation of 3D model from 2D drawing 


\section{Feature Identification}

This module recognises the different features inside the model and maps them accordingly. The identified features are converted into manufacturing features.

Main Functions:

- Feature recognition

- Feature mapping

- Feature conversion

\section{Setup Generation}

This module determines the different setups and appoints the identified manufacturing features to these setups. The dimensions of the raw material are also determined by this module. This module also determines the positioning of the required setup tools.

Main Functions:

- Raw material dimension determination

- Determination of the required setup(s)

- Appointing manufacturing features to setup(s)

- Determination of the required setup tools

- Determination of the positioning of the required setup tools

- Management of the fixture set

\section{Method Selection}

This functional module attaches manufacturing methods from the knowledge database to the identified manufacturing features by linking features to manufacturing methods.

Main Functions:

- Assigning manufacturing methods to manufacturing features

- Management of the manufacturing methods

- Management of the tool set

\section{Resource Selection}

Based on the identified manufacturing features and setups machines are selected which are able to produce the product. Several machines located at different production locations can be selected for the same product, making the location of production a logistic choice. Due to the fact that the machines located in the production environments have to comply to standards imposed on them by the system, there are not many differences between the machines, making the choice relatively easy.

Main Functions:

- Selecting resources required for production

- Management of the machinery database

\section{Instruction Generation}

Generation of NC-codes, setup instructions, tool lists etc. i.e. all the technical information and data which is needed on the manufacturing floor. This module also calculates the required machining times needed for the production of the parts. These times are required by Quote Management for the generation of the quotation. 
Main Functions:

- Tool path generation

- NC-code creation

- Setup instruction creation

- Tool list creation

- Machining time calculation

\section{Purchasing Applications Disc}

The Purchasing application disc is responsible for the supplier communication and the purchasing operations. It contains the functional modules for supplier relations management and for strategic and operational purchasing. The operational purchasing module purchases the raw materials and tools required for the manufacturing of products. The strategic purchasing module negotiates with suppliers about pricing and delivery agreements. An overview of the contents of this application disc is given in figure 11.8.

\section{Supplier Relations Management}

Supplier relations are managed in this functional module. Supply chain management

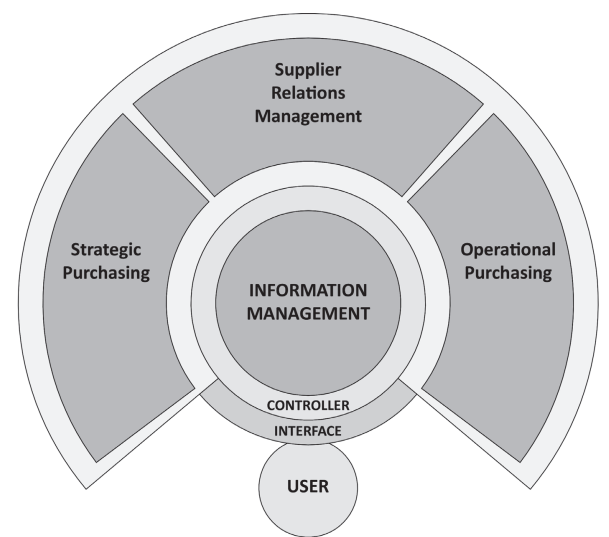

Figure 11.8 Purchasing Application Disc functionalities are also part of this module. This module manages and aligns all the interactions between the system and its suppliers. The results of negotiations performed in strategic purchasing (pricing agreements and delivery time spans) with suppliers are registered by this module. The performance of the suppliers is also tracked by this module.

Main Functions:

- Store supplier data

- Manage approved supplier list

- Update Supplier Scorecard

- Management of pricing agreements (and calculations) with suppliers

- Management of delivery time span agreements with suppliers

\section{Strategic Purchasing}

This functional module handles the strategic purchasing requirements. It negotiates with the different suppliers about fixed delivery time spans, terms and pricing agreements (or calculations). This module acts like an supply chain manager for the supply chain. These functions are performed manually by humans.

Main Functions:

- Supplier pricing negotiations

- Supplier delivery time span negotiations 
- Supplier terms negotiations

\section{Operational Purchasing}

This functional module handles the purchasing requirements which are needed to produce an order. The requirements for purchases are determined based on the information generated by the Process Planning and Logistics discs.

Main Functions:

- Request quotations from suppliers

- Determine purchasing requirements

- Generate purchase orders

- Place purchase orders

- Track purchase orders

\section{Logistics Application Disc}

Functional modules for the planning and scheduling of the production orders are located on the Logistics disc of the architecture. A workflow management module that executes all the workflows is also present on this disc. An overview of the contents of this application disc is given in figure 11.9.

\section{Capacity Planning}

Capacity planning concerns the capacity planning on the machines of the different production environments which are connected to the server environment. The capacity planning in this module considers the planning on the longer run based on

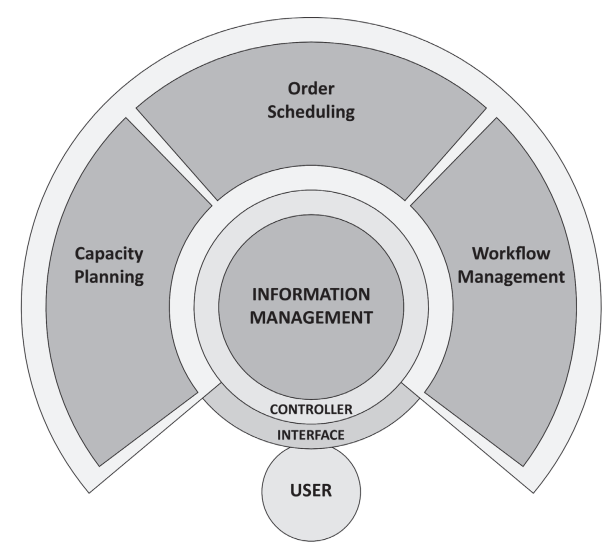

Figure 11.9 Logistics Application Disc expected orders. This module provides the estimated delivery time spans for the quotations which are generated by the Quote Management module.

Main Functions:

- Long term capacity planning

- Determination of delivery time span for quotations

\section{Order Scheduling}

The scheduling of production orders for the machines (or cells) located in the production environment is taken care of by this functional module. This planning is a detailing of the capacity planning into the operational level. The receiving of supplier deliveries and the delivery of products (incl. transportation) to customers or suppliers is also planned in this functional module. Pre-delivery operations like packaging are also planned by this functional module. Depending on the level of automation and speed thereof on the process planning disc these actions might also be planned by this functional module. 
Main Functions:

- Detailed planning of machine utilisation

- Detailed planning of tooling

- Detailed planning of inspection operations

- Detailed planning of setup operations

- Detailed planning of deliveries to the production environment

- Detailed planning of deliveries from the production environment

- Detailed planning of pre-delivery operations

- Planning of maintenance operations

- Updating the planning to actual situation

- Possible planning of process planning activities

\section{Workflow Management}

Description:

This functional module executes the different workflows. It also provides a status overview of the progress which is made by in the different workflows.

Main Functions:

- Execution of workflow scenario's

- Display of workflow status

\section{Manufacturing Application Disc}

The executing entities are located on the Manufacturing disc. The functional modules for tooling, inspection, internal logistics, dispatching and production are all members of this application disc. The disc receives its work orders and planning through the central information management kernel. There are many Manufacturing application discs, each representing a single production environment that is connected to the server environment. An overview of the contents of this application disc is given in figure 11.10.

\section{Inspection}

Inspection acts as a quality inspector and Figure 11.10 Manufacturing Application Disc inspects according to the plans generated by

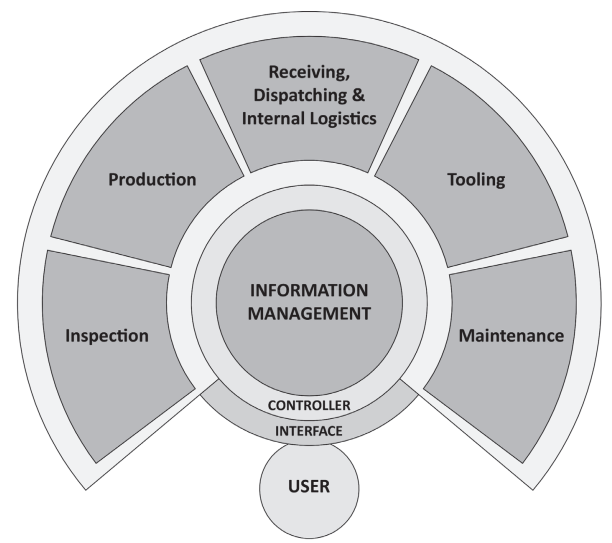
the quality disc. The results from the inspection are send to Quality through Information Management. SPC shop floor data capturing is also part of this module.

Main Functions:

- Inspection of incoming goods

- Inspection of (semi-)finished products (incl. FAI) 
- SPC Data capturing for quality control

- Nonconformance control

\section{Production}

This module represents the actual production on the machine (or cell) inside the production environment. The production is performed according the instructions and planning generated in the other discs of the architecture.

Main Functions:

- Producing products

- Nonconformance control

\section{Receiving, Dispatching \& Internal Logistics}

This functional module handles the physical receiving, dispatching and movement of goods and products in the manufacturing facilities. Storage (temporary) and packaging are also handled in this module. Incoming goods are forwarded to setup management or inspection or temporarily stored in the storage for further processing. The logistical tasks within the production environment are handled as well by this functional module.

Main Functions:

- Receiving goods and products

- Dispatching products

- Packaging of products

- Storage management

- Internal logistics

\section{Tooling}

This functional module manages the tools inside the production environment. Management of the tools includes preparing tools before use, replacing broken or used up tools and the tracking and tracing of tools. The preparation and disassembling of setups is also a function of this module.

Main Functions:

- Preparing tools

- Storage of tools

- Inspecting tools

- Tracking and tracing tool locations

- Preparing setups

- Disassembling setups

\section{Maintenance}

Maintenance acts as a manager for the different maintenance oriented tasks in the production environment. Examples of these tasks are the daily, weekly and monthly maintenance checks and large maintenance operations to the machines planned in conjunction with the Order Scheduling module

Main Functions:

- Perform machine maintenance 
- Calibration of machines (including inspection tools)

- Identify maintenance requirements

- Monitoring chip (scrap) level

\section{Business Administration Application Disc}

The functional modules that focus on the administrative and financial tasks are located on de Business Administration application disc of the architecture. An overview of the contents of this application disc is given in figure 11.11.

\section{Accounting}

The accounting functional module manages all the financial traffic within the system. The tasks performed by this functional module consist out of requesting and processing payments from customers, processing payments to suppliers and franchisees.

Main Functions:

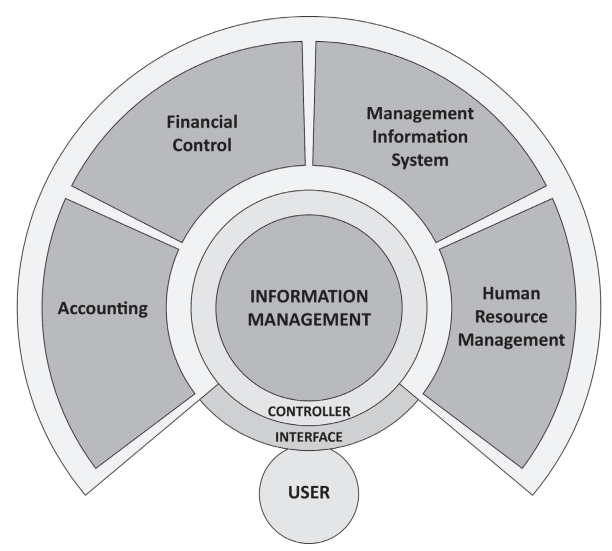

Figure 11.11 Business Administration Application Disc

- Process customer payments (facturation and monitoring)

- Process franchisee payments (fees and orders)

- Process supplier payments

- Process internal payments

\section{Financial Control}

The Financial Control functional module monitors and registers the financial state of the company. It is used by top management to get an insight into the liquidity and financial balance of the company.

Main Functions:

- Liquidity Control

- Financial balancing

\section{Management Information System}

The Management Information System is used by top management to get an insight into the performance of the CNC Worknet.

Main Functions:

- Management of performance indicators

\section{Human Resource Management}

This functional module is used for the required HRM functionalities. This module is used to monitor the performance of all personnel and to identify training needs. It manages and provides the training needs of all personnel. This functional module is also used for the hiring process of new employees. 
Main Functions:

- Provision of training

- Hiring

- Personnel performance monitoring

\section{Franchise and Marketing Application Disc}

The Franchise and Marketing application disc contains the modules that fulfil the franchise and marketing functionalities of the company. The franchising module analyses the overall performance of the standardised production plants connected to the network and scouts and analyses opportunities for the expansion of the franchise through opening new, or increasing the capacity of, standardised production plants. The marketing and branding modules are used to attract customers and present a single and uniform face to the customer. An overview of the contents of this application disc is given in figure 11.12.

\section{Franchise Management}

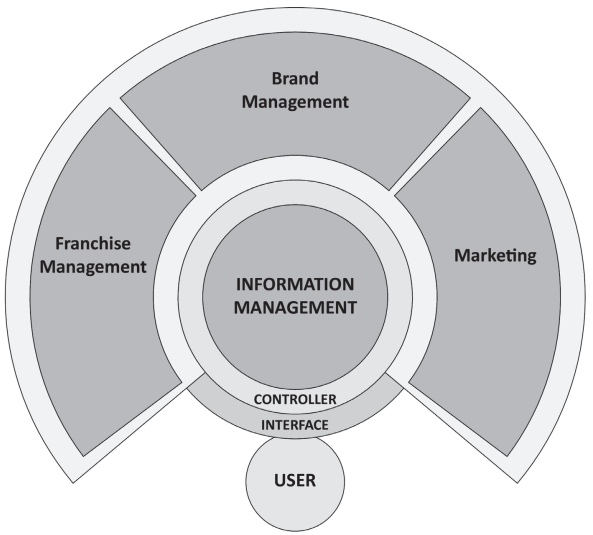

Figure 11.12 Franchise and Marketing Application Disc

The franchise organisation is managed in this functional module. Selection and acceptance of potential franchisees are tasks which are performed by this functional module. The communication with franchisees and monitoring their performance is also part of this module.

Main Functions:

- Selection and acceptance of new franchisees

- Performance monitoring of franchisees

- Franchise handbook management

- Franchisee data management

- Management of financial regulations with franchisees

\section{Brand Management}

This module acts as a marketer. It seeks to increase the company's perceived value to the customer and thereby increase its brand franchise and the brand equity.

Main Functions:

- Provision of uniform branding materials to franchisees

\section{Marketing}

This module provides for the marketing needs of the system. It sets up marketing actions in order to increase the revenue and attract customers. 
Appendices

Main Functions:

- Attracting customers 
